I

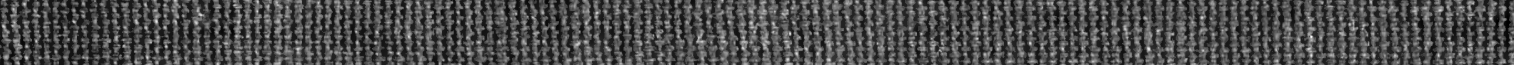

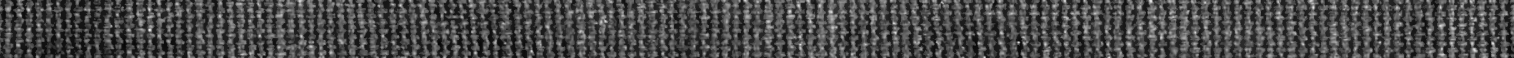

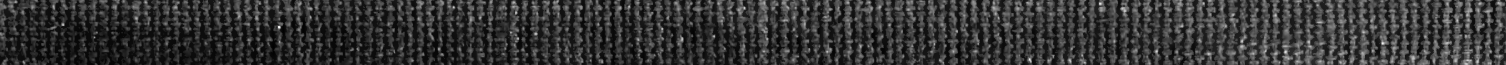

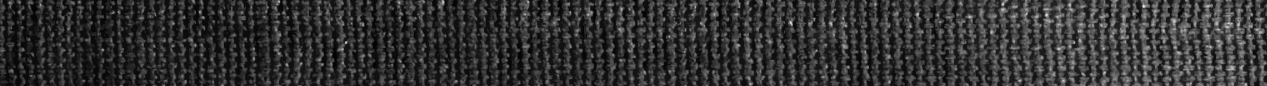

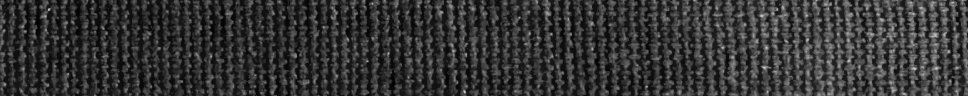

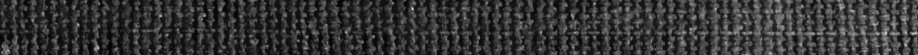

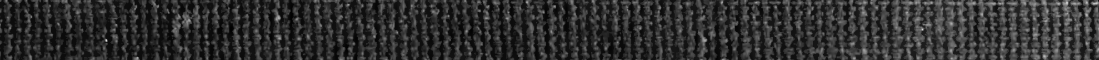

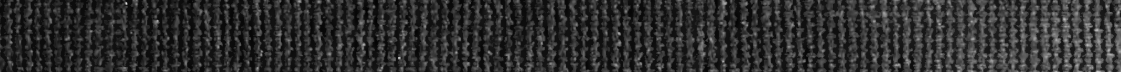

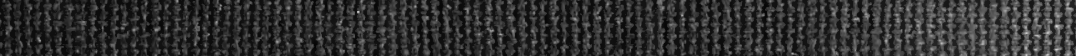
13.1.

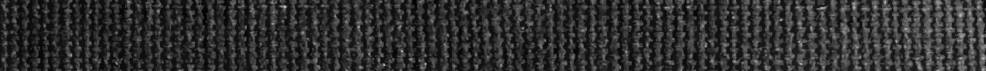

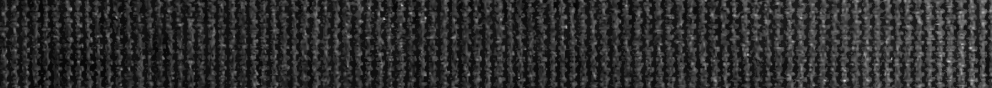

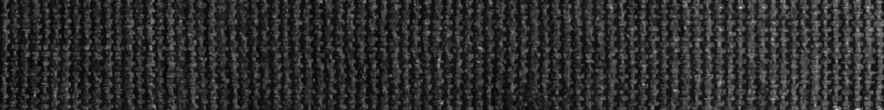
W 18. W.
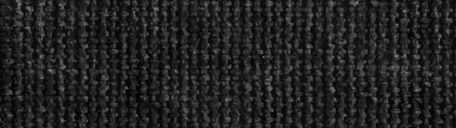

1.

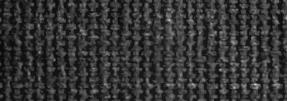

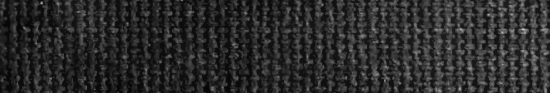
13 3. How

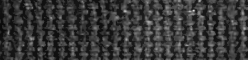
WIX

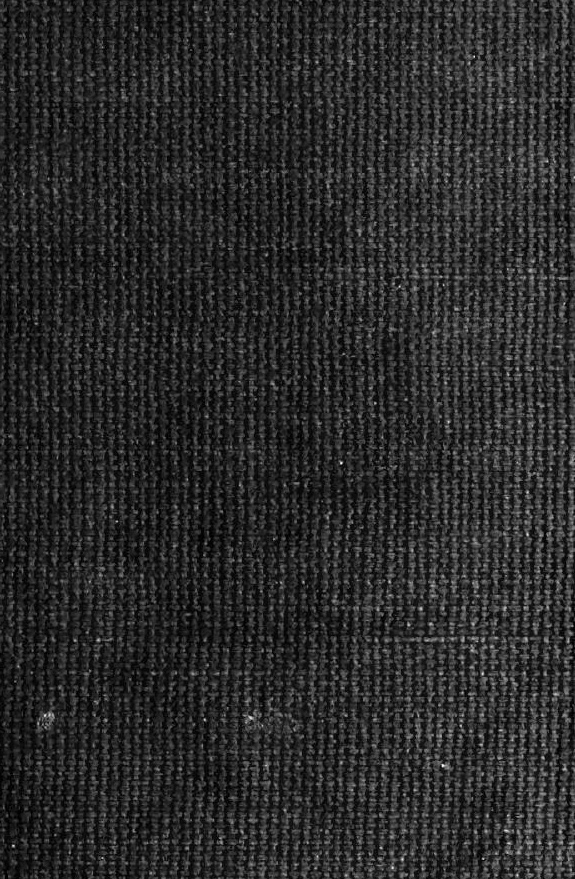




\section{MARINE BIOLOGICAL LABORATORY,}

Received 1937

Accession No. 9520

Given by Dr. . F R R . I I I I. e

Place, University of chicago

* * No book or pamphlet is to be removed from the Laboratory without the permission of the Trustees. 


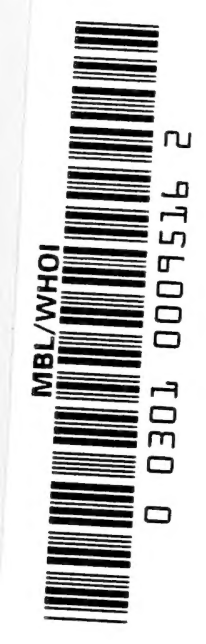



AMERICAN PERMIAN VERTEBRATES 
THE UNIVERSITY OF CHICAGO PRESS CHICAGO, ILLINOIS

\section{Agents}

THE BAKER \& TAYLOR COMUANY

NEW YORK

THE CAMBRIDGE UNIVERSITY PRESS

LONDON AND EDINBUBGH 



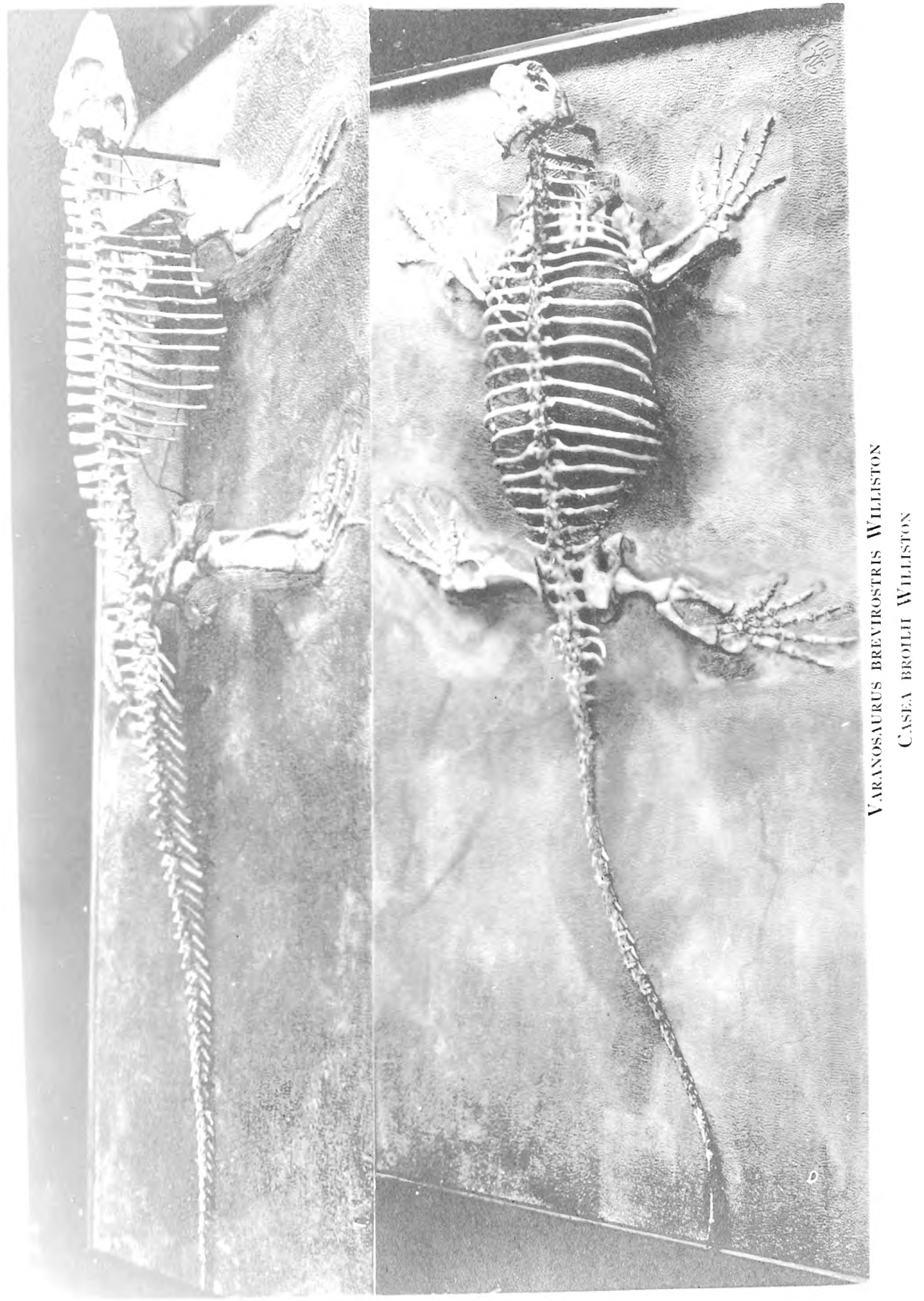




\title{
AMERICAN PERMIAN VERTEBRATES
}

B)

\author{
SAMUEL. W. WILLISTON \\ Profossen of Palcontology in the \\ Unisierity of Cbicago
}

THE UNIVERSITY OF CHICAGO PRESS

CHICAGO, ILLINOIS 
COPYRIGHT 1911 BY

The UNiversity of ChIC, Mo

All Rights Reserved

Published Oetober 1911

Composed and Printed By The University of Chicago Press Chicago, Illinols, U.S.A. 


\section{CON'TEN'TS}

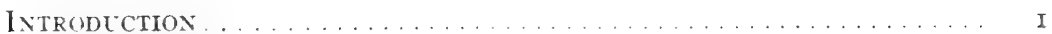

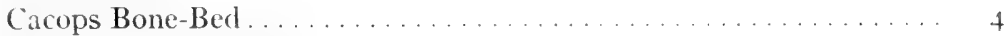

Craddock Bone-Bed . . . . . . . . . . . . . . . . . . 5

Permian of New Mexico.........................

Class Amphibia; Subclass Stegocephala ................. 9

Order Temnospondyli. . . . . . . . . . . . . . . . . . . 9

Family Eryopidae . . . . . . . . . . . . . . . . . . . . 9

Eryops grandis . . . . . . . . . . . . . . . . . . . .

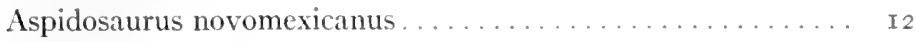

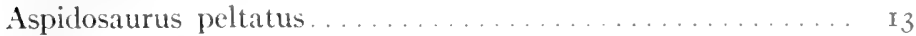

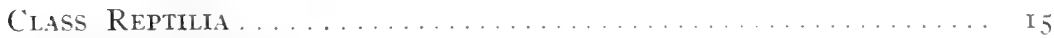

Order Cotylosauria . . . . . . . . . . . . . . . . . . . . .

Family Diadectidae . . . . . . . . . . . . . . . . . 6

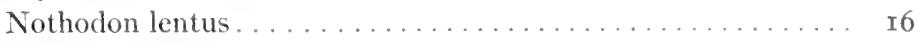

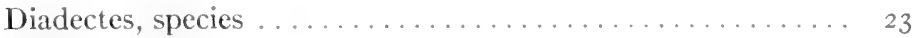

Family Limnoscelidae . . . . . . . . . . . . . . . . . . . . 23

Limnoscelis paludis . . . . . . . . . . . . . . . . . 23

Family Seymouriidae. . . . . . . . . . . . . . . . . 48

Seymouria baylorensis. . . . . . . . . . . . . . . . . . . 48

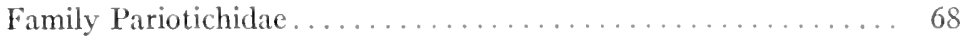

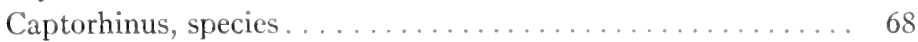

Captorhinus illinoiensis . . . . . . . . . . . . . . . . . . 69

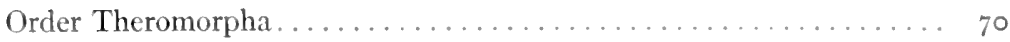

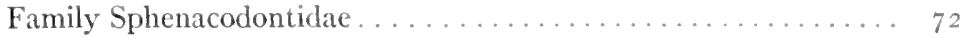

Clepsydrops.............................. 72

Clepsydrops natalis. . . . . . . . . . . . . . . . . . 73

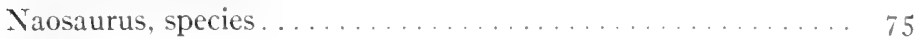

Sphenacodon ferox....................... 78

Family Poliosauridae......................... so

Ophiacodon mirus..................... 8I

Varanosaurus brevirostris . . . . . . . . . . . . . . . . . . $8_{5}$

Family Caseidae . . . . . . . . . . . . . . . . . .

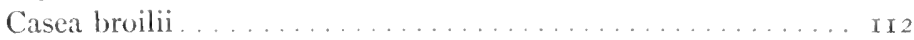

Trispondylus texensis . . . . . . . . . . . . . . . . . I I

Genus incertae sedis. . . . . . . . . . . . . . . . . 135

Platyhystrix rugosus . . . . . . . . . . . . . . . . . . I35

Species incertae sedis...................... I37

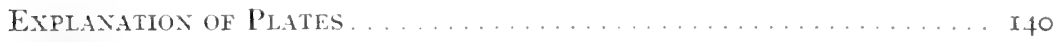

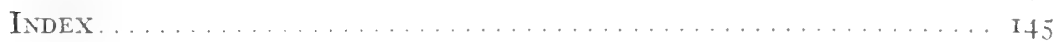

PLATES I-XXXIIII

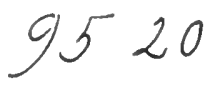





\section{IN'TRODUCTION}

The present work comprises a series of monographic studies, together with briefer notes and descriptions, of new or little-known amphibians and reptiles from the Permian deposits of Texas and New Mexico.

The material upon which these studies are based was, for the most part, collected during recent years by field parties from the University of Chicago under the charge of Mr. Paul Miller, assistant curator of paleontology in the University of Chicago, or of myself. The earlier collections of the University from Texas, made by Professor Case, have been discussed by him in various papers, especially in his monograph on the Pelycosauria, published by the Carnegie Institution in I908. In addition, I am permitted, by the kindness of Professor Schuchert, to include herein the results of the investigations by myself of the Permian collections from New Mexico in the Yale Museum. In order that these results may have a greater homogeneity than they would otherwise I repeat the description of the genus Limnoscelis published in the American Journal of Science for May, rgr r, with additions, omissions, and corrections. For the privilege of examining these important collections, so long neglected, and of publishing the results of my studies, I would here express my sincere thanks to Professor Schuchert. Farther on I give some data regarding the type collections of Professor Marsh from these New Mexico regions, and brief notes concerning the New Mexico fauna, as represented in these collections, will be found in the cited paper. I do not repeat them here, since a proposed further exploration of these deposits by Professor Case in conjunction with myself will doubtless furnish much more extensive and accurate information concerning them and their fauna, which will be published later by us. I may also say here that, in the future, it is proposed by Professor Case and myself to publish the results of our investigations of this important fauna, so long neglected, under joint authorship.

It is not my intention, however, to neglect the further exploration 
of the Texas deposits, opportunity permitting. The Texas Permian fauna is yet but imperfectly known; of the not less than thirty-five genera of land vertebrates recorded from those beds or known to me, scarcely a third are satisfactorily known; and the region is by no means exhausted. Careful search is sure to yield many new forms and more perfect specimens of others hitherto imperfectly known. I may, however, here express a caution that none save the most experienced collectors need attempt their further exploration with much hope of success. The beds are the most difficult of exploitation of any known to me in a field experience of thirty-five years. Usually the fossils are more or less hidden in concretionary nodular masses, almost invisible or indistinguishable to the untrained eye until they have been broken up and weathered, when the inclosed fossils have lost much of their value. Rarely single bones and even whole skeletons are found in clay deposits almost or quite free from matrix, but many such are not to be expected.

In the following pages I have not thought it worth while to enter extensively into many suggested morphological and taxonomical discussions. In my experience in vertebrate paleontology speculations based upon imperfect and incomplete material, while often fascinating as giving free rein to the imagination, are usually in the end found to be worthless and even misleading. The chief need in the paleontology of the early vertebrates is more facts, many more facts, and I have little faith in any system of classification based upon our present knowledge of these older land vertebrates. I shall hope to know enough about the vertebrates of the American Permian in the course of a few years to venture to present my views of their phylogenies, but at present these views are largely hypothetical. As Dr. Broom, in a letter to me, has said, of a few groups of reptiles, like the dinosaurs, crocodiles, pterosaurs, phytosaurs, rhynchosaurs, etc., we are justified in holding definite opinions, but as regards most of the other groups, often called orders, we are less sure than we were a dozen years ago. The more recent general classifications of the reptiles by Cope, Osborn, Boulenger, and others have offered suggestions of value, but they are by no means the real solutions of the reptilian and amphibian phylogenies. The recent classifications of Jaekel are not to be taken seriously. 
Certain morphological problems $\mathrm{I}$ have discussed in the following pages, and I have given what seems to me to be the legitimate conclusions regarding the immediate relationships of the forms under discussion. The present work, however, is offered more as a contribution to our knowledge of ancient reptiles and amphibians, with such summaries and definitions, based chiefly on American forms, as our present knowledge permits. The illustrations of the work throughout are by myself.

All the forms from the Texas deposits mentioned or described in the following pages as of specimens which I have studied, come from the upper or Clear Fork division.

Mr. Cummins has recently given an annotated list ${ }^{x}$ of the various genera of the Texas Permian with their localities or horizons, so far as could be obtained. My own experience quite confirms his opinion that there is a distinction between the faunas of the Wichita and Clear Fork divisions (no vertebrates are known, so far as I am aware, from the Double Mountain division above the Clear Fork, though footprints do occur in the shales of that division). The collections made by the University of Chicago expeditions in Texas the past few years have been almost exclusively from the Clear Fork division. These collections embrace, to the best of my recollection, the following forms:

Amphibia: Lysorophus, Diplocaulus, Trimerorhachis (apparently absent from the upper part), Eryops, Cacops, Dissorophus, Aspidosaurus, Cardiacephalus.

Reptilia: from the uppermost beds, Labidosaurus, Naosaurus, Dimetrodon; from lower horizons, Naosaurus, Dimetrodon, Clepsydrops, Varanosaurus, Trispondylus, Casea, Araeoscelis, Captorhinus, Diadectes, Seymouria, etc.

Perhaps the most characteristic of the upper beds is Labidosaurus, of the lower, Cricotus, and their horizons may be known as the Labidosaurus and Cricotus zones. On the other hand I feel quite confident that no definite line can be made between the two divisions, and at present Clear Fork can be used in a general way to designate the upper, and Wichita the lower, part of the Texas deposits.

${ }^{2}$ Journal of Geology, XVII (1908), 737. 
Many of the most important and interesting specimens obtained by us on these expeditions come from two isolated deposits which I call the Cacops and Craddock bone-beds, concerning which and the forms found in them the following will be of use.

\section{Cacops Bone-Bed}

Seldom in the history of paleontological exploitation has there been found a more remarkable deposit of early land vertebrates than that to which I give the name of the Cacops bone-bed, because of the genus the remains of which occur most abundantly in it. The immediate locality of this deposit is about five miles west of the Vernon road in the valley of the Wichita, not far from Indian Creek. The deposit was discovered by Mr. Miller in the autumn of I 909 , from a large quantity of washed-out bones lying in a small gully near the foot of some rather precipitous exposures. Only a portion of the remains were exhumed at the time of the discovery; the bed was thoroughly worked out by Mr. Miller the following year.

The numerous skeletons contained in the deposit lay upon each other through a thickness of about two feet or a little more; those near the top were more isolated, those lower down packed more closely together and more disturbed in their relations. As a rule the various skeletons are more or less united, but frequently legs, tails, and even single bones are found isolated. The material in which the remains occur is the dark red clay forming the greater part of the exposures of the Texas Permian deposits, but the bones themselves are incrusted with a thin, more or less adherent, hard matrix, sometimes removable with difficulty. The bones of the upper layers have a less thick incrustation, but in the lower ones the skeletons lie more closely packed together, the skeletons or parts of skeletons often being cemented together in masses of considerable size. Because of this it is often difficult to separate any one skeleton without disturbing the others. The remains lay in a space some six or seven feet in width by ten or twelve in length. As a rule the skeletons lie prone, but some have been found in a supine position. To develop all the skeletons or parts of skeletons in the deposit would require the uninterrupted time of a skilful preparator for 
not less than two or three years. As such an expenditure of time is neither practicable nor desirable at present, all that has been done so far, in addition to those needed for study and exhibition, is the separation of the various skeletons, so far as possible, from the clay in which they were imbedded, leaving them connected and associated by the cementing matrix. The material was brought to the laboratory in bandaged blocks of various sizes from fifty to four hundred pounds in weight, as it was found most convenient in the field to divide them. And even the preliminary separation of the skeletons has been done for but little more than half of the material secured-done in the hope of finding other forms than those discovered in the earlier examination. And this hope has been in part fulfilled. As this work goes to press a skeleton or part of a skeleton of another form, a very large species of Captorhimus, has been discovered. Among the skeletons and parts of skeletons so far worked out, in part or wholly, there are at least a dozen skeletons of Varanosaurus, as many or more of Cacops, including eight or ten good skulls, five or six of Casea, the skeleton of Captorhimus just mentioned, and a few bones of Seymouria. Not the slightest indication of any large or very small animal has been found so far. Of the species found among these skeletons, none was known to the earlier explorers of the Texas Permian, unless it be Seymouria, as represented in the fragmentary skull to which the name Conodectes was given by Cope. One was described by Broili seven years ago, and three at least and probably four are new.

The Cacops bone-bed lies, as well as I can estimate, two hundred feet at least below the topmost exposure of the Clear Fork division, about in the same horizon as, though perhaps a little higher than, and about six miles distant from, the Craddock bone-bed.

\section{Craddock Bone-Bed}

This deposit of bones, to which frequent reference is made in the following pages. was discovered in the autumn of I909 by Mr. Lawrence Baker of the University of Chicago expedition, near the west line of the Craddock ranch, and about six miles northwest of Seymour, Texas. The bones in this deposit extend through a 
thickness of about one foot over a considerable space, a few hundred square feet, imbedded in red clay like that of the Cacops bed. They are, unlike those of the Cacops bed, however, for the most part isolated, and generally more or less free from incrusting matrix, and usually in the most perfect preservation. Not a few, however, show effects of erosion, as though they had been rolled upon a beach of hard, shallow bottom. It is impossible at present to determine with assurance the taxonomic position of many of the isolated bones; nor can they be determined until the fauna of the Texas Permian is much better known than is the case at the present time. That there are representatives of several new genera and species among the remains secured is practically certain, but I hesitate to give names to isolated parts of the skeleton unless such parts are very characteristic, rendering the species recognizable in the future with certainty. The material secured includes two or three hundred bones, none of them associated save those of Aracoscelis. Among these I have, so far, determined the following: Dimetrodon, represented by $D$. incisious, and $D$. gigas, and perhaps another species; an allied theromorph reptile with a longer skull than that of Dimetrodon, but with a dentition very different, an undoubted new genus; numerous vertebrae of a very large species of Diadectes; numerous limb bones, girdles, etc., which I refer to Clepsydrops natalis, together with others of an allied more slender-limbed species; a number of vertebrae and limb bones of Seymouria; a single femur of a pariotichid shown in Plate XXXII, Figs. 6, 7; at least two genera of small reptiles represented by numerous limb bones, etc.; and perhaps half a dozen skeletons more or less incomplete, all found together in a space of a few square feet, of the slender little reptile which I have called Araeoscelis. Among the amphibian material, Trimerorhachis is represented by intercentra and parts of the skull; Diplocaulus by characteristic skull and vertebral bones; and at least three species of either Aspidosaurus or allied genera. In addition there are a few spines of two types of sharks.

The Araeoscelis material has not yet been fully prepared, but I doubt not that it is sufficient to make out most of the skull and keleton characters. The skull has a single temporal vacuity of 
large size, the body and tail are very long and slender, the pelvis of the pelycosaurian or Varanosaurus type, and the feet appear to be very much like those of the last-named genus, save that the limbs are very much more slender. The genus seems to be very closely allied to, possibly identical with, Kadaliosaurus from the European Permian.

I have given numerous figures of some of the most characteristic smaller bones in this bone-bed, not only because of their unusual perfection but because of their faunistic association.

\section{Permian of New Mexico}

Since the brief paper by Marsh in the American Journal of Science for May, 1878 , is rather inaccessible and isolated I have quoted his descriptions in the discussions of his types, and here give the introductory part of the paper as follows:

The United States Survey of the Fortieth Parallel, in charge of Mr. Clarence King, has made known the fact that a well-marked Permian horizon can be distinguished in the Rocky Mountain region; and deposits considered of this age are represented on the geological maps of that survey. This adds much interest to the vertebrate fauna known from near this horizon, and probably belonging to it, as hitherto no Permian vertebrates have been identified in this country, although not uncommon in Europe.

The Museum of Yale College contains an extensive series of reptilian remains belonging to a peculiar lacustrine fauna, which includes also amphibians and fishes. These fossils are from several localities in the West, but mainly from New Mexico, and the geological horizon appears to be in the upper portion of the Permian. These reptilian remains are in excellent preservation, and among them are several genera having the more important characters of the Rhynchocephalia, of which the genus Hatteria, of New Zealand, is the living type. The principal points of agreement are the separate premaxillaries, the immovable quadrate, and the biconcave vertebrae. Another character of much interest is the presence of certain hypaxial elements of the vertebrae, first observed by von Meyer in the Triassic genus Sphenosaurus, and called by him intercentral bones (Zwichenwirbelbein [sic]). These wedge-shaped bones are apparently the homologues of the cervical hypopophyses in the Mosasauria, and of the subcaudal attachments in the Odontornithes, and a few recent birds. These intercentral ossifications apparently exist in all the reptilia yet found in this new fauna, and hence serve to distinguish it. With this character is another of hardly less interest. The anterior rib-bearing vertebrae preserved have three separate articular facets for the ribs; one on the anterior part of the centrum for the head, and a double one above for the 
bifid tubercle. In the implantation of the teeth and their successional development, these reptiles resemble the Mosasaurs.

These characters, with others mentioned below, indicate two distinct families, which may be called the Nothodontidae and Sphenacodontidae, from the typical genera here described.

This paper by Marsh, of which the foregoing is the introductory part, was actually published on May 3, I878, five days prior to the publication by Cope of his paper on the Texas fauna containing the description of numerous new forms, and in which was proposed the family Clepsydropidae and the suborder Pelycosauria, a preliminary notice of which was published in the American Vaturalist for May, I 878, distributed (fide Cope) on April 22, giving priority to several of the generic names which later appeared in his Palcontological Bulletin, No. 29. The further history of the publication of these papers makes one of the most regrettable pages in the scientific and personal controversy between these two eminent men and need not be given here. Those who are curious may find further details concerning it in a paper published by Cope the following month in the American Naturalist (June, I878). Suffice it here to say that the names proposed by Marsh in his paper have an actual priority of five days in publication over those of Professor Cope, as distributed in his Paleontological Bulletin, No. 29, and over all the names applied to the Texas Permian vertebrates save that of Eryops, purporting to have been published the preceding November, and those published without description by Cope in the American Naturalist, for May, I878, as follows:

Diadectes, Bolosaurus, Epicordylus, Empedocles, Parioxys, Trimerorhachis, and Rhachitomus.

Under the strict rules of priority, as formulated by the International Committee on Nomenclature, even these names cannot claim priority over those of Marsh, since they were merely nomina nuda. If, however, any student would deny priority to them after reading the paper by Cope in the June number of the $N$ aturalist, he may; but I shall not.

All of Marsh's types came from a bone-bed. Very few of the bones were in anatomical relation, and numerous individuals of six or seven forms are represented among them. I designate the bed as the Baldwin bone-bed, in the descriptions. 


\section{Class AMPHIBIA \\ Subclass Stegocephala}

Cope, Extinct Batrachia, Aves, and Reptilia of North America, p. 6, I868 (Stegocephali, order).

\section{Order TEMNOSPONDYLI}

Zittel, Handbuch der Paleontologie, III, 380, I888.

Small to large, terrestrial stegocephalians, especially characterized by the large size of the intercentra, and the paired pleurocentra. Skull with all membrane bones of air-breathing vertebrates; more or less rugose; a parietal foramen present; teeth more or less labyrinthine, attached to premaxillae, maxillae, dentaries, vomers, palatines, and pterygoids; at least two large conical teeth on the palate. Parasphenoid usually large, rarely vestigial; pterygoid vacuities large. From twenty-one to twentyfour (?) presacral vertebrae; tail short or moderately long, rhachitomous or embolomerous, that is, composed of two disks, one bearing the chevrons and arch, the other intercalated; chevrons always forming a part of the large intercentrum. Clavicular girdle sometimes large, with rugose markings; at other times smaller and smooth, the interclavicle never with a long posterior stem; a cleithrum always present. Scapula and coracoid fused; a supracoracoid foramen present, as also a supraglenoid. Humerus rarely with entepicondylar foramen. Carpus ossified; hand pentedactylate. Pelvis fully ossified, without puboischiadic vacuity; a pubic or obturator foramen piercing the pubes. Tarsus ossified, the intermedium pedis always distinct; at least three ossa centralia; feet pentedactylate. Ventral and dorsal ossifications often present.

\section{Family Eryopidae}

Cope, American Naturalist, XVI, 334, I882.

Spines of vertebrae simple, or expanded distally, sometimes into a close-fitting or imbricated, more or less dilated, carapace; 
otic notch never closed behind; no dorsal dermal ossifications; a single pair of sacral ribs; tail long; ribs with uncinate processes; parasphenoid large.

\section{Eryops grandis Marsh.}

Ophiacodon grandis Marsh, American Journal of Science, XV, 2I I, May 3 , 1878. Rio Arriba County, New Mexico.

? Eryops reticulatus Cope, American Naturalist, I88r; ibid., 34, r884; Trans. Amer. Phil. Soc, XVI. New Mexico.

A second, larger species of apparently the same genus [Ophiacodon] is represented by portions of the jaws, and teeth, and various parts of the skeleton. In this species the dentary bone is angular at its anterior extremity, and triangular in section. Its external surface is rugose, as in the crocodiles. The crowns of the teeth are striate at the base, and the latter is furrowed vertically. The teeth are not so thickly set as in the smaller species, and the bases of the crowns are somewhat transverse.

MEASUREMENTS

Space occupied by ten anterior lower teeth.......... I40 $\mathrm{mm}$.

Depth of lower jaw at symphysis ............. I 29

Antero-posterior extent of symphysis............... 25

Depth of dentary bone below seventh tooth......... 30

Width of dentary at this point ............... 20

The present species was about ten feet in length, and the largest reptile yet found in this fauna. The remains are from New Mexico.

Among the material studied by Marsh from the Baldwin bonebed there is a considerable portion of a skeleton, probably all of one individual, of this species. The left mandible, with all its teeth broken away, the type specimen, has been made much more complete than when Marsh described it. In addition, there are parts of another mandible, numerous intercentra, pleurocentra, and neurocentra, the larger part of two scapulae, etc. Among the later collections from the same bone-bed there are two more or less complete skulls, two scapulae, a pelvis, portions of limb bones. and numerous vertebrae. All these parts probably belong to the 
one species, though this cannot be positively decided without further study and more material. The species is rather small for an Eryops, though it must unfortunately bear the name grandis, a name given to it under the misapprehension that it was a reptile. Evidently Marsh had not seen the description of Eryops megacephalus Cope at the time of the publication of his paper; otherwise he would not have fallen into the error of calling his species a reptile. The description of E. megacephalus is said to have been published the preceding November, but of this there is some doubt. That there were "various parts of the skeleton" among the material studied by Marsh must, of course, have been assumed, since he could not have recognized them without at the same time recognizing their generic distinction from Ophiacodon mirus.

A considerable number of species of Eryops have been described from Texas and New Mexico, but we are almost entirely ignorant yet of the real distinguishing specific characters, and their differentiation has been, for the most part, assumed.

In a recent paper I stated that Eryops had no uncinate processes on the ribs; in this I was in error. The specimen of Eryops mounted in the American Museum-an excellent one-has not only well-developed uncinate processes, but ventral ossifications as well, characters which associate the genus much more closely with the European Euchirosaurus than I had supposed. In the same publication I also spoke of a specimen with dilated spines which I was inclined to refer to the basal caudal region of Eryops. The American Museum specimen likewise shows that there were no dilated spines anywhere in the vertebral series in Eryops, from which it would seem certain that there is another genus of Eryopidae in Texas, possibly Anisodexis, even more closely allied to Euchirosaurus. Because of this close relation between Eryops and Euchirosaurus with dilated spines, and also because of the possession of the uncinate processes on the ribs, I am disposed to place the genus Aspidosaurus in the same family, all of them, as also various species referred in the past provisionally to Zatrachy's, presenting these characters and the open otic notch behind. 


\section{ASPIDOSAURUS}

Broili, Paleontographica, LI, I904.

Aspidosaurus novomexicanus, n. sp. Plate XXXVIII, Fig. I. Rio Arriba County, New Mexico. Specimen No. 8ro, Yale Museum.

The type specimen of this species is inclosed in a hard, rather fine-grained, dark-red, weather-worn sandstone nodule, which is worked with some difficulty. The front extremities, most of the pectoral girdle, save the left scapula and the upper end of the right one, the hind girdles and hind extremities, and the tail had been eroded away before the specimen was discovered by Mr. Baldwin. The specimen was sent in with specimen No. 809 of Limnoscelis paludis Will., and probably had been picked up in the wash among the fragments of that specimen.

As much as is prudent has been removed of the matrix covering the bones, as shown in the photograph. The skull was attached to the vertebral column at an angle dorsalward of nearly ninety degrees; it has been separated and placed in the plane of the remainder of the specimen; it has lost the nasal portion and much of the mandibles. The upper surface of the skull is markedly concave; its tabular angles are moderately produced into a rounded extremity, but are not turned downward to meet the quadrate, as in Cacops and Dissorophus. The temporal region has a deep emargination not unlike that of Cacops, though not inclosed behind by the tabulare. As this whole region was covered by the sandstone matrix, the absence of the posterior bar cannot be attributed to erosion, nor is there any indication that such a prolongation of the tabularia was present in the living animal and lost in fossilization, especially so as the region is alike on the two sides. Of course, this emargination was for the ear, confirming my views as to the nature of the temporal opening in Trematops, Cacops, and Dissorophus. There are only seven dorsal spinous shields, the first of which, as in Dissoroplus, is more than twice the length of the following ones; it is rounded in front. 'The last shield, also, is much broader antero-posteriorly than from side to side. The shields show little evidence of imbrication. About 
twenty pairs of ribs are visible, either at their ends or from above; and doubtless this was nearly the full number of presacral vertebrae. A fragment of the left ilium is present, and on the right side there appear to be two sacral ribs, though this is doubtful. The tail was wholly lost before fossilization. The ribs, as will be seen from the photograph, have the uncinate process characteristic of Eryops, Euchirosaurus, and Aspidosaurus, differentiating the form at once from the Trematopsidae and Dissorophidae. These processes are more slender in front, where they approach the proximal end of the rib. Posteriorly they become progressively broader and more remote from the proximal end till, at about the tenth presacral vertebra, they are merely distal expansions of the ribs themselves.

Among the material at the American Museum there are several small skulls, not twice the size of the present species, which have been referred to juvenile specimens of Eryops. In one of these I observe that the otic notch is relatively large, with tabular processes much like those of the present species. I suspect that this skull. at least, is really that of a species of Aspidosaurus.

From an examination of the tail vertebrae in the mounted specimen of Eryops of the American Muscum, I find the same structure as that figured by me in a late paper as coming doubtfully from the tail of either Eryops or Trimerorhachis. The figured vertebrae are too small to belong with an adult Eryops, but the structure is identical.

An examination of the type specimen of Otocoelus mimeticus convinces me of the absolute identity of the genus with Dissorophus, as previously recognized by Case.

?Aspidosaurus peltatus, n. sp. Plate XXXII, Fig. 7. Craddock bone-bed, Baylor County, Texas.

Among the material secured from the bone-bed on Craddock's ranch, as described on a previous page, there are at least two, and possibly three, species of temnospondylous amphibians which may, provisionally, be referred to this genus. Most characteristic of these remains is the dorsal spinous expansion herewith figured. This dorsal plate has, as a part of it, the upper end of a thin dorsal 
vertebral spine. The plate is gently and evenly convex above, slightly convex on the anterior thinned border, and correspondingly concave on the posterior thicker border. The upper surface is rather deeply marked by irregular pits and grooves, as is seen in the photograph. It is very evident that the plate did not overlap the preceding plate, as is the case in $A$. chiton Broili, the genotype. In the middle behind, however, the flat surface of the spine served to help support the following dermal plate.

Associated with this plate in the bone-bed are a considerable number of femora, and several humeri of the types figured and described by me in the Bulletin of the Geological Socicty of America, XXI, 270, Plate XV, Figs. 4, 5. The most typical specimens of the femora found associated with the type are shown natural size in Plate XXXIII, Figs. I-4, and Plate XXXII, Figs. 4, 6. While all these femora have the same general shape and high adductor crest, and the same absence of condylar ossification, they differ very materially in their slenderness, especially noticeable in Plate XXXII, Fig. 4, and Plate XXXIII, Fig. 3. That one or the other of these femora and one or the other of the types of humeri figured in the cited paper belong with the species represented by the dermal plate is quite sure, but, as it is impossible to determine which of them should bear the name $A$. peltatus, the dorsal spinous expansion shown in the figure may be considered the type of the species. The species seems nearest related to $A$. glascocki Case, but differs materially in the character of the sculpture, the thickness of the plate, and the relations of the vertebral spine itself.

There are various small intercentra in the collection, and fragments of jaws, which doubtless belong with one or the other of the species represented by the humeri and femora. 


\section{Class REPTILIA}

\section{Order COTYLOSAURIA}

Cope, American Naturalist, 334, I880.

Primitive, crawling, or subambulatory, terrestrial reptiles, of small to rather large size, with large head, short or no neck, heavy, thickset body, and a moderately long or short tail, the skin either bare or with bony ossicles; slender ventral ribs rarely present. Skull stegocrotaphic, with all or nearly all dermal bones characteristic of the Stegocephala; lachrymal (postnarial, adlachrymal) extending to the nares; septomaxillary usually if not always present; postorbital always distinct; dermoccipital always, and tabulare and supratemporal usually, present; a parietal foramen, sometimes very large; paroccipital (opisthotic) separate; stapes large; pterygoids articulating with vomers; transpalatine not yet demonstrated; teeth thecodont or acrodont, inserted on premaxillae, maxillae, vomers, palatines, pterygoids, dentaries, and sometimes the splenials. Prearticular of mandibles separate; splenial entering into mandibular symphysis; coronoid of moderate size. Vertebrae notochordal, twenty-three to twenty-five (?) presacrals, and one or two sacrals; intercentra always present. Ribs usually double-headed, in front, at least, and expanded but not emarginate posteriorly, sometimes single-headed or double-headed throughout, attached to intercentral space and diapophysis; free ribs on base of tail. Vestigial cleithrum sometimes present; clavicles large; interclavicle expanded anteriorly, with a long stem; no ossified sternum. Coracoid co-ossified with scapula; sutural division between coracoid and metacoracoid in glenoid fossa; a supraglenoid canal always present. Pubis and ischium large, plate-like, without puboischiadic vacuity, but with an obturator foramen piercing the pubes; ilium more or less dilated posteriorly above. Humerus with broadly dilated extremities, in very divergent planes; an entepicondylar foramen always present; no ectepicondylar fora- 
men; olecranon moderately produced. Four bones in the proximal row of the carpus; two free centralia, and five carpalia; hand pentedactylate; two bones in proximal row of tarsus, a single centrale and five tarsalia; feet pentedactylate; phalangeal formula, usually, if not always, 2, 3, 4, 5, 4 (3). Anterior ribs dilated and overlapping in all known American forms.

\section{Family Diadectidae}

Cope, Proc, Amer. Phil. Soc., XIX, 45, I880; Marsh, American Journal of Science, XC, 4I0, I878 (Nothodontidac).

Skull short and high, very rugose above; parietal foramen very large; prefrontals and postfrontals meeting broadly over orbits; a broad and rather deep otic emargination in posterior temporal region. The single row of teeth in maxillae and dentaries deeply thecodont, with narrow, transverse crown (except the most anterior ones) showing a median cusp and a lateral lower one on each side. A vestigial cleithrum present; vertebrae with thick. stout spines; one or two sacral vertebrae present; usually a hyposphene and hypantrum. Tail moderately long or short. Legs short and stout; carpus and tarsus fully ossified, the proximal carpal and tarsal bones relatively small; ungual phalanges broad and flat; no ventral ribs.

\section{NOTHODON}

Marsh, American Journal of Science, XV, 4 ro, May 3, I878; ? Diadectes Cope, American Naturalist, XII, 327, I878 (published April 22, fide Cope); Proc. Amer. Phil. Soc., XVII, 205, I878; Paleontological Bulletin, No. 29, 1878 (published May 8, fide Cope).

Yothodon lentus Marsh, op. cit. Plate XXXIV, Figs. 5-7; Plate XXXV, Figs. I-4; Plate XXXVI, Fig. 2. Rio Arriba County, New Mexico. Yale Museum.

This genus of reptiles may readily be distinguished by the dentition. In each separate premaxilla there are two slender pointed teeth. In front of the maxillary there are one or two smaller teeth, followed by a number with transverse crowns, resembling in form the premolars of some carnivorous mammals. These crowns, when unworn, have a central cusp, and on each side a tubercle, somewhat like that on the premolars of the genus Canis. In 
the present species the first and last of the transverse teeth are smaller than the middle ones. The legs were short, the long bones had their extremities covered with cartilage, but the carpals and the tarsals were well ossified. The centra were very deeply concave, and the tail was long.

The following measurements are taken from the type specimen of this species:

Length of maxillary bone............................. $65 \mathrm{~mm}$.

Space occupied by ten maxillary teeth.............. 55

Height of crown of second maxillary tooth . . . . . . . . I4

Height of crown of third maxillary tooth. ............ 9

Antero-posterior diameter . . . . . . . . . . . . . . 3

Transverse diameter. . . . . . . . . . . . . . . . 8

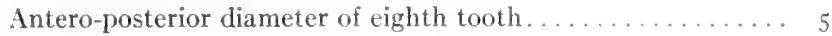

Transverse diameter...................... I5

The present species was about five or six feet in length, and herbivorous in habit. It was apparently slow in movement, and probably more or less aquatic. The remains at present known are from New Mexico.

Among the material from the Baldwin bone-bed of New Mexico in the Yale Museum which had been received at the time the above description was written, I find evidence of three individuals pertaining to this species, including the type specimen as figured; fragmentary remains of mandibles; the nearly complete upper part of two skulls, and an additional frontal bone; radius, ulna, tibia, and fibula. The skull bones were widely separated and scattered, and none of the bones had been mended. Whether or not the animal had a long tail it is even yet impossible to say from the specimens, as no two bones are in relation with each other.

Among the material acquired later there are evidences of additional skulls, but with the scattered and incomplete remains of them little can be done. Had the material been collected with modern care, there is little doubt that from among it almost perfect skulls might have been reconstructed, of especial value from the fact that the bones are free from matrix, undistorted, and separated at their sutures, with few cxceptions. Two have been partially restored, showing nearly the whole of the upper surface.

The superior surface of the skull is roughened throughout (Plate XXXVIII), save the supraoccipital region, with small punctulations and deep, pitlike or groovelike excavations, especially conspicuous over the parietal and frontal bones. From near 
each posterior angle (see Fig. I) there begins a distinct groove, including the pit mentioned by Case in Diadectes, running forward and inward on each side of the pineal vacuity, and on the frontal and nasal bones. Opposite the postorbital angle there is a branch leading outward, and the two main branches seem to meet in a

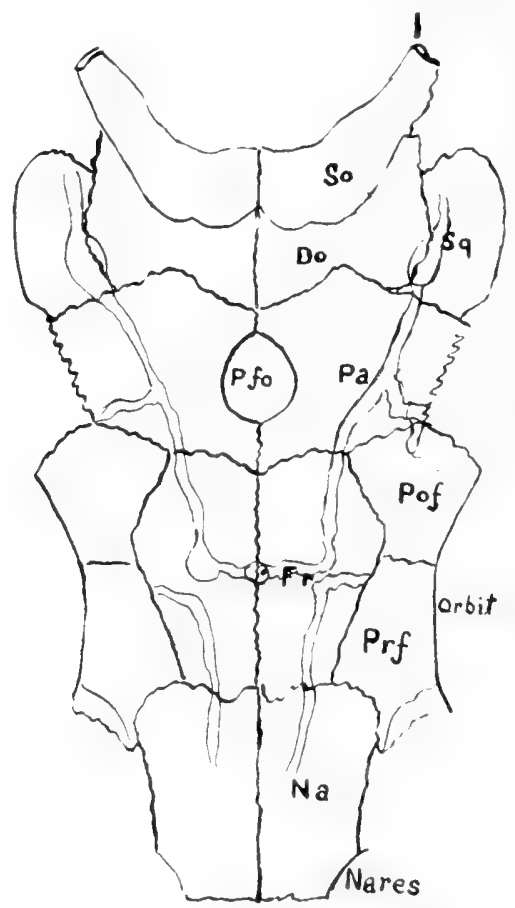

FIG. I.-Nothodon lentus Marsh. Diagrammatic outline of bones of top of skull, about one-half natural size. See, also, Plate XL. pit in the middle of the frontal bone, with a branch, or a distinct groove leading forward on the anterior part of the nasals. That these are mucous grooves is of course possible, but I suspect that they are, rather, grooves for the passage of veins beneath a heavy corneous plate which covered the whole of the upper surface of the skull.

The relations of the skull bones, so far as they have been reconstructed, of course, are very positively shown, since all, save the dermoccipital, were wholly separated at their sutures. These relations I show in the accompanying outline figure as placed in one plane, that is, without the foreshortening of the decidedly convex profile. The frontal bones, very strongly sculptured, are broader and thicker posteriorly, and give articulation on their outer sides to the prefrontal and postfrontal, which unite with each other, excluding the frontal from the margin of the orbit. The nasal bones, nearly as long as the frontal, have the general roughening of the skull surface, with a single groove on the upper side, obsolete anteriorly. The prefrontal is short, and it extends but little in front of the orbit, articulating with the nasal and, more broadly on the outer side, where it curves downward, with the lachrymal, which extends 
forward, as in other Cotylosauria, to form the posterior border of the nares. ${ }^{\mathrm{T}}$

The postfrontal, a short and thick bone like the prefrontal, has a thickened sutural border posteriorly for the postorbital. The parietals are rather small bones, touching each other for a short distance only in front and behind the "enormous" parietal foramen. In front they articulate by a broad, underlapping squamous suture with the frontal, on the outer side with the postfrontals and postorbitals, and with another element perhaps between them and what I here call the squamosals. Back of the parietals are the broad dermoccipitals, which are blended on the upper side with the supraoccipitals almost indistinguishably. I believe, however, that their sutural separation follows about the line as I have drawn it. On the under side, the cartilage supraoccipital forms the whole of the superior surface of the brain chamber posteriorly and on either side includes more or less of the semicircular canals and otic cavity. The brain surface runs upward and forward, in one specimen narrowing into a groove which leads into the pineal chamber; in the other specimen the anterior part of the groove has been broken away cleanly from the suture connecting the supraoccipital with the dermoccipital. It is clear that the supraoccipitals met the parietals in the middle, wholly excluding the dermoccipital from contact with the brain. The pineal opening, as has been said, is enormously large, twentythree millimeters in longitudinal diameter, by about twenty in the transverse diameter. Its walls are seven millimeters in height, vertical throughout the thickness of the roof bone, with sharp and rather protuberant edges below, save where the cavity continues back into the narrowed brain roof of the supraoccipital bone.

${ }^{I}$ I have for several years been much inclined to accept the conclusion reached by Jaekel that the real lachrymal of the reptiles is homologous with the so-called prefrontal of the reptiles and amphibians, but have been loath to accept the name proposed for the so-called lachrymal by Jaekel, "postnarial." Gaupp's more recent researches seem to prove the contention of Jaekel, but I am not at all inclined to accept the name proposed by Gaupp for the bone, "adlachrymal," in lieu of Jaekel's name. In the primitive condition of the bone it does not enter into the formation of the orbit at all, but forms a part of the posterior border of the nares, so that objection to the term "postnarial" is not pertinent on the grounds of its position, though remote from the nares in the higher forms. Nor can I see why the term "adlachrymal" is any more appropriate. 
Among other vertebrates I know of nothing to compare with this condition of the pineal vacuity, unless it be Casea; that the chamber lodged some part of the brain substance there would seem to be no doubt, possibly a part of the mesencephalon; if it lodged the pineal body only then it would seem very probable that the organ was functional. The surface of the parietal and frontal bones on either side of the brain surface and pineal chamber is entirely smooth, with no indications for sutural attachment of the descending plates described by Case.

Among the material acquired later there is a quadrate bone, but so very different in structure from that of either the Pariotichidae or Pelycosauria that I cannot understand it.

(of the limb bones I find four, all rather closely associated with the type, and doubtless the ones referred to by Marsh in his original description. They agree so closely in size and appearance that it is very probable they belonged to the one individual and that probably the type of the genus and species. I find no others in the collections which I can refer positively to Nothodon, though a fragmentary femur and a fragmentary humerus may belong here. The bones preserved are quite characteristic of the Diadectidae short, heavy, and stout. The left tibia, shown in Plate XXXV', Fig. I, is a very stout, short bone; its outer border is deeply concave and rather thin, less so than the inner and less thickened; the distal articular surface is crescentic in outline, the inner horn the thinner; the ventral surface is more deeply concave than the dorsal; the shape of the proximal articular surface is shown in the plate.

The left fibula (Plate XXXV, Fig. 2) has the upper articular surface oblique, and the lower end is much expanded; there is a marked protuberance near the outer distal border; it seems to be normal.

The left radius and the left ulna (Plate XXXV) from their association may belong in the same forearm. The radius is nearly symmetrical in shape, the lower extremity a little more expanded than the upper; the upper articular surface, somewhat compressed, is subtriangular in shape; the lower transversely oval; its inner border is a little thinner and a little more deeply concave than the 
outer. The sigmoid fossa of the ulna is large and concave; evidently the humerus has a considerable trochlear surface; the olecranon is not much produced, and was largely cartilaginous; near the extremity on the outer side there is a stout rugosity for muscular attachment. The radial border is deeply concave and stout; the inner border is thin and nearly straight. The distal extremity is considerably expanded, thick and angular on the radial side, thinner and rounded at the inner angle; doubtless a pisiform articulated here. Marsh speaks of an ossified carpus and tarsus. Among the numerous carpal bones there is none which I can positively refer to Nothodon. The ungual phalange shown in Plate XXXIV may belong with Nothodon, but since Eryops has similar ungual phalanges it may belong in that genus.

There are numerous vertebrae in the collection from different parts of the column which in much probability belong with Vothodon. For the most part the arches are separate, or have been so broken into fragments and dispersed that only a few have been restored to anything near completeness. The spine is stout, with a thick upper extremity (Plate XXXVI, Fig. 2), convex above and not much longer than broad; on each side above there is a ribbed thickening in the middle. The zygapophyses are rather stout, but there is no vestige of a hyposphene, so characteristic of Diadectes. The articular surface for the capitulum forms a distinct facet just back of the front margin of the centrum, and very low down. In this vertebra there is a small hypopophysial protuberance in the middle below and between the two capitular facets that reminds one of Elcobrosaurus Case. The centrum has a high and thin keel in the middle. The diapophyses were evidently of moderate length, but broken off in the specimen figured.

The type of vertebra described is very unlike that characteristic of the species of Diadectes from Texas, which resembles more the pariotichid type than the pelycosaurian, as does this. That these vertebrae belong with either Sphenacodon or Ophiacodon seems improbable, since no known forms of that group have elongated thickened spines; furthermore, the much greater number of vertebrae of the pelycosaurian type in the collection agrees better with the preponderance of skeleton and skull bones of the pelycosaurian forms. 
The sacral vertebra figured herewith must also be associated with this genus. The stout sacral ribs are turned downward, and their articulation is partly intercentral.

So far as the structure of the skull is concerned, as also the form of the limb bones, so far as they are recognized, there is nothing

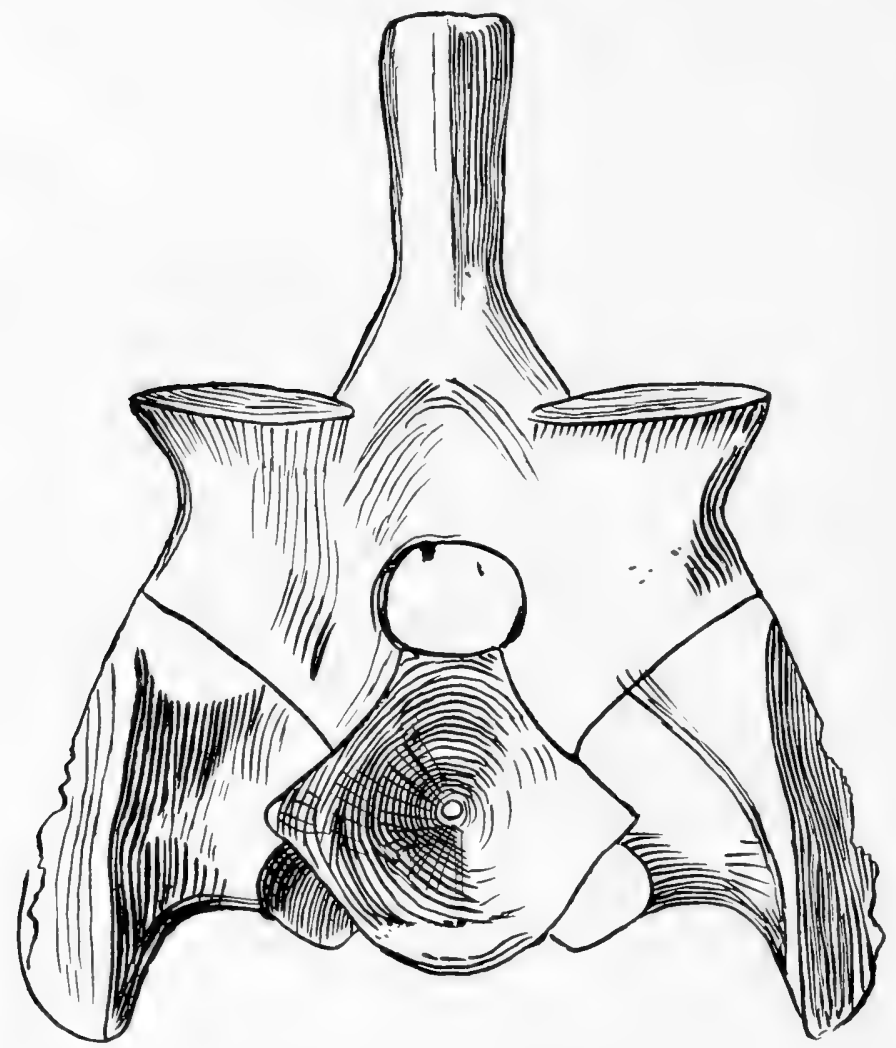

FIG. 2.-Nothodon lentus Marsh. Sacral vertebra, from in front, natural size.

in this genus to differentiate it from Diadectes, and inasmuch as the name Diadectes has priority of ten days or thereabouts over Nothodon it must stand, and inasmuch as a family name cannot be based upon a synonym, if the two names are synonymous the family designation Diadectidae must have precedence, notwithstanding the priority of Nothodontidae. If, on the other hand, 
Nothodon is proven eventually to be a distinct genus from Diadectes. the family name Nothodontidae Marsh has precedence over Diadectidae Cope.

Diadectes, sp.

In Plate XXXIV, Fig. 8, is given a photograph of an isolated tooth, showing the root, which I refer somewhat doubtfully to a small species of this genus. It was found associated with a very large species of Diadectes in the Craddock bone-bed.

\section{Family Limnoscelidae}

Williston, American Journal of Science, XXXI, 380, May, I9I I.

Allied to the Diadectidae, but the mandibular and maxillary teeth are elongate conical, those of the premaxillary very long, and three in number on each side; skull nearly smooth, elongate, depressed; no otic emargination; parietal foramen small; a single sacral vertebra; carpus and tarsus incompletely ossified; no hyposphene.

\section{LIMNOSCELIS}

Williston, American Journal of Science, XXXI, 380, May, I9I I.

Limnoscelis paludis Williston, op. cit. supra. New Mexico.

The types and only known material of this genus and species are two specimens, preserved in the Yale Museum, both from the same immediate locality in Rio Arriba County, New Mexico, and both inclosed in a like matrix, a rather dark, fine-grained sandstone, in nodular form. These two specimens seem to be specifically identical, as the slight differences observed between them may well be due to age or conditions of fossilization. Of one of them (No. Sog, Yale Museum collections) there is a nearly complete skeleton, save the skull and front feet and a part of one of the hind feet; the preserved parts lie, for the most part, in orderly articulation. The second specimen (No. 8I I) is almost perfect, the only missing parts that I observed being the right hind foot, and perhaps a part of the left hind foot, both of which had been more 
or less exposed and the bones somewhat weathered. This skeleton lies in the most orderly relations, with all its parts in close articulation, save such as had been disturbed by gravitation. It is without break, at least as far as the proximal third of the tail; some of the smaller caudal vertebrae may be missing, but, fortunately, the tail seems to be quite complete in the other specimen. This more perfect specimen (No. 8II), which may be considered the type of the species, was found among unpacked material only a few weeks before my departure from New Haven became necessary, and its preparation had not been quite completed. When fully worked out from the matrix and prepared for exhibition, it will be one of the most notable specimens of a reptile ever obtained from the Permian deposits of America.

The skeleton is evidently that of an animal which had died peacefully in some pool or body of water undisturbed by waves or currents; nor does it show any indications of extraneous forces. The animal at death rested with its ventral side downward upon a hard bottom, since all the bones had fallen, so far as was possible with their natural articulations, to a level, as is the case with fossils preserved in marine deposits. The skull and limbs are in perfect articulation, the vertebral column curved gently to the left, the pectoral and pelvic girdles intact and in position, and with all the bones of the limbs closely articulated, so far as they are preserved, at least, save a few of the terminal phalanges. The sacral vertebra is attached to the ilia, but the vertebrae immediately preceding and succeeding it had fallen to the level of the pubes and ischia. As the specimen lies in place it measures three feet four inches to the hind end of the ischia, while the articulated or nearly articulated tail of No. 809 has a length of forty inches to where the centra measure ten millimeters in diameter. Yet smaller, unarticulated vertebrae among the unassociated material indicate a possible length of the tail of forty-four or forty-five inches, or a total length for the the skeleton of about eighty-four inches.

Skull. -The skull of Limnoscelis paludis is remarkable in many respects, and fortunately this part of the specimen which serves as the type is noteworthy for its completeness and perfection of preservation. Like the remainder of the skeleton, with which it 
was in close articulation, it lay upon its ventral side, slightly depressed by its own weight in fossilization, and a little skewed to the right. As collected, it was broken in eight or ten pieces, the bone so firm that it permits the matrix to be removed very completely, which has been done by the skilful head preparator of the Yale Museum, Mr. Hugh Gibbs; not quite completely yet, the anterior palatal region being still invisible. Since the mandibles are clearly in natural relations with each other, save for the slight twisting. and the upper part of the skull is undisturbed, the obliquity has been corrected in the drawings-a matter of no difficulty. In a future paper a restoration of the skeleton will be given. Some facts of interest, especially the number and shape of the mandibular and maxillary teeth, were made out from the separated pieces before they were cemented together, characters which will again become visible when the preparation of the skull is completed. The surface of the skull is almost smooth with feeble indications of small pits.

The skull of Limnoscelis is remarkable among terrestrial reptiles for its elongated form and highly developed incisor teeth. The upper surface is nearly in one plane from the margin of the occiput to near the extremity of the rostrum, somewhat convex above in front of the eyes, and the parietal region is moderately convex on the sides. Fortunately the sutures of the skull nearly everywhere are quite distinct, even visible in the photograph as serrated or zig-zag lines. A few cracks are present, but they are not confusing save in a few cases, but those are in the most important part of the skull, the posterior temporal and occipital region. The sides of the skull, with the mandibles in place, are of nearly uniform height, that at the nostrils being quite what it is at the temporal region, unless there has been a slight depression in the latter place. From just in front of the orbits the skull widens very rapidly, the orbits themselves being nearly wholly concealed in top view by the overhanging roof of the skull. In front of the orbits there is a rather deep depression on each side. Back of the orbits there seems to have been a nearly vertical wall for some distance, and then convex broadly outward. The nares are of considerable size, oval in shape, and situated close to the 
anterior end of the skull. The orbits.are relatively small and situated far back, the distance between orbits and nares being greater than the extent of the skull posteriorly. They are oval in outline, somewhat narrowed in the specimen, their planes nearly

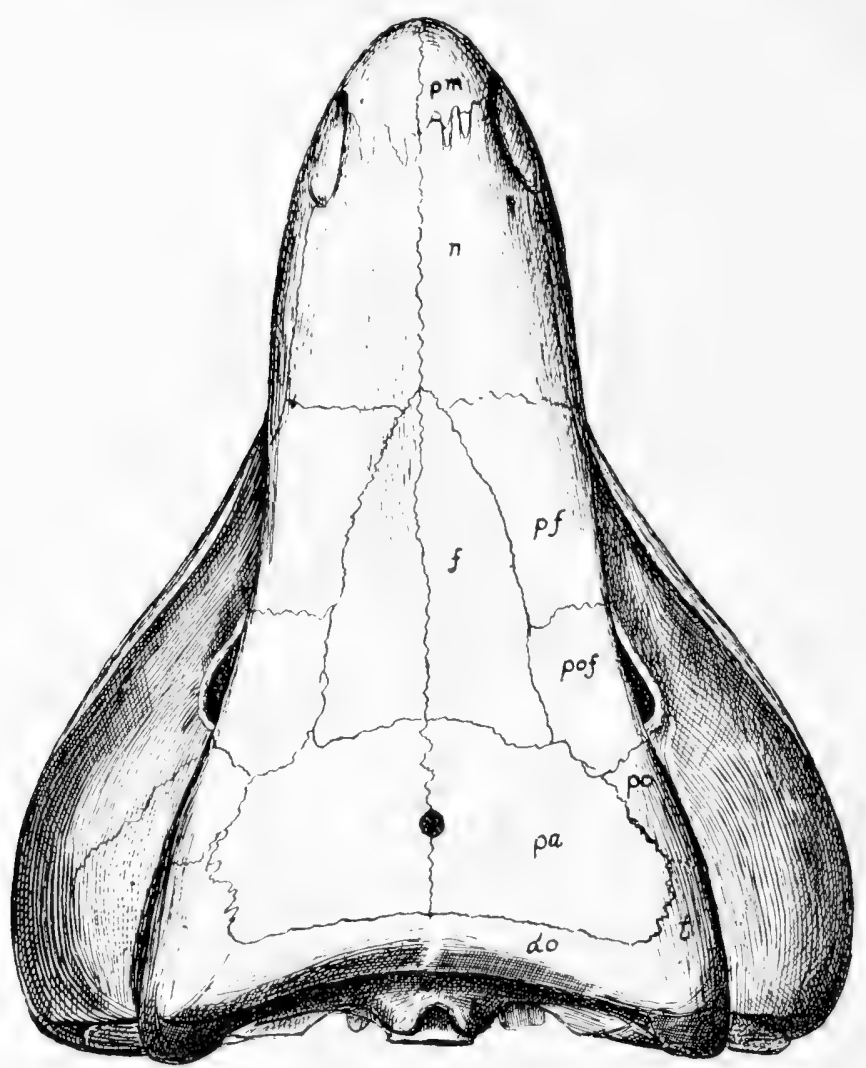

FIG. 3.-Limnoscelis paludis Will. Skull from above, two-fifths natural size. $p m$, premaxilla; $u$, nasal; $l$, lachrymal; $f$, frontal; $p f$, prefrontal; pof, postfrontal; po, postorbital; $p a$, parictal; do, dermoccipital; $t$, tabulare.

parallel to each other and nearly vertical, the posterior part turned a little outward.

The premaxillae are very massive bones, strongly protuberant in iront. The suture uniting them with the nasal is strongly digitative, beginning at the front end of the nares. Each premaxilla has three large, conical, and recurved teeth. In the specimen 
the interior one on the right side had been lost before fossilization, but its mate is complete; the second and third teeth are successively smaller, but of the same character as the inner one, long, conical, and recurved. The bases of two are present on one side, with indications in the matrix of their length. Doubtless when the skull is finally prepared the missing parts will be found. The long tooth lies in the specimen as I have figured it, directed downward and backward, and closely applied to the end of the mandible.

The maxilla has quite the same relations as in the other American cotylosaurs where it is known, a rather narrow bone united with the premaxilla below the nares, with the lachrymal throughout nearly its whole length above, and with the jugal posteriorly below the orbit, which it joins by a long, oblique, serrated suture. The precise number of teeth I cannot be sure of. On the left side the teeth are hidden by the obliquely compressed mandibles from the outer side; on the right they are not perfect. Before the parts were cemented together, Mr. Gibb worked out the left maxillary and mandibular teeth from the inner side in large part, and these have been used to complete the figures in the drawing. There are at least twenty in the maxilla, and perhaps more. The anterior ones are longer and stouter, conical like the incisors, and somewhat recurved. Their attachment to the bone is more or less pleurodont. The posterior teeth are shorter, but are also nearly circular at their bases. There is but one row. The nasals are very large bones, occupying nearly the whole of the upper surface of the skull in front of the orbits, and are gently convex or flat. The lachrymals, as in probably all Cotylosaurians, are elongate, forming the posterior border of the nares and a part of the anterior border of the orbits. As in the Diadectidae, and quite unlike the condition in the Pariotichidae, the small frontals do not take any part in the orbital border, which is formed by the prefrontals and postfrontals; as in the Diadectidae, both these bones are short and broad, reaching scarcely beyond the orbit in front or behind. The parietals are short, broad bones forming most of the superior surface of the skull back of the orbits; the parietal foramen is of the usual size, very unlike the enormous one of the Diadectidae. The sides of the skull back of the orbit are formed chiefly by the 
squamosal, very clearly distinct from the small quadratojugal on the lower posterior margin, but not distinguishable at present from the postorbitals and epiotics quite to my satisfaction. Back of the parietals are the narrow transverse dermoccipitals, which seem to be quite distinct from a small bone at the outer angle, which doubtless is the tabulare (epiotic). The structure of the posterior part, the occipital region, is somewhat confusing, and I do not feel at all sure of my determinations. The discussion of this region I reserve for a later paper, hoping that additional material may be forthcoming. The structure of the palate, so far as it has been developed in the specimen, is most interesting. so closely resembling the "rhynchocephalian" type that a few years ago, had it been found without other parts of the skull, it would have unhesitatingly been located in the "Diapsida" and "Diaptosauria." The specimen has not yet been thoroughly cleaned in the anterior part, so that I can say nothing of the romers. The palatines and united pterygoids are, as in Labidosaurus and Pariotichus, separated by a more or less elongated interpterygoidal space. The eminence in the region of the transverse, if the bone be distinct, as I think it is, is crowned by a row of five or six teeth, evidently more or less conical in life, but unpreservable in the preparation of the skull. In front of these teeth I can find evidence of but a single tooth, located as I have marked; I am not quite sure of it, but in all probability there were others. Opposite the front end of the basisphenoid, the pterygoid on each side articulates with a stout basipterygoid process of the basisphenoid, quite as in the lacertilians, the first evidence I have seen among the Permian vertebrates of a real articulation at this place. The pterygoid has a pit or depression on the inner side for the head of this large process. Back of these processes the pterygoids resemble remarkably the like processes of the lizards, a not very wide, rather stout. obliquely placed process reaching backward to articulate with the lower inner side of the quadrate. In the middle the large basisphenoid is conspicuous; unlike that of the Diadectidae it is stout and rounded below, where it gives off the basipterygoid processes. Anteriorly it gives off the so-called parasphenoid. But the "parasphenoid" in this case is a thin vertical plate, thickened poste- 
riorly to join the anterior end of the basisphenoid, very much as in Trinacromerum among the plesiosaurs. In the specimen the front part lies obliquely in the matrix an inch or more in width, with the lower margin, that visible in its normal position, narrow. Behind the rounded median convexity of the sphenoid, the bone

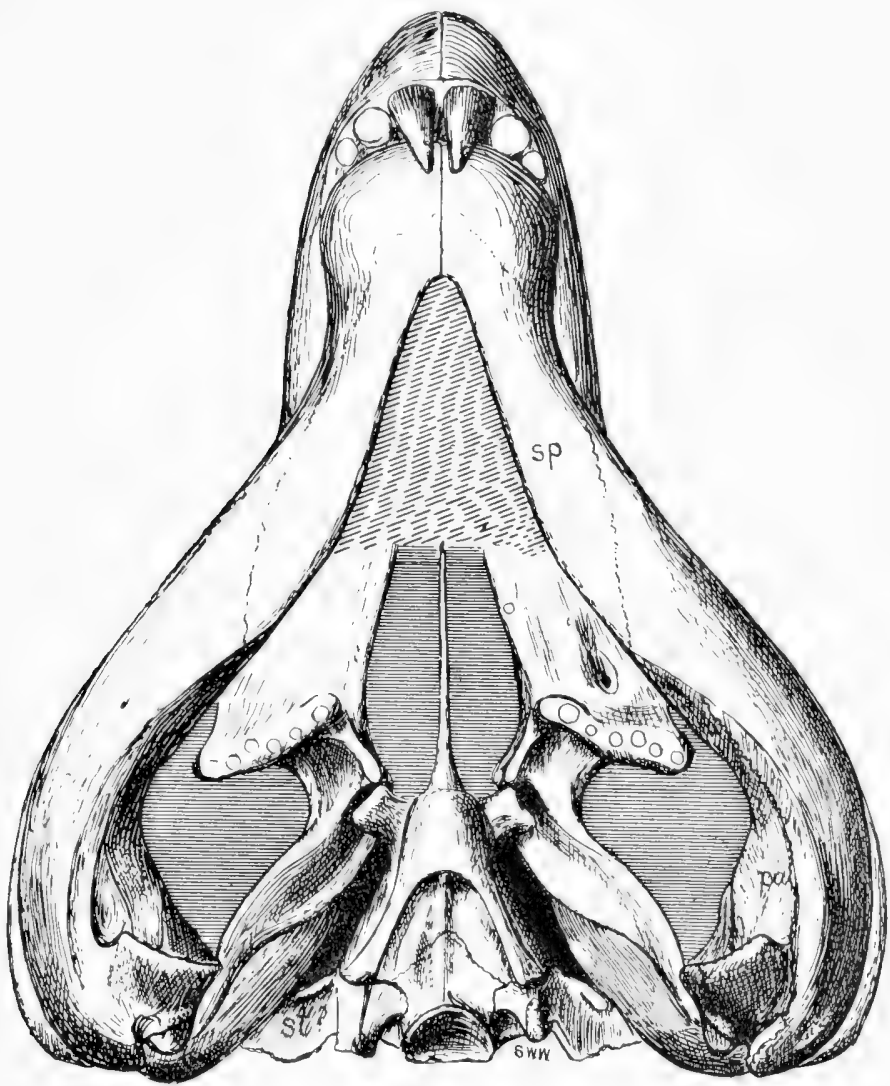

FIG. 4.-Limnoscelis paludis. Skull, from below, two-fifths natural size. sp, splenial; $p a$, prearticular; st, stapes (?).

is broadly concave in the middle, on either side of which the usual basisphenoid process is directed downward, backward, and outward, to end in a rather stout projection. In the middle of this concavity the sutural line for union with the basioccipital is evident. The occipital condyle is quite flat or even concave, as in Diadectes and 
Pareiasaurus, a strong indication of relationship. On either side of the basioccipital I think I have interpreted the bones of the posterior palatal and occipital regions, but I prefer to wait before publishing my conclusions, in the hope of getting additional material of this form the coming season.

The mandibles of Limnoscelis are very powerful, indicative of the carnivorous habits of the animal in life. They lie in perfect relation to each other, save that they are a little skewed to the right. They are broadly separated behind, with a long convexity on the sides, and again expanded at the front end. The teeth are only partly visible from without; the one or more large ones in front opposing the premaxillary teeth is wholly hidden; nor can

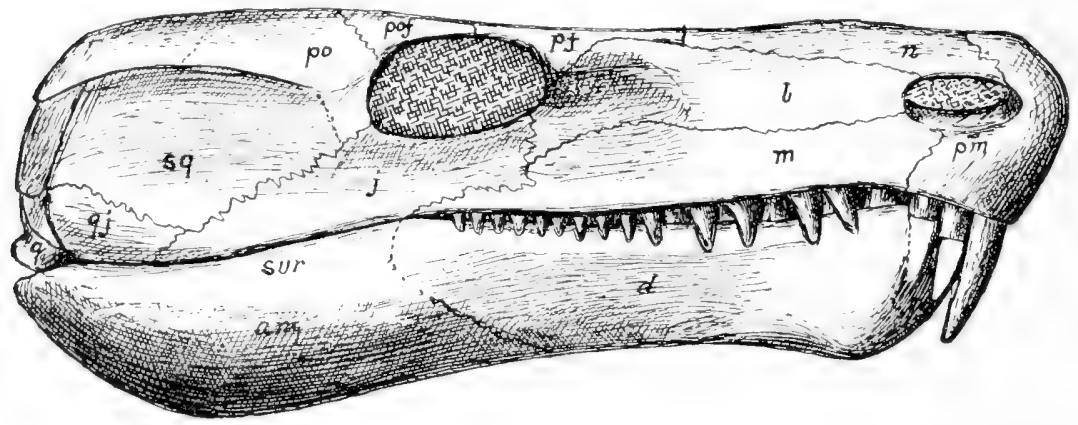

FIG. 5-Limnoscelis paludis. Skull, from side, two-fifths natural size, pm, premaxilla; $n$, nasal; $l$, lachrymal; $m$, maxilla; $p f$, prefrontal; pof, postfrontal; po, postorbital; $j$, jugal; $s q$, squamosal; $q j$, quadratojugal; $q$, quadrate; $d$, dentary; sirr, surangular; ang, angular.

the number be made out with certainty. The postarticular process is small, not extending back of the quadrate, or if so, for a few millimeters only. Externally the suture separating the angular from the surangular passes forward near the upper part of the bone, and backward nearly to the extremity. On the inner side of the mandible the structure is peculiar. A broad flange is directed inward, nearly vertically, opposite the middle of the articular surface, concave in front. The suture separating the prearticular from the articular is very conspicuous, passing back over the flange. In front the prearticular passes far forward, between the upper opening to the cavity of mandible and the 
elongated opening of Meckel's groove near the middle of the inner side, before the middle of the bone antero-posteriorly. A fracture of the mandible a little in front of the articular shows a large cavity with an elongated opening above back of the teeth. The elongated vacuity is bounded by the angular below, by the splenial in front:

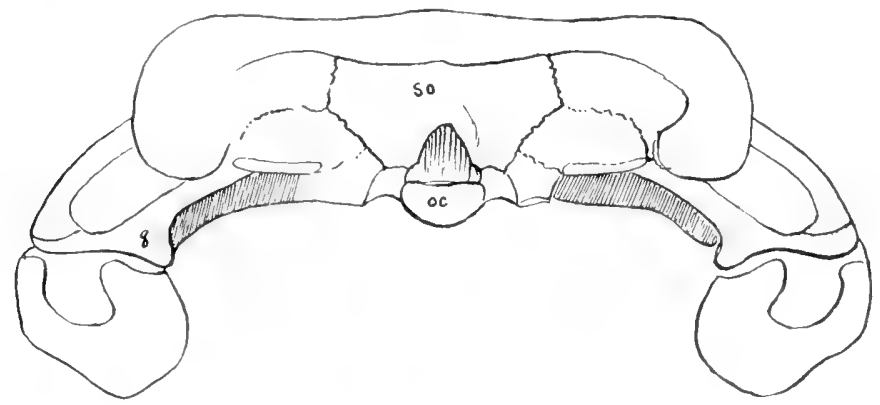

FIG. 6.-Limnoscelis paludis. Outline of back of skull, two-fifths natural size.
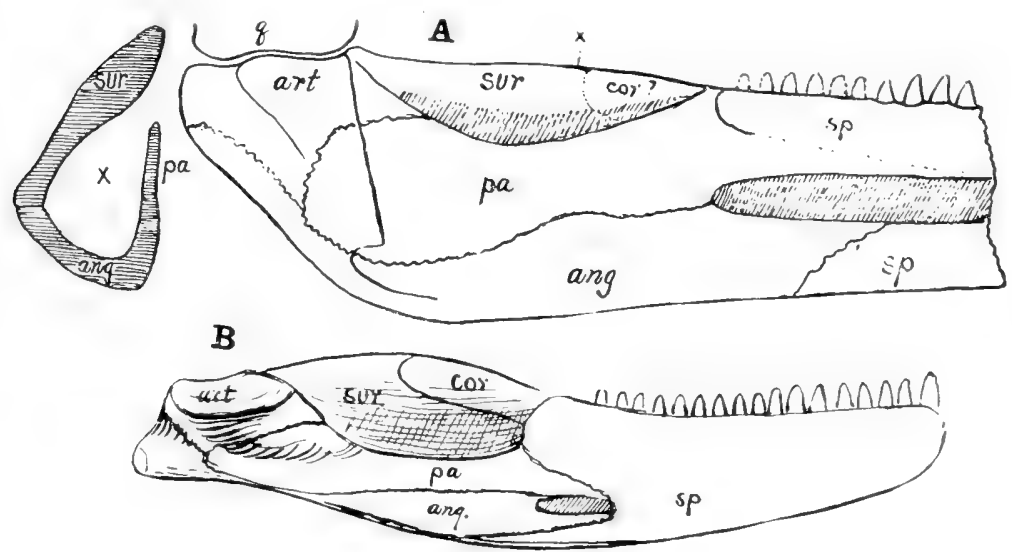

FIG. 7.--Inner sides of mandibles, one-half natural size. A, Limnoscelis paludis; $B$, Labidosaums hamatus. art, articular; q, quadrate; sur, surangular; cor, coronoid; $p a$, prearticular; ang, angular; sp, splenial.

by the prearticular above behind, anteriorly apparently by the coronoid; it is evidently merely the exposed groove. The splenial is very broadly visible on the under side of the mandible, the suture between it and the dentary beginning some distance in front of the posterior end of the median symphysis, and extending 
back nearly as far as the posterior end of the internal vacuity. On one side a piece about two inches in extent of this bone has been peeled off from the dentary, showing the bone to be thin, not more than six or eight millimeters in thickness. In front, the splenial turns upward to cover the inner side of the mandible below the teeth, covering the groove for Meckel's cartilage anteriorly. Interesting is the fact that the existence of a separate prearticular bone is demonstrated beyond doubt in this genus. and also that the splenials meet in a median anterior symphysis as in Labidosaurus, the early long-snouted crocodiles, Plesiosauria, etc. I give herewith a figure of the inner side of the mandible of Labidosaurus, showing a very similar arrangement of all the bones; the suture separating the prearticular from the articular is very evident in part, if not all its course.

The separate prearticular bone is evidently characteristic of the Cotylosauria if not all the early reptiles and amphibians. I have, I think, demonstrated its existence in the Plesiosauria, though Andrews, in his latest paper on the plesiosaurian mandible, ${ }^{1}$ has not distinguished the suture separating it from the splenial. The prearticular, with the same relations as those of the plesiosaurs and cotylosaurs, is also present in the ichthyosaurs, though called the coronoid by Merriam, Gilmore, and Andrews. In all cases it passes below the large posterior opening of the mandible for the entrance of the nerves, the vacuities below and in front of the bone being for the most part merely openings into Meckel's groove, as in the crocodiles, Erpetosuchus kansensis Moodie, etc.

Vertebrae.-Eighteen presacral vertebrae have been cleared of the matrix, in a continuous series curved to the left. The lengths of these vertebrae are almost exactly the same throughout; in front of the exposed ones the vertebrae above the pectoral girdle have not yet been cleared of their matrix; the space in which they lie corresponds almost exactly to that of the five vertebrae following them, and that is probably the number yet hidden. In front of these the atlas and axis have been partly exposed, giving twenty-five as the total number of presacral vertebrae, two more than is known to exist in Seymouria, and probably two more

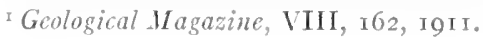


than in Captorhinus laticeps Will. The number in Limnoscelis will later be determined with certainty. The first of the series exposed, the eighteenth presacral, has a shallow fossa or flattened surface below in the middle, which fossa increases in depth posteriorly,

a very characteristic feature which seems to differentiate the genus from others previously known, especially Diasparactus Case. The outline of the centra, both on the sides and below, antero-posteriorly, is deeply concave. The arch has a marked resemblance to that of Diadectes, and, according to Broom, to that of Pareiasaurus also, and is very different from the type characteristic of Labidosaurus

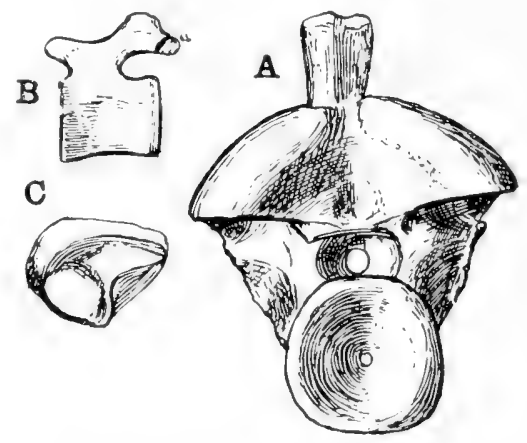

Fig. 8.-Limnoscelis paludis. A, posterior dorsal vertebra, from behind; $B$, twenty-second or twenty-third caudal vertebra, from the side; $C$, ulnare.

and Seymouria. It differs from that of Diadectes especially in the absence of all indications of a hyposphene; but, if I am correct, Nothodon, which is of course a diadectid, also lacks the hypo-

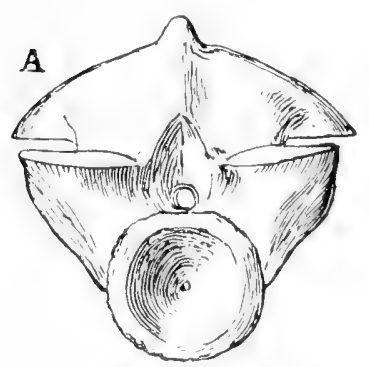

FIG. 0.-Limnoscelis paludis. Posterior dorsal vertebra, one-half natural size. $A$, from in front; $B$, from the side.

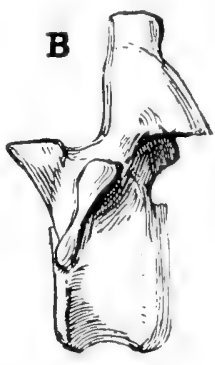

sphene, rendering the character in consequence merely of generic value.

All the observed ribs are single-headed, but expanded; that is, without an emargination distinguishing the head from the tubercle. In Diadectes, or at least in such species as I have been able to study of this genus, the ribs anteriorly are distinctly double-headed. The transverse processes are short throughout the series, scarcely extending on the sides beyond the margin of the zygapophyses. This character has been given by 
Case as a distinctive one for his genus Diasparactus, but, in a large species of Diadectes from Texas I do not find any appreciable difference in the prominence of the processes, at least in the posterior presacral region. The spines are moderately elongate through the series, thickened and somewhat rugose at the upper end. There are large intercentra between the centra below, and as the vertebrae lie in the matrix a considerable space is left between the adjacent vertebrae for cartilage, indicating a very flexible, though not very firm spinal column. The spines, of the posterior part of the column at least, are about one inch in length. The first presacral spine is rather broad and expanded above, the second and more anterior ones are more slender. There is but one sacral vertebra, which has a very broad, stout, sacral rib on each side, turned directly downward so as to cover nearly the whole of the inner side of the ilium at its junction with the ischium and pubis, its antero-posterior width being $60 \mathrm{~mm}$., its vertical width where it joins the ilium. $40 \mathrm{~mm}$. The ribs immediately in front and behind are small and slender and do not seem to touch the ilium at all. Case has described Diadectes as having two sacral vertebrae. but in the specimen in the Chicago collections, of a large species, the structure of the sacrum seems to be quite as in Limnoscelis; and this is also the case in a new genus of Diadectidae, which Professor Case will describe from a specimen in the University of Chicago collections, collected by Mr. Miller.

The first chevron occurs at the hind end of the third caudal vertebra, the first one visible above the ischia from below; the first three or four of the caudal vertebrae have short free ribs, as in other genera of American Cotylosauria. The tail, as preserved in specimen No. 908, is rather slender, with short spines and chevrons, precluding the idea that the animal was natatorial in habit. The terminal vertebrae are a little elongated.

Pectoral girdle and extremity. - The pectoral girdle lies in very orderly arrangement, with little if any distortion. Both clavicles are in articulation with the interclavicle, scapulae, and cleithra. The clavicles have the usual cotylosaurian form, curving under the anterior end of the interclavicle and the anterior margin of the coracoid, curved and somewhat spoon-shaped below. The long. 
dilated, scapular part is curved upward in a vertical plane and obliquely backward in the articulate skeleton, reaching nearly to the upper end of the scapula, flattened from side to side above. The cleithrum is small and vestigial, smaller than in Diadectes, a slender, cylindroid bone, reaching quite to the superior anterior angle of the scapula, but not expanded over the end, as in the temnospondyls. It is dilated at its lower end to articulate with the attenuated upper extremity of the clavicle, lying between the clavicle and the front margin of the scapula. It is only a little more than two inches in length. The scapula is very short. The blade above is narrow, thinner, and curved outward on its front part, thickened at its posterior superior border. Its upper end is truncated, and doubtless had a suprascapular, cartilaginous continuation, possibly the representative unossified of the upper end of the cleithrum. The glenoid fossa is deep and large, the stout metacoracoid extending far back relatively. The posterior border of the scapula is curved nearly uniformly from the angle to the extremity of the preglenoid facet, which is large and flattened. There is a distinct supraglenoid fossa a little below the middle of the bone, between the

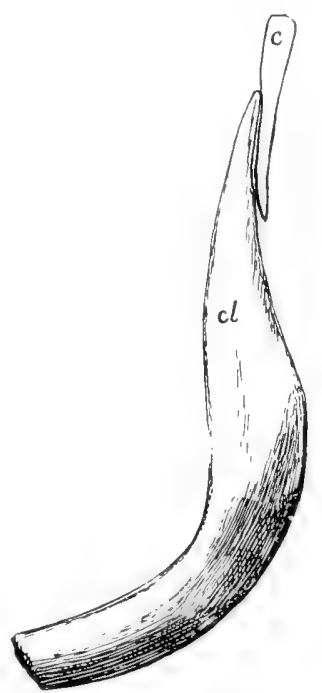

FIG, ro.-Limnoscelis $p a-$ ludis. Left clavicle and cleithrum from in front, two-fifths natural size. borders which diverge near the middle of the length of the scapula; it is pierced in the usual temnospondyl way for the passage of the supraglenoid canal. I have observed this foramen in this position in scapulae which I refer to the genus Ophiacodon, but usually in the Pelycosauria the opening pierces the bone in front of the scapular margin. I had supposed that this foramen was characteristic of these old orders of reptiles, never having seen any reference to it in literature of other orders of vertebrates. But I am surprised to find that it is quite typical of certain lizards, and it perhaps occurs in other reptiles. In the present 
reptile I have observed for the first time in any form other than the amphibia the inner opening of the foramen or canal back of the border of the subscapular fossa, which I have called the glenoid foramen. That the canal perforates the bone to open in the glenoid fossa I am not prepared to affirm. I find, however, that the foramen is also present in the Diadectidae, and perhaps in other cotylosaurians. Its presence removes the last distinguishing character between the temnospondyl and cotylosaurian pectoral girdles. One

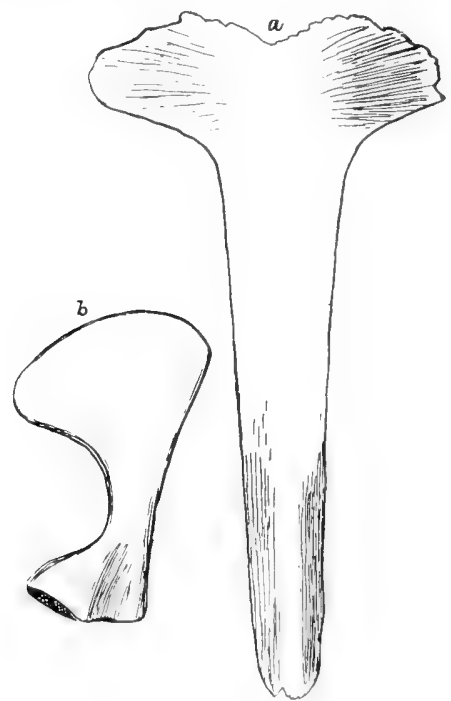

Frg. II.-Limnoscelis paludis. Interclavicle and hyoid, two-fifths natural size. may distinguish them now only by the smaller size of the cleithrum in the reptiles!

The suture separating the posterior coracoid is situated not far back of the supracoracoid foramen, which is unusually large. The limits of the anterior coracoid are not distinguishable; the bone is thinned, rounded on the anterior angle, which is slightly underlapped by the clavicle, and, with the metacoracoid, is curved inward nearly to a horizontal plane, approaching its mate of the opposite side, but separated by the stem of the interclavicle. The interclavicle reaches a little farther back than the hind angle of the metacoracoid, and is of moderate width; its front part is dilated and mostly hidden from view, as in the other Permian reptiles.

In each skeleton there is a pair of bones found lying just back of the coracoids, and nearly below the vertebrae, of the nature of which I am not fully satisfied, though there would seem to be little doubt but that they are unusually large hyoids (Plate XXXIII, Fig. 2). They are about three inches in length, greatly expanded on their distal, thin end, with a somewhat curved and narrowed shaft deeply concave in outline on one side, less so on the other, thickened and truncate for articulation at the proximal end. The 
two bones in each specimen lie with the thin ends nearly in apposition, as though they had joined each other in life.

Humerus. - The humerus is a remarkably short and thickset bone, resembling that of Diadectes more closely than that of any other genus that I know. The ectocondyle is more expanded and turned inward than in that genus, however, nor is the proximal expansion so much twisted from the plane of the entocondyle as is the case with the humeri of more terrestrial Permian reptiles. The entepicondylar foramen is large, situated not far from the lower extremity of the lateral process. The ulnar expansion is broad and flat, and occupies a plane divergent from that of the proximal inner side of about fortyfive degrees. The capitellum is very large and rounded, situated on the outer angle of the bone, as seen from the ventral side, and is remarkably close to the lateral process. The ectocondyle is remarkably stout and protuberant, and is directed almost rectangularly, or even at an acute angle backward, termi-

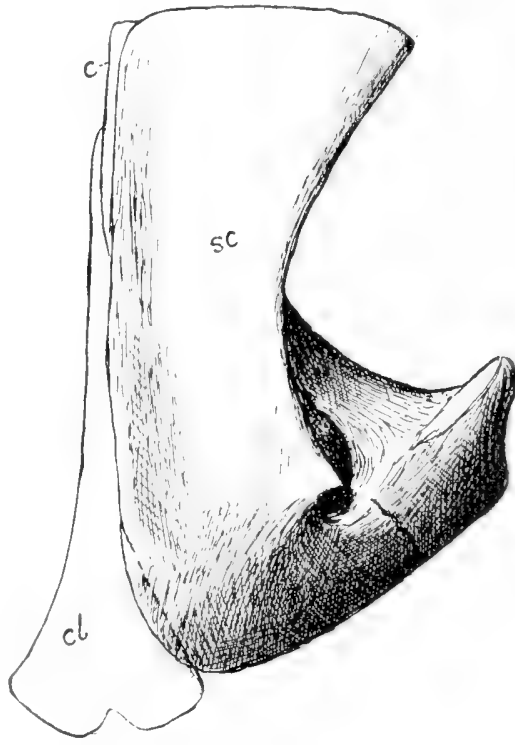

FIG. I2.-Limnoscelis paludis. Left capula, with clavicle and cleithrum, twofifths natural size. Sc, scapula; $c$, cleithrum; cl, clavicle.

nating very near the middle of the bone transversely, and above the groove for the ulna on the dorsal side. It is an interesting fact that not only the structure of the humerus, but also the whole anterior limb, resembles not only that of Diadectes, but also that of the amphibian Eryops, suggesting similar habits in all three animals, and possibly, too, genetic affinities. There is a moderately stout ectepicondylar process, as in Desmospondylus, Seymouria, Diadectes, Eryops, etc. It is situated a little below the lateral process on the radial side. 
Radius, una.-The radius and ulna are very like those of Diadectes and Eryops, rather short and stout bones. The two lie in position on each side, as shown in the figure, the upper end of the radius partly lodged in the lower end of the sigmoid fossa. and the two are in one plane. The radius has the capitulum truncated and hollowed for articulation with the humerus, the extremity strongly convex on the dorsal, flattened on the ventral side. The shaft of the bone is moderately narrowed, and its two borders are nearly symmetrically concave. The lower extremity is more expanded, with its end truncate and flattened for articulation with the radiale and intermedium, the inner side the thicker. Just above the inner distal angle there is a characteristic protuberance, which evidently came in close contact with the ulna. The ulna is a more slender bone and is a little longer; it is thick and massive at its upper end, the shaft more slender than that of the radius, and the lower end moderately expanded. Its radial border is deeply concave, its inner border nearly straight to the lower fifth. The sigmoid fossa is deep, winding obliquely about the bone, and fits accurately the curved trochlear surface on the distal and dorsal side of the humerus. Evidently the elbow joint was a strong and firm one. The distal extremity of the ulna is subtruncate, its border somewhat oblique to that of the radius, but with the angle broadly rounded for articulation with the pisiform. Both radius and ulna have the dorsal side convex, the ventral more flattened.

Front foot.- Lying in close articulation with the radii and ulnae are the proximal carpal bones, four in number on each side, the radiale, intermedium, ulnare, and pisiform. The pisiform is a small bone, thinned along its free border and articulating in its usual position between the ulna and ulnare. The ulnare, the largest of the carpal elements, is an irregularly oval bone, articulating rather broadly with the ulna and the intermedium, but without distinct facets for the other carpal elements. The smaller intermedium is much thickened, articulating with the ulna, ulnare, and the radius, with a very small free border between the ulna and the radius. The radiale is the smallest of the three, almost vestigial in fact, elongate, ovate in shape, with the radial border straight and flattened, the outer end obtusely pointed; it merely 
touches the intermedium. The ventral surface of all three of these bones is flattened, the dorsal more rounded, that of the radiale obsolete. Especially remarkable is the fact that all of these proximal carpal bones save the pisiform are very small, smaller than in Diadectes even, and much smaller than in other known Permian reptiles.

The remaining bones of the right foot were found nearly all connected, for the most part in the relations of the living animal. The foot had been slightly twisted in fossilization, disturbing somewhat the relations of the metapodials. Of the phalanges all were found in association save two terminal ones, the distal phalanges somewhat confused in the three middle fingers. The three distal carpal bones were found in the positions shown in the figure, but there were no traces of others, and they could have hardly escaped notice had they

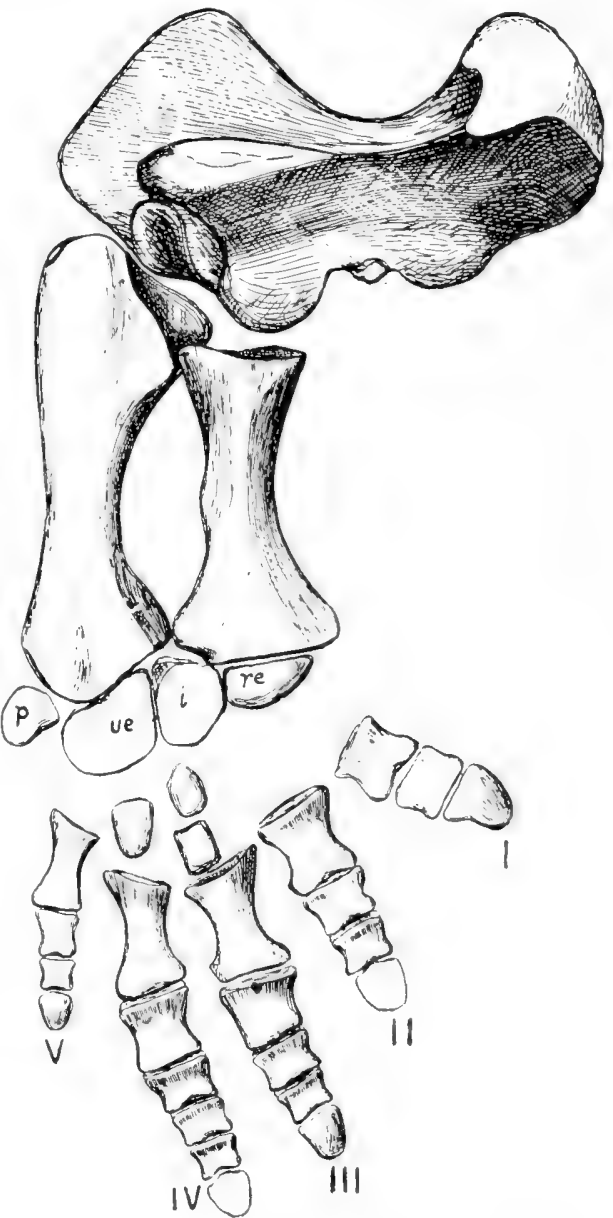

FIG. I3.-Limnoscelis paludis. Right front leg, dorsal side, two-fifths natural size. re, radiale; $i$, intermedium; ue, ulnare; $p$, pisiform; $\mathrm{I}-\mathrm{V}$, firstfifth digits. been fossilized with the others. Evidently these nodular bones represent the centrale and the third and fourth carpalia. Fortunately the bones of the left foot were found in the matrix in as 
natural relations as one could wish, and they will be so retained in the prepared skeleton. The block containing the distal carpals and the digital bones had been separated in collection from that containing the forearm and proximal carpals, and was not accurately readjusted. The three carpal nodules are quite as in the other hand with no traces of others; from which facts I have no doubt that they were the only ones ossified, and they but imperfectly. Of the digits the bones of the three middle toes were all in perfect articulation save the ungual phalanges of the second and fourth digits, which are missing. Of the first digit, the ungual phalange is displaced and the phalanges of the fifth have not been adjusted to the metatarsal. However, these digits were preserved in perfect articulation in the right foot. From these facts, which I have given in detail because of their importance, it is certain that the phalangeal formula is, as is seen, 2, 3, 4, 5, 3, fixing for the first time the foot structure in an American cotylosaurian, and save for Procolophon, in any member of the order. My figure was made by simply tracing the outlines of the various bones as they lie in position and transferring them. The only doubt that remains is the precise width of the space I have left for the carpal elements; it may be a trifle too broad. As is seen, the foot is remarkably broad and flat, lying in the matrix in nearly one plane, with the phalanges short, the ungual ones broad and hooflike as in Diadectes, and probably also Eryops. The foot resembles that of Diadectes somewhat, save that the proximal carpal bones are large, and the distal row seems to be fully ossified in that genus.

Three years ago I expressed the opinion that the phalangeal formula $2,3,4,5,3$ (4) was the primitive one for land reptiles, if not for land rertebrates, as observed in Eosauravus copei. Broom is of the opinion that this is the formula in Propappus and he has proven it to be that of Procolophon. Dromopus agilis Marsh, as figured by the author and Matthew, shows a similar phalangeal formula. These footprints are from near the upper part of the coal measures in the ricinity of Osage. Kansas. Marsh thought that they were made by a lacertilian rather than an amphibian, a natural error considering the lacertilian form of the prints. 
They probably come from some microsaurian reptile not unlike Eosauraous copei.

Pelvic girdle and extremity. - The pelvic girdle lies in natural articulation, with but little disturbance; the right pubis is a trifle compressed, and the extremity of the left ilium had been broken

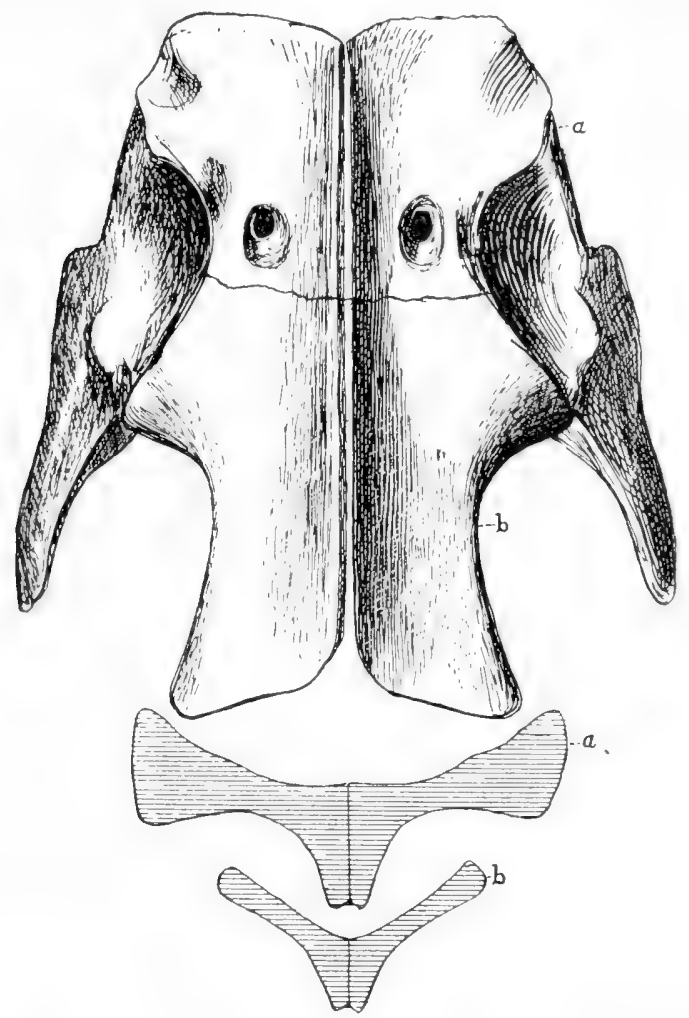

FIG. I4.-Limnoscelis paludis. Pelvis, from below, two-fifths natural size. a, cross-section through pubes at $a ; b$, cross-section through ischia at $b$.

off and turned aside before fossilization. Both femora are closely articulated in the acetabula, directed obliquely dorsad and cephalad. The pubes and ischia lie in a subhorizontal position, with a protuberant carina along the middle, deeper anteriorly. This keel, however, is not formed by the downward deflection of the margin of the bones, but by the increased depth of the symphysis, as will be seen from the cross-sections of the figure, sections made at points 
of fracture in the specimen. The ischia have an angular margination in the middle, the sides curving outward and upward to the rounded posterior angle. The sutural division between ischium and pubis is at about two-fifths of the length from the front end of the pelvis. The pubic foramen is remarkably large at the bottom of a rather deep fossa situated a little in front of the ischio-pubic suture, and not far from the acetabular border. The acetabulum is deep and large, with an overhanging, nearly horizontal roof-like process, at the upper posterior part. In life the

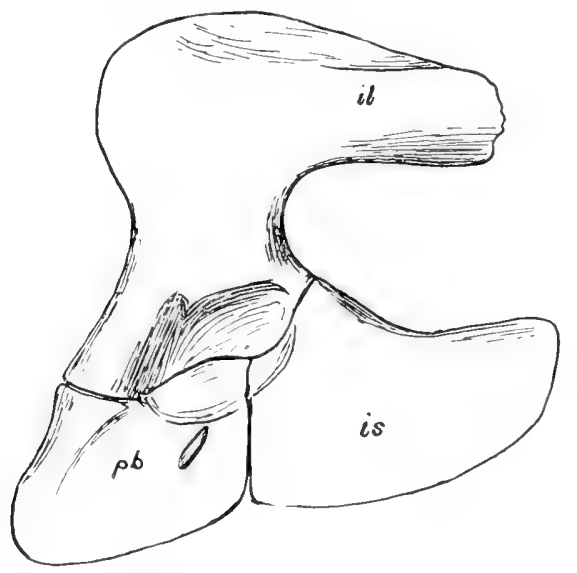

FIG. I5.-Limnoscclis paludis. Diagram of pelvis, from the side. il, ilium; $p b$, pubis; is, ischium. cavity looked almost directly outward. The ilium is relatively small; it is flattened and thinned above and in front, with a rather stout, narrow process directed backward and a little outward, nearly horizontal. Upon the whole, the structure of the pelvis is nearlyidentical with that of Diadectes and the Pariotichidae, and even of Eryops and Cacops, save in the form of the ilium; in Diadectes, broader above and produced backward; in the temnospondyls without iliac projections either in front or behind. While there is but a single sacral vertebra in Limnoscelis and Seymouria, in Cacops there are two, a precise reverse of what has often been supposed to be diagnostic characters of these two classes of vertebrates. The femur is of the characteristic Diadectes type, short, stout, and expanded, with a heavy, protuberant trochanter, and a large digital fossa. The trochanter has a large facet, 20 or more millimeters in diameter, looking backward, and is rugose; the adductor ridge is pronounced and oblique. The tibia, like the femur, is short and stout, with a greatly expanded upper end, and a strong cnemial protuberance. The outer side is deeply 
concave in outline, the inner less so. The lower extremity is much thickened. The fibula is a more slender bone than the tibia, and is longer. Its proximal end is thickened and subquadrate in shape; the lower end is thin and considerably expanded.

Hind foot.-As already stated, the foot bones of specimen No.8I I were more or less weathered. From the wash numerous toe bones and the ends of the epipodials with attached carpals had been gathered up by Mr. Baldwin, and some of them still retain enough of their original matrix to show their relationships, but how many of them are irretrievably lost cannot be determined at present. Fortunately, however, in specimen No. 809 the tibia and fibula of both sides were preserved in position with the tarsal bones attached; fortunately, since one would hardly have identified the tarsal bones correctly had they been found isolated, so very different are they from the corresponding bones of the Pariotichidae or Pelycosauria. The tibiale is nearly cuboidal in shape, with a slight notch only between the articular facets for the tibia and fibula. Its outer facet is thickened for union with the fibulare, but I

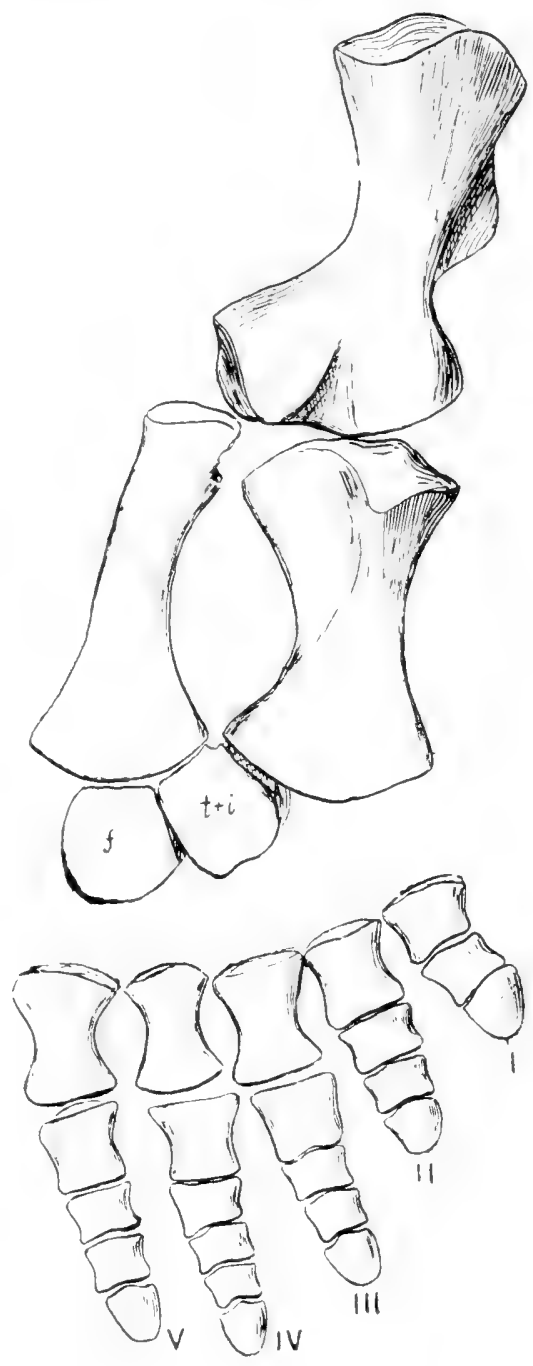

lis, 16.-Limnoscelis paludis. Right hind leg, dorsal side, specimen No. 809, twofifths natural size. $t+i$, fused intermedium and tibiale. 
see no perforating foramen between the two bones. The distal and inner facets are also very broad, subquadrate in outline, with rounded angle. The fibulare is a larger bone, but much thinner than the tibiale; its tibial side is the thickest. I identify these two bones as the usual fused tibiale and intermedium, and the fibulare, but it is not impossible that the tibiale has been entirely lost, after fusion, and that what really remains are the intermedium

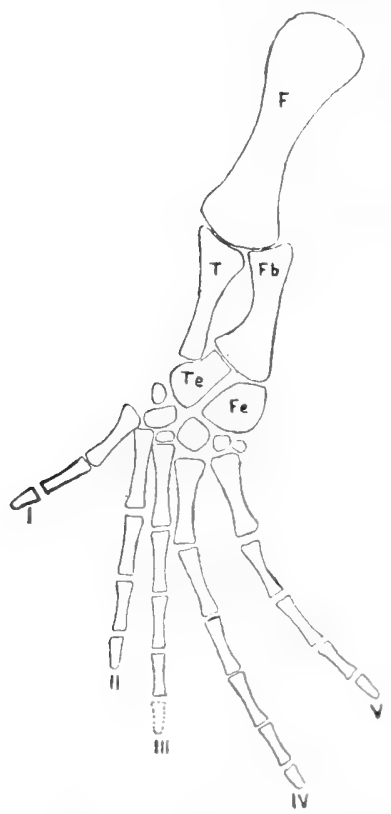

Fig. I7.-Eosauravus copei Williston. The oldest known reptilian tarsus and foot. Middle Pennsylvanian. and fibulare. I have so far found no evidence satisfactory to me that the tibiale and intermedium are ever present in adult reptiles as distinct bones. I am aware that Broom has provisionally recognized a separate intermedium in Howesia, and that other instances have been cited, but I think they are all open to doubt. The separation of the intermedium of the hand is a very persistent character in the Amniota, man himself even having the same bones that are found in the temnospondyls in the proximal row of the carpus. In the tarsus, however, there was an early specialization as far back as early Carboniferous times, and I do not think there was ever a reversion to the amphibian type.

Of the left foot of specimen 908 only these two tarsal bones and a number of separated toe bones have been recovered. Of the right foot, however, all the bones of the toes were preserved in their natural relations in the matrix, or with but slight distortions, the metatarsals all lying in one plane, apparently quite in the positions they occupied in life. The block containing them had the phalanges of the first toe, the first one of the second toe. the first two of the third toe, and all four of the fifth toe in close articulation, those of the first and fifth toes strongly flexed. With this block, but separated, were the phalanges of the middle toes. the two each of the second and third and all five of 
the fourth toe severally connected by matrix, but not positively attachable to the basal bones of their respective digits, because of the effacement of the matrical surfaces in collecting. That they belong with these toes is, however, beyond doubt, both because of their perfect anatomical association and the peculiarities of the matrix. The formula as is thus seen is, like that of the front feet, the primitive one for reptiles, $2,3,4,5,4$. The phalanges, as of the front feet, are all remarkably short and broad, and I may also add, relatively thin. The ungual phalanges, as have been described for Diadectes, which they resemble, are short, broad and hoof-like rather than claw-like, with a thin rounded extremity, the bones possibly incased in a horny nail in life. I can hardly conceive of a foot of this character being used for burrowing, notwithstanding Case's comparison of the similar feet of Diadectes with those of the gopher. The right front foot, as preserved in the matrix, had the tibia and fibula, with their attached proximal carpals, pressed downward somewhat below the proximal ends of the metatarsals, but not a vestige is preserved in the matrix of centrale or tarsalia, nor is there any tarsal bone preserved with either specimen, save the four sets of proximal ones. It is not at all impossible, however, that vestigial, nodular tarsalia may have been ossified, but it is not very probable that they were. Chondrification was evidently here a specialization, and in accordance with the almost universal rule among terrestrial vertebrates we should expect that the process would develop more rapidly in the hind than in the front feet.

As bearing upon the probable aquatic adaptation of the carpus and tarsus of Limnosclis and their chondrification, it will be of interest to compare the several stages of evolution in their progressive adaptation to aquatic life in the American genera of mosasaurs, figures of which will be found in my work upon the mosasaurs in the fourth volume of the University of Kansas Geological Survey. In Clidastes (Plate XXXIII) it will be observed that the proximal row of carpal bones is fully ossified, all four of them large. the radiale largest of all. The centralia have disappeared, or what is less probable have united with adjacent bones. Of the carpalia the first and fifth have disappeared, leaving the second, third, and fourth of nearly equal size. In the restorations the fifth and first 
digits are placed in immediate contact with the bones of the first row; probably in life they were separated by a cartilaginous interval. In Platecarpus (Plate XLIV), the radiale and pisiform have disappeared, the intermedium and ulnare alone remaining with the third and fourth carpalia, the second gone. In Tylosaurus (Plate XLVIII) the ulnare alone remains of the carpus, and that very small and nodular, though in other specimens a very small, nodular intermedium is sometimes found. In Clidastes hyperphalangy is just beginning, no finger having more than two extra phalanges; in Platecar pus hyperphalangy had progressed until four or more may have been acquired in some of the digits, while in Tylosaurus as many as twelve phalanges are known in the longest fingers. In the tarsus of Clidastes (Plate XXXVI) the co-ossified tibiale and intermedium have their usual articulations, with only one of the other tarsal elements remaining, probably the fourth tarsale. In Platecarpus (op.cit., p. I66) we have the same bones, but all of them reduced. In Tylosaurus (Plate L) the tarsus is not well known, but, evidently as in the carpus, there is only one mesopodial bone, the fibulare, and that is reduced; and hyperphalangy here too is carried to its greatest extent among mosasaurs.

Briefly, it is seen from these illustrations that specialization has progressed in the mosasaur limbs in nearly equal pace in the front and the hind ones, though, if Dollo is right, in Mosasaurus (and (lidastes?) the loss of the fifth toe behind indicates the usual greater specialization of the hind feet over the front ones, as in terrestrial animals, though we know that this is not always the case among aquatic animals. Again, they show very conspicuously that, as in the Thalattosuchia, specialization begins on the radial and tibial sides, and progressively extends to the ulnar and fibular sides. Perhaps this is the explanation of the greatly reduced size of the radiale in Limnoscelis, as well as the reduced size of the tibiale and fibulare, which have reached nearly the condition found in Platecarpus. And, as I have elsewhere stated, it is evident that Clidastes, so far as the limbs are concerned at least, is the most generalized genus known of the Mosasauria, Tylosaurus the most specialized.

No indications whatever of ventral ribs are present in either specimen. In their place, however, the whole ventral region was 
covered by a sort of plastral sheath of imperfectly ossified or calcified material. Patches of this sheath were found scattered about in the matrix below the posterior vertebrae and adjacent regions. some of them two inches or more in diameter. I have not yet had an opportunity to examine the substance microscopically but to the unaided eye it appears to be loose bone tissue. It is quite certain that the animal did not have distinct ventral ribs, or osseous dorsal scales.

IIabits and relationships of Limnoscelis.-It is almost superfluous for me to point out, so evident will it be to everyone, that Limnoscelis must have been a subaquatic or marsh-dwelling reptile. Of the poorly ossified or cartilaginous carpus and tarsus the evidence is almost positive, and there can be but one explanation, subaquatic habits. The limbs as a whole indeed are strongly suggestive of the turtles. The relationships of the genus are unquestionably closest with Diadectes of any forms that we know, from which it differs chiefly in the elongated skull, the conical, prehensile teeth, the absence of the ear cavity posteriorly, the small size of the parietal foramen, the smoothness of the skull surface, the non-expanded ribs, their apparently single-headedness throughout, the absence of hyposphenes, and the feebly ossified carpus and tarsus. It agrees well with Diadectes in the general structure of the limbs, the arrangement of the skull bones, especially the union of the prefrontal and postfrontal over the orbit, the general structure of the vertebrae, with cylindric or prismatic spines, etc. It agrees with both Diadectes and Parciasaurus in the very characteristic flattened occipital condyle; and I believe that when we know more of the structure of the skull of the latter genus we shall also find more evidences of affinity in these groups, to such an extent that the three genera and Propappus also may perhaps be placed in the same suborder of reptiles; possibly also Pantylus. 


\section{Family Seymouriidae}

IVilliston, Journal of Geology, XIX, 237, May, I9I I.

Skull triangular, depressed, tuberculate. A deep and narrow otic notch in the temporal region. Teeth slender, conical, not elongated in front. No cleithrum. Arches of presacral vertebrae greatly expanded and with vestigial spines; ribs double-headed throughout; a single sacral vertebra; tail short; no ventral ribs. Legs short and stout; carpus and tarsus fully ossified; ungual phalanges not dilated; tibiale and fibulare small. Digital fossa extending to midway of femur, the adductor crest prominent. Occipital condyle not flattened. An intertemporal bone in skull.

\section{SEYMOURIA}

Broili, Paleontographica, LI, 8I, I9o4; Desmospondylus Williston, Bull. Geol. Soc. Amer., XXI, 280, igio; Conodectes (?) Cope, Amer. Nat., XXX, 398, I896; Proc. Amer. Phil. Soc., XXXV, I29, I896.

Seymouria baylorensis Broili, Paleontographica, loc. cit., Pl. XIII. ff. I-3; Williston Jour. of Geol., XIX, 232, May, I9It. PIs. XXVI-XXIX.

Desmospondylus anomalus Williston, Bull. Geol. Soc. Amer., XXI, 280, PI. XVI.

There are few Permian vertebrates of more interest than that to which the name Seymouria baylorensis has been given. The genus and species were originally described by Dr. Broili from two imperfect skulls, a clavicular girdle and a few anterior vertebrae. discovered on West Coffee Creek, in Baylor County. Texas, not far from the town of Seymour. The characters, as given by Dr. Broili, were most remarkable, almost incredible for a reptile, including a deep otic notch, previously known only among amphibians, and the presence of all the dermal temporal elements of the skull known among the Stegocephala, that is the "epiotic," dermoccipital, supratemporal, intertemporal, squamosal. and quadratojugal. And there was nothing whatever in the specimen as described by Broili to distinguish the creature from an amphibian, save the single occipital condyle and the structure of the palate. These two type 
specimens preserved in the museum at Munich have remained until recently the only known ones of the genus. Two years ago I found on East Coffee Creek, not far from the locality whence the types came, several vertebrae and some fragmentary limb bones, which I referred provisionally to some unknown form allied to Labidosaurus, but could in nowise associate with Scymouria. Later a series of vertebrae and numerous limb bones were found on West Coffee Creek, in the immediate vicinity of the locality whence came the original types, imbedded in clay and intimately associated with an incomplete skeleton of Trimerorhachis. Among this material were parts of two skeletons of almost identical size, and very much smaller than the type specimen. Because of their immaturity, for they are doubtless juvenile specimens of $S$. baylorensis, they show certain embryonic characters, such as the separation of the arches and the unusually large size of the intercentra, not seen in the adult specimens. With no parts in common with the type specimens, as described by Broili, I described these specimens as pertaining to a new genus and species, Desmospondylus anomalus (Plate XXIX), though suspecting that they might belong to some previously described genus known only from fragmentary remains. More recently a few bones of this species have been detected among the skeletons of Cacops, Iraranosaurus, and Casea of the remarkable Cacops bone-bed near Indian Creek, two or three miles south of West Coffee Creek. And yet other imperfect specimens belonging to the same genus and species have been recognized among the material obtained in earlier years, now forming a part of the Chicago University collections.

In May, rgio, however, Mr. Miller was so fortunate as to discover on the Wagner ranch, about a mile west of the Craddock ranch, and about the same distance west of the spot where the type specimens of Trematops and Trispondylus were discovered, a remarkable specimen of this species which is almost without equal among Permian specimens from Texas for perfection of preservation. The specimen was contained in a large, dark-red, hard-clay nodule that had been wholly washed from its bed, and broken into four pieces scattered on the hillside. The only visible part of the specimen which led to its detection was a small part of the cranial 
table of the skull, where a chip had broken away from the nodule. The tail in part was in a protuberance of the nodule that had been broken off, and was not recovered; I doubt not that a diligent search in the vicinity later will be rewarded by even this part of the skeleton. Hidden in this nodule, which showed but little erosion from the rain and frost, the skilful preparation of $\mathrm{Mr}$. Miller has revealed a very nearly complete skeleton in closest articulation from the skull to the sixth caudal vertebra. The animal was doubtless fossilized in a prone condition, since the spinal column has an undulating curve as pressed downward from the apparently upward convex curve it had in the recent skeleton: the tail was curved downward to the end of the ischia, like that of a dog, the horizontal position beginning with the sixth caudal vertebra; and it is this part which is lost. The pectoral girdle is nearly in position, the right scapula and clavicle pressed slightly forward, the head turned slightly in the same direction. The right arm, fully articulated, lies close to the side of the body, directed backward, the hand bones more or less intermingled with the bones of the right foot. The left front leg was flexed at the elbow and turned forward; its metacarpals alone are preserved. The pelvis also lies quite in position below the last lumbar, the single sacral and the first four caudal vertebrae, the parts all in close articulation, save the right ilium, which is very slightly separated at the ischiadic suture. Both femora are in close articulation in the acetabula, directed forward, upward, and a little inward, and quite alike on the two sides. And both the forelegs are closely articulated with their respective femora, as are the individual bones with each other on each side. Both feet evidently lay close by the sides of the body originally, but with the collapse of the abdomen they have been dragged somewhat away from the ends of the leg bones.

No attempt has been made to free any of the bones, nor could they be separated without danger, since they are rather soft in texture, with a thin, white outer layer that easily breaks away. and many of the bones, especially those of the skull, have this layer divided by many delicate cracks, as though the skeleton had been more or less exposed to the atmosphere before fossilization 
finally occurred. One thing is evident, the skeleton had been subjected to but very slight or no disturbance from wind. waves, currents, or predatory animals after death. Nor do the parts of the skeleton show distortion or compression, as is so often the case with bones in this and other formations.

Skull. - The skull is very perfectly preserved, the short exposure of the cranial table had injured it but slightly, and in no wise affected its shape; unfortunately, however, it prevents the certain corroboration of the sutures observed by Broili, a matter of less regret since the wellpreserved skulls studied by him, at least in this region, apparently leave little or no doubt as to the structure. The teeth also, because of their extreme delicacy, could not be worked out entire from the hard matrix. This, however, is not to be greatly regretted, since between the two sides one is able to determine the dentition quite satisfactorily, in the upper jaws at least. In the outline figure I have inserted those sutures copied from Broili's drawings in dotted lines, while

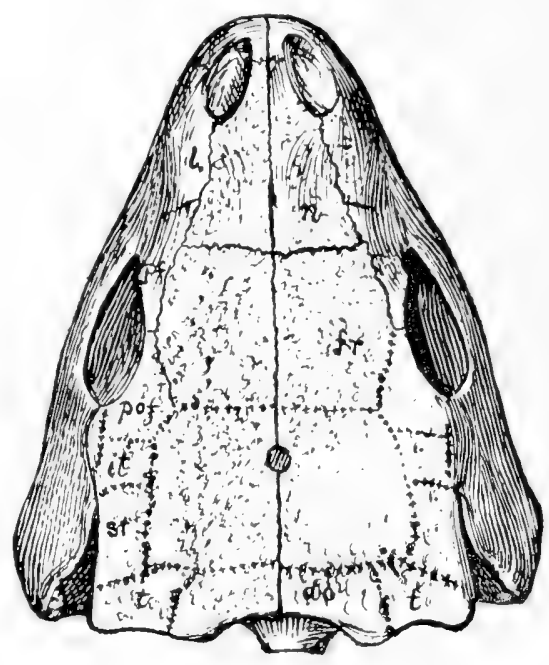

FIG. 18.-Seymouria baylorenis. Skull, from above, one-half natural size. $n$, nasal; $l$, lachrymal; pf, prefrontal; pof, postfrontal; fr, frontal; it, intertemporal; st, supratemporal; do, dermoccipital; $t$, tabulare. those satisfactorily determined in this specimen are shown in continuous lines; others about which I am uncertain I have figured in lines of small crosses.

The skull is elongate, triangular in shape, nearly flat on the upper surface between the temporal regions and as far forward as the interior part of the orbits, the surface over each orbit somewhat convex. Thenceforward to the tip of the muzzle, the profile is somewhat convex from side to side, with a steep declivity on each side in front of the orbit. The nares are rather large and oval, or 
subtriangular in shape. The orbits, situated a little back of the middle of the skull, are not large, trapezoidal in shape, the roof somewhat convex, the anterior inferior angle acute. The plane of their opening looks outward and a little upward. The otic notch has for its roof the thickened outer border of the cranial table, its immediate upper border undulating in outline, the anterior ends somewhat constricted, both on the upper and lower margin, by a slight protuberance, leaving the extremity in the shape of about three-fifths of a circle, probably for the auditory meatus and stapes. From the protuberance on the lower margin, the border of the notch curves downward and backward convexly to the

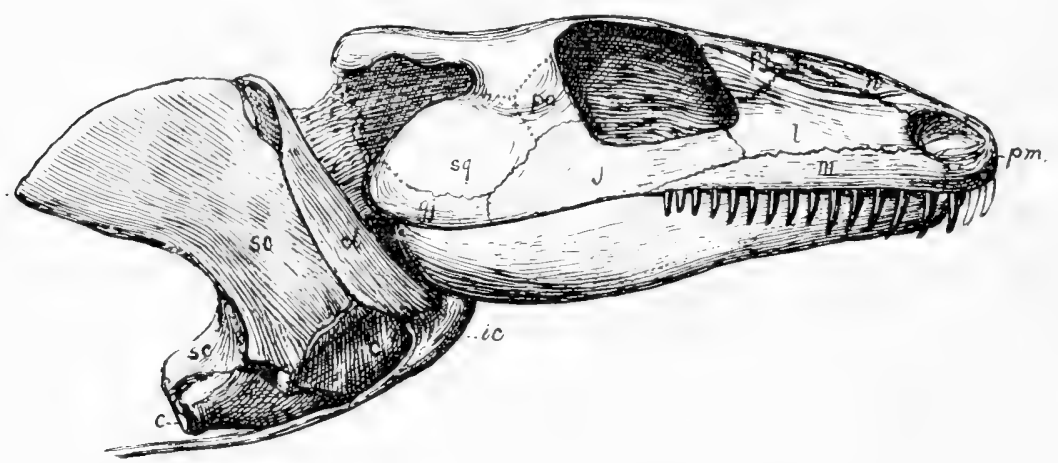

FIG. I9.-Seymouria baylorensis. Skull and pectoral girdle, from the side, onehalf natural size. $p m$, premaxilla; $m$, maxilla; $l$, lachrymal; $n$, nasal; $p f$, prefrontal; $j$, jugal; $p o$, postorbital; $s q$, squamosal; $q j$, quadratojugal; $c l$, clavicle; $i c$, interclavicle; sc, scapula; $c$, coracoid.

quadrate articular end. The positions of the sutures, as shown in the figure, will need no explanation. On the upper side, those made out with tolerable certainty are indicated by lines of small crosses. those copied from Broili by dots. I am least sure of the intertemporal, a remarkable stegocephalian bone unknown in other reptiles; I think, however, there are indications of it in this specimen. The sutures, as shown, agree clearly with those given by Broili. The maxillary teeth are elongate and slender, curved downward and gently backward. I cannot be sure of the number in the premaxillae, but there were at least three, and the ones remaining are shorter than those following them in the maxillae. I count eighteen 
teeth in each maxilla, though there may be one or two more or less, the longest of them in the middle or front part; they are placed close together and are evidently labyrinthine in structure. They extend back nearly as far as the posterior inferior angle of the orbit. The mandibular teeth cannot be made out in the closed condition of the jaws. The mandibles are rather slender, meeting in a short symphysis, curving broadly outward behind, and are broadest below the posterior part of the orbit. The articular bone is produced very slightly.

The occipital region of the skull is obscured by the articulated vertebrae above and the clavicular arch below; I can say nothing concerning it. And of the palatal region only the anterior part, in front of the clavicles, is visible. Broili describes these regions as follows:

The basioccipital, showing only a comparatively small surface, has a well formed, lightly convex occipital condyle. The basisphenoid has its lateral processes considerably developed as keel-like elevations; anteriorly it is drawn out into a pointed, dagger-like parasphenoid, projecting into the space between the pterygoids. The anterior wing of the pterygoid is, at the beginning, gently emarginate, forming the interval for the parasphenoid, but it soon unites with the corresponding wing of the opposite side. The extent of the united pterygoids in front is considerable, though how great cannot be said because of the imperfect preservation of the specimen. The posterior process of the pterygoids extends dorsalward in the region of the quadrate, forming on one side the border of the inferior temporal vacuity, on the other taking part in the formation of the otic notch. On the margins of the anterior processes of the pterygoid which form the interpterygoid vacuity, as also on the elevation, there are traces of small teeth; but the preservation of the specimen does not permit the determination of the number.

In the present specimen only the very broad pterygopalatine plates in front of the temporal vacuity have been exposed. They slope upward on each side at an angle of nearly forty-five degrees. The separation of the sutures, alike on the two sides, seems to differentiate the pterygoids, palatines, and vomers. The palatines are narrow, reaching back only to the beginning of the declivity representing the transverse bone; the union between the vomers and pterygoids is broad. I can distinguish no teeth of any kind on any of the bones; doubtless they were present, though in all probability very small. 
The presacral vertebrae, as stated, are all in close articulation; the number is positively fixed at twenty-three. It is worthy of note how common this number of presacral vertebrae seems to be among the early land vertebrates. It is the number I concluded was present in the temnospondyl Trematops, apparently the number in Sauravus, Hylonomus, Eosauravus, and in Captorhinus. In Limnoscelis there are. apparently, twenty-five, though this is not certain. In Cacops, a temnospondyl, there are twenty-one, with perhaps twenty-four in Eryops. Among the higher reptiles, Casea has twenty-four, Varanosaurus and Dimetrodon, twenty-seven.

Nothing is more conspicuous in the skeleton of Seymouria than the great development of the neural arches of the presacral vertebrae, especially posteriorly; and the abrupt change from the broad overroofing form of the presacrals to the narrow, more slender form of the caudals. Not much can be seen of the atlas and axis, but, from the third vertebra, the arches increase rapidly in transverse expansion to the eighth or ninth; that is. throughout those bearing the distally dilated ribs. With the ninth, the arches have acquired nearly or quite their full width, remaining uniform to the sacrum. On the first three or four vertebrae there are distinct, though small, spines, perhaps six or eight millimeters in height; from the fourth to the sacrum the spines are mere tubercles. The structure of the posterior vertebrae will be made sufficiently plain from the figures given in Plate XIII, Figs. 5-8, from a vertebra found in the Craddock bone-bed, and from an isolated specimen found on Coffee Creek. The zygapophyses, it is seen, are very broad and flat. The diapophyses are small protuberances rising high up from the sides of the anterior zygapophyses; from the eighth vertebra to the sacrum they do not project beyond the border of the zygapophyses; in front, however, they extend beyond them conspicuously. their expanse as great as on the posterior vertebrae. The centra are subcylindrical, with the lower border shorter, in some very much shorter, than the length of the neural canal, allowing space for the large intercentra. The intercentra are not as large proportionally in the adult specimens as in the young. as figured and described by me in Desmospondylus (Plate XXIX). Nevertheless they are unusually large for a reptile in the adult even, so large 
that the head of the rib articulated with them on the sides. The sutures separating the arch from the centrum are not visible in the adult specimens.

The single sacral vertebra resembles that immediately preceding. except that it is larger and stouter, but no wider, and its diapophyses are very heavy and stout, though not extending farther outward. The arch was somewhat injured in preparation, and I can say little regarding its spine, though enough is left to indicate that it was longer than on the vertebrae immediately in front. It probably was nearly as long as the spine of the first caudal vertebra. Five caudal vertebrae are preserved in position, together with a part of the sixth. Their arches, it is seen, are very much narrower than those of the presacrals, but their centra, at least in front, are not much smaller. The spines are elongate, rather slender, and pointed, and are directed obliquely backward. The diapophyses do not extend outward as widely as those of the sacrum. The chevrons, preserved on the fourth and fifth vertebrae, are unusually stout.

Many of the ribs cannot be exposed in their entirety. The transverse processes of the atlas and axis do not bear ribs, but, lying below them and above the clavicle on the left side are two slender ribs, partly exposed, that evidently belong here. From the third vertebra to the ninth the articulated ribs are expanded distally and quite surely overlap each other at their ends, since the antero-posterior extent of the middle ones is greater than the length of the centra bearing them. The terminal expansion is greatest on the sixth, where the width is twenty millimeters. The expansion of the seventh is materially less than that of the sixth, and that of the ninth is not more than two or three times greater than the width of its shaft. As far as the eighteenth or nineteenth at least - as far as I am able to follow them- the distal end is slightly greater in breadth than the width of its shaft. In length the ribs do not vary much, at least the first eighteen or twenty pairs do not. Posteriorly the ribs are clearly double-headed, and I believe that they are so throughout, though I cannot be quite sure of the first three or four pairs.

The single sacral rib on each side has a heavy tubercle for union 
with the diapophysis, below which it is broadly dilated anteroposteriorly, fitting closely the whole, or nearly the whole, of the inner side of the upper, dilated part of the ilium, from the extreme posterior angle forward, leaving no space whatever for the attachment of a second rib, however small. Five caudal ribs are in place on the right side, loosely attached to the ends of the diapophyses. The first of these, on the first caudal vertebra, is separated from the sacral rib and is slender like the following ones; its distal end, as preserved, is pointed, and the rib is shorter than the next following one. I cannot be sure but that the end is the result of fracture, the more so as a part of a rib lies transversely below it. In the figure I have restored the rib, with lines, to the form of the following ones, but I am inclined to believe that the whole rib is present, and that the one below it belongs with the opposite side. However, even if short, it could have had no part in the support of the ilium, nor did it even touch it, proving conclusively, for the first time, I believe, the presence of but a single sacral vertebra in a reptile. All of the caudal ribs preserved are slightly dilated and flattened at their distal extremity. They do not decrease much in length, from which it would appear that the tail in life was ribbed for a considerable part of its extent.

Pectoral girdle and extremity. - The pectoral girdle has suffered little distortion or displacement; on the right side it is thrust forward a little, or, on the opposite side, backward. The expanded parts of the clavicles, in close articulation with the interclavicle, lie under the occipital region, close up to the angle of the jaws. The ascending more slender part of the clavicles is applied rather closely to the quadrate, permitting very little lateral movement of the skull on the vertebral column. The larger part of the interclavicle is hidden above the clavicles, leaving only a diamondshaped surface exposed in the middle behind. Its stem is stout and rather broad, oval in cross-section, tapering slightly to about its middle, and then gently expanded to the extremity, which reached as far as the eighth or the beginning of the ninth vertebra, and far back of the coracoid. The clavicles are much dilated on the ventral side, with a convex thin border in front to near the angle of the jaws, where it turns sharply upward, backward, and a 
little outward. This ascending part is thin on the ascending outer convex border, its anterior surface looking outward at an angle of nearly forty-five degrees, to near the top, where the bone is continued more slenderly quite to the upper angle of the clavicle. touching or articulating with the front border. For the greater part of its extent the thin border projects out from the scapula, and is not applied to its outer face. On neither side is there any indication of a cleithrum, and as no indications of this bone were found by Broili in his specimens, I think it may be said definitely there was none. In its absence the genus is differentiated from both Diadectes and Limnoscelis and allied to Labidosaurus. The right scapula lies very perfectly in place and is visible in nearly its whole extent from without, save the lower front angle overlain by the clavicle. On the left side it is thrust back more, and is partly hidden beneath the overlying humerus. The blade of the scapula is considerably broader above than below; its

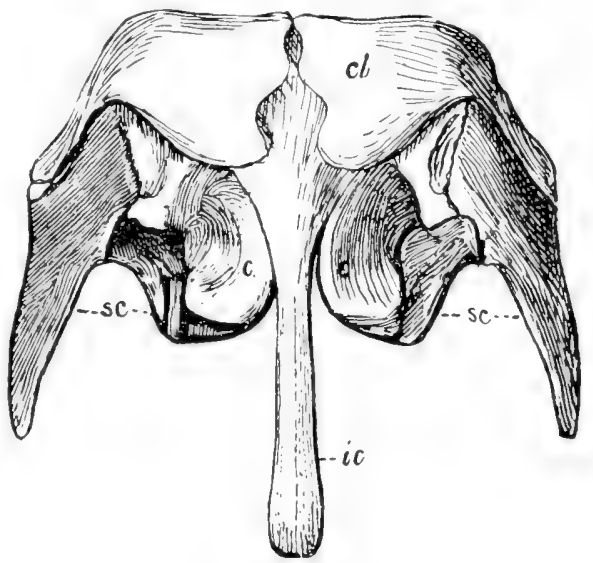

FIG. 20--Seymouria baylorensis. Pectoral girdle, from below, one-half natural size. $c$, clavicle; ic, interclavicle; $c$, coracoid; sc, scapula.

posterior border is rather deeply concave, its anterior thin, and the upper end is truncate, thicker posteriorly, for cartilage. The suture separating the scapula from the coracoid, as in other vertebrates from Texas where it has been observed, passes forward from just above the posterior glenoid facet, through the middle of the anterior facet, to the front border rather high up. The supraglenoid fossa is rather broad and has at its upper part the usual supraglenoid foramen. The glenoid fossa is short anteroposteriorly, truncated posteriorly, with a cartilaginous border, very much as in Varanosaurus, as figured in Plate $\mathrm{V}$. It is evident that here too the real, so-called coracoid was never ossified, but remained 
as a cartilaginous extension throughout life. The scapula mentioned by me in my paper on Cacops (Bull. Geol. Soc. Amer., XXI, 268, near bottom) as having the posterior part unossified I find really belongs with Seymouria, though resembling in other ways that of Cacops so much as to be practically indistinguishable. The supracoracoid foramen pierces the bone in its usual place, below the scapula-coracoid suture a little in front of the preglenoid facet, at the bottom of a rather large fossa. Between this foramen and the posterior cartilaginous border the smooth surface shows not the slightest indication of a suture. Inasmuch as the sutures elsewhere are all more or less patent, it is quite impossible that the posterior coracoid should be ossified here, and even if ossified it must be merely vestigial and wholly below the scapula. There cannot be the least doubt but that the posterior bone, the so-called coracoid, is unossified in Seymouria, as in Varanosaurus, and that precisely this same condition with the sutures in the same place I have observed in a scapula-coracoid which I refer provisionally to Aspidosaurus peltatus, described elsewhere in this work. The coracoid of all these forms consists exclusively of the anterior element, the so-called procoracoid. That this bone has entirely disappeared in all later reptiles, giving place in its entirety to another bone, here unossified, with like attachments, and with its perforating supracoracoid foramen in the same position. I cannot believe. On the other hand, Broom has brought arguments to show that the coracoid process of the mammals really represents the posterior element, and that it is the anterior one, the procoracoid, which has disappeared in the mammals. Whether his views, the ones generally accepted for all the later vertebrates, will eventually be proven beyond doubt for the mammalia, I am not competent to predict. That there have been two divergent methods of development of the coracoid in the amniota is not, of course, impossible, nor perhaps at all improbable. The absence of a perforating coracoid foramen in the mammalia, and its almost universal presence in the reptilia (absent only in the Pterosauria, and I am not sure but even in that order the opening back of the glenoid fossa as I have described it really represents this foramen) may indicate a different mode of ossification. In any event it 
seems to me utterly improbable that the coracoid as ossified in the Seymouria and Varanosaurus is not identical with the bone supposed to be (without proof) the fused coracoid and procoracoid of the Lacertilia, Dinosauria, etc. I at first adopted the terms of Howes and Lydekker, calling the anterior bone in these animals the real coracoid and the posterior one, the metacoracoid, but, in deference to the arguments brought forward by Broom, I will beg the question, until its final decision, by simply calling the two bones the "anterior" and the "posterior" coracoids. The only thing that I wish to insist upon is that the coracoid of Seymouria and Varanosaurus is absolutely identical with the coracoid of the Lacertilia, Dinosauria, Crocodilia, etc.

The humerus (Plate XXIX) is a remarkably short and stout bone with a large ectepicondylar process, characteristic of this genus, the Diadectidae, Limnoscelidae and Eryopidae, but not found in the Pariotichidae, and most of the temnospondyles. The median or ulnar process is also large, and the entepicondylar foramen is of unusual size; the entocondyle is greatly expanded. The radius, as preserved in this specimen, is a more slender bone than the one figured by me in Desmospondylus, possibly indicative of specific differences. Its shaft is only moderately stout, the proximal end subcylindrical and truncated, and but moderately expanded at the distal end, less than is shown in the figure. The olecranon is well developed. There are several carpal bones lying in association with their respective arm bones, though but little can be said regarding their identities and associations; they are all small. The hand bones of the right side are more or less intermingled with the bones of the right foot, and some of them cannot be differentiated. On the left side, however, four metacarpals are yet lying in orderly relations, and it is from the two sides that I have restored the hand as shown in the figure. Among the phalanges are one or two of small size, demonstrating the slenderness of the fingers, and their consequent differentiation from those of Limnoscelis and Diadectes. The number of phalanges, as given in the figure, both of the front and the hind feet, is assumed, but there can be little doubt but that the formula was the primitive one, as in Limnoscelis. 
Pelic girdle and extremity.-The pelvis has suffered little distortion or displacement, lying below the first two presacral, the sacral, and the first two or three caudal vertebrae. The sutures between the different elements are all rather widely separated. The pubes are subquadrate or trapezoidal in outline, considerably broader at their front border than at the pubo-ischiadic suture. The front border of each is gently convex in outline, and the two are convex from side to side below, without the median keel so characteristic of Limnoscelis. The rather small obturator foramen

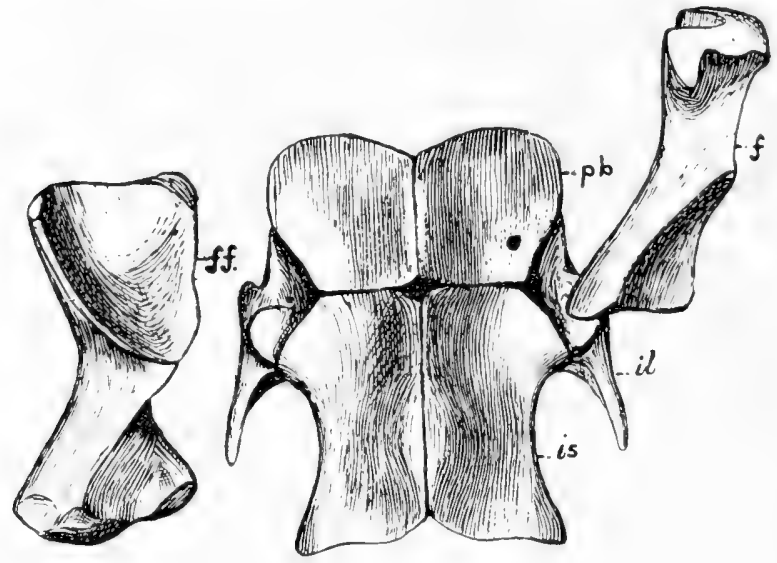

FIG. 2I.-Seymouria baylorensis. Pelvic girdle and femora, from below, onehalf natural size. $\quad p b$, pubis; is, ischium; $i l$, ilium; $f$, right femur, tibial side, as articulated; $f f$, femur of Craddock bone-bed specimen, ventral side, a little more than half natural size.

is situated not far from the acetabular ischiadic angle. The ischia are very nearly twice the length of the pubes, rather deeply concave on the sides back of the acetabular angle, somewhat expanded behind; the posterior border with an undulating outline, but without a very pronounced median emargination. In the middle there is a pronounced keel, thickest and broadest about midway of the bones. The ilia are unusually narrow antero-posteriorly between the upper and lower expansions; they are relatively high. The front border is nearly vertical, gently convex anteriorly above; the upper border is thin, sloping downward and outward to a narrow process posteriorly. The posterior iliac notch is deep and 
broad, the border sloping upward in a curve from the ischiadic suture; the hind end of the process reaches as far back nearly as the hind end of the first caudal vertebra. The ilia are in perfect articulation with the sacral ribs which were attached high up, their upper margins even showing above the iliac border in its middle. The proximal end of the rib of the first presacral vertebra lies against the upper front margin of the ilia, evidently extending a short distance beyond the margin freely in life. The inner side of the pelvis of course cannot be seen, and the acetabula are partially filled by the proximal ends of the femora. It is apparent, however, that the pelvic opening was large and roomy. The femora, as has been stated, lie in close articulation with their respective acetabula, both directed upward, forward, and a little inward, the knee on each side precisely reaching the end of the posterior zygapophyses of the fourth presacral vertebra; and their positions are identical on the two sides, the large digital fossa looking almost outward and slightly ventrad. The femur agrees closely with the one referred by me to Desmospondylus n. sp. in the cited paper from the Cacops bone-bed, save that it is slightly larger. In the accompanying figure the femur is shown in the position in which it lies on the left side; with it is a figure of the ventral side of the Cacops bone-bed specimen a little more enlarged. Like the diadectid. limnoscelid, and eryopid femora, it is remarkable for the enormous size of the digital fossa and the high adductor crest. On the two sides the bones of the forelegs are in close articulation with their respective femora, both flexed at an angle of very nearly forty-five degrees, and directed a little outward. Evidently they had lain closely by the side of the abdomen; and the posterior ribs are yet hidden between the forelegs and the vertebra in large part. The tibiae, so far as they have been exposed, agree well with the one figured of Desmospondylus. They are remarkably short and stout bones. The upper ends of the fibulae are yet partly hidden below the tibiae, with which they are in perfect association; distally they are remarkable for their great expansion, indicative of a broad foot.

On the left side the proximal tarsal bones are nearly in position with the ends of the leg bones, and in close union with each other. They are remarkably small. The tibiale is subcircular or sub- 
quadrate in shape, nearly as thick as broad. The fibulare is broader from side to side than longitudinally, a little narrower than is shown in the figure. On the radial side three tarsal bones and a part of a fourth are seen nearly in place, evidently the centrale and the first, second, and third tarsalia. The first tarsale is a very small bone; the second is larger, larger somewhat than is shown in the figure; and the centrale is also very small. On the outer side a part of a small tarsale is seen closely applied to the fibulare. The fourth and fifth metatarsals cover the other tarsalia. indications of which are seen below them. It is very evident that the tarsus was small, the bones being all closely articulated with each other without intervening cartilage. The five metatarsals lie in natural positions, the proximal end of the fifth, only, thrust up a little over that of the fourth. The first is a very short bone, its width proximally equaling its length; the third is the broadest and heaviest; the fourth is the longest; while the fifth is only a little shorter, indicating a strong fifth toe. In articulation with the first metatarsal is its first phalange; the short first phalange of the fifth toe also lies closely in relation with the metatarsal, while its second phalange has been thrust in between the fourth metatarsal and its first phalange. A little distance beyond the three middle metatarsals are a series of three small phalanges, evidently distal ones of these toes, the intervening ones hidden or missing; they lie upon or rather below the distal ends of ribs, which has caused their displacement. From these phalanges it is quite certain that the toes distally were slender, with narrow ungual phalanges quite unlike those of Limnoscelis and Diadectes. As I cannot place these small phalanges in their respective toes, they are not indicated in the restoration. Nor, of course, can it be said definitely what the phalangeal formula was, though there would seem to be little doubt that this genus agrees with Limnoscelis in having the primitive one, $2,3,4,5,4$.

From the material described, I have made, after painstaking study, the restoration as shown in the figure, about one-third natural size. The conjectural parts, shown by the uniformly ruled lines. are the length of the tail, the structure of the carpus, and the arrangement of the phalanges. The length of the tail I have esti- 
mated from the accurately measured taper of the six proximal vertebrae, and upon the whole, I think it is too long. However, it is possible that the distal vertebrae may have been elongated, and the tail even longer than is shown. At the first opportunity search will be made in the locality where the specimen was found for the missing part, and I doubt not that the search will be successful.

Relationships.-From the above description and figures it is evident, I think, that the relationships of Seymouria are not very intimate with any other reptiles known from the Permian; at least any that are tolerably well known. In the skull the presence of the deep otic notch, the arrangement and number of the temporal bones, the slender, elongate teeth, longest in the maxillae, and the shape, all differentiate the genus widely from either Diadectes or Limnoscelis, as well as the chief forms now referred to the Pariotichidae, and also from the known foreign forms. The speculation again recurs as to whether or not the temporal vacuity of the higher reptiles may not have arisen by the prolongation of the tabular angle to meet the quadrate and the consequent inclusion of the ear-notch. Precisely this did occur in some of the contemporary temnospondyls. Against the probability of this is the fact that the quadrate must have changed somewhat its relations with the contiguous bones; although as a matter of fact we do not know what the relations of the quadrate were in any temnospondyl. I do not think that this would be impossible, since I cannot understand the condition in Cacops and Dissorophus, unless the flat process bordering the posterior bar in front is really the quadrate. However, speculations on this subject are premature. Among the Cacops material that has been recovered since my description of the genus was published are not less than eight good skulls, and there are doubtless as many more yet to be recovered. It will be strange if, from among all this material, the detailed structure of the skull is not finally determined. The transfer of the ear-cavity from the inclosed opening in Cacops to a place back of the vacuity is, however, quite another matter.

In any event it is certainly very remarkable that this cotylosaur reptile with all its other strange amphibian affinities should mimic 
so closely the temporal structure of the real amphibians, while, on the other hand. real temnospondyls should mimic equally curiously the temporal condition of the higher reptiles.

Of the skeleton back of the skull the structure is largely primitive both in the pectoral girdles and limbs and the vertebrae, which approach those of the temnospondyls more closely than do those of any other known reptile. The absence of the cleithrum differentiates the form, though not widely, from Diadectes, Limnoscelis, and Pareiasaurus. The pectoral girdle offers nothing distinctive. The presacral vertebrae differ widely from those of Limnoscelis, Diadectes, and Pareiasaurus in the almost entire absence of dorsal spines, and the great lateral expansion of the arches, agreeing much better with those of Labidosaurus. Indeed, the vertebrae of this last genus are, in their general characters, so similar that they have been confused. Nor is there anything distinctive in the pelvis; it, too, is of the "old-fashioned" type. In the limbs, however, we get certain apparent resemblances that would seem to ally the genus with Diadectes and Limnoscelis, but, as I have stated elsewhere, I have little faith in the genetic value of these characters. I believe they are more of an adaptive nature. Not only do the limbs resemble those of Diadectes and Limnoscelis more than those of Labidosaurus, but this resemblance extends to the temnospondylous amphibians as well. especially Eryops, in the short legs, short, thickset mesopodials, broad feet, enormous humeral entocondyle, the presence of an ectepicondylar process. very large adductor crest, and enormous digital fossa of the femora. etc., as well as the general absence of condylar ossifications-for in all these forms the joints were formed largely by cartilage which never ossified and the sutures remained separated longer and more completely than in the Pariotichidae.

However, it is very much of a question whether these resemblances are so much the result of heredity and relationships as of adaptive, parallel, or convergent evolution. We have been speculating on the presumption that the known temnospondylous amphibians like Cacops, Eryops, Euchirosaurus, are, if not the actual ancestors of the reptiles, their first or second cousins. But this presumption is, in my opinion, quite unjustified. Moodie 


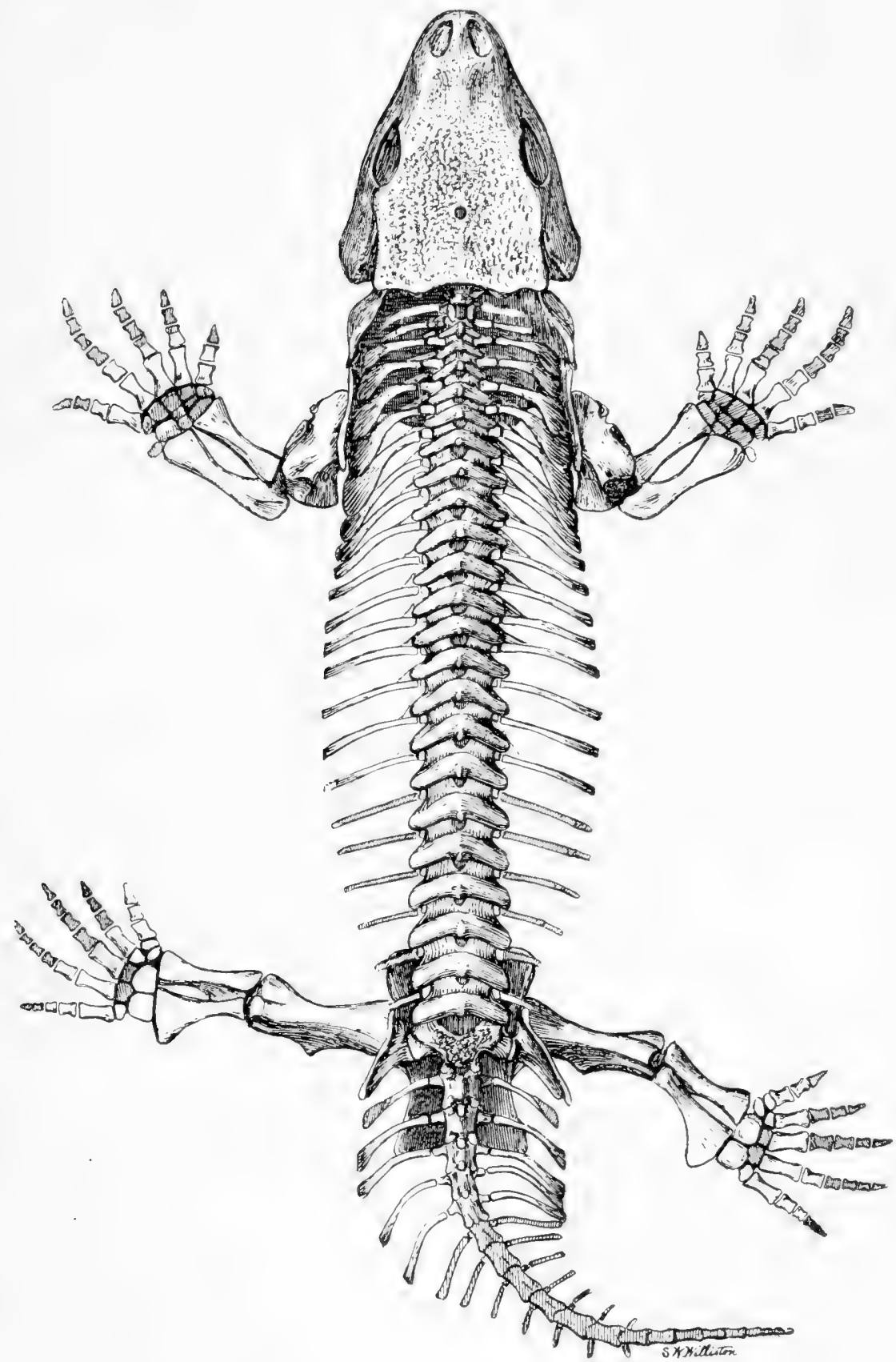

Fig. 22.-Seymouria baylorensis. Skeleton, from above, a little less than onethird natural size. 
has urged that the reptiles arose from the Microsaurs-that is, the Microsauria as usually accepted-but while I do not agree with him I do believe that he comes nearer to the real truth than is the belief that reptiles have arisen from the known types called temnospondyli. The divergence of the reptilian stem must have occurred early, in Pennsylvanian if not Mississippian times, and what we have in the Permian, or even Permo-Carboniferous beds of Texas, Illinois, France, and elsewhere are the modified, perhaps very much modified, descendants of these early divergent phyla. The view of Osborn that the Cotylosauria were the primitive reptiles from which all modern forms have arisen has been doubtfully accepted; and his conclusion that the reptilia are divisible into two subclasses, the Diapsida and Synapsida, is no longer received by students of the reptilia. At the beginning of the Permian or even earlier we have, as is well known, at least four divergent phyla of reptiles, the Cotylosauria, the Theromorpha or therocrotaphic forms, the Proganosauria, with aquatic adaptions. and the Proterosauria or double-arched forms. It is a very interesting fact that the chief divergences in all these phyla are found in the temporal region of the skull. The pectoral and pelvic girdles, the vertebrae, and the limbs even, differ less among them all than do they in some later orders of reptiles; we surely will find greater modifications among the modern Squamata. Did we not know the skulls of any of these forms we would have little cause to separate them ordinally. The chief differences in the skull consists of the absence or presence of one or more vacuities in the temporal region. I still believe with Cope, Woodward, and Osborn that these temporal characters are the most crucial ones in reptilian taxonomy. And yet were such characters as those of Cacops or Dissorophus and Trematops to be found among reptiles, we would probably accept them as of ordinal value. Among the cotylosaurs we see a considerable divergence in the known forms. The presence of a vestigial cleithrum in some cotylosaurs and some theromorphs attests a not very remotc common ancestry, and this ancestry could not, of course, have been any of the known Microsauria, since a bone or organ once lost never reappears, even as a vestige. Furthermore, Aracoscelis, which is now known definitely to possess 
a single large temporal vacuity and foot structure not unlike that of Varanosaurus, was an animal which had diverged in other respects widely from its contemporary reptiles. It had developed an ectepicondylar foramen, and had become a very swift-moving reptile.

In summation: The evolution of the land vertebrates had developed so far by the close of Carboniferous times that reptiles of considerable diversity of habits and structure had arisen, and it would be unreasonable to suppose that the temnospondyls and cotylosaurs were exceptions, that they still retained their primitive characters unchanged or almost unchanged; that the many resemblances between such creatures as Diadectes, Seymouria, Limnoscelis, and Eryops were the result of heredity rather than adaptive evolution. We have been deceived time without end, and are yet often deceived in every group of animal and vegetable life by resemblances which we impute to heredity - that is, to blood relationships-rather than to adaptations to like environmental conditions. Of course, it will be conceded that animals whose habits and environments have changed little have probably not changed their structure greatly. The marsh turtles have continued for millions of years with not very great modifications of their skeletal structure; and I do not wish to say that all the resemblances between Diadectes and Eryops, for instance, are necessarily of adaptive origin, but simply that we have many more facts to learn before we can say that they are of genetic origin. The most that we can expect to discover in the Permian fauna are the ways in which the evolution of the reptiles from the amphibians has occurred; to discover archaic forms that, one by one, bridge over the class differences between the amphibians and reptiles. And in this we have been very successful; there is scarcely a detail in the whole structure of the reptiles whose origin is yet inexplicable; distinguishing characters, one by one, have been completely or largely broken down, but we have, nevertheless, not yet found a creature about which there is doubt as to its position in the two classes when fully known. 


\section{Family Pariotichidae}

Cope, Proc. Amer. Phil. Soc., 631, I883.

Reptiles of small to moderate size, with a large, pointed head, short legs and tail. Skull roughened, narrowed in front of the orbits; either tabulare or supratemporal absent, sometimes both; a dermoccipital always present; occipital condyle rounded. Teeth implanted in two or more rows on maxillae, one or more on mandibles. Presacral vertebrae twenty-three or twenty-four in number, the arches low, but not transversely expanded, the spines low and small; two sacral vertebrae. Dorsal ribs with expanded proximal end, their articulation continuous from the intercentral space to diapophysis; weak or absent in lumbar region; the anterior dorsal ribs distally expanded (in all ?). Slender ventral ribs are present. No cleithrum in pectoral girdle. Limb bones with well-developed articular surfaces; digital fossa of femur not elongate; the adductor ridge not prominent; tibiale and fibulare large; front feet pentedactylate; phalangeal formula apparently reduced.

The above definition is based exclusively on Captorhinus and Labidosaurus; I have never studied closely either Isodectes or Pariotichis. The former genus I believe will be found quite distinct; if the latter is also, it must retain the family name Pariotichidae and another be chosen for Captorhinus and Labidosaurus. All the species which Cope referred to Pariotichus, save the typical one, are now known to be much more closely related to the genotype of Captorhinus (C. angusticeps) and must be referred to that genus.

\section{CAPTORHINUS}

Cope, Proc. Amer, Phil. Soc, XXXIV, 443, 1896.

? Captorhinus, sp. Plate XXX, Figs. 6, 7.

A single femur found in the Craddock bone-bed shows such decisive pariotichid characters that there can be no doubt of its relationships. In size it is intermediate between that of the smaller forms of Labidosaurus and the larger forms of C'aptorhinus, but. of 
course, its specific identity cannot be determined from a single specimen and the few associated vertebrae found in the bed. The figures will show sufficiently well these characters and the bone does not need further description. In Plate XXIV, Figs. 8-Io, I give several illustrations of the femur of Labidosaurus hamatus, with which the Craddock specimen may be compared.

? Captorhinus illinoiensis, n. sp. Plate XXIV, Figs. 5, 6, 7.

A well-preserved femur among the Gurley type collections from the Illinois bone-bed is shown in the cited figures.

Its resemblance is so great to the femora mentioned above, in the small digital fossa, the protuberant trochanter, the well-ossified articular extremities, and especially in the shape of the lower articular surface, that I have little doubt the bone belongs to some undetermined species of a true Pariotichid, a group never before recognized from these beds. It is true that no vertebrae of the peculiar pariotichid type have been recognized from this horizon. Certainly the femur does not belong with Clepsydrops, as the genus is now recognized, where Case has located it and figured in his Pelycosauria, Plate V, Fig. 7 . 


\section{Class REP'TILIA}

\section{Order THEROMORPHA}

Cope, Amer. Nat., XII, 829, I878; Proc. Amer. Phil. Soc., 38; Proc. Amer. Assoc. Adv. Science, XXXIII, 471, I885.

Crawling reptiles of small or large size, carnivorous or herbivorous in habit, with a single, lateral temporal, vacuity. A dermoccipital bone present, but the identity and relations of the other temporal elements unknown or in dispute. A septomaxillary probably always present; lachrymal (adlachrymal, postnarial) not reaching the nares (Edaphosaumus?). Teeth thecodont or acrodont, inserted on premaxillae, maxillae, palatines, pterygoids, and sometimes the splenials. Vertebrae deeply biconcave or notochordal, from twenty-four to twenty-seven or more in front of the sacrum; two or three sacrals; tail moderately long. Intercentra always present. Ribs double-headed throughout, attached to diapophysis and intercentral space; slender ventral ribs sometimes present. Cleithrum rarely present; clavicles and interclavicles large, the latter with a long stem; no ossified sternum. Coracoid fused with scapula; posterior coracoid bone forming only the posterior part of the glenoid cavity, sometimes unossified. Pelvis plate-like, rarely with a small, median, puboischiadic vacuity. Humerus with entepicondylar, rarely also with ectepicondylar, foramen; usually widely expanded at the extremities. Carpus with four proximal bones, two centralia, and four or five carpalia. Tarsus with dilated tibiale and fibulare; no separate intermedium; a single centrale and five tarsalia. Phalangeal formulae, 2, 3, 4, 5, 4 (3). No dermal ossifications.

The term Pelycosauria was proposed by Cope for a suborder of Rhynchocephalia, based upon Clepsydrops and Dimetrodon, and published for the first time (fide Cope) in Paleontological Bulletin, No. 29, on May 8, 1878. Later, in the American Naturalist of the same year for December, he proposed the ordinal term 
Theromorpha to include the two suborders Pelycosauria and Anomodontia, the latter term used in a wider sense than is now recognized. As a usual thing, priority is not much respected in the use of classificatory terms above the genus. As proposed by Cope the suborder Pelycosauria was coextensive with the family Clepsydropidae, to which after was added the Poliosauridae by Case. If we extend the term to include all the therocrotaphic reptiles from the Permian of America, from Naosaurus to Aracoscelis, as an order it displaces the ordinal term Theromorpha, unless the order be retained to include the African forms grouped by Broom in his order or superorder Therapsida; in the latter case it would take precedence over all others. If, later, it is shown that all the American forms are coherently distinguishable by valid group characters from the Therapsida, and provided that no higher rank is given to the whole assemblage than an order, the American forms, by the extension of the boundaries of the suborder Pelycosauria, may be distinguished from the African suborder Therapsida. But there is little probability of any unanimity of opinion in this. Broom insists that the groups Therocephalia, Dromasauria, etc., are at least of subordinal value, and certainly the differences between the phytophagous Casea and Dimetrodon are as great as between the Dromasauria and the Therocephalia, each of which would likewise be entitled to subordinal distinction.

It is, however, quite impossible to satisfactorily distinguish all the imperfectly known forms at present, and as it is quite certain there are many more therocrotaphic forms to be discovered in Africa and North America, to say nothing of the forms that may be expected from other parts of the world, it seems most expedient to resuscitate the term Theromorpha for our American genera at least; and as nothing much is to be gained in the present state of our ignorance by dividing our American genera into various suborders, the term Pelycosauria may be held in abeyance, or used only to distinguish the long-spined theromorphs.

I recognize, then, the following groups of American theromorphs: Sphenacodontidae (Clepsydropidae), Poliosauridae, Edaphosauridae. Caseidae, and Araeoscelidae. 


\section{Family Sphenacodontidae}

Marsh, Amer. Jour. Science, 4II, May 3, I878; Clepsydropidae Cope, Proc. Amer. Phil. Soc., XVII, 529 (published May 8, fide Cope, as Paleontological Bulletin, No. 29).

Carnivorous reptiles with high skull, anisodont teeth, and greatly elongated dorsal spines. Cleithrum (always?) present; sacrum with three vertebrae; pubes with greatly elongated, plate-like expansion in front. Of moderate to large size.

Under the assumption that Sphenacodon has elongated dorsal spines, of which, however, there is no evidence and much improbability, the family name Clepsydropidae is quite synonymous with Sphenacodontidae. If Sphenacodon has only moderately elongated spines, and a general identity of its other characters with Dimetrodon or Clepsydrops, it may perhaps require the modification of the characters given above; or the family name may be recognized as distinct.

\section{CLEPSYDROPS}

Cope, Proc. Acad. Nat. Sciences, Philadelphia, 407, I875.

The genotype specimen of this genus consists of a series of isolated vertebral centra from the so-called Permian of Illinois. In my opinion vertebral centra are wholly unreliabie in this order as generic types, to say nothing of species; they may be proven eventually to belong to either of several related genera. However, Cope in 1878 referred a species from the Permian of Texas to the same genus, which he called $C$. natalis, and it is from this homotype that all the distinctive characters of the genus have so far been derived. It is very probable, merely as a matter of exclusion, that Cope correctly identified his Texas genus with Clepsydrops, since we know that the limb bones associated with $C$. natulis do closely agree with limb bones found associated with the type, but not anatomically so, from the Illinois bone-bed. And here is perhaps one of the best arguments against the strict rulings of the international committee on nomenclature. If, fifty years hence, 
as is not unlikely, it is definitely proven that the original types are equally, perhaps more, characteristic of a genus distinct from that including the Texas species referred to Clepsydrops, it would be in defiance of common sense to introduce a new name for the latter because the identity of its type is in dispute.

Clepsydrops natalis (?) Cope, Proc. Amer. Phil. Soc., XVII, 509, 529, I878; Case, Pelycosauria, 42, 90, Pls. IV, V, VI, Igo8.

Among the material from the Craddock bone quarry there are numerous limb bones and other parts of the skeleton which agree so closely with the descriptions, and especially with the figures, of this species as given by Case, that I believe there can be little doubt of their correct determination. They are, like all other specimens from this quarry, in such excellent preservation that I have given figures of many of them and rather full descriptions. That they all belong in the same species is doubtful, however.

Femora.-Two forms of femora are shown in Plate XXX. Figs. I, 2, and Plate XXXII, Fig. I. The upper extremity is truncate, the surface subcrescentic in outline, much narrower in the femur shown in Fig. I than in that of Fig. 2. The trochanteric ridge is high up; the digital fossa shallow. The distal extremity is slightly convex dorsoventrally; the outer condyle is usually much broader; both the popliteal and extensor grooves are shallow. The stouter femur has decidedly thicker ends and is a little wider than the other. The shaft is oval in cross-section, and is more slender in the one shown in Fig. I than that of Fig. 2. These differences seem too great for specific identity. The slender femur may be provisionally designated as Clepsydrops A.; the more robust as $B$. In addition to the larger femora of nearly uniform length there are numerous ones in the collection, one of which is shown in Plate XXX, Fig. 3, of much smaller size, agreeing better with Clepsydrops $A$., save that, as would be expected of juvenile bones, the ends are less well ossified.

Tibia.-A left tibia, which in size seems to agree well with the larger femora, is shown in Plate XXX, Fig. Io, and may be referred to one or the other of the forms represented by the femora. perhaps better with the more slender one; it is very perfect. 
That it belongs with the femora seems probable because, not only agreeing in size, it shows the same lack of articular ossification so characteristic of this genus. The bone is much curved; the shaft slender; the upper extremity much expanded. The outer border is very deeply concave, as is also the posterior. The upper end is gently convex, with angular margins; it is elongate, with a small anterior projection. The lower, sharply truncate end is obliquely ovate in shape; the posterior inner part narrower.

A smaller tibia, about three-fifths the length of the larger one. agrees in general characters, save that the cnemial convexity is less pronounced. It probably belongs with femora referred to Clepsydrops.

The fibula shown in Plate XXX, Fig. I , in much probability belongs with Clepsydrops, but this is not at all certain. The shaft is only moderately slender; the lower end is much dilated. and the articular surface is not at all oblique to the long axis of the bone, as in the same plate, Fig. 9. Various carpal and tarsal bones preserved evidently belong with this genus, and especially the astragalus shown in plate XXXII, Fig. 9, and the calcaneum shown in Plate XXXI, Fig. Io, and Plate XXXII, Fig. I .

Humerus (Plate XXXI, Fig. 3).-There are several humeri which agree well with those referred to C. natalis by Case and Cope, and doubtless of the same species as one or the other of the large femora figured in Plate XXX. Like the femora, the extremities were largely cartilaginous in life, the condyles undeveloped. The lateral process reaches about one-third the length of the bone; the plane of the inner side above is at about sixty degrees with that of the lower end. The entepicondylar foramen is large, and is remote from the border. The upper angles of the cartilaginous borders of the condyles are nearly opposite each other, and are low down. the two sides of the bone nearly symmetrical below the lateral process.

With the half-dozen large humeri there are as many more of small size, a half or less the length of the larger, which doubtless are of young animals; one is shown in Plate XXX, Fig. 5. They agree in general with the larger ones, except that the shaft is more slender and the ends less well ossified, the lateral process is rela- 
tively smaller and the entepicondylar process is relatively much larger. They also agree well with the specimens referred to Clepsydrops from Illinois.

Ilium.-Because of the number, shape, and size I refer several ilia to this genus and species, one of which is shown in Plate XXXI, Fig. 2. It has a rather narrow and elongated posterior process. The upper border is much higher and thinner in front than behind, the hind extremity with a small cartilaginous surface. The inner side shows marked rugose surfaces for two sacral ribs; there may have been a third. The outer side has a distinct curved ridge for muscular attachment.

Ischinm.-A well-preserved ischium, because of its size, doubtless belongs with one or the other of the ilia like that just described; it is shown in Plate XXXI, Fig. 4. It is of the typical pelycosaurian shape with sharp cartilaginous borders; the blade convex on the outer, concave on the inner, side, with a thick border for the acetabulum. Several small or very small ischia of the same shape are among the collection, but as the ischia of the Permian reptiles in general are very uncharacteristic bones, they can only be referred to this genus doubtfully.

Quadrate.-A very complete quadrate, which because of its size may be provisionally referred to this genus, is shown in Plate XXXI, Figs. 5, 6. The roughened elongated surface on the posterior side for union with the cranial bones is very conspicuous. The condylar surfaces are perfect; the outer elongate part separated from the inner, more triangular one, by a deep groove.

Articular.--Several articular bones in perfect preservation may belong with this genus. I figure one in Plate XXXI, Figs. 8, 9 . showing the characteristic form of the bone; it is of interest as proving the absence of an anterior or prearticular process to the bone; that is, the prearticular bone is distinct.

\section{NAOSAURUS}

Of the real skeletal structure of Naosaurus, notwithstanding the various restorations that have been published, very little is known aside from the precaudal vertebrae, the pelvis, and perhaps the 
humerus. The skull, pectoral girdle, and limbs have all been assumed to be like those of Dimctrodon, which have been used in the restorations. But I am very skeptical indeed of the legitimacy

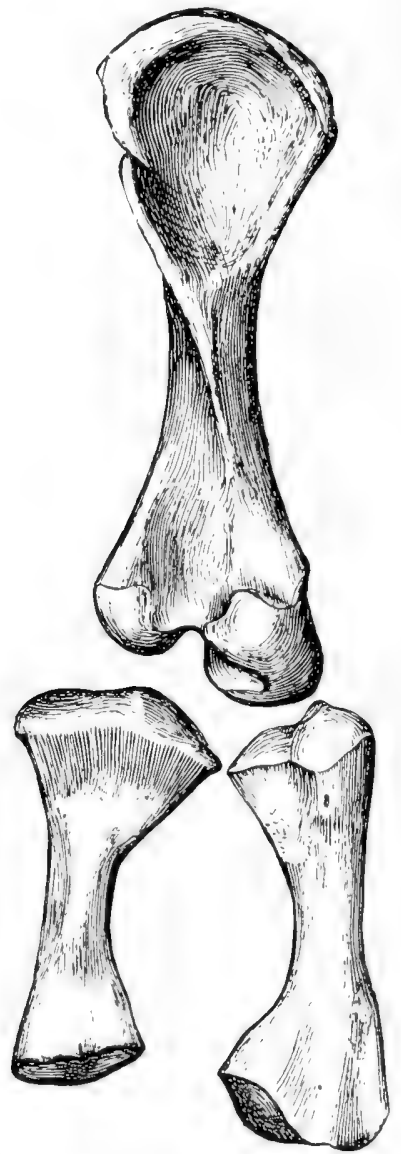

FIG. 23.-Naosaurus, or new genus. Right femur, tibia, and fibula, ventral side, two-fifths natural size.

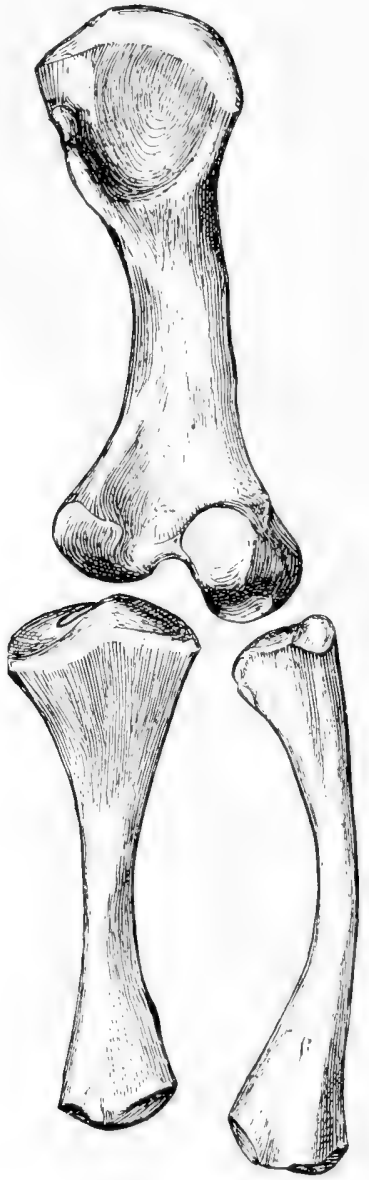

IIG. 24. - Dimetrodon incisivus Cope. Right femur, tibia, and fibula, ventral side, two-fifths natural size.

of this assumption. I believe that when the skeleton is fully known it will prove to be very unlike that of Dimetrodon. Case has been inclined to the belief that Naosaurus is a synonym of 
Edaphosaurus, known only from the skull, and I myself would be inclined to this belief, were it not that the two known specimens of Edaphosaurus are altogether too small to go even with the smallest of the known specimens of Naosaurus. On the west side of Hog Creek, near Seymour, Texas, I found, two years ago, a very perfectly preserved specimen, consisting of the right femur, tibia, and fibula and part of the astragalus, all in close articulation, bones unlike anything hitherto known from Texas. I am much inclined to think that they really belong with Naosaums, though that conclusion is reached merely by exclusion. I give herewith figures of these bones, ventral views, in contrast with like views of the corresponding bones of Dimetrodon incisivus, made from an unusually perfect specimen from the Craddock bone-bed, all drawn to the same scale. It will be observed that the femur is much more slender than that of Dimetrodon, the digital fossa is deeper and longer, the trochanter more prominent, the adductor ridge also more prominent and continued half-way to the outer condyle, instead of ending with the trochanteric eminence. The lower extremity is more gradually dilated, though the distal articular surfaces are much alike. The tibia and fibula are characterized by their remarkable shortness and stoutness, so short and stout that, had they been found isolated, they would have been referred to the Eryopidae or Diadectidae. The fibula in contrast with that of Dimetrodon. here for the first time figured, is very different, though having the same general characters and articular surfaces; its shaft is very stout and its lower end much expanded. The tibia has its ends rather larger than those of Dimetrodon, while scarcely two-thirds as long; its shaft is stouter. That the leg belongs to a zygocrotaphic reptile I am assured because of its general resemblance to that of Dimetrodon, but that the habits of the animal were very unlike those of Dimetrodon is equally evident. However, there is certain evidence of a still unnamed reptile from these beds, found in the Craddock bone-bed, of large size, but with slender jaws, and this leg may possibly belong with that form, which will be described and figured later. Should the form prove new, as it undoubtedly is if not Naosaurus, it may be known as Brachycnemius dolichomerus g. s. nov. 


\section{SPHENACODON}

Sphenacodon ferox Marsh, Amer. Jour. Science, XV, 4ro, May 3. I 878 .

In the present genus the anterior teeth are somewhat like those of the reptile described above, but the posterior, or more characteristic ones, are totally different. The crowns are much compressed, and have very sharp cutting edges, without crenulations. In the present species the carnivorous teeth are crowded together, and the crowns placed slightly oblique, and twisted. The jaws were comparatively short and massive. The rami of the lower jaws were apparently united by cartilage only, and the symphysis was short. The vertebrae are deeply biconcave.

Measurements from the type of this species are as follows:

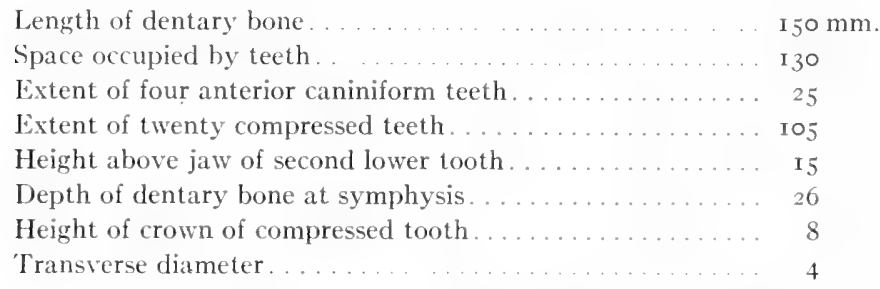

This reptile was about six feet in length, and carnivorous in habit. Its remains are from the same locality in New Mexico that yielded those of Nothodon.

The type specimen is shown natural size in Plate XXXIV, Fig. I, a left, incomplete dentary. The second tooth, while agreeing with his measurements, is incomplete; the fracture is evident. yet apparently Marsh did not observe it. The tooth was probably twice the length shown in the figure. There appears also to have been a very small tooth in front, of which only a slight indication of the alveolus remains. That this specimen is the holotype, aside from the general agreement of the measurements, is assured by the fact that it was the only bone in the entire collection which had been mended, by the gluing together of the seven separate pieces of which it was composed. And there is no other specimen in the entire collection which will agree with his description. In immediate association with this dentary, in the same lot and collected with it, are two maxillae, which agree in size, color, and condition of preservation. There can be scarcely a doubt but that they belong 
with the same individual as did the dentary and may be considered as part of the type. These were the only specimens in the lot studied by Marsh. Later finds by Baldwin show several other mandibles and maxillae, but the numerous pieces into which they were broken were widely scattered through the collection. They were, if seen at all by Marsh, probably not attentively examined. It is surprising, however, that in an entire collection from this horizon, and this bone-bed, a collection including perhaps hundreds of vertebrae, I can find no indications of long, Dimetrodon-like spines. Marsh stated that the vertebrae are deeply biconcave, but the fact is that not a single vertebra can be certainly correlated with the type specimen or species. There are twenty-four teeth or sockets for teeth in the dentary, a number somewhat under the usual one in Dimetrodon. The first and third, as preserved, are of nearly equal size; they are longer than the ones following, are more pointed and convex above. The second tooth in life was probably twice the length. The remaining teeth are of nearly equal size, save the last four, the roots of which are distinctly smaller. The fourth and the sixth have each a distinctly worn facet on the outer side, which fits precisely the outer facets of the caniniform tooth of the corresponding maxilla. In the left maxilla (Plate XXXVII, Fig. I), there are two smaller teeth in front of the very large caniniform tooth. Back of this tooth there is a cavity on each side, apparently for a tooth of considerable size. This condition is noted by Case as characteristic of the Clepsydropidae, with rare exceptions; in another dentary of smaller size in the collection the alveolus is filled, the three large teeth being all nearly of one size. Back of this cavity there are twelve teeth or cavities for teeth. They are all of a slightly larger size than those in the dentary, and, with the caniniform tooth biting in the place shown by the worn facets, the teeth would extend back of the lower ones about fifteen millimeters. The whole number in the maxilla was but sixteen, a smaller number than is known in species of Dimctrodon. None of the teeth is serrated on its margins. It is evident from the position of the anterior process in front of the first tooth that the border of the diastema was not ascending. The remainder of the collection obtained later by Baldwin, evidently 
from the same horizon. and some at least from the same "bonequarry." has several maxillae and mandibles and other parts of the skull of this same genus, and apparently this same species. Strangely, however, as I have already stated, among the numerous vertebrae accompanying them and the other genera I can find none with long spines. Such vertebrae as have been restored have rather short thin spines, resembling those of Varanosaurus. etc., together with others which I refer to Nothodon. I give a figure of a premaxilla from among these skulls. For the description of limb bones, some of which may belong with this genus, see under Ophiacodon.

\section{Family Poliosauridae}

Case, Pelycosauria, I8, I908.

Primitive Pelycosauria with low, flat, acuminate head, sometimes elongate, the maxillary with straight tooth line. One or more teeth at the anterior end of the premaxillary and dentary, and one or more teeth in the maxillary enlarged somewhat above the others. Maxillary teeth not separated from the premaxillary teeth by a toothless interval. Vertebral spines low and the neural arch free from the centrum through life in some (Poliosaurus). Abdominal scutes present. Sacrum with two vertebrae. Long-bodied forms with long tail; probably aquatic.

The above definition by Case includes the most essential characters of this family, though the assumption that the animals were probably aquatic is evidently wrong, and the separation of the neural arches in Poliosaurus is not a family, nor even a generic, character, since I doubt not it was due always to age. To these characters may be added, as based chiefly upon the skeletons of Varanosaurus described further on, the following:

Twenty-seven presacral vertebrae (which number, however, may be only of generic value); pubis elongated and expanded anteriorly as in Dimetrodon; no cleithrum; the lower temporal arch is incomplete below in some, perhaps all, the known genera. To this family belong with assurance the following genera: Poliosaurus, Ophiacodon, Theropleura, Varanosaurus, Poccilospondylus, and other known yet undescribed forms. It is very doubtful whether Elcabrosaurus belongs here, or indeed whether the name is not a synonym. 


\section{OPHIACODON}

Marsh, Amer. Jour. Science, XV, 4II, May 3, I878.

Ophiacodon mirus Marsh, loc. cit.

A third genus of reptiles allied to the last described [Sphenacodon] is indicated by various well-preserved remains from the same locality. The teeth are all carnivorous in type, conical in form, and all are similar. Those in the anterior part of the jaws are recurved, and in general shape resemble those of serpents. The rami of the lower jaws were united only by cartilage. The vertebrae are very deeply biconcave, and even perforate, and the intracentral bones large. In the present species the teeth are nearly smooth, and somewhat compressed.

The following measurements indicate the size of this reptile:

Extent of anterior sixteen teeth in dentary ........... $75 \mathrm{~mm}$

Extent of anterior five lower teeth............... 20

Height of crown of fourth lower tooth............. I0

Depth of lower jaw at symphysis.............. I5

Extent of seven anterior maxillary teeth.............. 33

Height of crown of first maxillary tooth . . . . . . . . . . 9

Antero-posterior diameter of crown . . . . . . . . . . . 3

This species was about as large as those described above, and is from the same geological horizon in New Mexico.

The type specimen of this genus and species, a mandible, is figured in Plate XXXI, Fig. 3. Some of the long teeth had been gummed together with mucilage, but other fragments were still separate, and yet others have not been recovered. Fragments of an upper jaw from which the measurements had been taken I have not thought necessary to figure. In addition, I find three or four mandibular bones and several maxillae, all of them of a somewhat larger size than is the type specimen. All of these specimens are from among the original collection studied by Marsh. I find no other evidences of the skull among the material acquired later.

With this genus I associate provisionally a considerable number of limb bones and vertebrae which were associated with the type specimen, including five humeri, the best and largest of which I have figured; a complete radius and a complete ulna, and parts of two or three others of each bone; at least five scapulae, none of 
which has been restored complete; a half-dozen ilia, of which one of the smallest I have figured; at least three pubes, and as many ischia, none of which has been made complete; five femora, four of about equal size, one of which I have figured, the fifth, though no longer and resembling the others in shape, is a distinctly stouter bone; six tibiae of nearly equal size, one of which is figured; four fibulae of nearly equal size, one of which I figure; and numerous hand and foot bones, many of which probably belong with this genus. Besides these limb bones there are numerous vertebrae, of which five or six are in one series, with the intercentral bones in position, probably the ones referred to this genus by Marsh. I figure an isolated one from the later collections.

From the later collections, as already stated, I find no limb or skull bones of these forms, though there are not a few vertebrae with short, thin spines. Among these later collections there are a number of mandibles and maxillae agreeing quite with the type of Sphenacodon ferox, and a few limb bones which, though incomplete, seem to differ in their greater slenderness and more Dimetrodon-like form.

I refer these limb bones and vertebrae to this genus, rather than to Sphenacodon, because they agree better with the poliosaurid than the clepsydropid type, though their positive identity must depend upon their future discovery in actual juxtaposition.

The figures of the typical specimens of mandible, together with Marsh's description, will render the skull of Ophiacodon easily recognizable. The anterior teeth are long and recurved, and somewhat flattened, not only in these specimens, but also in impressions of perfect teeth yet preserved in the matrix. The posterior teeth are almost cylindrical and scarcely at all compressed; they are all shorter, and but slightly recurved. Several of the mandibles are somewhat larger than in the type specimen. The mandible may have had a length of from I 50 to 200 millimeters. The specimens indicate a relatively slender and small skull of the poliosaurid type, too small, it would seem, to belong with some of the limb bones, were it not there is similar disparity in size shown between the mandibles and limb bones in the specimens of Theropleura retrowersa Cope figured by Case (Pelycosauria, Plate III). 
As stated, there are numerous vertebrae in the collection that have the general characters of the one figured in Plate XXXVIII, Fig. 3. The larger part of the vertebrae, however, have not yet been restored from their fragments, and it is quite possible that among them later will be found two distinct types; one of them belonging with Ophiacodon, the other with Sphenacodon. The centrum of the posterior dorsal or lumbar vertebra shown in the figure is rather shorter and stouter than others; it has a thin keel below. The co-ossified rib has a slender, capitular process, and a heavy tubercular one, uniting with both centrum and arch. The rib, broken away in the specimen, was probably about fifty millimeters in length. The spine is broad and flat, with thin edge; its height is less than four times the diameter of the centrum, though rather more elongated than in Varanosaurus. Anterior dorsals in the collection have similar spines, as also caudals, and it is because of this character that I assign the vertebrae to Ophiacodon rather than to Sphenacodon, and which forces the conclusion that the genus belongs among the Poliosauridae.

\section{PECTORAL GIRDLE AND EXTREMITY}

Claiscle. - There are numerous clavicles in the collection, one of the most complete of which I have figured in Plate XXXVI, Fig. 4. It is a rather slender bone, only moderately expanded at its mesial extremity. The outer or dermal surface of this part is coarsely striate. This clavicle is of poliosaurid type, and quite unlike the clepsydropid.

Scapula.-There are six or eight scapulae in the type collection, all of nearly uniform size, but still unfortunately much broken and fragmentary. The supraglenoid foramen pierces the supraglenoid fossa, not opening on the dorsal side of the scapula, as I have observed it in all other theromorphous forms from the American Permian. There is no process on the upper margin of the posterior coracoid, above the glenoid cavity, so conspicuous in Dimetrodon.

Humerus (Plate XXXV, Fig. 5).- The humerus differs from that of most species of Dimetrodon in its greater relative terminal expansions, its shaft being less slender and shorter. The 
ectepicondylar process is much more prominent and transverse in position. The concavity of the radial side is much deeper. With the humerus of $D$. incisivus the resemblance is somewhat greater. It also resembles the humerus from New Mexico assigned by Case to Dimetrodon navajoicus, but I feel assured the forms are of different genera. Because of its size and general characters the present specimen may well belong with Sphenacodon, rather than Ophiacodon.

Ulna (Plate XXXV, Fig. 9).-The ulna is a distinctly less slender bone than that of Dimetrodon; its olecranon process is not produced in the specimen figured, and scarcely so in other fragmentary specimens. The sigmoid fossa is not as deep, and the shaft is broader.

Radius (Plate XXXV, Figs. Io, $\mathrm{x} \mathrm{I}$ ).- The radius also is less slender than in Dimetrodon. The bone is moderately expanded at either extremity, with the concavities of the sides nearly equal. The upper, articular end is nearly semicircular in outline; the lower one, subcrescentric, with the outer horn the thinner.

\section{POSTERIOR GIRDLE AND EXTREMITY}

Ilium (Plate XXXVII, Figs. 4, 5).-Among all the bones of the posterior girdle and extremity there is none so characteristic as the ilium. The present ilium differs materially from that of Dimetrodon, resembling more that of Theropleura or Varanosumrus in its narrow posterior prolongation and the presence on the inner side of the strong, horizontal, keel-like projection, quite as Case has figured it in Theropleura. The articular surface for the ischium is much longer than that for the pubis, and the two meet in nearly a right angle. Of the five or six ilia in the collection, the one figured is the smallest.

Ischinm. - The ischia, of which there are several in the collection. all incomplete, agree quite with those of Theropleura, as figured by Case (Pelycosauria, Plate III, Fig. 6). The ischia generally in the Permian reptiles are uncharacteristic.

Pubis.-The pubes seem to be quite similar to those of Varanosaurus, having a strongly projecting anterior plate, twisted to a horizontal position in the articulated skeleton. This bone: as 
described in I'aranosaurus, has a like form in both the Poliosauridae and Clepsydropidae.

Femur (Plate XXXVII, Fig. 3). - The femur resembles that of Theropleura more closely than that of Dimetrodon in its relatively greater terminal expansions and especially in the greater extent of the digital fossa, which reaches nearly a third of the length of the bone. Four femora of the collection are very nearly of the size and shape of the one figured; a fifth has a materially stouter shaft, though differing in no other way that I can see.

Tibia (Plate XXXV, Fig. 6) and fibula (Plate XXXV, Fig. 7).-These bones are not very characteristically different from those of either Theropleura or Dimetrodon. Both are considerably curved away from each other, the outer border of the fibula nearly straight, the inner deeply concave.

There are also four tibialia and four fibularia which scarcely differ from those of Dimetrodon, save in size; and numerous tarsal and carpal bones of different kinds. Perhaps some of them belong with Nothodon.

As I have said, the differences between these bones and corresponding ones of Dimetrodon are so striking that I cannot believe that they belong with Sphenacodon, which in its skull characters is scarcely distinguishable from that genus. It is for this reason that I refer them provisionally to Ophiacodon, though, it must be confessed, the entire absence of long-spined vertebrae in the collection coming from this bone-bed throws much doubt over their determination, as well as the affinities of Sphenacodon.

\section{VARANOSAURUS}

Broili, Paleontographica, LI, 7I, I904; Case, Pelycosauria, 20, 79, I908.

Varanosaurus brevirostris, n. sp. Plates I-XIII.

The genus Varanosaurus was defined by Broili from a considerable part of a skeleton found on West Coffee Creek, Texas. which he referred to a new species, $V$. acutirostris. ${ }^{x}$ The type

${ }^{ \pm}$Broili, op.cit., p. 7I, Pl. X, Fig. 2; PI. XI; PI. XII, Figs. 22-32; Case, op. cit., PI. II. 
specimen of Broili's species consists of a fairly complete skull, thirty-four vertebrae in a more or less continuous series, including the sacrum and basal caudals, and parts of the girdles and limbs. So far as this material goes Broili's descriptions and figures apply well to the abundant material herein described, and there can be no doubt of their generic identity. Indeed, it was not until I had critically studied the skulls and compared them with Broili's figures and descriptions that I was forced to recognize the specific distinction of our form. In his choice of a generic name Dr. Broili was very happy, since the general resemblance of the genus to Varanus is very striking.

The material of $V$. brevirostris herein described, and, I trust, faithfully figured, forms a part of that of the remarkable bonebed described on the preceding pages as the Cacops bone-bed, situated about five miles west of the Vernon road. near the Wichita River, in Baylor County, Texas.

The remains of Varanosaunus from this bone-bed, all of which are referred with assurance to the single species, comprised originally not less than twenty-five skeletons, of which six or eight in greater or less perfection have been recovered from the blocks of matrix in which they were brought to the museum. The development of these skeletons is, however, very tedious, each requiring about two months of continuous work. For this reason not much has yet been done with others than the one described and mounted, save where it was found necessary or desirable to complete or corroborate the knowledge furnished by the single specimen. Unfortunately. so far but three skulls have been found in the matrix. and one of these is a mere fragment. There still remains nearly a half of the material secured unexamined, and it is almost certain that when this shall have been worked out other skulls will be detected. But to wait until this is done would delay the publication of the work unduly. I can therefore promise within the next few years another paper upon the skull, not only of Varanosaums, but also of Casea, and I content myself here with a preliminary description, together with a reconstruction of the skull as based upon the material so far worked out, material which furnishes the more essential characters of the reptile, but which still leaves 
many details concerning the sutures especially which are impossible to determine with anything like assurance.

Skull.-Of the three specimens of skull which have so far been prepared, one, that belonging with the mounted skeleton, is a fragment consisting of the right maxilla and the corresponding part of the mandible. It is, however. of considerable interest, since the teeth are in good condition. The second specimen, the skull shown in the photograph of the mounted skeleton, lacks the end of the rostrum in front of the hind margin of the nares; the posterior arch supporting the quadrate of the right side is injured, and the left arch and quadrate are lacking; the skull is slightly skewed

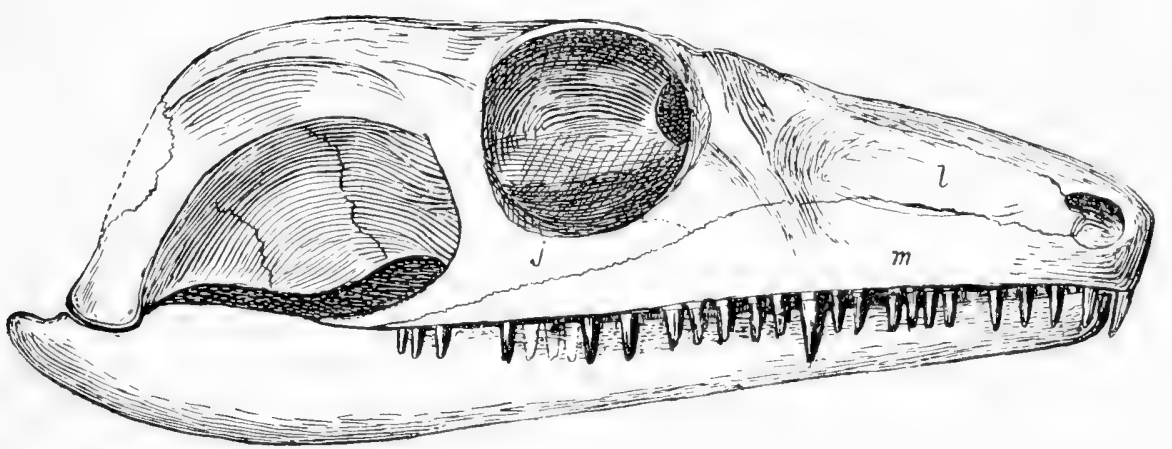

FIG. 25.-Varanosaurus brevirostris Williston. Skull, from the side, twothirds natural size.

to the right. The third skull, the best of the three, has the region in front of the middle of the orbits very nearly perfect, and but slightly skewed; the left orbit is complete, but the left quadrate is lacking, as also the posterior orbital bar of the right side. The right posterior arch supporting the quadrate is pressed downward and somewhat outward, narrowing the temporal vacuity somewhat; but this bar is shown in apparently normal form in the other skull. The mandibles of both specimens have been crowded upward and inward, obscuring the palate so much that no attempt has been made to free this region from its incrusting matrix. Fortunately in both skulls, on both sides, the lower temporal region is nearly or quite uninjured, leaving no doubt as to the 
structure here. The drawings here given are in part a composite of the three specimens, all of which quite agree in size. For comparison I also give an outline sketch figure of the skull of Varanosaurus acutirostris, copied from the original by Broili.

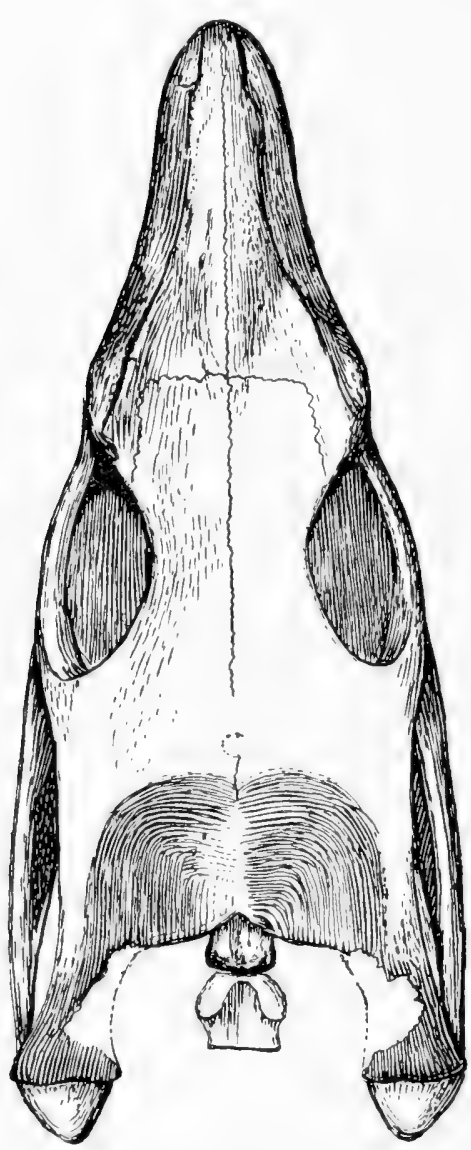

FIG. 26.-Varanosaums brevirostris Williston. Skull, from above, two-thirds natural size.

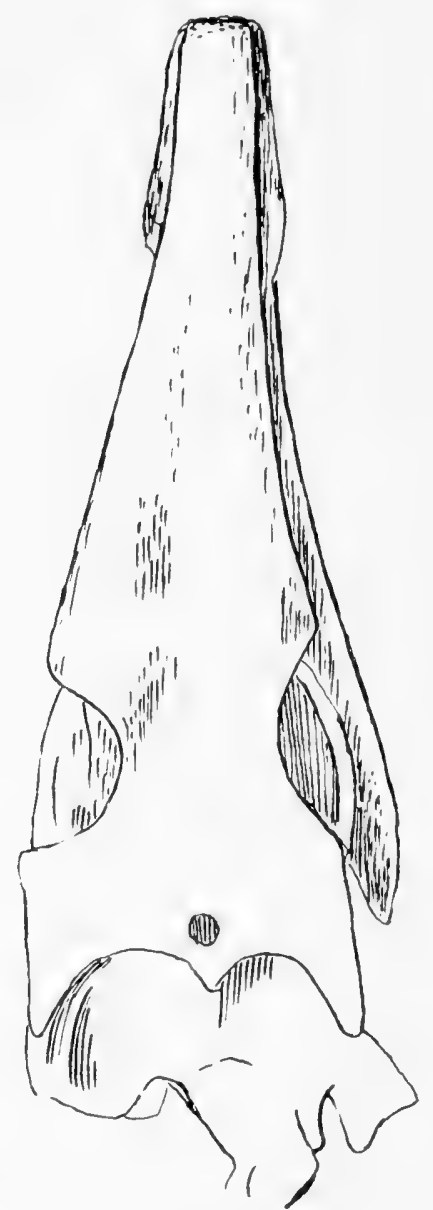

FIG. 27.-Varanosaurus acutrirostris Broili. Skull, from above, two-thirds natural size. After Broili.

The upper surface of the skull between and immediately in front of the orbits is gently concave. At the upper anterior angle of the orbit there is an elevated protuberance, which extends 
forward as a ridge on the sides of the face to about midway between the orbit and the hind border of the nares; and another pronounced ridge extends downward and forward nearly to the alveolar margin opposite the large mandibular tooth. The profile of the face in front is gently convex to the extreme front end, which overhangs slightly the alveolar margin. On either side the face is somewhat pinched in, forming a somewhat shallowly concave fossa on each side. The nares are small, situated near the extremity of the rostrum, and they are directed laterally. The orbits are nearly circular in outline, with a heavy, thickened anterior border, more pronounced above back of the antorbital elevation. Within the orbit is seen a descending plate on each side, reaching apparently nearly or quite to the pterygoid, from the frontal above, emarginate in front, altogether resembling the rhinencephalic chamber figured by me in Cacops (Bull. Geol. Soc. Amer., XXI, Plate VIII). The posterior bar of the orbits is moderately stout, bounding the large temporal vacuity in front. Posteriorly on each side above a thickened sinuous bar extends backward and then downward to the extremity of the quadrate; this bar is not quite complete on the upper and inner sides behind in either skull. Between these suspensorial bars the occipital surface slopes downward from not far back of the orbits in a broad, flattened, or somewhat convex surface to the upper border of the foramen magnum, with a thinned. rounded contour on each side, as seen from above. The occipital condyle projects moderately beyond this border; it is gently convex at its end, somewhat heart-shaped, and has a dimpling in the middle, the remains of the notochordal canal. The odontoid, in articulation with the skull in both skulls, is shown in the figure from above.

The most remarkable character in the skull of Varanosaurus is the absence of the lower temporal arcade; a character wherein the genus differs from all other known genera of reptiles, save the Squamata. The jugal bone ends as a slender, pointed process, a short distance beyond the pointed extrenity of the maxilla. Perhaps in life there was a ligamentous connection between this extremity of the jugal and the quadrate, but there is no roughening in these specimens indicative of such. Unfortunately the precise 
curvature of the upper posterior border of the vacuity cannot be determined. In one specimen the arch is very complete and undistorted, but it has been partly broken away from the side of the skull above and pressed outward and downward; in the other the outline scems to be quite normal, as I have figured it. The vacuity is very large, comprising nearly the whole of the side of the skull back of the orbits, with thin margins above and on the sides, open for the greater part of the distance below between the teeth and the quadrate. In this space the quadrate is shown in both specimens as a broad, oblique plate extending inward and forward, nearly as far as the posterior border of the orbit, articulating above and exteriorly with the suspensorial arch, doubtless chiefly the squamosal; below and within with the pterygoid. Its articular surface below is broad from side to side. The squamosal doubtless reaches nearly to the articular end on the outer side. There are no indications of sutures here, as generally elsewhere. Doubtless also the quadratojugal is entirely wanting.

The palatal region, as already stated, cannot be laid bare from below, because of the mandibles, but in one specimen the pterygoid and palatines have been laid bare from above back of the front margin of the orbit. They meet or nearly meet in the middle line below the orbits and seem to be in contact with thescending plates from the frontals; they are in close contact on the sides with the maxillae as far back as their extremity; back of these is the free transpalatine process, which reaches as far as the extremity of the jugal and a considerable distance back of the orbit.

The teeth are slender and conical, extending back to the extremity of the maxillae and for some distance back of the orbits and below the temporal vacuity. I count not more than thirty in each maxilla, with not more than three in each premaxilla. Opposite th: pronounced antorbital ridge, directed downward and forward from the antorbital elevation and at about two-fifths the distance beiween the orbit and the hind margin of the nares, there is a stout maxillary tooth on each side, nearly twice the length of those in front and behind. The other maxillary teeth are of nearly equal size, perhaps somewhat smaller in front. The most anterior one of the premaxillae is a little elongated. The mandibles are so 
closely united with the maxillae that the character and number of the teeth cannot be made out.

Varanosaurus acutirostris Broili, so far as the skull and skeletal characters are determinable from the figures and descriptions by the author in the incomplete condition of the type specimen, agrees well with the present species, save in the skull proportions and the teeth. As seen in the figure, the skull of $V$. acutirostris is more elongated and slender, the length in front of the orbits being equal to three times the diameter of the orbits, the orbits situated back of the middle of the skull. In the present species the length in front is scarcely more than twice the diameter of the orbit, and the orbits are in front of the middle of the skull. Furthermore. there is no large tooth in the position of the mandibular tooth of the present species, the enlarged tooth of $V$. acutirostris being much farther forward. Furthermore, and more important, Broili gives fifty-four as the whole number of teeth in the upper jaws of this species, while there are not more than thirty-four in I. brevirostris. Notwithstanding these differences, so great is the general resemblance between the two that I have been reluctant to admit the distinction of our species. But such differences cannot possibly be due to either age or individual variation. I have therefore given to the present species the name Varanosaurus brevirostris.

In the phylogeny of the reptilia we have assumed a high degree of importance for the different structural variations of the temporal region; and, in general, I believe that this assumption is justified. We recognize at least three and perhaps four chief types of reptiles. four chief phyla perhaps, as based upon the structure of this region: The cotylosaurian or stegocrotaphic type, in which the temporal region is wholly arched over; the double-arched or saurocrotaphic type, as I have called it, in which there are two temporal vacuities, the upper one bounded below by the union of the squamosal and postorbital, the lower by the jugal and quadratojugal; and the single-arched or therocrotaphic type, in which the single vacuity is bounded below by the jugal and quadratojugal; and perhaps a fourth type in which the upper arch and vacuity alone are present. bounded by the squamosal and postorbital below. But I do not feel so certain as to the distinction between these two latter types. 
Certainly in the Pelycosauria, and perhaps all the Theromorpha, the quadratojugal does not enter into the boundary of the lower vacuity and the bone is often, perhaps usually, absent. The distinction, then, must be made exclusively on the union of the postorbital with the squamosal below for the upper vacuity, their separation for the lower. But this distinction is a not very conspicuous one; in the plesiosaurs, for instance, the postorbital unites with the squamosal only in a slight point of contact; separate them an inch and the vacuity would become the lower one as in the Theromorpha. since there is doubtless no quadratojugal in the Sauropterygia. On the other hand, Broom figures the squamosal of Tapinocephalus as broadly meeting the postorbital (Geological Magazine, VI, 543), even more broadly than in the plesiosaurs, and yet the opening is assumed to be the lower one! I confess that to me the distinction between the upper and lower vacuities seems to be one without a difference; nor can I see any evidence, in the temporal vacuities, of phyletic distinctions between the various single-arched types. Perhaps I am dull, but I am inclined to believe that all single-arched reptiles have arisen from a single type.

It has been assumed that the squamate temporal arch has arisen from a double-arched form by the loss of the lower arcade and the development of streptostyly. But I believe that we are now convinced that the Squamata are of quite as primitive a descent as is the rhynchocephalian type, as urged by Huene and myself. In Iranasaurus we have, in addition to the many marked skeletal resemblances, presumably homoplastic, the loss of the lower arcade. While it is improbable that such a type originally gave origin to the Squamata by the development of an upper vacuity and the evolution of streptostyly, yet it is an interesting fact that just such changes are all that are necessary to convert Varanosaurus from a theromorph into a squamate, aside from the rib attachments, so far as we yet know.

Vertebrae and ribs (Plates I, II, III).--The vertebral column, as shown in the mounted skeleton. was found in perfect articulation from the skull to the forty-seventh caudal vertebra. A few of the spines of the anterior vertebrae protruding from the surface of the 
block of the matrix as collected had been broken off and lost, some six or seven in all; four of these have been replaced in the skeleton by corresponding vertebrae of another skeleton, but the figures given are those of the single specimen. This series is composed of twenty-seven presacral, two sacral, and forty-seven caudal vertebrae, to which may be added a few, perhaps half a dozen, minute terminal ones that were lost. Of the atlas, only the odontoid could be recovered from the matrix; the arches were so impressed upon a fragment of the occipital region of the skull that they could not be separated. The figure in the plate, together with others of a closely allied form from the Craddock bone-bed (Plate VII), will show the shape of this bone sufficiently well I hope. Its posterior surface is deeply concave, in apposition with the centrum of the axis; the perforation continues through the bone with a small aperture in front, which coincided with a small pit in the end of the occipital condyle. The upper surface of the odontoid is slightly concave for the floor of the neural canal. The bone in the middle reaches the ventral side, separating the atlantal and axial intercentra. The surface for the atlantal intercentrum is a little larger than that for the axial. On either side in front there is a somewhat oblique surface for the articulation of the atlantal arch. In the plate I give the outlines of the basioccipital and atlantal intercentrum found attached in another skeleton of the same species. The atlantal intercentrum, it is seen, is relatively small, not much larger than the axial, with only small attachment for the arch, which must have rested for the most part, if not entirely, upon the odontoid or pleurocentra, as in Poecilospondylus Case. It is very evident that we have to do here, as in Dimetrodon, with a primitive condition of the atlas, a condition in which it differs very slightly from the ordinary vertebra, one in which the atlantal arch is supported almost wholly by the pleurocentra, articulating not only by the usual zygopophysial way with the axis, but apparently with the exoccipitals as well, as shown in Dimetrodon, by an articular surface on either side of the foramen magnum. These may be for an unrecognized proatlas. Several very perfect atlantal arches are preserved among the Craddock bone-bed material. which will be figured and discussed elsewhere. 
The axis has a rather long, stout, not very high spine; it has feeble articulations in front for the atlantal arches. It has a rather short, but stout diapophysis on each side, directed downward and somewhat posteriorly, for the axial rib, which, however, has not yet been recovered in natural relations.

Of the succeeding twenty-five presacral vertebrae, the spines are nearly uniform in character, save of the posterior five or six. They are vertical in position, flat and thin, a little broader above, with a very thin front edge and a somewhat thicker posterior one, and are equal in height to about three times the vertical diameter of the centra; the upper end is rather squarely truncate. With the sixth presacral the spines begin to incline a little forward, becoming successively more oblique and more pointed and rounded at the end. The highest spines are those between the tenth and fifteenth presacrals, but the increased height is not great. The zygapophyses are nowhere very broad or stout, their articular surfaces looking uniformly obliquely outward and inward. The shapes and positions of the diapophyses are shown sufficiently well by the figures, and need but a brief description. As seen in Plate II, Fig. $x$, they are the largest, stoutest, and longest on the anterior vertebrae, about opposite the upper end of the scapulae, from the twentieth to the twenty-fourth presacral, quite in the corresponding part of the column in the lizards. Anteriorly they are directed more downward and backward; on the twenty-first and twenty-second downward; on all the following directly outward. From the twenty-first backward, they decrease gradually in length and in stoutness. The last five diapophyses - that is, those of the first five presacrals-have short ribs co-ossified with them, as in other Permian reptiles as a rule, the head descending a little on the body, leaving a small foramen between it and the tubercle.

The centra, unlike those of Casea, are of nearly uniform length throughout, somewhat shorter and higher posteriorly; anteriorly the "pinching in" of the sides produces a rather sharp keel below. but posteriorly this keel is broader and more rounded. Intercentra are in place, as shown in the figures, between various ones of the vertebrae; they are of moderately large size, larger than in (asea. Between the third and fourth, and the fourth and fifth, and less 
so between the fifth and sixth, the intercentral spaces are large, the cartilaginous surface extending back a considerable distance on the underside of the succeeding centra. Evidently there was considerable mobility between the vertebrae here.

Ribs (Plate I).-Most of the ribs of this skeleton were found in close articulation with the vertebrae, but they were so slender and frail and so firmly cemented together by the matrix as they lay partly folded over each other that only a few could be extricated in good shape. In the figures I give illustrations of some of the best of these, those found associated with the fifteenth to the eighteenth presacral vertebrae. As is seen in the figures, they are very distinctly double-headed, the head articulating as usual in the intercentral space, the tubercle to the end of the diapophysis. They are very gently curved in nearly one plane, very unlike the stout ribs of Casea, and they are relatively slender. Evidently, as in lizards, they had a long, cartilaginous continuation. On the first three or four presacrals they are little more than tubercles, gradually becoming longer, and becoming free, or nearly so, on the sixth.

Ventral ribs.- It is very evident that the whole underside of the abdominal region of Varanosaurus was covered by slender and numerous rentral ribs, lying close together and doubtless meeting in a V-shaped angle in the median line. Only isolated patches of these ribs have been recovered. In a single piece fifty millimeters in length and twenty-five millimeters in width I count fourteen ribs, continuous and parallel. Freed from their incrusting matrix they are little more than one millimeter in diameter, and I doubt not that some of them reached a length of four or five inches; the longest I have observed are about three inches.

The sacrum (Plate III; Plate IV, Fig. 8; Plate VI, Fig. 7; Plate XI). -This is composed of two vertebrae, which through their massive ribs have a firm union with the pelvis. The spines are nearly vertical, or convergent, somewhat rounded, and pointed at their extremity, narrower and rather stouter than the preceding ones. The zygapophyses are not very heavy; the centra are rather sharply carinate below, and an intercentrum is present between the two. The anterior ribs, much the larger of the two pairs, arise from the anterior two-thirds of the centrum and the corresponding part of 
the arch, with both of which they are closely fused, with only indications of the distinguishing sutural attachments. A few millimeters from the origin the rib contracts into a stout trihedral or prismatic shape, and then immediately expands into a wide extremity with a periphery of about three-fifths of a circle whose chord is above, hollowed into a deep cavity which looks nearly upward in the articulated skeleton. The rib is so directed that the plane of the anterior end of the centrum passes through the middle of the cavity and the posterior fifth of the acetabulum. The second pair of ribs are more slender and are directed more obliquely forward. The base, attached as in the first pair, is less robust, the shaft more slender, and the simple terminal expansion curves somewhat downward to be attached to the posterior expansion of the ilium, wholly back of the acetabulum; the extremity is suturally attached at the anterior corner with the posterior part of the end of the first rib.

Caudal vertebrae (Plate III).-Forty-seven caudal vertebrae were found associated in the mounted specimen in an uninterrupted and nearly straight series, and they have been mounted practically without disturbance of the matrical attachments. Perhaps a half-dozen of the minute terminal ones were missing. The centra throughout are nearly uniform in length. Chevrons were found associated with many, if not the most, of the vertebrae, but the delicate structure of many of the smaller ones rendered it inexpedient to attempt their recovery; some of those posteriorly were appressed against the centra and have been left in that position. Figures are given in the plate of those chevrons recovered in this specimen, and in the photograph of the skeleton others are seen that have been modeled to correspond with isolated or attached ones.

The first four or five centra have a rather sharp keel below, becoming a little more obtuse posteriorly. By the sixteenth or seventeenth the centra have lost nearly all of the lateral concavity or depression, and thenceforth a cross-section through the middle forms a rather regular semioval figure. Between the second sacral and the first caudal there is space for a small intercentrum. Below the first and second caudals the space is moderately large, yet 
altogether too small for the attachment of a chevron. That between the second and third is larger. At the end of the third there is a large facet for the attachment of a chevron, whose union was almost wholly with the third. Lying near these were several large chevrons with an obtuse extremity, and a shorter one with a more pointed extremity. I have figured this short one as attached to the end of the second centrum, with the three large ones following it; on further reflection I very much doubt whether there was a chevron attached here - in other words, there were doubtless two pygal vertebrae as in Casea and other forms; otherwise the chevrons would have projected into the pelvic cavity, as they have been so often figured in Diplodocus.

The spines of the anterior caudal vertebrae are nearly vertical; at the sixth the spine is shorter, more pointed, and inclined a little forward. With the twelfth - that is, the vertebra bearing the last transverse process or co-ossified rib-the spines have become mere tubercles, and thence onward they do not change much, becoming entirely lost before the end of the tail.

The ribs of the first four caudal vertebrae are attached by a short, stout proximal end to both arch and centrum. On the underside near the body a pit or cavity seems to indicate the natural division into head and tubercle, the capitular portion descending lower on the front margin of the centrum. These four ribs decrease in size; they are all pointed, with the point curved directly backward parallel with the axis of the tail, and they are horizontal. The much smaller fifth rib is directed outward horizontally and is also pointed at its extremity. The following ribs or processes decrease in length, terminating as a small tubercle on the twelfth; they ascend on the centrum as far back as the eighth. Thence to the last one preserved in the connected series, the forty-seventh, the centra are similar, becoming gradually more slender, the spines finally becoming obsolete; their chevrons are slender to the extremity.

Pectoral girdle and extremity (Plates IV-VIII).- The ossified pectoral girdle is composed of the scapula and so-called procoracoid, clavicles, and interclavicle. The posterior coracoid, the so-called true coracoid, is unossified in all the numerous specimens 
examined; and there is no trace of cleithrum in any of the specimens examined.

The upper end of the scapula is moderately expanded in nearly a plane, its upper margin very slightly convex, and squarely truncated, as though for a cartilaginous suprascapula; this border is about three millimeters in thickness. The posterior margin is thickened and rounded, and nearly straight for fully one-half the length of the conjoined bone. The anterior border is thickened moderately on the upper fourth, thinned and irregular in outline for the remainder of its border. The inner surface above is gently convex antero-posteriorly, convex on the corresponding outer surface. Below, the posterior border turns a little backward and outward to end in the preglenoid tuberosity. On the inner surface a thickening begins below the middle posteriorly, turning backward in a broad sweep to terminate in the cartilaginous border for the coracoid or metacoracoid. Between these two borders the surface for the most part is convex, and has no fossa or foramen as in the other reptiles and the amphibians. The upper part of the glenoid fossa is shallow. At some distance above the preglenoid tuberosity and back of the middle of the outer surface there is a small foramen piercing the bone; this is the usual supraglenoid foramen, as I have called it, but situated unusually far forward and in front of the border; its position in Dimetrodon is very near to this border, while in scapulae which $I$ have referred to Ophiacodon (see antea) this foramen pierces the supraglenoid fossa, as in the Cotylosauria and amphibians. The scapula-coracoid suture runs almost straight from a little above the middle of the coracoid border, through the middle of the preglenoid tuberosity or facet to the angle immediately above the anterior emargination of the so-called procoracoid. The suture is clearly indicated in various specimens, and in one the two bones are separated. The lower part of the scapula turns inward, so that the coracoid as a whole is nearly horizontal. This latter bone is much wider behind and is thin throughout the most of its extent, its inner border lying by the side of the interclavicle, thinned throughout most of its extent and for the most part nearly straight; the front border is also thin, with a subangular protuberance and a deep angular 
emargination above it, a coracoid fenestra, between the anterior angle of the bone and the angle into which runs the coraco-scapular suture. This emargination reminds one forcibly of the similar emargination or fenestra in many lizards, and is, it seems to me, furcher proof of the identity of the coracoid in these two groups of animals. At the posterior end the cartilaginous border for the posterior coracoid bone is thickened and rather broad; it is formed almost equally by the scapula and the anterior coracoid bone; that of the scapula a little larger and more protuberant posteriorly. The thickened preglenoid tuberosity juts outward and backward, and includes between it and the glenoid fossa a little in front a rather large and deep fossa, bounded behind by a rather prominent margin formed by the two bones nearly opposite the preglenoid tuberosity of the outer side; in front of this margin and in the narrow fossa formed by it, the subscapular fossa, the supracoracoid foramen opens as usual.

The absence of a posterior coracoid bone in this genus, as in Seymouria described in the preceding pages, is remarkable. On both sides of the pectoral girdle in this skeleton the humeri lay quite in natural position, indicating its undisturbed condition, but separate ossifications of the posterior coracoids were not preserved. It was not, however, till many other girdles of Varanosaurus had been observed with the scapula quite like the one figured and no remains of separate bones in the place of the posterior coracoids that I became fully assured of their entire absence in this genus; that the non-occurrence was due neither to displacement of separate ossifications nor to jurenility. As it would be absurd to suppose that all the numerous skeletons of Varanosaurus found in this remarkable deposit were juvenile animals of one size or very nearly one size. it is quite certain that Varanosaurus had no ossified posterior coracoid in life. The whole pectoral girdle of Varanosaurus thus has an almost absolute superficial identity with that of the lizards. Under the usual interpretation, however, the large ossified coracoid of Varanosaurus, with its close resemblance to the coracoid of Varamus, for instance, in its supracoracoid foramen and fenestra, is the procoracoid. In other words, it is assumed that the coracoid of Varanosumus has disappeared gradually by 
the encroachment upon it of the posterior bone, the so-called true coracoid, which here in this genus was so degenerate that it no longer was even ossified. It seems to me that the utter absence of any proof that such has been the course of evolution in the pectoral girdle of reptiles - for no intermediate form has ever been discovered, no form in which the posterior bone has even reached as far forward as the supracoracoid foramen-is sufficient to throw great doubt upon the hypothesis, a doubt that becomes quice conclusive in the proof afforded by the various specimens of these and other Permian reptiles.

It is a curious fact also that a posterior coracoid bone has never been observed in any temnospondyl, though the sutural division between the scapula and coracoid I have observed in specimens referred to Aspidosaurus to be quite as in Seymouria.

Interclavicle (Plate IV, Figs. I, 2).-The interclavicle is shaped, almost ludicrously, like a miner's shovel, with an expanded anterior end and a long curved handle. The anterior end in shape is quite like that of a playing card spade, thin on its margins, concave above in both directions, but more so transversely. The "handle" is more than three times the length of the "blade" and is of nearly. uniform width, somewhat narrowed anteriorly and pointed at the end; its upper side is nearly flat, the underside convex from side to side. In side view the bone has a rather long and deep concavity above to the posterior third, which is gently convex above. The concavity of the upper side and convexity below are nearly uniform to the extreme front end; and this shape is doubtless normal, not the result of pressure, since two observed specimens agree.

Clavicles (Plate IV, Figs. 3, 4).-The two clavicles in the present skeleton, as also others which have been developed, were almost perfectly in place, attached to the interclavicle; and they are complete save for the extreme tip, which has been lost in preparation. The inner end was expanded from before back, more nearly like that of Dimetrodon, a little thickened along the anterior margin, quite thin on the posterior and inner sides, concave above to fit the end of the interclavicle, with a flattened or prismatic shaft, and so curved that it is pointed almost directly 
upward in the articulated skeleton. The upper end gradually narrows, its flattened face in front and external. In the articulated skeleton it lies against the front margin of the scapula, scarcely overlapping it. As articulated, the two upper extremities of the clavicles are less than two inches apart; the anterior border is directed obliquely backward, the margin below projecting forward and upward. As stated, no indications whatever have been discovered in any skeleton of a cleithrum; it was assuredly absent.

Humerus (Plate VI, Figs. I-6).-The humerus is of the "oldfashioned" type, broadly expanded at each extremity and with a slender shaft in the middle. The planes of the two ends meet each other in an angle of about seventy degrees, that of the proximal turned outward from the horizontal. The proximal articular facet is elongated, narrower at the inner than at the outer side; its surface is moderately convex, with the chords of its curves almost at right-angles to the planes of the proximal end, indicating an almost horizontal position of the end in life. On the dorsal side of this extremity, which is convex from side to side, there is a considerable rugosity near the upper inner part, for muscular attachment. The ventral surface is flat or gently concave for the most part, and the lateral process is turned forward, so that its thickened extremity looks ventrad and is placed at about the upper third of the bone. The distal extremity is much more expanded than the proximal. The articulations for radius and ulna are turned somewhat ventrad; the larger inner one, for the radius, arises mostly from the ventral surface, that for the ulna in large part from the dorsal, on either side of which, on the dorsal side, there is a rather deep groove. On the more thinly expanded inner side, at about the lower third of the bone, is the large epicondylar foramen, which pierces the bone from above downward and is covered by a thin and slender bridge of bone. On the outer side, above the condyle, there is a projection protruding beyond the inner margin of the bone, from which it is separated by a narrow. but deep vertical groove, a process characteristic of some, if not all. the zygocrotaphic reptiles, but wanting often in the Cotylosauria. especially the Pariotichidae. The expanded and somewhat angular inner condyle has a facet of considerable size for the attachment 
of the flexor muscles. The outer condyle is less expanded, is more thickened, and has considerable surface for the extensor muscles. The shaft, near the middle of the bone, is much contracted and very short, subrotund or prismatic in cross-section.

Radius (Plate VII, Figs. I-4).-The radius is a slender bone, about three-fourths the length of the humerus, with only moderately expanded extremities. It was found in this specimen closely articulated with both humerus and ulna, as shown in the figures (Figs. I, 2). Its proximal articular surface is broader on the dorsal than on the palmar side, shallowly concave above for the capitellum. The shaft is curved, with the concavity on the ulnar side, the outer margin thinner for the interosseous membrane. The lower extremity is transversely oval, the end concave, the dorsal side convex, the palmar more concave.

Ulna (Plate VII, Figs. I, 2, 3, 6).-The ulna is a little longer than the radius, and is much more expanded at its extremities than that bone; the shaft at its narrowest place, the lower third, is more slender. The sigmoid surface is concave and is almost continuous with that of the radius for the capitellum in the articulated condition. The olecranon is produced but little, and has also a concave ligamentous surface for the attachment of the triceps. The radial border is concave throughout, the inner border convex for fully three-fourths its length, as far as the most slender part of the shaft. The distal extremity, narrower than that of the radius, is flattened oval and is concave in the end.

That minor differences in the shapes of the bones of the skeleton are not necessarily due to specific differences is apparent in many of our specimens. In Plate VIII, I have figured the radius and ulna of another skeleton, in which such differences are very apparent, without corresponding differences in other parts of the skeleton; they certainly belong in the same species.

Front foot (Plate VIII; Plate VII, Fig. 5).-The foot, as it is figured in Plate VIII, is nearly wholly that of a single specimen, but it has been completed in part and the position of various bones determined by the aid of several other specimens. Unfortunately many of the phalanges of the three middle bones have not yet been found associated, though the most of them, as outlined, 
have been found in connection with the carpus, but more or less disturbed in their relations. The complete, or nearly complete carpus has been found in three specimens, with more or less of the metacarpals and phalanges in anatomical association with them, so that their positions are positively assured, as also their relations with the forearm. The carpus is of the same general structure as that of Dimetrodon (Plate VII) save that the outer centrale and fifth distale were never ossified. Although the pisiform in Dimetrodon has never been found in place I doubt not that it has the same articulations as in Varanosaurus, Casea, Limnoscelis, Trispondylus, etc., articulating in the interval, as in modern reptiles, between the ulna and ulnare. In the different carpi found with the bones in place there is a small interval between the radiale and the first and second carpalia, doubtless filled out in life by a small cartilage representing the unossified centrale, quite as in the hind feet. And this is also the case with the fifth carpale. Although several carpi have been examined with carpals and metacarpals all in place and in the positions shown in the drawing, there is invariably a small unossified space at the proximal end of the fifth metacarpal. As it is altogether improbable that this carpale should have been lost in all these specimens, I am quite assured that it was never ossified. The fifth finger is more reduced than is the fifth toe, and doubtless this explains the vestigial condition of the carpale.

The metacarpal of the first finger is very small, and the finger is very short. This finger, with the bones articulated, has been observed in two different specimens quite in the position given in the figure, closely appressed to the second finger, and this doubtless was its normal position in life. The much-elongated fourth metacarpal in itself indicates an elongated fourth finger, and the phalanges preserved, if I have correctly placed them, substantiate the conclusion. The ungual phalanges are quite like those of the hind foot, strong and well curved. In the drawing the phalanges not found in actual relations are shown by the uniform shading; and two or three of the distal ones are conjectural.

Pelic girdle and extremity (Plates IX-XIII).- The pelvis of Varanosaurus is noteworthy for the small size of the ilia and the large size of the pubes and ischia, suggesting the pelvis of the Sauropte- 
rygia. The ilium has a long, thin, and narrow process, directed horizontally backward. Its upper margin is thin, crest-like, scarcely projecting above the sacral ribs. The anterior superior border in front of the sacral rib is thickened and rounded. Fully three-fifths of the acetabulum is formed by this bone. It has a strong overhanging ridge or process directly above the cavity. On the inner side distinct facets are visible for the attachment of the sacral ribs, the large one in front and below, the smaller one almost wholly on the posterior process behind and above. The pubic and ischiadic borders meet in a little more than a right angle. A little in front of the angle on the inner side there is a vertical depression or groove continuing upward the depression leading into the obturator foramen.

The pubes are remarkable for their large size and forward extension. They are broadly expanded in front to the full width of the pelvis, extending forward almost parallel with the plane of the vertebral column above them. The two bones meet in a long, nearly horizontal suture, leaving an angular emargination in the middle behind where they turn downward into the true brim of the pelvis. From side to side above the surface is convex, and the surface below is concave transversely. The thickened lateral borders turn downward from the pubo-ischiadic suture and inward to the horizontal table, and then outwardly horizontally and forward. In the middle behind the distance between the two bones is narrowed to form a $\mathrm{U}$, turning deeply downward into the narrow trough formed by the two ischia. The pubic foramen is a little in front of the ischiadic border, piercing the bone vertically as the continuation of the shallow groove beginning above the ilium. The inferior orifice of the foramen is an oval opening of considerable size situated in the angle between the descending flange and the acetabular margin.

The ischia are shaped very much like those of the long-necked plesiosaurs, hatchet-shaped bones which descend to meet each other angularly, considerably below the plane of the pubic expansion, into which cavity the downward deflection of the posterior borders of the pubes open. They are massive bones, the acetabular border especially protuberant and heavy. The outer 
surface is slightly concave, with the posterior upper thickened margin curved outward. The two bones meet in an acute angle, forming a deep, narrow floor to the pelvic cavity. Between the pubes and ischia there is a rather large diamond-shaped opening; and this opening was doubtless pervious in life, that is, it could not have been filled up by cartilage. I think, a distinct premonition of the pubo-ischiadic vacuity of the Chelonia, if not of all modern reptiles.

The peculiar structure of the pubes in this genus allies it with the true pelycosaurs much more closely than with the Caseidae. In life the animal rested in repose wholly upon the ischia, while in the Cotylosauria the support of the body was equally distributed, in some at least, upon both the pubes and the ischia, in both of which the symphysis was far more massive than in the Pelycosauria. Just what is the significance of the much elongated, expanded, and platelike pubes I do not understand.

The femur (Plate XII, Figs. I-5) is moderately expanded at either extremity, rather slender in the middle. The proximal end shows a flattened surface, broader on its inner side, and curved backward and narrowed at the outer side. The trochanter, on the tibial side, is prominent, continuing backward the inner surface of the bone; it has a small oval facet at its extremity, directed proximad and ventrad. Between this projection and the outer and proximal sides there is a broad, shallow, digital fossa, which extends downward for a distance of about two-fifths of the length of the bone. The trochanteric elevation is continued for a short distance as a distinct adductor ridge. The shaft at the middle is nearly circular in cross-section, and the bone is not much curved. The inner border of the bone is deeply concave throughout; the outer one much less so. The distal articular surface looks, for the most part, inward at an angle of about twenty degrees, and backward at about forty-five. Of the articular surface that part on the outer side for the fibula is the broader, as in Dimetrodon, with a considerable antero-posterior extent, its outer margin concave in outline. The tibial articular surface is large, subtriangular in shape, and fully as wide as the fibular surface antero-posteriorly. The intercondylar groove in front is deep, that behind is shallow; the width of the articulating surface connecting the fibular with the 
tibial is about one-third that of either side. The popliteal surface is shallowly concave, occupying the lower fourth of the bone.

The tibia (Plate XII, Figs. 6-- I ) is a little more than three-fifths the length of the femur, and has a much-dilated proximal extremity, a slender, curved, subtrihedral shaft, and a moderately expanded lower extremity. The distal end is curved backward so that the truncated distal extremity is at an angle of nearly forty-five degrees with the long axis of the bone. The greater diameter of the proximal articular surface is nearly transverse in position in the articulated skeleton. The cnemial elevation in front is not very broad or high, the surface on the outer side of it partly underlying the fibula in articulation; that on the inner side is convex. The distal extremity is subangular on the inner anterior part; the other sides more rounded.

The fibula (Plate XIII, Figs, 2, 3), hitherto almost unknown among the Texas reptiles, is a very slender bone, and is distinctly longer than the tibia, the planes of its two extremities slightly twisted on the longitudinal axis at an angle of ten or fifteen degrees. The proximal end is convex on its outer dorsal side, gently concave on the tibial. the proximal articular surface long and narrow, oblique both inwardly and anteriorly. The distal extremity, much the broader, is also convex on the dorsal, concave on the ventral side, with a round distal outline. extended higher up on the more expanded inner side. The articular surface, long and narrow with a slight sigmoid curve, is directed somewhat obliquely forward. The slender shaft is nearly straight in its middle part, or slightly curved in outline.

Foot (Plate XIII, Fig. I; Plate IV, Figs. 6, 7).-The astragalus, or tibiale plus intermedium, is subquadrangular in shape, its proximal end, that for the partial articulation of the fibula, the stoutest. The anterior or dorsal surface is concave throughout. with its margins elevated; the posterior or plantar surface is nearly flat above. The fibular surface joins the calcaneal border in a little more than a right angle; this surface is a little broader from side to side than from back to back, is gently concave, with its plane rectangular to the anterior surface. The large tibial articular surface is oblique to the greater plane of the bone, as also to the 
antero-posterior plane. It is broader above and more convex on the anterior side. The outer articular surface, for the calcaneum. is divided by a deep transverse groove near its lower third, which in apposition with a similar but less deep groove on the inner side of the calcaneum forms the canal for the perforating artery, whose posterior orifice is almost wholly within the astragalus. Below the groove there is only a narrow surface for union with the calcaneum. The distal surface is divided into two facets, the outer oblique one for articulation with the fourth tarsale, the inner or longer one for articulation with the centrale or its cartilaginous representative. These surfaces are nearly flat.

The calcaneum or fibulare (Plate IV, Figs. 6, 7) is as broad as long, somewhat wider, but no longer than the astragalus. The proximal border on the inner side forms, with the astragalus, the articulation for the fibula, rather more on this bone than on the astragalus. The articular surface on the inner side for the astragalus is grooved, as already described, for the perforating canal; it has an angular process on the back side projecting into the emargination of the astragalus at the place of the groove. The distal articulation for union with the fourth and fifth tarsalia forms an angle with the distal surface of the astragalus. The outer border, that between the fibular and tarsal surfaces, comprises about one-third of a circle and is relatively thin, much more so on the lower part.

Of the tarsalia, the fifth and the second are small. the fourth the largest, the third and first subequal in size. Each bone supports exclusively its own metatarsal. The fifth articulates with the calcaneum, and for a considerable extent the outer articular facet of the fourth; the first tarsale articulates with the centrale and the second tarsale; the fourth joins broadly the calcaneum, and for a considerable extent the outer articular facet of the astragalus; the third tarsale articulates with its adjacent tarsalia and with the centrale or possibly the astragalus. The second tarsale, of which only a small oval facet is seen from in front, articulates proximally with the centrale, and laterally with the adjacent tarsalia; the first tarsale is flattened and thinned. and evidently has much freedom of movement, since it is invariably 
found more or less dislocated from the other tarsal bones; its outer border, that for articulation with the second tarsale, is thickened and rounded; the upper border, meeting the other in an angle, articulated with the centrale, while the distal border, that between the second tarsale and the metatarsal, is short, thin, and free; the inner upper border is also free, but is longer and thicker.

In the articulation of the tarsal bones as described and figured, a small space is left at the distal end of the astragalus, between it and the inner tarsalia, which must have been filled in life by a small centrale; but no such bone has been found in the numerous specimens recovered, some of them with the foot in nearly complete condition. The bone, if present, must have been thin in front view, rather wide perhaps from side to side. Because of its constant absence in the specimens studied I am convinced, as in the front foot, the bone remained unossified in life, represented, I doubt not, by cartilage.

The phalangeal formula, as determined beyond peradventure, is typically the primitive one, that of the lizards and rhynchocephalians; 2, 3, 4, 5, 4. Of the metatarsals, the first is as broad as long, with a thicker border anteriorly at its proximal end. The next three metatarsals progressively increase in length, the third rather the stoutest of all. They are somewhat imbricated proximally, the dorsal margin overlapping the thinner inner side of the next outer bone. The fifth metatarsal is the most slender. about the length of the second, and is somewhat divergent from the fourth; the position in which it is figured is that shown by several specimens. Of the proximal phalanges the first of the fourth digit is the longest, the lengths decreasing as follows in the others: iv-I, iii-I, V-I, iv-2, ii-I, i-I, iii-2, ii-2, i-2, iii-3, iv $-3, v-3, v-4$. The claws are long, considerably curved, somewhat flattened, but not very sharply acuminate. That of the third toe is the largest; that of the fifth is small; this is the only bone of the whole foot that has not been found in perfect articulation. The close articulation of the digital bones shows clearly a distinct curvature inward or anteriorly of the second, third, and fourth toes, and as distinctly outward of the fifth toe; the first must have 
been nearly straight. Altogether the foot, like the hand, was of a rather swift-running terrestrial crawling animal, showing no indications whatever of aquatic habits.

Restoration (Frontispiece).-The mounted skeleton of Varanosaurus, as shown in the photograph, is composed, save the skull, almost exclusively of a single individual, of which the bones were found in almost complete articulation from the fragmentary skull to the forty-seventh caudal vertebra. The left hind foot was incomplete and has been restored from another specimen, as also the right front foot, which is that of another skeleton, the bones of the left front foot occurring in a more or less disturbed condition. Several of the spines of the anterior dorsal vertebrae were broken off and lost, as protruding from the block of the matrix; they have been replaced by others from another skeleton agreeing accurately with them save for the complete spines. The figures of the plates, however, are made exclusively from the original specimen. A number of the ribs in the mounted skeleton are made of plaster-of-paris, copies of the real ribs found in position, but which could not be extricated from the hard matrix upon which they were lying without destroying them; three or four of the most anterior ones are conjectural; these will be replaced by real ribs, since discovered in other skeletons from this region. The skull, as stated, is that of another skeleton, that to which the third, fourth, fifth, and sixth vertebrae of the mounted skeleton belongs. In mounting the skeleton, one of Varanus has been used as a guide to the position. The hind legs have been placed more forward than is usual in the skeletons of lizards, because of their relative shortness, but the body has been left in a resting position quite prone upon the base. The skeleton, as mounted, measures just forty-four inches in length.

\section{RELATIONSHIPS OF VARANOSAURUS}

It is very evident that Varanosaurus is intimately related to Poliosaurus Case and Poccilospondylus Case, the former very imperfectly known, the latter known from a considerable part of the skeleton. The present genus seems to be distinct from either, especially in the shape of the vertebral centra, though I am not 
quite satisfied as to the value of this character. The relationships of Varanosaurus with Theropleura Cope, as identified and figured by Case, are very evident. But this genus includes much larger forms with very noticeable differences in the structure of the limbs. And it is also very apparent that the genus Ophiacodon Marsh is a nearly related genus, clearly differentiated, however, by the teeth and limb bones, as I identify them in the following pages. These five genera, then, in the order of priority, Ophiacodon Marsh. Theropleura Cope, Poliosaurus Case, Varanosaurus Broili, and Poccilospondylus Case, so far as now known, are closely related genera of the family Poliosauridae, distinguished by characters given on a preceding page. I suspect also that Dimetrodon navajoicus Case will be found eventually to belong in another genus of thè same group.

The relationships of the family, using Varanosaurus as the type, are in some respects very evident with the Clepsydropidae, in others apparently divergent. Perhaps the chief relationships will be found in the pelvis, and especially in the pubes. Both families have a distinct pubo-ischiadic vacuity; both have the same peculiar expansion of the pubes, with the outer border thickened and the inner expanse horizontal or even convex above; both have the same disproportionate size of these bones as compared with the ischia. On the other hand, the Clepsydropidae have three sacral vertebrae, while the Poliosauridae have but two. The vertebrae are alike in the two groups, with the same rib attachments and transverse processes. The feet, moreover, are quite similar; and the spines, while of nearly uniform length, in Varanosaurus are distinctly elevated and thin, not enlarged at their upper ends.

Widely different, however, are the skulls in the two groups, in the elongated form, almost isodont teeth, the incomplete temporal arch, the sloping occiput, and the depressed form.

Case believes that the Poliosauridae are the more generalized of the Pelycosauria, and in some things they are, but not in all; the incompleteness of the temporal arcade is certainly a significant specialization.

The resemblances between Varanosaurus and the so-called Proganosauria are evident; whether they are really evidences 
of genetic relationships, or merely primitive or "old-fashioned characters," I am not prepared to express a decided opinion, but I believe that they are genetic. Of the possession of two temporal vacuities by Stercostermum or Mesosaurus there is no evidence furnished by the numerous skulls that have been studied, and I am firmly of the belief that there is but one. In the elongate rostrum with posterior nares we have an aquatic modification. which of course means wide specialization and adaptation to different conditions. In the vertebrae there is a distinct resemblance. as also in the ribs, which have been described as single-headed and attached to the centrum, but attached below a transverse process. I feel sure that the mode of union is like that of Casea, and that the ribs are really double-headed, and their massiveness is paralleled by the somewhat similar condition in Casea. The posterior ribs were probably more or less anchylosed to the vertebrae, as in both Casea and Varanosaurus. In the pectoral girdle there are but few real differences. McGregor thinks there is no procoracoid, but I have little doubt but that the structure here is quite as in the Pelycosauria; the genus resembles those of the Theromorpha too closely to be otherwise. The scapula is more expanded, but that is an aquatic adaptation. The front extremity seems to be quite like that of Varanosaurus; the expanded humeri, the entepicondylar foramen, the structure of the tarsus. and probably that of the feet, save the absence of claws. So, too, the pelvis and hind extremity are very like. The pelvis has an interval between the pubes and ischia as in Varanosaurus, the tarsus is almost identical, and the feet, save the claws, also. Upon the whole, given a single temporal vacuity, as I am confident the Proganosauria had, I see no reason why the genera should not be located in the same order with Varanosaurus, but in a separate suborder, because of their aquatic adaptations. In any event I have not a bit of faith in their rhynchocephalian relationships.

\section{Family Caseidae}

Williston, Science, XXXIII, 631, I9I I.

Crawling phytophagous theromorphs with short, broad, depressed head, large body, long tail, and short legs, from four to 
five feet in length. Skull short, depressed, tuberculate, with very large parietal foramen, small lateral temporal vacuity, inclosed below, and with blunt conical teeth in maxillae and mandibles, few in number. Teeth on vomers, palatines, and pterygoids. Spines of vertebrae short, stout, and of uniform length. Twenty-four presacral vertebrae, three sacrals. No cleithrum. Pubes not longer than ischia, not projecting forward in an expanded plate: no pubo-ischiadic vacuity. Ribs very large and heavy; no ventral ribs. Feet pentedactylate.

\section{CASEA}

Williston, Jour. Geol., XVIII, 590, I9I0.

\section{Casea Broilii Williston, ibid. Plates XIV-XXIV.}

Skull.-But a single skull of Casea ${ }^{\mathrm{I}}$ has so far been detected in the blocks of matrix, a part of specimen No. 656, and that not in the most satisfactory condition. It was found closely crowded below the jaws of a Cacops and the pectoral girdle and anterior limbs of a Taranosaurus, and was separable with difficulty from the rather hard, concretionary matrix. The skull is a little depressed and somewhat skewed to the right, the palate pressed upward and to the left. The nasal region is not quite complete, especially of the right side, and the temporal arch of the left side was broken and the parts somewhat displaced, so that they cannot be accurately. readjusted. I give several figures of the skull as I have partially reconstructed it after careful study and measurements. Fortunately the mandibles are quite perfect. The skull in many respects is remarkable, presenting no decisive relationships with any known form, though, of course. because of the single temporal vacuity, allying the genus and family more or less with the true Pelycosauria. Unfortunately in the present skull, as in others of the remarkable deposit in which these skeletons were found, the sutures for the most part cannot be made out, or, if so, only conjecturally. I find by careful examination with a lens indications of some of them, and it is not at all improbable that with more material for

\footnotetext{
since this was written a second one has been found, but has not been prepared.
} 
comparison the structure of the skull will be finally determined with accuracy and completely. Of the material secured from this bone-bed there yet remains fully one-half inclosed in large blocks of matrix, and it is very probable, indeed almost certain, that several skeletons of this form will yet be found among them. For this reason, with the single skull I have not thought it worth while to give hypothetical sutural lines, or attempt to discuss its intimate structure. The skull is remarkably broad and flat, concave above

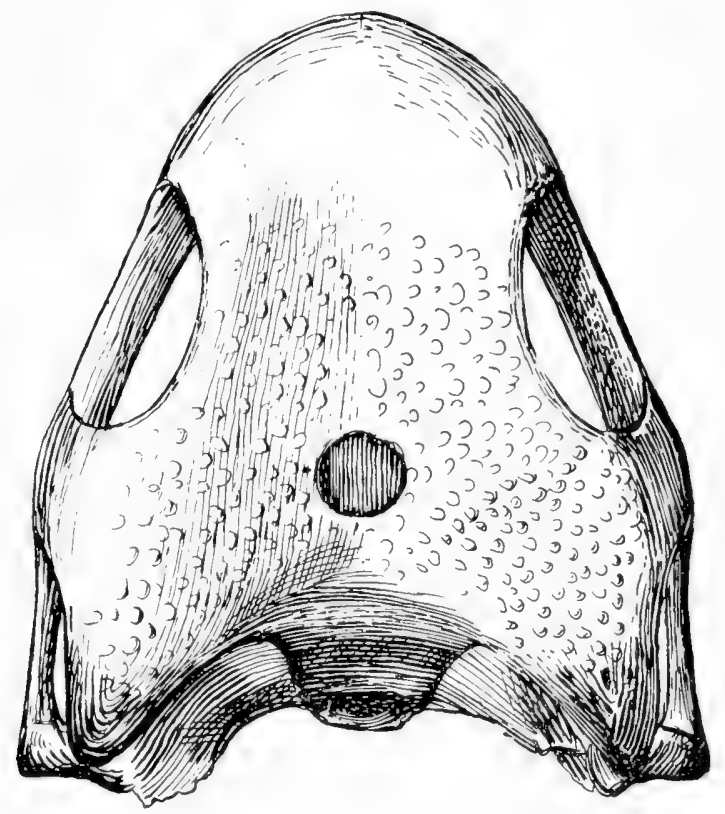

FIG. 28.-Casea broilii Williston. Skull, from above, natural size.

transversely as preserved, perhaps in life less so or nearly flat. The nasal region is protuberant and bulbous, overhanging the teeth both in front and on the sides; there is an enormous parietal foramen, larger even proportionally than in Diadectes, and the largest I know in any vertebrate; the single vacuity, clearly the lower one, is not large, and is invisible from above; and the teeth are remarkable for their large size, small number, and obtusely conical shapethey are evidently phytophagous. The upper surface of the skull is strongly rugose for a zygocrotaphic reptile. The rugosities are 
oval or rounded eminences, separated by irregular pits or valleys. The width between the temporal vacuities is very great, only a little less than is the length of the skull. Indeed, so markedly cotylosaurian is the shape of the skull and so noticeable are the rugosities, that before the temporal vacuities had been worked out I concluded, notwithstanding the skeletal characters, that the animal was a real cotylosaurian. However, notwithstanding these resem-

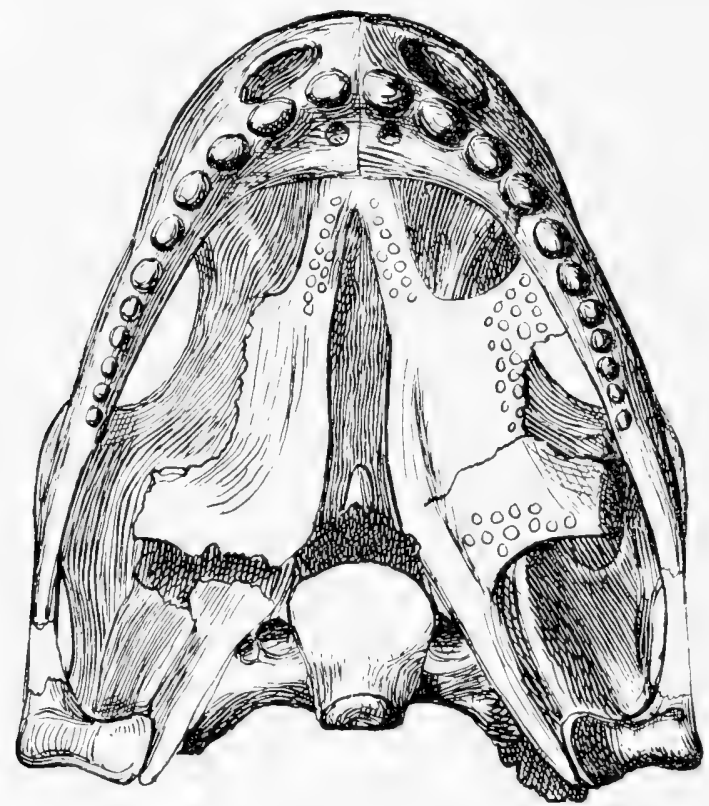

FIG. 29.-Casea broilii. Skull, from below, natural size.

blances, and others of the pelvis, there are other characters quite at variance with those of the Cotylosauria.

The width between the orbits is also very great, fully one-half the width of the skull in its widest place. The parietal foramen is situated just back of a line drawn through the posterior margins of the orbits, and sutural lines seem to indicate that the frontal bones border it in front. Neither temporal vacuity, as stated, is quite complete, and that of the right side as preserved is smaller than that of the left; possibly in my reconstruction I have made it a trifle too long. The quadrate of the left side had been pressed 
back a little, and that of the right a little forward. I have equalized their positions in my drawings to correspond with the cotylar surfaces of the united mandibles. The upper and anterior borders are quite perfect and the anterior part of the right jugal arch is undistorted on the right side. Each posterior angle of the skull roof is extended strongly backward, outward, and then downward, and is attached to the posterior margin of the quadrate. Below there is an interval between this extension and the neck of the quadrate, which seems to be analogous with the quadrate foramen. The postorbital bar is nearly vertical, with a gentle convexity out-

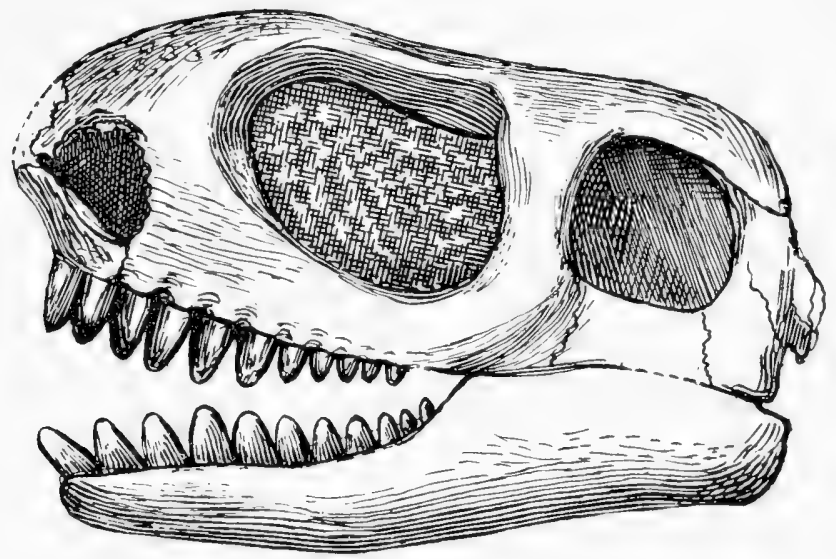

FIG. 30.-Casca broilii. Skull, from the side, natural size.

ward. It is rather narrow, about one-fourth the width of the orbits antero-posteriorly. The orbits are very large; they look almost directly outward and a little forward; they are a little longer than high, and a little deeper posteriorly. Their anterior margins above reach nearly as far forward as the front end of the maxillae. On neither side is the narial opening quite complete, their superior and posterior margins more or less broken away, but it is not probable that they are much smaller than I have figured them. The width of the skull in front, just in front of the orbits, is distinctly greater than the width between the front ends of the maxillae immediately below, from which it follows that the anterior part of the skull overhangs the teeth, and the nares are quite in- 
visible from above; their orifices looking somewhat downward. The premaxillae project strongly forward and upward to meet the projecting nasals. The skull also is deepest in front of the orbits, indicating a large nasal cavity, which perhaps may have been of service in the same way that the large nasal cavity of $A m b l y$ rhyuchus is; indeed, in general shape the skulls of these two animals have a curious resemblance. The premaxillae, which were found attached to each other and somewhat disconnected from the maxillae, have each two large teeth, in the articulated position directed downward and not at all forward. The narrow plate back of them is nearly horizontal, while the attenuated nasal processes, as stated. curve upward and forward. The maxillae are broad and stout in front, narrower and thinner below the orbits. Each has nine teeth, the four posterior ones small. The occiput is broad, sloping downward in the middle, and is markedly concave from side to side. The roof bones of the skull, doubtless the dermoccipitals, extend downward and backward broadly in the middle to the upper margin of the foramen magnum; the rounded and thickened border each side roofing over a narrow post-temporal vacuity. The occipital condyle is small, with a distinct pit in the middle, and, as in other American Permian reptiles, is composed exclusively of the basioccipital. The foramen magnum is rather large, bounded broadly on the sides by the exoccipitals, above by the cartilage supraoccipital. The exoparoccipitals ${ }^{I}$ form broad, gently concave plates, articulating distally with the underside of the angular roof extensions, doubtless the tabulare or squamosal. The quadrates are visible for most of their extent. They are, as in other Texas Permian reptiles, somewhat fan-shaped bones sloping downward. inward, and forward, the upper margin articulating with the roofbones in front of the broad paroccipital, and probably also with the distal end of the same bones. They reach anteriorly nearly as far forward as the hind margin of the orbits. Their cotylar surface is transverse, broader internally than externally.

The palate bones are so much confused in the specimen that only the more important characters can be made out. The vomers are

${ }^{2} \mathrm{~V}$. Huene is in error in saying that the term paroccipital was proposed by Huxley. It was proposed by Owen in $\mathrm{I}_{3} 8$ and should take precedence over opisthotic, a term introduced by Huxley many gears later (I864). 
united with each other in the middle line, at least in front, and have on each side a row of small teeth, double, perhaps triple, behind. The pterygoids are separated in the middle line, how broadly I cannot determine. I can distinguish no teeth on them, but laterally, doubtless on the palatines, there are several rows; this part is not complete on either side, and I cannot be sure there was no posterior palatine foramen, but in all probability there was none. On the transverse part behind, the part which abutted freely against the mandible, and corresponding to the transverse bone, if distinct. there are also evidences of teeth, but I cannot say how many. Posteriorly the pterygoids send back a broad plate, as in other Permian reptiles, to articulate with the lower inner side of the quadrates lying along the anterior inner expansion of the quadrate. In Labidosaurus and Limnoscelis, at least, this anterior expansion of the quadrate is visible above and to the inner side of the pterygoid process, but in Casea the quadrate slopes outwardly, the pterygoid lying along in its inner margin. I cannot distinguish the stapes with certainty.

The basioccipital is a broad, flat plate, narrowed behind for the condyle. It is quite smooth, and without processes. It is somewhat detached in the specimen, and, as figured, evidently comprises the basioccipital only, and not the basisphenoid, of which I find no certain evidence. In front of the basioccipital there is a triangular cavity, from which the basisphenoid may have been lost. On each side of the basioccipital there appears to be a large foramen, the jugular. Each pterygoid sends up a broad plate, above the inner side of the transverse process, to the roof, which it joins opposite the large pineal foramen, forming the side of the brain case, and continuous with the brain walls posteriorly. This plate, of course. must represent the epipterygoid, springing as it does from the pterygoid, a bone supposed to be distinct from the alisphenoid by Baur (orbitsphenoid? Gaupp).

Mandibles.-Both mandibles were found nearly in place in articulation with the cranium, and both are very perfectly preserved and prepared. Together they form a broad $v$, nearly in the shape of an equilateral triangle. The two sides meet in a firm but small symphysis, which includes the anterior ends of 
the splenials. The coronoid is rather low, rounded, and thin. Reaching as far back as the teeth is the large opening of the inner side. The articular was free on one side; it is a small bone, without an anterior or pre-articular process, concave on the upper surface for the quadrate. There is no post-articular process. The sutural surface for the union of the articular bone is nearly vertical, and shows a distinct suture running through the middle between the angular and surangular bones, both of which reach quite to the hind end of the mandible. Below and in front, the pre-articular borders the lower margin, as usual, of the internal vacuity.

Teeth.-The teeth of Casea are very characteristic, unlike any that have hitherto been made known from the American Permian. There were eleven on each side above and below: two on each premaxilla, nine on each maxilla, and eleven in each dentary. The anterior six of each jaw are materially larger than the posterior five, the last of which are very small. The two premaxillary teeth and the first four of the maxilla and front six of the mandibles are very stout, conical, nearly circular at their base, but more rounded at the apex, and perhaps a little flattened from within outward. They are somewhat pleurodont in their attachment. but probably have roots firmly inserted in the bone. Those of the upper jaws are vertical in position, while the first six or more of the mandible are more or less prognathous, the anterior ones directed outward and forward at an angle of forty degrees or more. None of the teeth have a sharp apex, and the rows are almost continuous, the base of the crowns almost touching. The teeth are evidently phytophagous.

Presacral vertebrae.-The presacral series comprises twentyfour, all found in close articulation with skull and sacrum and a considerable part of the tail in specimen No. 657. The vertebrae shown in Plate XV are the connected series of specimen No. 655 , from the eighth to the sacrum, with a disconnected third vertebra. The first seven figured in Plate XIV are of specimen No. 6.57. The vertebrae of No. 655 had been prepared and drawn in the confident expectation that the series would be found to be complete. an expectation, however, which resulted in disappointment. 
So far as this series can be compared with that of No. 657, many of which have not yet been cleaned from the rather hard incrusting matrix, they agree absolutely, the vertebrae of No. 657 being possibly a trifle larger than those of No. 655. The second presacral of No. 657 is shown in Plate XIV, Fig. 2. The vertebrae throughout are easily distinguishable from those of all other genera, save Trispondylus perhaps. Very remarkable is the disparity in size between the most anterior and the most posterior of the presacral series, a difference so great that had the vertebrae been found disconnected and isolated, they would not have been associated in the same individual - the diameters of the third vertebrae being at least a third less than those of the first presacral, as may be seen by comparison of the axis shown in Plate XIV, Fig. I, with the second presacral of the same individual shown in same plate. Fig. 2. The centrum of the first presacral is only a little broader than long. concave below, "pinched in" on the sides so as to give a rounded, lower border, somewhat keel-like, but with no indication of the median fossa, so characteristic of the caudal centra. The centra become rather rapidly narrower, the tenth or eleventh presacral being nearly twice as long as broad, deeply concave on the sides but not keel-like below. The length begins to diminish noticeably after the twelfth, or the one bearing the longest ribs. Thenceforward the centra diminish gradually in size, both transversely and longitudinally, as will be seen by comparison of the third with the last in Plate XV. The spines are of nearly uniform length throughout, perhaps a little shorter anteriorly. They are oval in cross-section, and a little dilated at the extremity, the top subcircular in the most posterior ones, elongated oval in the middle and anterior ones, and beginning with the tenth or eleventh presacral they become relatively more dilated antero-posteriorly through the thoracic region. The zygapophyses are broad and flat posteriorly, narrower anteriorly, their articular surfaces looking at only a moderate angle outward or inward. The centra are, of course, deeply conically concave, with a narrow continuous notochordal canal through the middle. The figures of the first seven vertebrae were made, as stated, from another specimen, No. 657. The matrix of this specimen is unusually hard and the 
spines of one or two of the vertebrae could not be recovered entire, nor could the smaller bones of the atlas be worked out. The spines of these vertebrae are a little less dilated.

As far forward as the sixth or seventh vertebra back of the skull the transverse processes are much alike, standing out horizontally from the sides of and a little below the anterior zygapophyses, a little thickened at the extremity. Their length increases gradually and slightly to the eleventh or twelfth presacral and are thence nearly uniform to the fifth, where they become less stout, a little shorter, and are directed more downward. This slight distinction may be sufficient to distinguish these five vertebrae as cervical; there are, of course, no other characters. Back of the fifth postcranial the centra are about the same length below as above; the third and fourth have the lower border distinctly shorter than the length at the upper part of the centra. This diminished shortness seems to be entirely normal in the single series. In none of the presacral vertebrae of the three series have any intercentra been found, nor is there much space for them in the intervals between the centra. The presence of intercentra at the base of the tail and between the sacral vertebrae is, however, sufficient evidence of their existence in life throughout the series; but they were probably quite small in the presacral series and may not have been well ossified throughout.

Axis.-The axis has a remarkably stout spine, as shown in Plate XIV, Figs. I, Ib. Small zygapophysial articulations were probably present on the sides in front, but the border of the specimen was slightly injured here in preparation. The spine is nearly as long antero-posteriorly as the centrum, in the shape of an obtuse wedge, the end rounded, its front border a little thinner than the hind one. The transverse processes are apparently complete. They are short, and are situated lower down than in the following vertebrae; the rib, which was not preserved with the specimen, was doubtless small and short. All parts of the atlas were preserved in the specimen, but because of their small size only the odontoid could be extricated from the matrix, as shown in the figure. It differs very materially from the odontoid of the Clepsydropidae or Poliosauridae. It is relatively large, thinned below, 
transversely concave on the upper surface, and has a conical cavity on the posterior side, which in life was in apposition with the concavity of the axis, and was for the notochord, which, however, did not extend through the bone. Very evidently the intercentra of both the atlas and the axis were relatively large bones.

Ribs (Plate XVII).- The ribs of Casea are remarkable for their size and length. They were found in all three specimens in position as far forward as the sixth or the seventh; the more anterior ones were not recovered and have necessarily been restored in the mounted specimen, and I suspect that they were somewhat longer on these anterior vertebrae than they have been restored. The first four presacral vertebrae have the ribs firmly co-ossified with the arch and centrum, leaving a small foramen between head and tubercle. The ribs of the fifth presacral were less firmly united and in the two specimens examined had dropped away. though their union is seen to be a sutural one. The ribs of the first presacral are rather slender and are directed a little forward and upward, their extremities being higher than their capitula. The next three pairs increase rapidly in length; they are directed outward, a little forward, and then curve downward strongly at their extremities. Like all the preceding ribs preserved they are remarkably thick and stout. The longest ribs of the series occur at the middle of the presacral series. They are, as preserved, for the most part quite regularly curved, nearly cylindrical, very stout, tapering a little distally. The tubercular part is not sharply indicated as it lies against the end of the diapophysis, nor is there a distinct facet on any of the centra for the union of the capitulum, which must have been quite in the intercentral space, a little below the middle of the centrum, leaving a very considerable foramen in the articulated condition. The distal end is truncate. indicating a cartilaginous continuation, but this continuation was probably very short, since the ribs in articulation for the most part curve inward at the lower end and may be compared with the shorter ribs and costal ribs of the lizards combined. Evidently. the underside of the body between the ribs was quite flat, otherwise the belly would have been strongly protuberant below the level of the pelvis and pectoral girdle. There is not the slightest 
indication in any of the recovered specimens of ventral ribs, such as occur so commonly in Varanosantus and other genera of the Poliosauridae, and it is assumed that were they existent some indications of them would have been found in the various specimens.

Sacrum (Plate XVI, Fig. I; Plate XX, Fig. 6; Plate XXIII, Fig. 6).- The sacrum of Casea is composed of three vertebrae, differing from those immediately preceding and succeeding chiefly in their short and expanded ribs. These vertebrae articulate freely with each other, and have free, though small, intercentra below. The centra are convex from side to side below, compressed on the sides. The spines are proportionately a little stouter than those immediately preceding the sacrum, their upper extremity nearly as broad as long. The ribs are attached quite like the preceding ones, but are stouter, and like the three or four succeeding pairs, by a short head reaching below the middle of the centrum and articulating in part with the preceding centrum across the intercentral space. The tubercular part is very stout and heavy, extending high up on the arch. Between the head and tubercle the small foramen is persistent, as in the posterior lumbar vertebrae. The shaft of the ribs is subcylindric or prismatic, dilated at about the middle part into a broad flattened plate, broadly convex outwardly and curved downward so that its lower border is about on a level with the lower margin of the centra. The expanded ends of the first and second pairs are about equal in size; that of the third is smaller, but little more than half that of the first. It is stouter at its extremity and does not descend quite as far. The extent of these three ribs appears to be slightly greater than the greatest extent of the ilia antero-posteriorly. Their union with the ilia was a comparatively loose one, chiefly ligamentous, the ends of the ribs merely touching the ilia, which show no sutural markings for their union.

Caudal vertebrae (Plate XVI).-No single tail yet recovered is quite complete. That of specimen No. 655 comprises seven vertebrae, as figured in Plate XVI, Fig. I; that of No. 656 comprises about twenty in a continuous series with the sacrum and complete precaudal series; the incomplete tail of No. 657 has not been freed from the matrix, but has twenty-two vertebrae in the series con- 
tinuous with the sacrum; a fourth specimen found isolated, but which in all probability belongs with those of the other skeletons, includes a connected series of caudal vertebrae, eighteen in number, beginning just where the spine is becoming obsolete. This last specimen has been used in connection with the series of No. 657. It is possible that one or two vertebrae may have intervened between the vertebrae as united, but this is not very probable, since the junction is made where all the characters seem to agree. The last vertebra of No. 658 measures six mm. in transverse diameter; continuing the same taper, seven vertebrae have been modeled from plaster and added in the restoration, making the approximate number of vertebrae in the entire tail fifty in number, or almost the same as that of Varanosaurus, where the complete, or nearly complete, series of a single individual was found intact. The tail, however, as a whole, like the preceding part of the spinal column, is stouter than in Varanosaurus, and less compressed.

Co-ossified ribs, or vestiges of ribs, are found on the first seven or eight of the series. The first three pairs extend quite the width of the sacrum, thence decreasing rapidly in length till they are mere tubercles. The second pair, the largest, are directed outward, and then horizontally backward, to a point about opposite the middle of the next vertebra. The third pair, more slender, are directed outward, with an anterior curvature, barely escaping the tips of the preceding ones. Like the preceding ribs, the caudal ribs are double-headed, and are co-ossified with arch and centrum; on the hinder ones the tubercle seems to be in large part attached to the centrum. The spines, so far as they were recovered from the matrix, become successively shorter, terminating as a mere tubercle at about the eighteenth vertebra; and they are quite thin at the extremity, slightly more thickened anteriorly. Beginning with the third in No. 656, the fourth in No. 655, the underside of the centrum has a distinct longitudinal median groove or fossa, decisively distinguishing the genus from all others. This fossa is narrow and well marked, extending to the last of the series as preserved, and doubtless quite to the extremity of the tail. From the third or fourth to the seventh or eighth, the centra are very distinctly shorter below than above, and both 
the specimens as preserved showed a downward curvature of the tail in this region. The last intercentrum is between the second and third caudal centra, and is of extraordinary size, in marked contrast with the small ones found between the sacral vertebrae. Chevrons begin in the next interval, that is, at the hind end of the third vertebra, the usual place for the chevrons to begin in the Permian reptiles, and several were found in No. 657 quite in position. They are rather short; those found in position were broadly and firmly connected, articulated in the intercentral space, and broadly connected proximally. They articulate in a very oblique position, the upper posterior surface being grooved for more than half their length for the lodgment of vessels; some are slightly expanded at the distal end. Other chevrons from succeeding vertebrae are very short and broad. From the eighteenth vertebra to the extremity the chevrons must have been very small, which, with the entire absence of spines, rendered the tail for the greater part of its extent nearly cylindrical. The tail shows conclusively that the animal was in no degree whatever natatorial in habit.

Pectoral girdle and extremity (Plates XIX, XX).-The material of the pectoral girdle is, unfortunately, not complete. No clavicles have yet been found with either of the specimens; that is, no clavicles which indubitably belong with this form. A solitary interclavicle, figured in Plate XIV, Fig. 6, probably belongs with this form, since it cannot belong with either Varanosaurus, Cacops, Seymouria, or Captorhinus, the only other genera found in the bone deposit. It was found isolated. Two scapulae were recovered associated with specimen No. 655; of the left one, the upper end is missing, and of both, the anterior border is more or less mutilated. The interclavicle figured differs materially from that of Varanosaurus in the shortness of the posterior stem, shortness that would seem to agree better with the large flat trunk of this genus. The specimen is shaped much like a small spoon, and is not quite complete on its anterior, dilated part. The dilated part is concave on the upper side, convex below, and is somewhat rugose on each side for the articulation of the clavicles. The posterior part is slender and nearly straight, a little wider and thinner posteriorly. The scapula-coracoid is remarkable for the 
great development of the coracoid part, and the relative slenderness of the upper, scapular part, which is preserved complete on one side. This part is moderately thick, convex internally, concave externally. The front border, for about twenty millimeters, is thickened and rounded, that part above the extremity of the clavicle. Below this the border is thin, and for the most part is lost in both scapulae. The glenoid articulation is large and well formed, that on the preglenoid facet looking downward, backward, and outward; that on the metacoracoid looking more directly outward and a little backward. The supracoracoid foramen is, as usual, a little below and in front of the margin of the preglenoid facet. I find no supraglenoid foramen, either in the supraglenoid fossa, which is very shallow, or on the outer side in front, as in Dimetrodon and Varanosaurus. The very large coracoid turns inward horizontally and is a little concave longitudinally. Sutures between the coracoid elements, or between them and the scapula, are not distinguishable, but, in all probability, that separating the metacoracoid. which, unlike the condition in Varanosaurus, is well ossified, passes directly inward at about the middle part of the fossa. The fossa on the inner side, into which opens the supracoracoid foramen, is rather short. Just back of the metacoracoid facet on the upper border of the bone there is a rather prominent process corresponding with the more prominent one in the same place in Dimetrodon. Possibly its presence is indicative of genetic affinity, since it is absent in other known scapulae.

Humerus (Plate $\mathrm{XX}$, Figs. I-3).-The humerus, while in general resembling that of I'aranosaurus, presents several marked differences, distinguishing the two forms immediately. The planes of the extremities are almost at right angles to each other; the slender shaft of the bone, as seen from the front, is distinctly above the middle; the entepicondylar foramen is larger, and is not situated so close to the inner margin; the ectepicondylar process is broader and more protuberant, and the entocondylar dilatation is produced more inward in a direct line, and is thickened. The lateral process is much stouter and projects more inward; the capitellum forms almost a hemisphere, the chord of its convexity looking forward at an angle of about forty-five degrees, and its articular surface 
is not at all visible on the dorsal side of the bone, whereas the trochlear surface is only a little less conspicuous on the dorsal than on the ventral side. The humerus, moreover, is relatively much stouter and longer than in Varanosaurus, whereas the femur is distinctly smaller and shorter. The resemblance of the bone to the humerus of Trispondylus is much closer than to the humerus of Varanosaurus, as will be described later.

Both forearms of specimen No. 655 were recovered, the right one associated with humerus and hand, the left bones isolated; and in addition a radius and an ulna were found associated with a humerus of No. 656. Some of these bones are slightly bent or otherwise distorted, and the ones figured in Plate XX, Fig. t, the left bones of No. 655, are not quite as perfect as are the right ones of the same specimen, outlines of which are given in the accompanying text figure. Both ulna and radius are longer bones than are the radius and ulna of Varanosaurus and are not as much expanded at their extremities. The ulna has the inner border nearly straight, the radial side deeply concave; the radius is nearly straight on the ulnar border, moderately concave on the outer side. The interval between the two bones is much narrower than in Varanosaurus.

The hand bones of the right side of specimen No. 655 were found close by the distal end of the radius and ulna, but so confused that their natural articulations, save in a few cases, could not be determined from their positions. Ten or eleven carpals were more or less attached together, the full number of these; the radiale. ulnare, and pisiform are easily distinguishable by their size and shape. The ulnare resembles that of Varanosaurus (in the restored skeleton, the bone is reversed). The radiale is smaller and more rounded on its proximal surface, permitting apparently greater lateral movement of the hand. The intermedium and second centrale are both rather small, and cannot be differentiated in the single specimen. The fourth and fifth carpalia were attached in natural positions and are determinable with certainty; the fifth is of considerable size, as would be expected from the large size of the fifth finger. The third carpale is also in all probability correctly placed, because of its large size. The chief doubt is 
regarding the first and second carpalia and the first centrale; these three bones were found closely attached, the centrale very small, almost vestigial, the first and second so closely united that I am not certain that more than one is really present. They are all small. The metacarpals and phalanges found associated are shown in the text figure in unbroken lines, but with nothing to guide in their location save that two pairs of phalanges were found articulated as indicated in the figure by the plus sign placed near the joint. That the hand had the primitive phalangeal formula, 2, 3, 4, 5, 3, there can be scarcely a doubt, and I have so collocated the bones. It is quite certain that both the first and fifth fingers were much longer and better developed than is the case in Varanosaurus. The hand, it is seen, is very much like the foot, and fully as large if no larger; it was broad and rather short, but with strong and powerful claws, as shown in Plate XIX, Fig. 4.

Pelvic girdle and extremity (Plates XXI-XXIII).-The pelvis, preserved in three specimens, is perfect and almost undistorted in No. 655. The

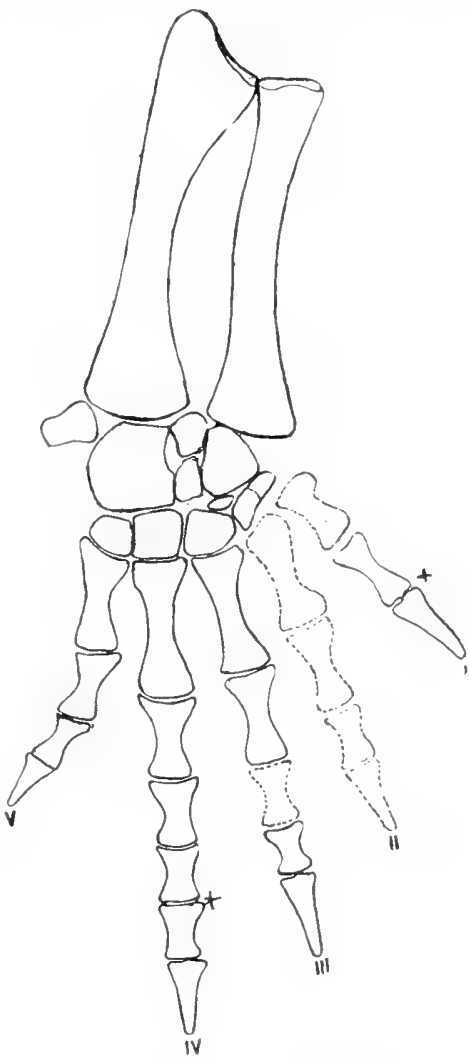

FIG. 3I.-Casea broilii. Right front leg, one-half natural size. two sides meet in a moderately firm horizontal symphysis, a small notch only at the junction of the four bones remaining unossified as a small pubo-ischiadic fenestra. The ilium is conspicuously different from all those hitherto observed in the American Permian in having a prominent anterior projection and only a small posterior one. It is somewhat helmet-shaped, con- 
tracting into a rather narrow neck just above the acetabulum, with a rather deep notch posteriorly, the antero-posterior extent of the bone below being not quite as great as that above. The anterior border is thicker and much more extensive, the deepest part being about midway between the pubic symphysis and the superior angle. The posterior border is $U$-shaped, with nearly equal arms. On the inner side the lower part is convex antero-posteriorly. The sacral ribs doubtless were attached at their extremities by ligaments extending the full length of the bone above. The pubes and ischia are not very different in shape, and of about equal size. The pubis has a thin anterior margin in front of the acetabulum with a distinct pectineal process near the acetabular margin. In articulation the two pubes leave a deep V-shaped emargination, the thickened symphysial margin confined to the posterior part of the inner border. The obturator foramen pierces the bone obliquely, its external orifice just within the acetabular margin on the posterior two-fifths of the bone. The ischium has a thin, convex posterior margin, the two bones in symphysis showing only a small $\mathrm{V}$-shaped exmedian excision. The thickened symphysial margin is formed in nearly equal parts by the three bones, that of the ilium the greater. The ilium has an overhanging process above. The pubo-ischiadic suture passes directly inward at the middle of the inferior margin of the acetabulum and divides the horizontal part of the pelvis into nearly equal parts.

Femur (Plate XXII, Figs. I-4). - The femur is relatively short in comparison with that of Varanosaurus, but somewhat stouter. The head is broad from side to side above, thinned at the outer posterior angle. The digital fossa is shallow but broad. The trochanter is prominent, directed backward and a little inward. The shaft of the bone in the middle is rather slender and prismatic in shape. The fibular condyle as usual is much deeper anteroposteriorly than the tibial, and the latter is placed at a sharp angle.

Tibia (Plate XXII, Figs. 5, 6).-The tibia is short and thickset, rather slender in the middle, much expanded at either extremity, the inner border gently, the outer border deeply, concave. The lower extremity is expanded somewhat obliquely backward and inward. has its articular surface broadly oval, its long diameter a 
half greater than its lesser. The upper extremity is very broad from side to side with a not very deep groove in front between the heavy cnemial expansion and the broad inner part of the head. Anteriorly the border of the bone is very gently concave in profile, posteriorly rather deeper.

Fibula (Plate XXII, Fig. 7, 8).-The fibula is relatively short, much expanded at either extremity, slender in the middle. The outer border is straight or gently convex, the inner deeply concave. The lower extremity is much expanded from side to side, its somewhat convex border squarely truncated; its anterior surface is nearly flat, the posterior concave in the middle, the sides thicker. The upper extremity is considerably expanded obliquely forward and inward; convex on the outer anterior side, concave on the inner; the anterior part thin, the posterior part thick; the upper articular surface for the most part looking upward, forward, and inward.

Foot (Plate XXIII).- Two feet, both right ones, have been recovered, belonging with specimens Nos. 655 and 657 . Neither is quite complete, the latter having the bones very slightly smaller and more slender. In both specimens the tarsus is completely articulated and united with the metatarsals. In No. 655 the first, in No. 657 the fourth and fifth digits have the first and second phalanges also attached. Four ungual phalanges are preserved in No. 657; three in No. 655. In addition there are four isolated phalanges in each foot. These phalanges I have located in the drawing as seems most probable, leaving four that are unrepresented, indicated in the drawing by outlines. A sign indicates the joints in which there was no matrical contact. In No. 655 the first digit was lying in the position shown in the drawing; in No. 657 the metatarsal was divaricated in the matrix, very much as in the foot of Varanosaurus.

The foot as a whole is very noticeably different from that of Varanosaurus, in the relatively greater size of the tarsus and first and fifth digits. The astragalus is more elongated, narrower distally, and the tibial articulation is more nearly parallel to the inner side; the foot was placed at a greater angle with the long axis of the foreleg. The fibulare is also more elongated, and the 
perforating canal is at a greater distance from the distal ends of the bones. In the distal row the bones are all decidedly larger but have the same articulation. The centrale is well ossified, separating the tibiale from the first tarsale, more broadly in front than behind.

The first metatarsal is a short, stout bone, about half the length of the fifth, which is the longest of the series. It bears a single rather long and stout phalange and a large claw. This toe was probably divaricable in life. The fourth and fifth metatarsals are not very different in length, but the fifth is the stouter. The claws (Fig. 4) are large, much curved, and pointed, with a stout inferior tubercle for the insertion of the flexor tendon. It is, of course, assumed that the phalangeal formula is of the primitive kind, as in Varanosaurus, and I do not think there can be doubt of this, although the absence of three or four phalanges leaves the positive proof of this for future investigation. If my arrangement of these phalanges is correct the fifth toe is but little shorter than the third. Altogether it is very certain that the foot was broader and stouter than that of Varanosaurus and is nowise indicative of climbing or even markedly cursorial habits.

\section{RESTORATION}

The mounted skeleton as shown in the frontispiece is, as has been explained in the foregoing pages, a composite of three different skeletons, Nos. $655,656,657$. Of No. 655, from the base of the tail to the seventh postcranial vertebra, the ribs, the scapulae, right foreleg, left radius and ulna, pelvis, the right hind leg, and the left femur. Of 656 , the skull and first seven vertebrae; while the tail is in part from another specimen. These various specimens in the many bones they have in common agree perfectly in characters and almost absolutely in size, so that the composition in nowise affects the form and appearance of the skeleton. The parts shown which are more or less conjectural are the first six or seven pairs of ribs, the posterior chevron bones, the distal six caudal vertebrae, and a few of the phalanges of both front and hind feet. The left humerus, hand, tibia, fibula, and foot have been modeled after the right ones. As has been explained there are other skeletons 
of this form still inclosed in the blocks of matrix in the museum, and sometime in the future, when they are worked out, even these plaster portions will be replaced by actual specimens. The interclavicle, as explained, was an isolated bone. The skeleton at first sight impresses one with the incongruity between head and abdomen. The head is relatively small for so large a reptile and the trunk is relatively very large. The ribs are not only large and strongly curved, but they extend back in unusual length almost to the pelvis. The front legs are longer and stronger throughout than the hind ones; the feet are broad and flat. It is very evident that the creature was a terrestrial reptile, not a climber. That it was herbivorous in habit, the teeth show conclusively, and doubtless the very large abdominal cavity is correlated with its food habits. The head has in shape a curious resemblance to the aquatic lizard Amblyrhynchus, but the resemblance ends there. The slender, cylindrical tail forbids any assumption of aquatic habits, as do also the long and strong claws. In much probability the animal was a river plains inhabiting type, perhaps feeding upon succulent meadow vegetation.

\section{TRISPONDYLUS}

Williston, Jour. Geol., XVIII, 592, I910.

Trispondylus texensis Williston, ibid. Plates XXV, XXVI.

The known remains of this genus and species consist of a single specimen found intimately associated with the type specimen of Trematops milleri Williston, near the west line of Craddock's ranch, in the vicinity of Seymour, Texas. The specimen was exposed and more or less broken and weathered, inclosed in an obdurate matrix. The parts recovered are a nearly complete right humerus, with attached radius and ulna; numerous carpal and hand bones; eighteen vertebrae in four series, the first of which is in the cervical region, the second more posterior, with the distal end of the interclavicle attached, the third series yet farther back, and the fourth of eleven, including three caudals, three sacrals, and five lumbars; the right innominate; the right 
femur, and various fragments of the pectoral girdle and other bones.

Unfortunately none of the vertebrae has the spine complete, but various fragments indicate that they were short. The centra are impressed on the sides, rounded transversely below; the trans-

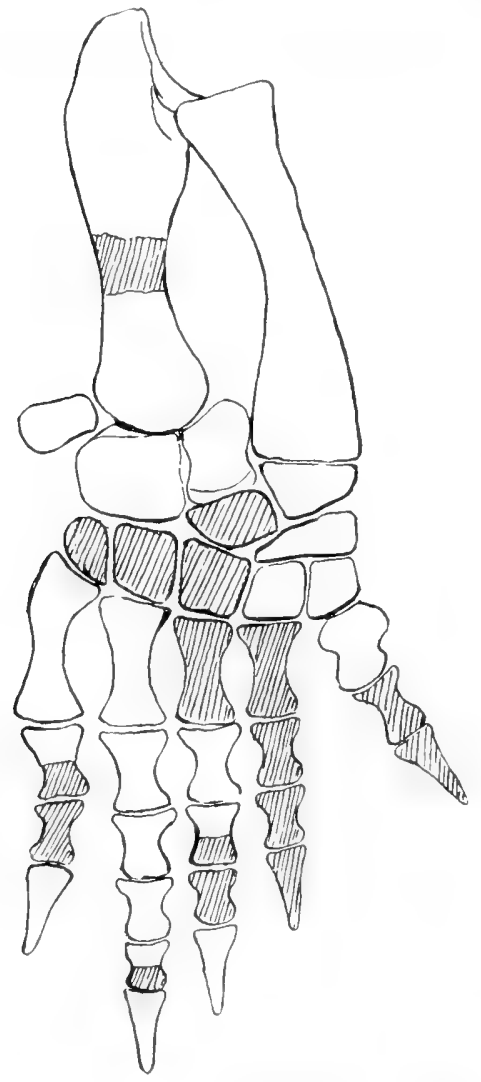

FIG. 32.-Trispondylus texensis. Right forearm and foot, one-half natural size. verse processes are like those of Casea, standing out rather broadly from the sides of the arch; and yet-attached ends of ribs indicate their stoutness and mode of attachment as in Casea. The posterior centra are noticeably stouter and larger than the more anterior ones. The two most anterior vertebrae are evidently from not far back of the skull, probably the fifth and the sixth. They are, as in Casea, very much shorter than the posterior vertebrae, so short and small that they were at first mistaken for median caudal vertebrae. The centra are nearly as broad as long, and the transverse processes are a little shorter than the more posterior ones. Intercentra are present in a few of the intercentral spaces. The sacrum is almost identical with that of Casea, the expansion of the first pair of ribs nearly equal to the combined widths of the two posterior pairs. The three attached proximal caudals have co-ossified ribs, and, so far as they are preserved, they seem to be quite like those of Casea.

The humerus preserved is stout, resembling that of Casea very much. Between the two bones the characters are quite complete, 
save that the ectepicondyle is eroded away. The median process on the dorsal side near the proximal ulnar angle is very pronounced, rounded, and roughened. The ventral radial plane of the lateral process, looking ventrad, laterad, and distad, is flat and separated from the dorsal surface by a very distinct angular ridge, very characteristic of this genus and of Casea. The entocondyle extends nearly to the full length of the bone, and is thickened, not ending considerably before the distal extremity of the bone, and thin, as in Casea. The hemispherical capitellum is extended into a rounded protuberance on the outer distal side of the convexity. The right ulna was found attached to the humerus rectangularly; a small part of the middle of its shaft is missing. It is a stout bone, with a well-developed olecranon, the distal extremity expanded and thickened, and nearly semicircular in outline. The right radius, found connected with the proximal carpals, is nearly straight on its outer side, deeply concave on the ulnar border. The proximal end is transversely truncated, oval in outline and gently concave, the distal border rather broad, thinned on its ulnar margin. This bone, like the ulna, is concave on the ventral side, nearly straight on the dorsal. The carpals of both sides are preserved in part, those of the proximal row in position, as also the first centrale and the first two carpalia; three other carpalia cannot be positively located; the bones of the fourth finger are articulated. I locate the bones of the wrist and hand in the figure as it seems they should go, those unknown or doubtfully known uniformly shaded. The radiale is small but thick, nearly triangular in shape on the dorsal side. The intermedium is unusually large; its position as regards the radius is shown in the figure as it is preserved in the right wrist. The ulnare is short. I am not sure but a little of the lower margin is gone, as it is figured. The metacarpals and phalanges are very stout, as are also the claws.

Of the right innominate, the ilium, the whole of the acetabulum, the larger part of the pubis, and a part of the ischium are preserved attached to the sacral ribs. The pubis and ischium appear to be very much like those of Casea; the pubis is surely not of the clepsydropid type. The ilium, however, is quite unlike that of Casea, in that it is prolonged backward and not at all forward, 
reaching a little beyond the hind end of the ilio-ischiadic suture. The posterior iliac notch is deep and narrow, its upper border, that is, the lower border of the posterior prolongation of the ilium, is quite horizontal. As in Casea, the internal side of the upper part of the ilium shows no indications whatever of sutural union with the sacral ribs; it is evident that their attachment was ligamentous only and not very extensive.

The right femur as preserved is in good condition, but its condyles are a little worn. The digital fossa is elongated and rather deep, the trochanteris ridge extending a little beyond the lower end of the fossa. The summit of the trochanter is at the junction of the upper and middle thirds of the bone; other characters will be seen in the figures.

\section{MEASUREMENTS}

Length of cervical vertebra.............. I2 $\mathrm{mm}$.

Transverse diameter of centrum of same......... I 2

Length of centrum opposite the hind end of interclavicle I3

Transverse diameter of same............. I2

Length of fifth presacral vertebra ........... I6

Length of fourth presacral vertebra........... I 7

Length of third presacral vertebra............ I7

Length of second presacral vertebra.......... I 8

Length of first presacral vertebra............ I9

Transverse diameter of centrum of same........ 20

Length of sacral vertebrae.................60

Expanse of first sacral ribs................ 80

Extent of sacral ribs attachment. . . . . . . . . 53

Length of first and second caudal vertebrae....... 40

It is evident that the relationships of this genus, so far as the parts preserved indicate, are with Casea. Indeed, the characters are so much alike that until the ilium was secured I was disposed to place them both in the same genus. The backward prolongation of the ilium is, however, more than a specific character. The species is considerably larger than Casea, but was in life probably of similar proportions, attaining a length of perhaps four and a half feet. Unfortunately nothing whatever is known of the skull. 


\section{PLATYHYSTRIX}

Williston, Science, XXXIII, 63I, I9I I.

\section{Platyhystrix rugosus. Plates XXXVI, XXXVII.}

Ctenosaurus rugosus Case, Bull. Amer. Mus. Nat. Hist., XXVIII, I9io.

? Zatrachys apicalis Cope, Amer. Nat., XV, ro20, December, I88I.

This species was based by Case on a few neural spines of remarkable character, some of which had been associated by Cope with his type specimen of Zatrachys apicalis, evidently the ones which he describes as "narrow flat bones, which I suppose to be neural spines, which are ornamented with inosculating ridges." The species was referred provisionally by Case to the genus Ctenosaurus Huene, from the European Trias. The essential part of Case's description is as follows:

"The spines here described are not very long, the base is narrowed with almost equal antero-posterior and transverse diameters. The upper portion becomes thinner, and is elongated in the anteroposterior diameter. The sides of the spines, from the base to the top, are covered with small irregular bosses similar to those on the skull of many amphibians. Some of the spines are more slender and less expanded antero-posteriorly at the top than others, but all have the characteristic sculpture. Fragments of scapulae and limb bones associated with the spines are typically pelycosaurian in form."

In the Yale collections of the Arroya bone-bed of New Mexico are several spines which I must identify specifically with those described by Case, though none agrees precisely with his description. One of these is shown in Plate XXVI, Fig. I, two-thirds natural size. It is nearly complete; some of the fragments from near the lower end had crumbled so that actual contact could not be made, and it is possible that the interval I have left may be slightly too great or too small. The centrum immediately associated with the spine in all probability belongs with it, though 
contact could not be secured. In its porous texture and peculiar black, glossy exterior it agrees perfectly with the lower extremity of the spine, and is unlike other bones in the same lot. The height of the spine as drawn is two hundred and eighty millimeters, considerably more than twice that of the specimens described by Case (one hundred and thirteen millimeters). The antero-posterior expansion of the upper extremity is nearly fifty-five millimeters, while the length of the centrum is but twenty-three millimeters.

This spine is most extraordinary. It is very thin and flat throughout, save at the lower portion, where it changes into the oval stem. The upper border, also, is a trifle thicker and it has a gentle sigmoid curvature, which, however, I attribute to postmortem causes. On the lower part, especially, there are longitudinal, somewhat inosculating ridges, and, scattered irregularly over the bone, are a considerable number of small, irregular bosses, or excrescences. Throughout this portion of the spine-that is, above the oval pedicel-the anterior and posterior borders show narrow groovings for ligamentous attachments. Associated with these spines are a few fragments of another, apparently from the same animal, and so far as they go, quite identical with the one figured.

The spine figured in Plate XXXVII, Fig. 6, natural size, I at first ascribed to an amphibian, and possibly correctly, but, because of the almost identical appearance of the bosses, it would seem almost certain that it belongs in the same creature as do the longer spines. It resembles very much a lumbar spine of Naosaurus in its peculiar curvature. Above the zygapophyses, as in the long spine, the bone is nearly cylindrical or slightly oval in cross-section. But this thickness is retained throughout or is even greater at the beginning and the end of the rugosities; and the upper extremity is expanded somewhat, club-shaped. The nodular excrescences are strongly protuberant, very irregular in position and scarcely symmetrical on the two sides. No reptilian centra are preserved, or at least have been so far discovered in the collection, to which this spine could be attached; indeed, the arch is quite similar in form to those of Eryops, found associated with the specimen. There 
are two or three small intercentra in the collection of suitable size for this arch. Notwithstanding these facts, such an elongate curved spine for an amphibian would be most extraordinary and unheard of and the absolute identity of the lateral markings in this and the flat spines renders it almost certain that they all pertain to one species of reptile.

Associated with these spines are a lot of surface fragments of similar spines. They all agree in having inosculating ridges and irregular bosses. Some are thicker and stouter, like those described by Case for the base of his spine, having their diameters nearly equal; others are quite thin, but they all agree in their characters. Among them are two fragments having the lower end of the lateral excavated surface with a short interval of rounded smooth spine, and then on each side a very irregular large nodosity, the spine again contracting below them.

If there are two different forms of animals represented by these various specimens, then evidently one is the Ctenosaurus rugosus of Case; the other, Zatrachys apicalis of Cope. But I believe that they all pertain to one form, which may be Cope's $Z$. apicalis.

Certain it is that the creature or creatures possessing these most peculiar spine structures will be found to be among the most remarkable of vertebrates.

\section{SPECIES INCERTAE SEDIS}

Numerous limb bones, as well as vertebrae, from the Craddock bone-bed are indeterminable. Not only because of their intimate faunistic association, but because of their perfect preservation and unique types I give figures and brief descriptions of some of the more important ones. Some are undoubtedly new to science, but nothing will be gained by giving them names. To facilitate reference to them, however, I have designated them by arbitrary signs, consecutive letters with the number 104, the lot number under which they are registered in the University catalogue. I have figured some of the smaller forms only; later studies of the vertebrae and girdles may indicate by elimination the relationships of some of the forms. It is very probable that most of the specimens here described belong among the zygocrotaphic reptiles. 
Femur Io4 A (Plate XXX, Fig. 4).- There are more than twenty femora of this type, all of the same or nearly equal size, conclusively indicating their adult character. The articular ends are rather sharply edged, indicating more or less cartilaginous surfaces, but not nearly to the extent characteristic of Clepsydrops. The digital fossa is rather large; there is no distinctive trochanter or adductor ridge. The shaft in the middle is nearly circular in crosssection. The popliteal fossa is rather shallowly concave and broad.

Tibia Io4 B (Plate XXXIII, Fig. 8).--There are two complete tibiae of this type, and parts of several others. They are, like the larger tibia, shown in Plate XXX, Fig. Io, deeply concave on the ventral side. The lower end is sharply truncate and transversely oval. It is possible that this tibia belongs with femur I04 A, but it seems to be too long.

Tibia ro4 C (Plate XXXIII, Fig. 7).-This type, of which I have found but a single specimen, agrees so well with the larger form provisionally referred to Clepsydrops that it may be merely a juvenile specimen. Its proportions, however, are somewhat different, but perhaps no greater than those observed between the juvenile and adult femora referred to Clepsydrops.

Fibula ro4 D (Plate XXXII, Fig. 3).-A very slender right fibula of peculiar form. The surface shown is nearly in one plane. The upper articular surface is very oblique, as is seen in the photograph, and is of an elongate crescentic shape. The external lower surface turns backward and is gently concave, separated from the convex dorsal surface by a rounded ridge.

Fibula ro4 E (Plate XXXIII, Fig. 9).-A second fibula of precisely the same length as the preceding and of like slenderness is quite surely of a different genus. The upper articular surface is not oblique and the tibiale side is more concave in outline, nor is the lower extremity at all like that of the preceding fibula, but agrees better with that of the fibula of Varanosaurus.

Fibula ro4 F (Plate XXX, Fig. 9).- This fibula may possibly be a juvenile form of that shown in Plate XXX, Fig. II, and referred provisionally to Clepsydrops, but the upper extremity is twisted more obliquely to the shaft, the shaft on the concave side is thinner, the lower border is more oblique to the axis of the bone, etc. 
Radius $\mathrm{TO}_{4}$ G (Plate XXXIII, Fig. 6).- This, the largest of the radii preserved, indicates an animal of considerable size and slenderness. The upper extremity has evidently been injured; its expansion is nearly as great as that of the lower extremity, but the long axis of its articular end is very oblique to the plane of the lower end. The bone is very concave on its ventral side, the dorsal border nearly in one plane or a trifle convex. A little above the distal end on the ulnar side there is a sharp ridge; evidently the small radius shown in fig. 5 belongs to the same species.

Radius $\mathrm{IO}_{4} \mathrm{H}$ (Plate XXXIII, Fig. Io).-This small radius, even though juvenile, is evidently of a different form from either of those previously described. The two ends are expanded in the same plane, the bone is nearly flat on the ventral side, and the lower end is but slightly expanded. There are in addition to this, other small radii of less slender form.

Radius 104 I (Plate XXXII, Fig. 2).- It is not improbable that this radius may belong with some one of the different forms of amphibians represented by the femora and humerus described on page I4, which I refer provisionally to Aspidosaurus or allied new forms. It has, however, the same general characters of the more slender radii described.

Tibia ro4 J (Plate XXXII, Fig. 5).-This tibia, of considerable size, is very peculiar in the very much flattened upper end (the lower end in the figure) with very shallow concavities on either side of the cnemial convexity. It is not curved as much as the tibia referred to Clepsydrops, and is very unlike that form. Its unlike form also precludes the possibility of its being a juvenile specimen of a Dimetrodon.

Ilinm I04 K (Plate XXXI, Fig. I).-In much probability this ilium belongs with femur Io4 A. It is very unlike any ilium hitherto figured or described from the Permian of Texas. The upper helmet-shaped expansion is high and thin, the front border is thicker and curved gently forward, the upper thin border convex throughout. The posterior iliac notch is very small; the anteroposterior diameter of the bone in its narrowest place much less than that of the ilium referred to Clepsydrops (Fig. 2). The inner side shows rugosities apparently for three sacral ribs, but this is not certain. 


\section{EXPLANATION OF PLATES}

[All the figures are by the author, and are of natural size, except where otherwise stated.]

Frontispiece.-Mounted skeletons of Varanosaurus brevirostris Williston, and Casea broilii Williston, a little less than one-sixth natural size. Walker Museum, University of Chicago. Skeletons collected, prepared, and mounted by Paul C. Miller.

Plate I.-Varanosaurus brevirostris Williston. Fig. I, dorsal ribs, $a, b, d$, left, from behind, $c$, right, $d d$, same as $d$, from in front; Fig. 2, odontoid of atlas, axis, and third to fifteenth vertebrae, from the side.

Plate II.-Varanosaurus brevirostris Williston. Fig. 2, fourth to fifteenth (thirteenth to twenty-fourth presacral) vertebrae from below; Fig. 2, sixteenth to twenty-seventh (first to twelfth presacral) vertebrae, from the side; Fig. 3, the same, from below.

Plate III.-Varanosaunus brevirostris Williston. Sacral and caudal vertebrae in continuous series to the forty-seventh, as found in articulation; with anterior and distal chevrons.

Plate IV.-Varanosaurus brevirostris Williston. Fig. I, interclavicle and clavicles in articulation; Fig. 2, interclavicle from left side; Fig. 3, left clavicle, from below; Fig. 4, right clavicle, from in front; Fig. 5, right scapulacoracoid, from behind; Fig. 6 , right proximal tarsals, $a$, tibiale; $b$, fibulare; Fig. 7, the same, ventral side; Fig. 8, sacrum, from below.

Plate V.-Varanosaures brevirostris Williston. Right scapula. Fig. I, from outer side; Fig. 2, from inner side; Fig. 3, from above; Fig. 4, from below.

Plate VI.-Varanosaurus brevirostris Williston. Fig. I, right humerus, ventral side; Fig. 2, the same, ulnar side; Fig. 3, the same, dorsal side; Fig. 4, the same, radial side; Fig. 5, the same, distal end; Fig. 6, the same, proximal end; Fig. 7 , sacrum, from in front; Fig. 8 , first presacral vertebra, from in front; Fig. 9, twelfth presacral (fifteenth postcranial) vertebra, from behind.

Plate VII.-Varanosaurus brevirostris Williston. Fig. I, left radius and ulna, dorsal side; Fig. 2, the same, ventral side; Fig. 3, left ulna, radial side; Fig. 4, left radius, ulnar side; Fig. 5, ulnare, ventral side; Fig. 6, left ulna of another individual, dorsal side; Fig. $7, a$, odontoid of undetermined pelycosaurian, from in front, $b$, from the side, $c$, from behind; Fig. 8 , carpus of Dimetrodon incisizus Cope, ventral side, two-thirds natural size $(R$, radiale; $U$, ulnare; $C_{\mathrm{I}}, 2$, centralia; $\mathrm{I}-5$, carpalia).

Plate VIII.-Varanosaurus brevirostris Williston. Left forearm and hand, dorsal side. 
Plate IX. Varanosaurus brevirostris Williston. Right innominate. Fig. I, from without; Fig. 2, from within. $I L$, ilium; $I S$, ischium; $P B$, pubis.

PLATE X. -Varanosaurus brevirostris Williston. Pelvis, from below, the lower figure, a photograph, two-thirds natural size.

Plate XI.-Varanosaurus brevirostris Williston. Pelvis and first five caudal vertebrae, from above.

Plate XII.-Varanosaurus brevirostris Williston. Fig. I, left femur, ventral side; Fig. 2, the same, fibular side; Fig. 3, the same, tibial side; Fig. 4, the same, dorsal side; Fig. 5, the same, distal end; Fig. 6, left tibia, ventral side; Fig. 7, the same, dorsal side; Fig. 8, the same, fibular side; Fig. 9, the same, inner side; Fig. Io, the same, proximal end; Fig. II, the same, distal end.

Plate XIII.-Varanosaurus brevirostris Williston. Seymouria baylorensis Broili. Fig. I, Varanosaurus, right foot, dorsal side; Fig. 2, Varanosaums, right fibula, ventral side; Fig. 3, Varanosaurus, right fibula of another individual, dorsal side; Fig. 4, Scymouria, anterior vertebra, from the side; Fig. 5, the same, from in front; Fig. 6, Scymouria, posterior vertebrac, from below; Fig. 7, the same, from above; Fig. 8, the same, from the side.

Plate XIV. - Casca broilii Williston. No.656. Fig. I, first seven postcranial vertebrae, $a$, the odontoid from side and behind, $b$, the axis from behind; Fig. 2, second presacral (twenty-third postcranial) vertebra from in front, with co-osified ribs, the right also from below; Fig. 3, right mandible, from outer side; Fig. 4, the same from inner side, without articular; Fig. 5, mandibles, from above. Fig. 6, interclavicle.

Plate XV.-Casea broilii Williston. Third postcranial vertebra from side and below; eighth to twenty-fourth (first presacral) vertebrae from the side, the fourteenth also from below and the seventeenth from above.

Plate XVI.-Casea broilii Williston. Fig. I, sacrum and first seven caudal vertebrae, from the side, the sixth also from below, specimen No. 655; Fig. 2, first ten caudal vertebrae, from the side, the third, fourth, and fifth also from below, No. 656 ; Fig. 3, first chevron, from behind, No. 656 .

Plate XVII.-Casea broilii Williston. No. 655. Fig. I, fourteenth postcranial vertebra, with ribs, from behind; Fig. 2, twenty-first postcranial vertebra, with ribs, from behind; Fig. 3 , twenty-second vertebra, with ribs, from in front.

Plate XVIII.-Casea broilii Williston. Fig. I, IO, rib of tenth postcranial vertebra; I2, rib of twelfth vertebra; I5, rib of fifteenth vertebra; I8, rib of eighteenth vertebra; Fig. 2, second caudal vertebra, from below; Fig. 3, third sacral vertebra, from behind; Fig. 4, first sacral vertebra, from in front; Fig. 2, specimen No. 656; all others, No. 657 .

Plate XIX.-Casea broilii Williston. Fig. I, right scapula from outer side; Fig. 2, left scapula, from below; Fig. 3, right scapula, from behind; Fig. 4, two distal phalanges of thumb, as articulated; Fig. 6, fifth metacarpal; 
Fig. 7, fourth metacarpal; Fig. 8, distal caudal vertebrae. Figs. I-7, No.655; Fig. 8, No. 658 .

PLATE XX.-Casea broilii Williston. Specimen 655. Fig. I, right humerus, ventral side, with $a$, distal end; Fig. 2, the same, dorsal side; Fig. 3, the same, ulnar side; Fig. 4, right ulna; Fig. 5, right radius; Fig. 6, sacrum and first caudal vertebra, ventral side.

PLATE XXI. - Casea broilii Williston. Specimen 655. Fig. I, left innominate, outer side; Fig. 2 , the same, inner side. $i l$, ilium, $i s$, ischium, $p b$, pubis.

PLATE XXII.-Casea broilii Williston. Specimen 655. Fig. I, right femur, dorsal side and distal end; Fig. 2, the same, ventral side; Fig. 3, the same, outer side; Fig. 4, the same, tibial side and proximal end; Fig. 5, right tibia, ventral side and distal end; Fig. 6, the same, outer side and proximal end; Fig. 7, right fibula, dorsal side and distal end; Fig. 8 , the same, tibial side and proximal end.

PLATE XXIII.-Casea broilii Williston. Specimen 655. Fig. I, right hind foot, dorsal side; Fig. 2, right tibiale and fibulare, proximal ends; Fig. 3, right tibiale, inner side; Fig. 4, ungual phalange; Fig. 5, outline of tarsal bones, from plantar side; Fig. 6, sacrum, from above.

PLATE XXIV.-Fig. I, Trispondylus texensis Williston, right femur, ventral side, with attached proximal end of tibia, two-thirds natural size; Fig. 2, the same, inner side; Fig. 3, Trematops milleri Williston, left femur, ventral side; Fig. 4, the same, inner side; Fig. 5, Captorhinus illinoiensis Williston, left femur, ventral side; Fig. 6, proximal end of same; Fig. 7 , distal end of same; Fig. 8, Labidosaurus, species, right femur, ventral side; Fig. 9, distal end of same; Fig. Io, proximal end of same.

PLate XXV. - Trispondylus texensis Williston. Fig. I, right humerus, ventral side; Fig. 2, the same, outer side; Fig. 3, proximal end of radius; Fig. 4 , proximal end of ulna; Fig. 5, distal end of radius; Fig. 6, distal end of ulna; Fig. 7, metacarpal and phalanges, as articulated; Fig. 8, metacarpal; Fig. 9, ulnare.

PLATE XXVI.-Seymouria baylorensis Broili. Skull and anterior vertebrae, from above.

PLATE XXVII. - Seymouria baylorensis Broili. Skull and pectoral girdle, from below.

PLATE XXVIII.-Seymonia baylorensis Broili. Upper figure, skull and pectoral girdle, from the side; lower figure, the skeleton as exposed in the nodule, much reduced.

PLATE XXIX. - Seymouria baylorensis Broili (type of D. anomalus Williston). Fig. I, right humerus, $a$, from side, $b$, from in front; Fig. 2, left tibia, ventral side; Fig. 3, radius; Fig. 4, right femur, from behind; Fig. 5, left femur, from Cacops bone-bed, natural size; Fig. 6, undet.; Fig. 7, left ilium, from without; Fig. 8, posterior dorsal vertebra, from in front; Fig. 9, dorsal centrum, from behind; Fig. Io, dorsal centrum, from in front; Fig. II, the 
same from above; Fig. I2, the same, from the side. All figures, save 5, twice natural size of the embryonic specimen, and about equal to adult size.

Plate XXX.-Craddock bone-bed. Fig. I, Clepsydrops, left femur, ventral side and proximal end; Fig. 2, Clepsydrops, left femur, dorsal side; Fig. 3, Clepsydrops, juvenile left femur, dorsal side; Fig. 4, gen. nov. left femur, dorsal side, with proximal and distal ends; Fig. 5, Clepsydrops, juvenile left humerus; Fig. 6, pariotichid genus indet., left femur, dorsal side; Fig. 7 , the same, ventral side; Fig. 8, gen. indet. radius; Fig. 9, gen. indet. fibula; Fig. Io, Clepsydrops (?), left tibia, ventral side; Fig. I I, Clepsydrops (?), fibula.

Plate XXXI.-Craddock bone-bed. Fig. I, gen. nov. left ilium, outer side; Fig. 2, Clepsydrops, left ilium, outer side; Fig. 3, Clepsydrops, right humerus, ventral side; Fig. 4, Clepsydrops, left ischium; Fig. 5, Clepsydrops (?), quadrate, inner side; Fig. 6, the same, distal end; Fig. 8, Clepsydrops (?) articular, from above; Fig. 9, the same from below; Fig. 1o, Clepsydrops, fibulare.

PLATE XXXII.-Craddock bone-bed. Fig. I, Clepsydrops, femur, dorsal side; Fig. 2, radius, indet.; Fig. 3, fibula, indet.; Fig. 4, Aspidosaurus, femur, ventral side; Fig. 5, tibia (reversed), indet.; Fig. 6, Aspidosaurus, femur, ventral side; Fig. 7, Aspidosaurus peltatus Williston, dorsal shield, from above; Fig. 8, diadectid tooth; Fig. 9, Clepsydrops (?), astragalus, from in front; Fig. Io, astragalus, indet., dorsal side; Fig. II fibulare, indet.

Plate XXXIII.-Craddock bone-bed. Figs. I, 2, 3, 4, Aspidosaurus, spp. femora, ventral side; Figs. 5, 6, radii, indet.; Figs. 7, 8, gen. nov. tibiae, dorsal side; Fig. 9, fibula, indet.; Fig. I0, radius, indet.; Fig. I I, Aspidosaurus, ilium, from without.

Plate XXXIV.-New Mexico, Yale collections. Fig. I, Sphenacodon ferox Marsh, type, left dentary, from without; Fig. 2, Sphenacodon ferox, left premaxilla, from within; Fig. 3, Ophiacodon mirus Marsh, type, right dentary, from without; Fig. 4, Ophiacodon, right clavicle, external side; Fig. 5, Nothodon lentus Marsh, type, left dentary, from the side; Fig. 6, the same, from above; Fig. 7, Nothodon lentus, posterior tooth, from behind; Fig. 8, Eryops, ungual phalanx; Fig. 9, Eryops, sacral rib; Fig. 10, Ophiacodon (?), right neural arch of atlas; Fig. II, the same, from without.

Plate XXXV.-New Mexico, Yale collections. Fig. I, Nothodon lentus Marsh (probably, with the three following, a part of type specimen), left radius, with proximal end; Fig. 2, N. lentus, left ulna, ventral side; Fig. 3, N. lentus, left fibula, ventral side; Fig. $4, N$. lentuts, left tibia, dorsal side, with $l$, proximal end; Fig. 5, Sphenacodon (?) Ophiacodon (?), right humerus, ventral side; Fig. 6, Ophiacodon, tibia; Fig. 7, Ophiacodon (?), fibula; Fig. 8, Ophiacodon, left ulna, ventral side; Fig. 9, the same, dorsal side; Fig. ro, Ophiacodon, radius; Fig. II, the same, ulnar side. Figures two-thirds natural size.

Plate XXXVI.-New Mexico, Yale collections. Fig. I, Platyhystrix 
rugosus Case, dorsal vertebra, two-thirds natural size; Fig. 2, Nothodon lentus Marsh, dorsal vertebra; Fig. 3, Ophiacodon, posterior dorsal vertebra; Fig. 4, Ophiacodon (?), Sphenacodon (?), last lumbar and first sacral vertebra, from in front; Fig. 5, Ophiacodon mirus, part of left maxilla, type specimen.

Plate XXXVII.-New Mexico, Yale collections. Fig. I, Sphenacodon mirus, Marsh, left maxilla, from within (part of type specimen); Fig. 2, Sphenacodon ferox, left premaxilla, from without; Fig. 3, Ophiacodon (?), Sphenacodon (?), left femur, dorsal side; Fig. 4, Ophiacodon, left ilium, from without; Fig. 5, the same, from within; Fig. 6, Platyhystrix rugosus Case, spine of posterior vertebra.

Plate XXXVIII.-New Mexico, Yale collections. Aspidosaurus novamexicanus Williston, type specimen, from above, about one-half natural size; Fig. 2, Limnoscelis paludis Williston, a little reduced; Fig. 3, Nothodon lentus Marsh, top of skull, reduced. 


\section{INDEX}

Adlachrymal bone, I9

Amphibia, 9

Araeoscelis, 6

Aspidosaurus novomexicanus, r2; peltatus, I3

Baker, Lawrence, 5

Brachycnemius dolichomerus, 77

Broili, Ferdinand, 48, 53, 85

Cacops bone-bed, 4

Captorhinus, 68; illinoiensis, 69

Case, E. C., I

Casea broilii, I 12

Caseidac, characters of, II I

Clear Fork division, 3

Clepsydrops, 72 ; natalis, 73

Clepysydropidae, 72

Conodectes, 48

Cope, E. C., 8

Coracoid, structure of, 58,98

Cotylosauria, characters of, $I_{5}$

Craddock bone-bed, 5

Ctenosaurus rugosus, I 35

Cummins, W. F., 3

Desmospondylus anomalus, 49

Diadectes, r6; species, 23

Diadectidae, characters of, 16

Diasparactus, 34

Dimetrodon incisivus, 76 ; navajoicus, 84

Diplodocus, 97

Dissorophus, I3

Double Mountain division, 3

Dromopus agilis, 40

Elcabrosaurus, 8o

Eosauravus copei, 44

Erpetosuchus kansensis, 32

Eryopidae, characters of, 9

Eryops, I3; grandis, ro

Euchirosaurus, II

Gibb, Hugh, 25

Huene, F。 V., 92

Kadaliosaurus, 7

Labidosaurus, mandible of, 3I

Limnoscelidae, characters of, 23

Limnoscelis paludis, 23; relationships of,
Marsh, O. C., 7

Mesosaurus, III

Miller, Paul C., I, I40

Moodie, R. L., 64

Mosasauria, evolution of paddles, 45

New Mexico, Permian of, 7

Nothodon lentus, I6

Nothodontidae, 16

Ophiacodon mirus, 8 I

Otocoelus mimeticus, I $3_{3}$

Pareiasaurus, 47

Pariotichidae, characters of, 68

Paroccipital, I I6

Pelycosauria, 70

Phalangeal formula, 40

Platyhystrix rugosus, I3.5

Poecilospondylus, 80

Poliosauridae, characters of, 80

Poliosaurus, 80

Postnarial bone, I9

Prearticular bone, 32

Proganosauria, relationships of, III

Propappus, 47

Reptilia, 15; origin of, 64 ; tarsus of, primitive, 44

Schuchert, Charles, I

Seymouria baylorensis, 48; relationships of, 63

Seymouriidae, characters of, 48

Species incertae sedis, I37

Sphenacodon ferox, 78

Sphenacodontidae, 72

Stegocephala, 9

Stereosternum, III

Tapinocephalus, 92

Temnospondyli, characters of, 9

Temporal arches and vacuities, 92

Therapsida, 7 I

Theromorpha, characters of, 70

Theropleura retroversa, 82

Trispondylus texensis, I3I

Varanosaurus acutirostris, 85 ; brevirostris, 85 ; relationships of, Io9

Wichita division, 3

Zatrachys apicalis, I 35 


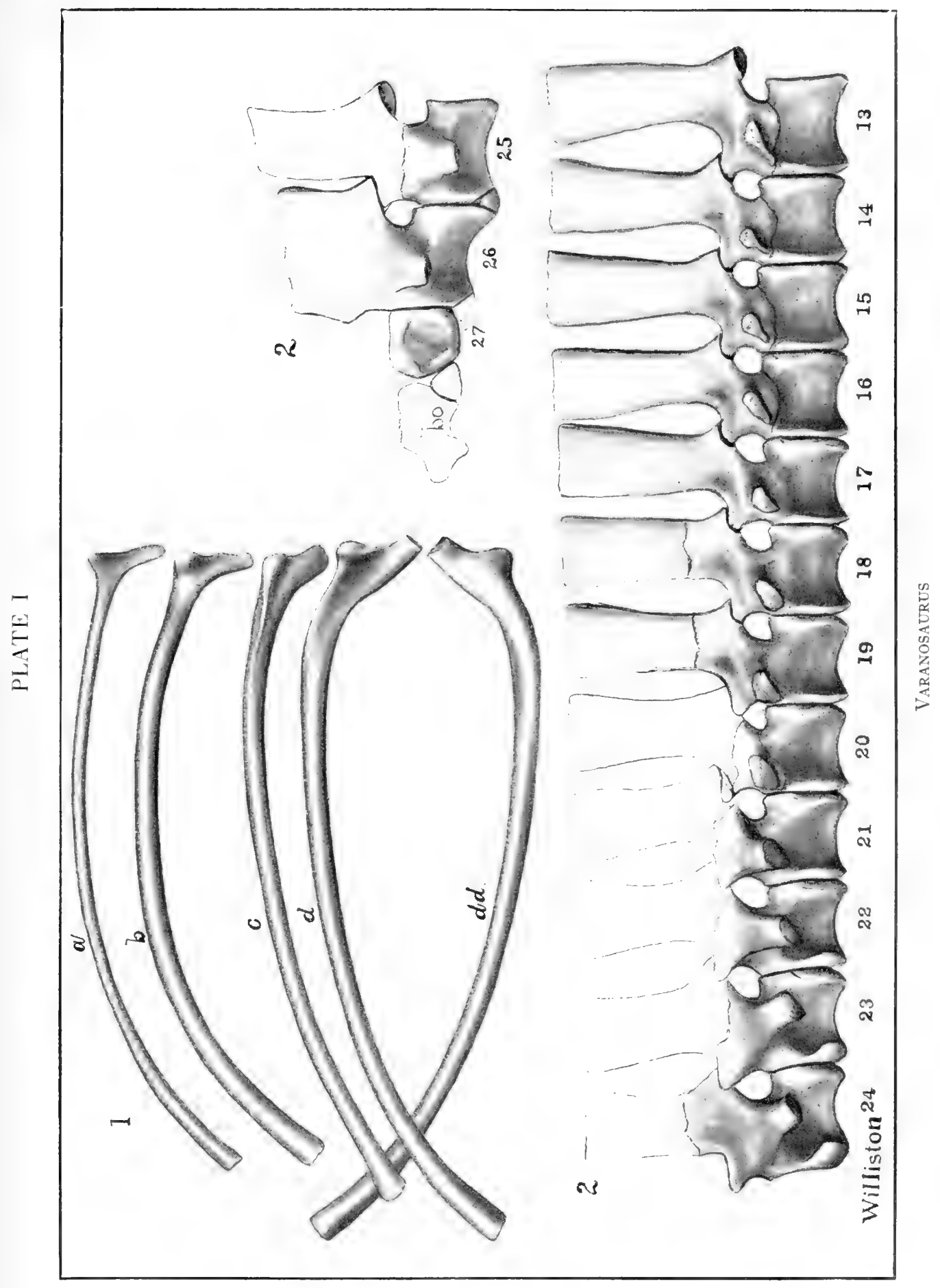





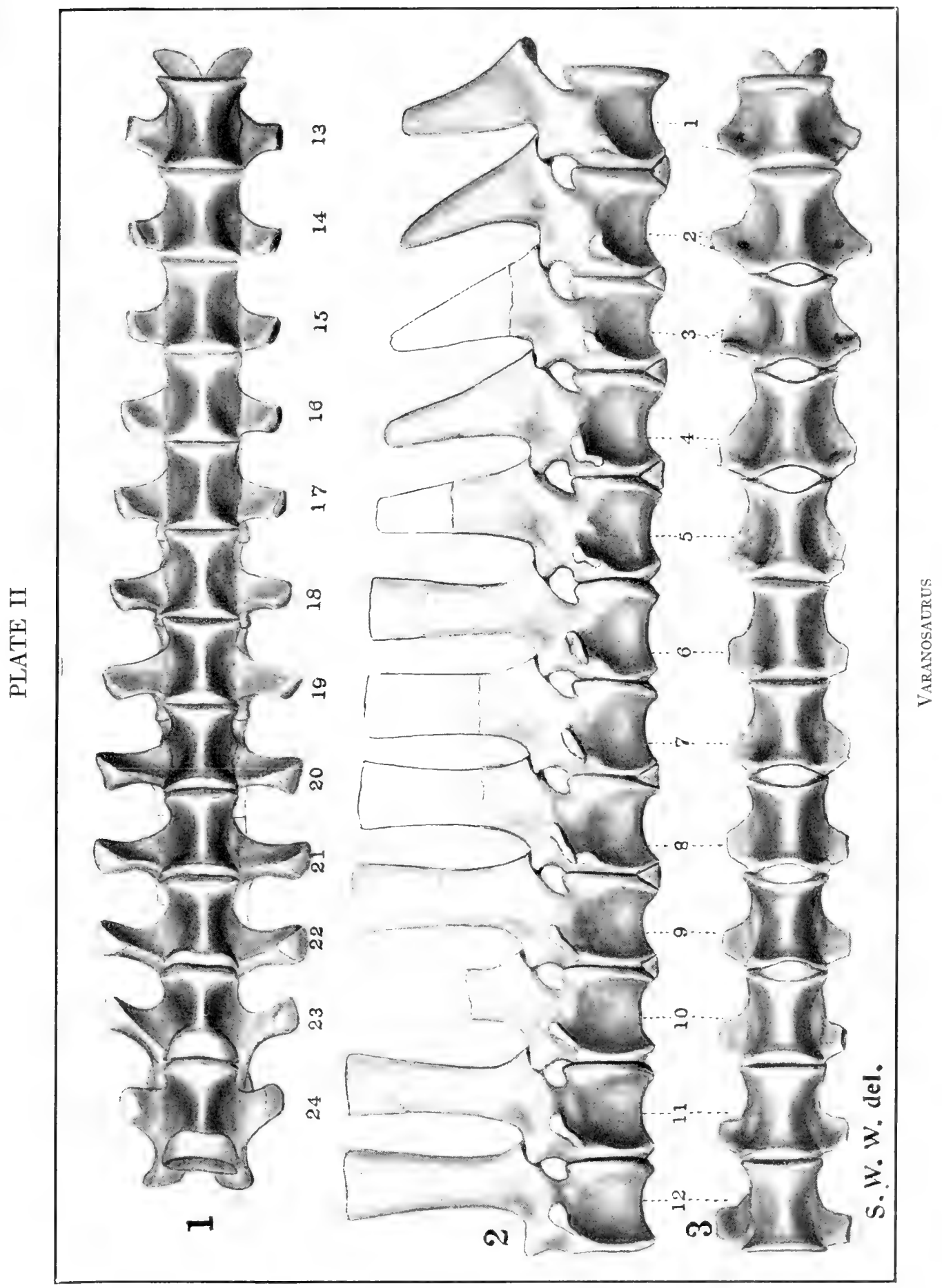





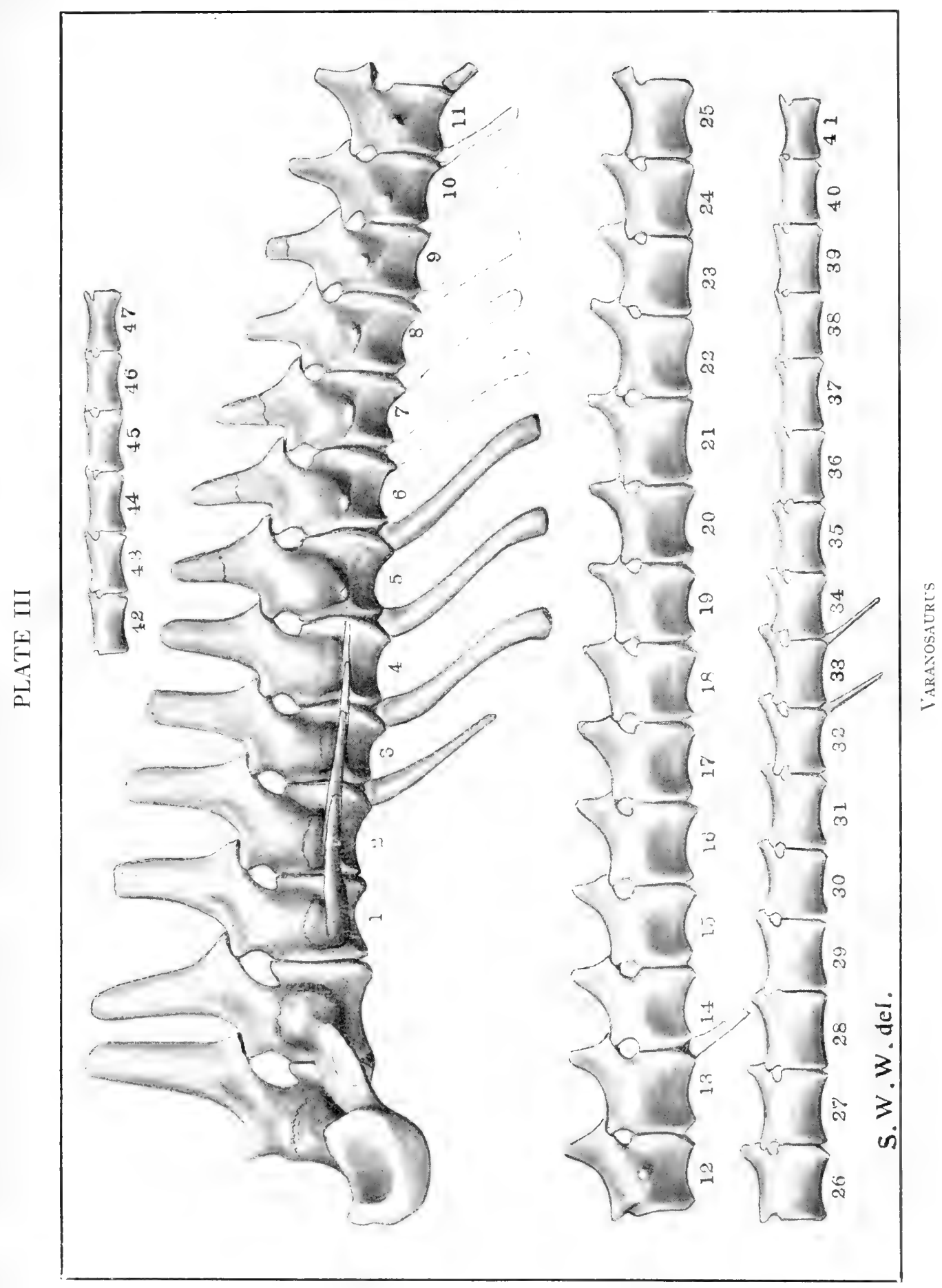





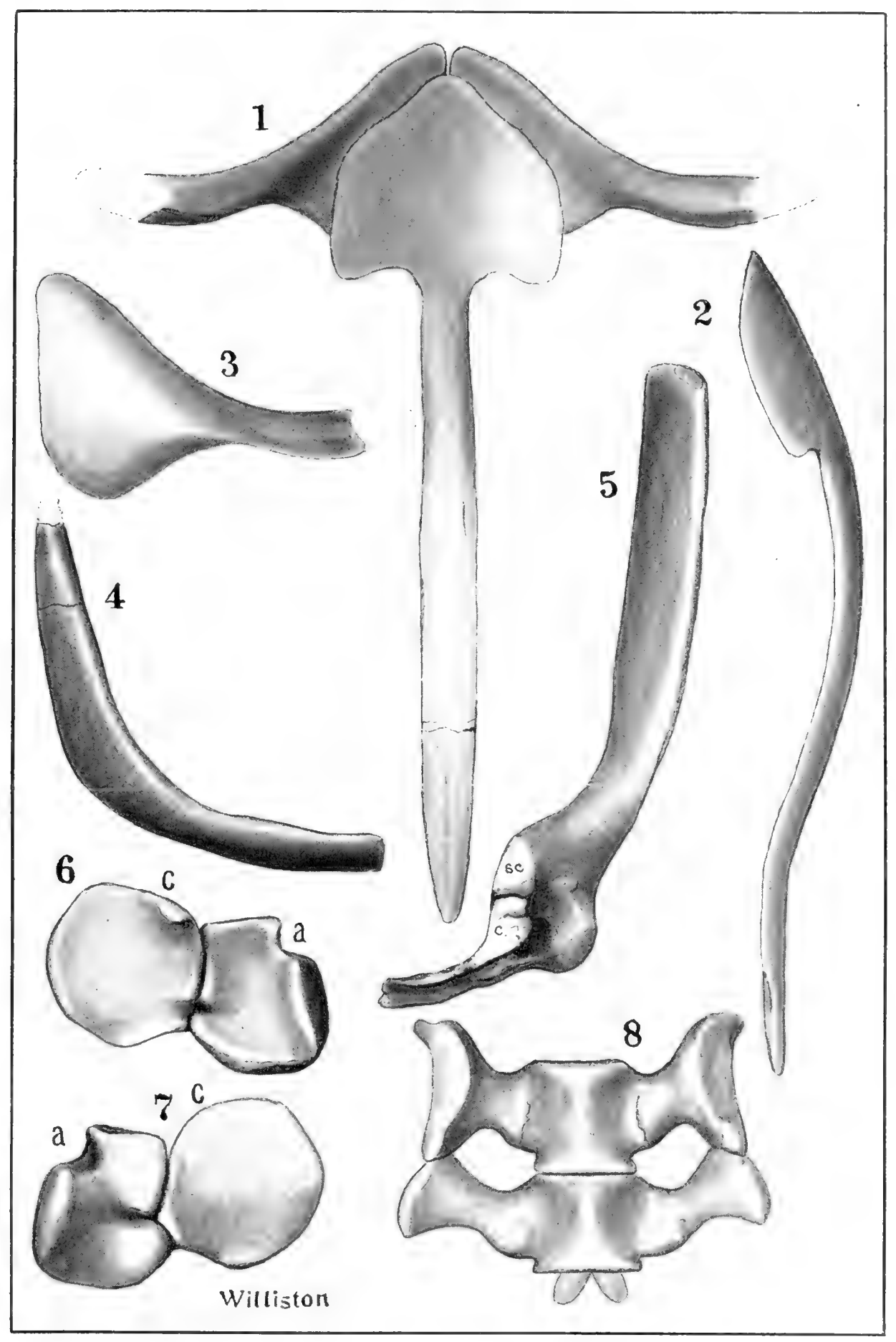

VARANOSAURUS 
PLATE V

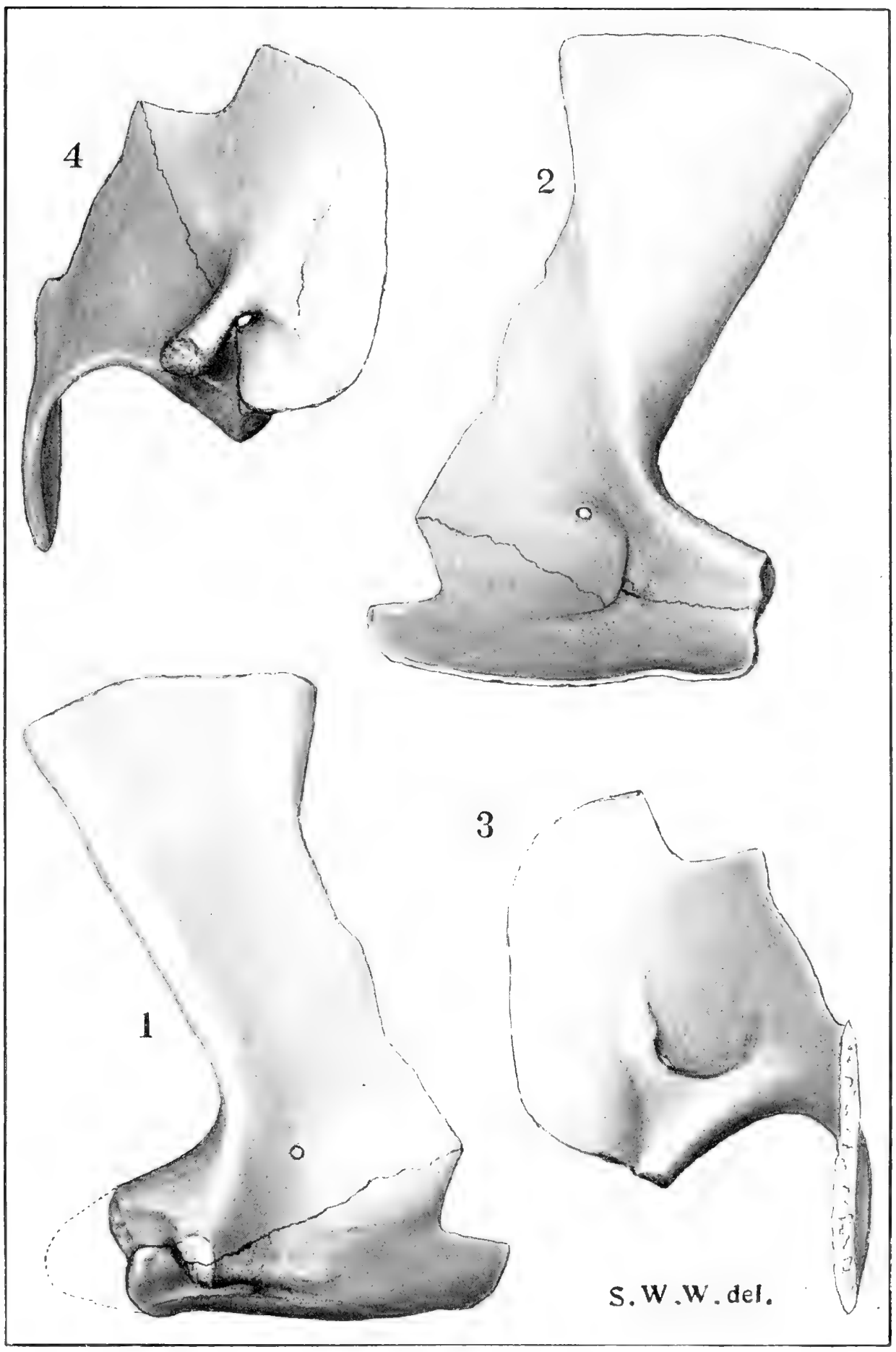

VIRANOSAURUS 

PLATE VI

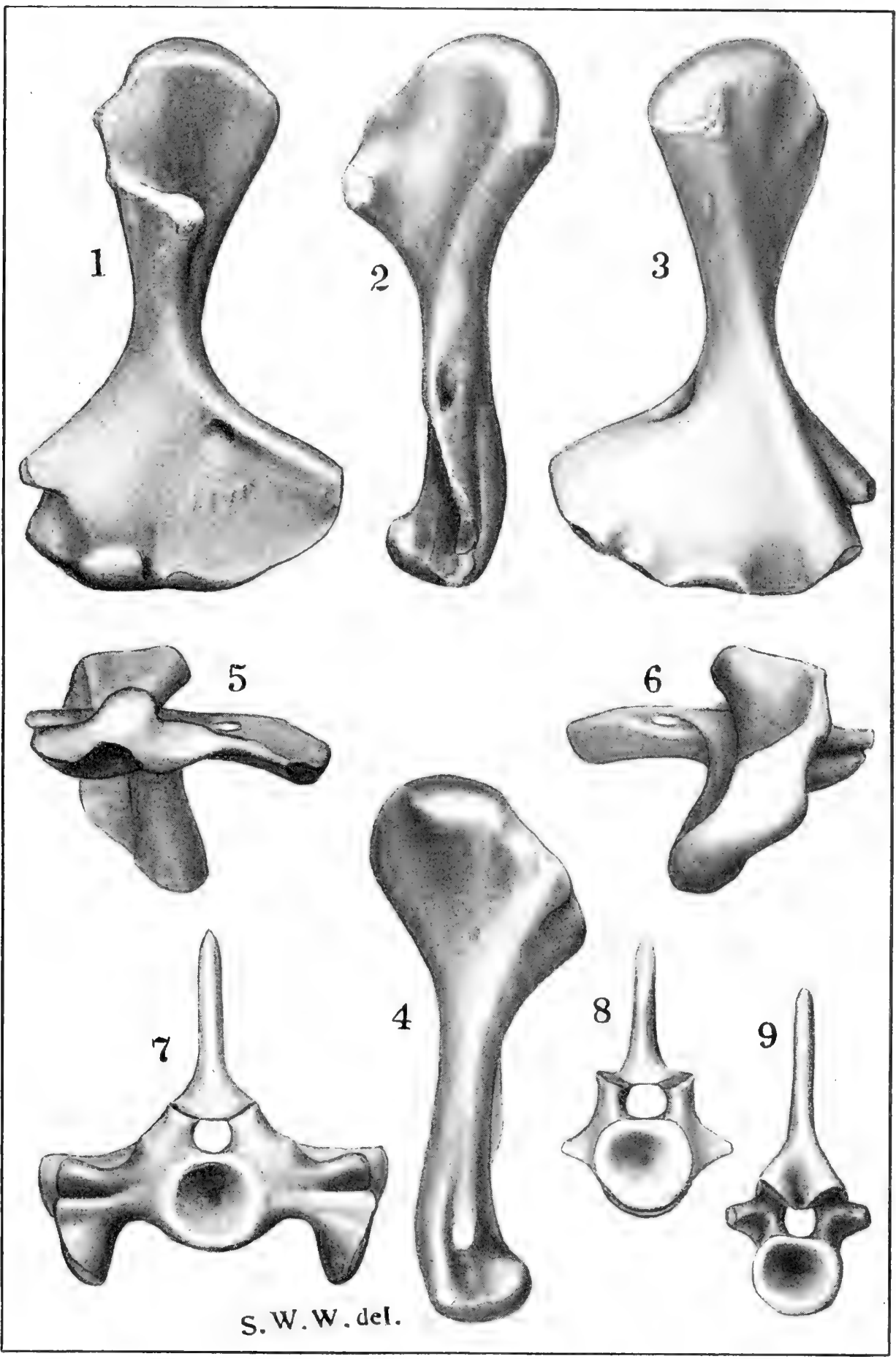

VARANOSAURUS 


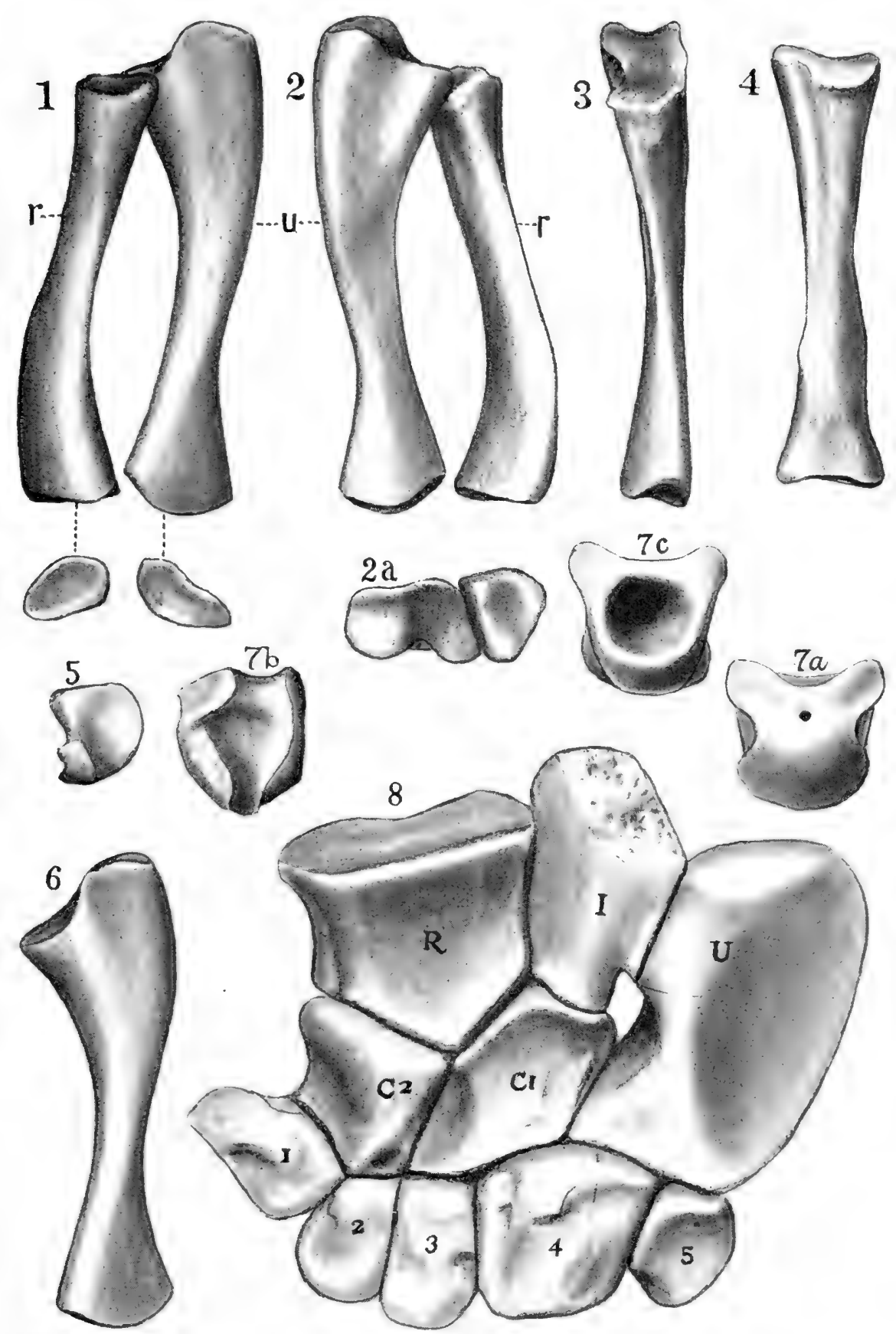

Willistou 


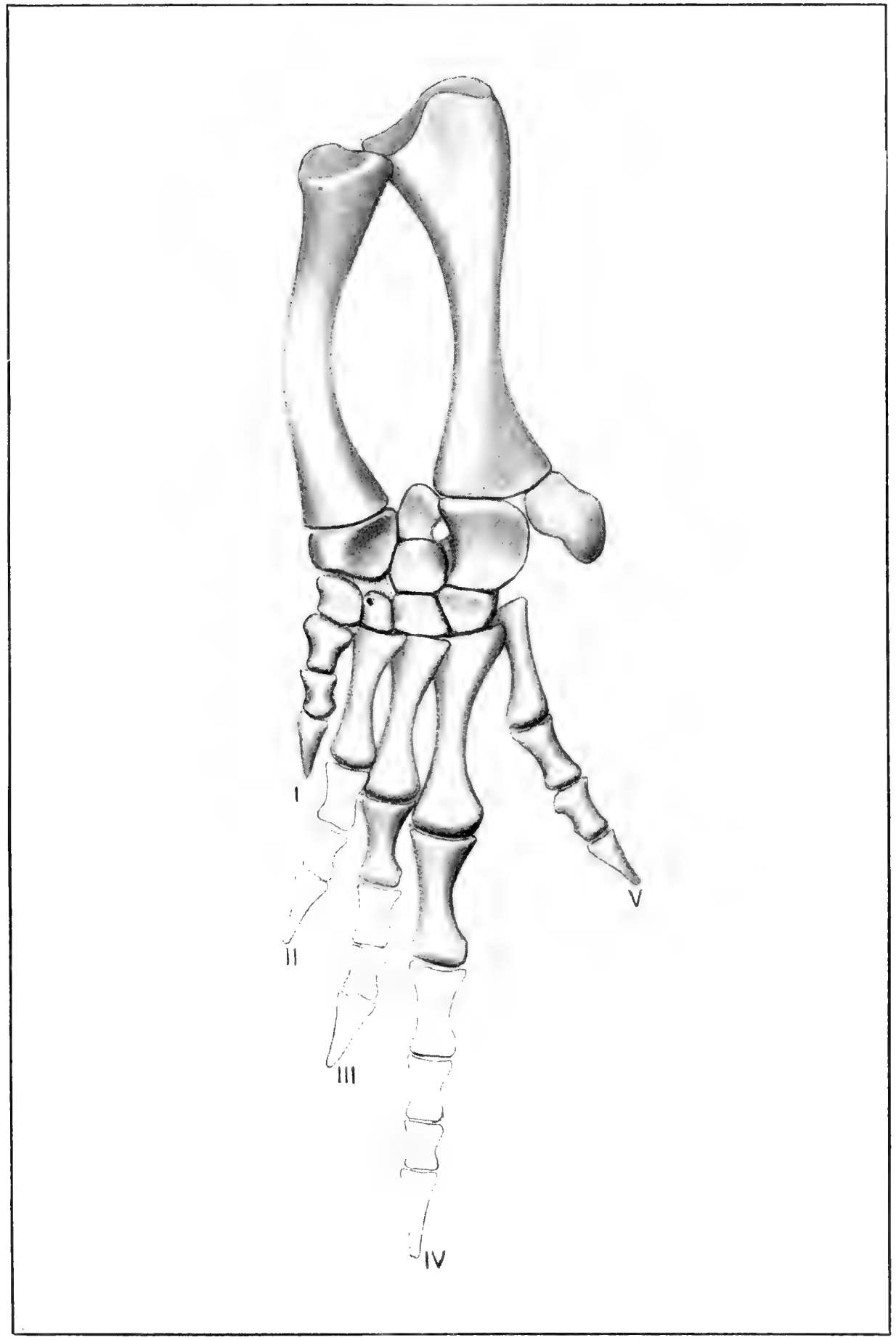



PLATE IX
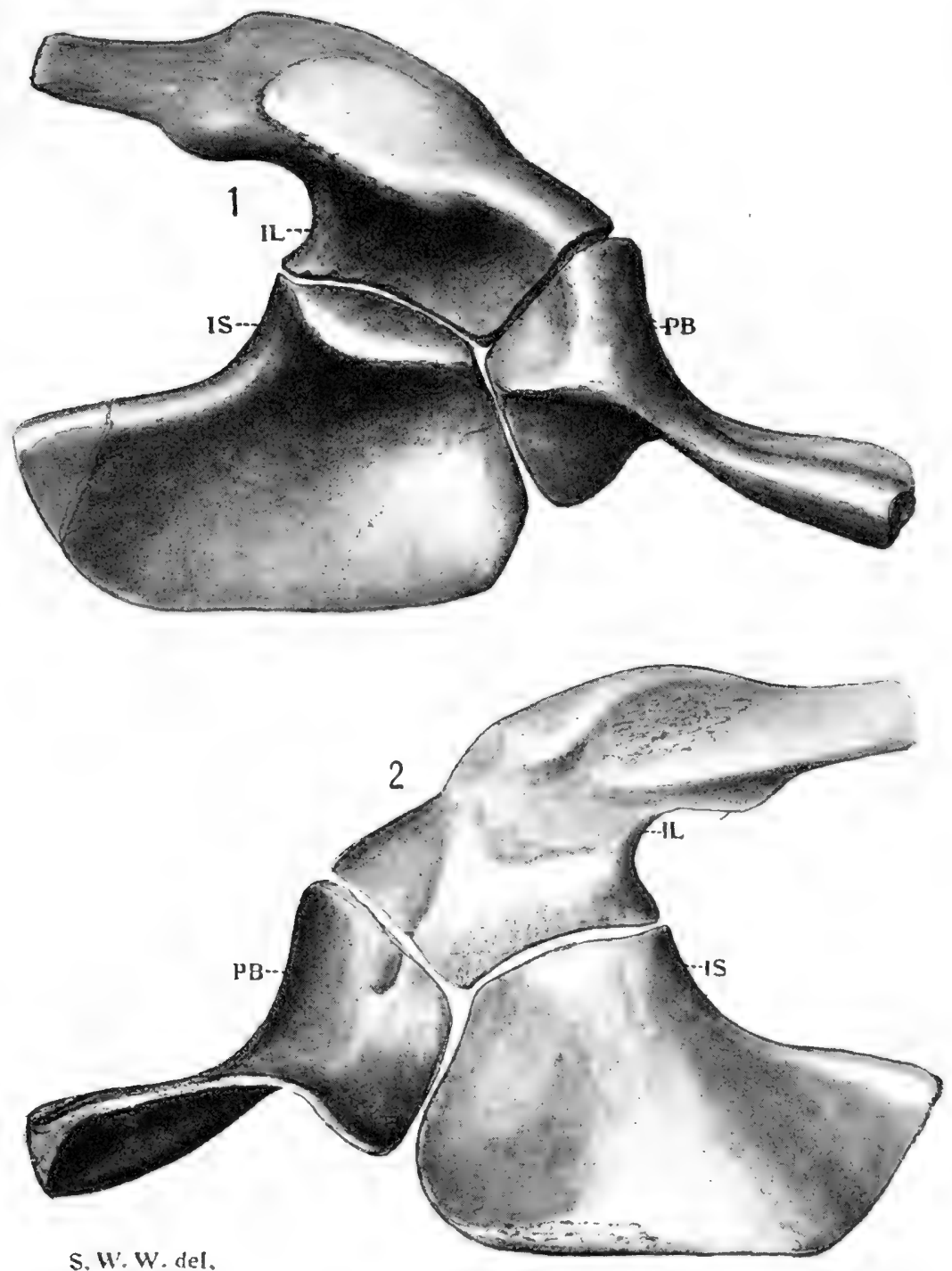

VARANOSAURUS 

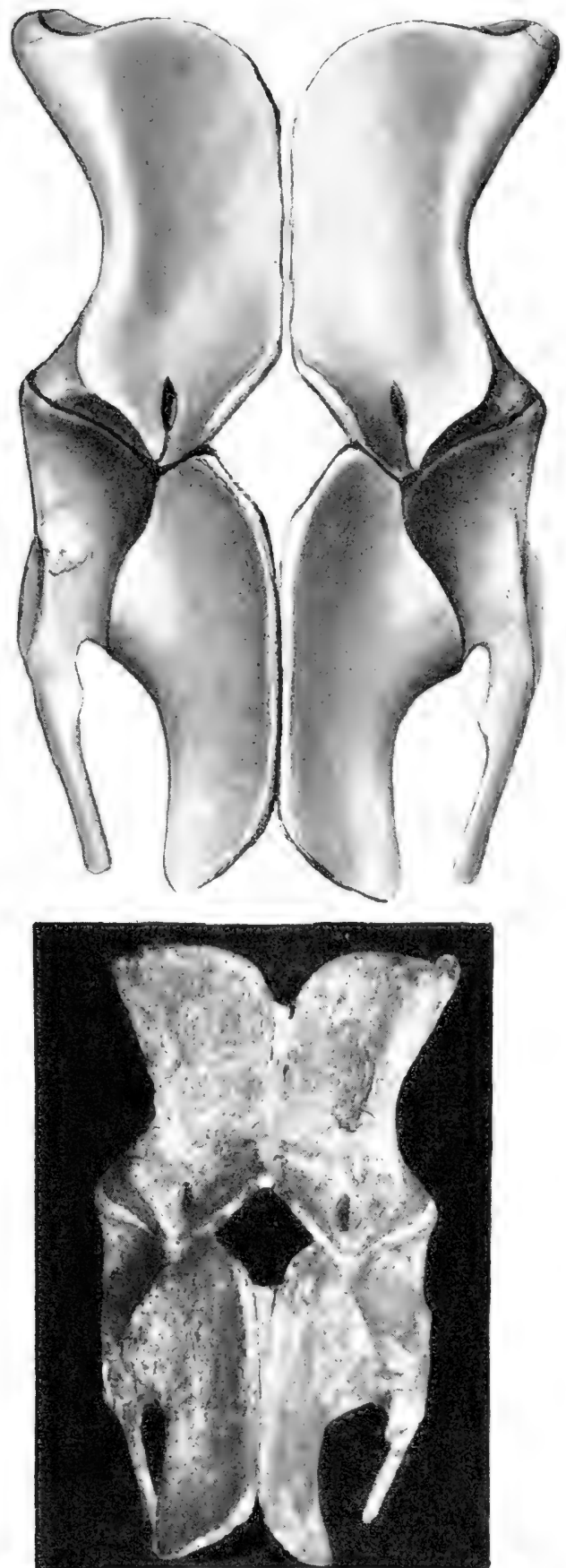

PLATE XI

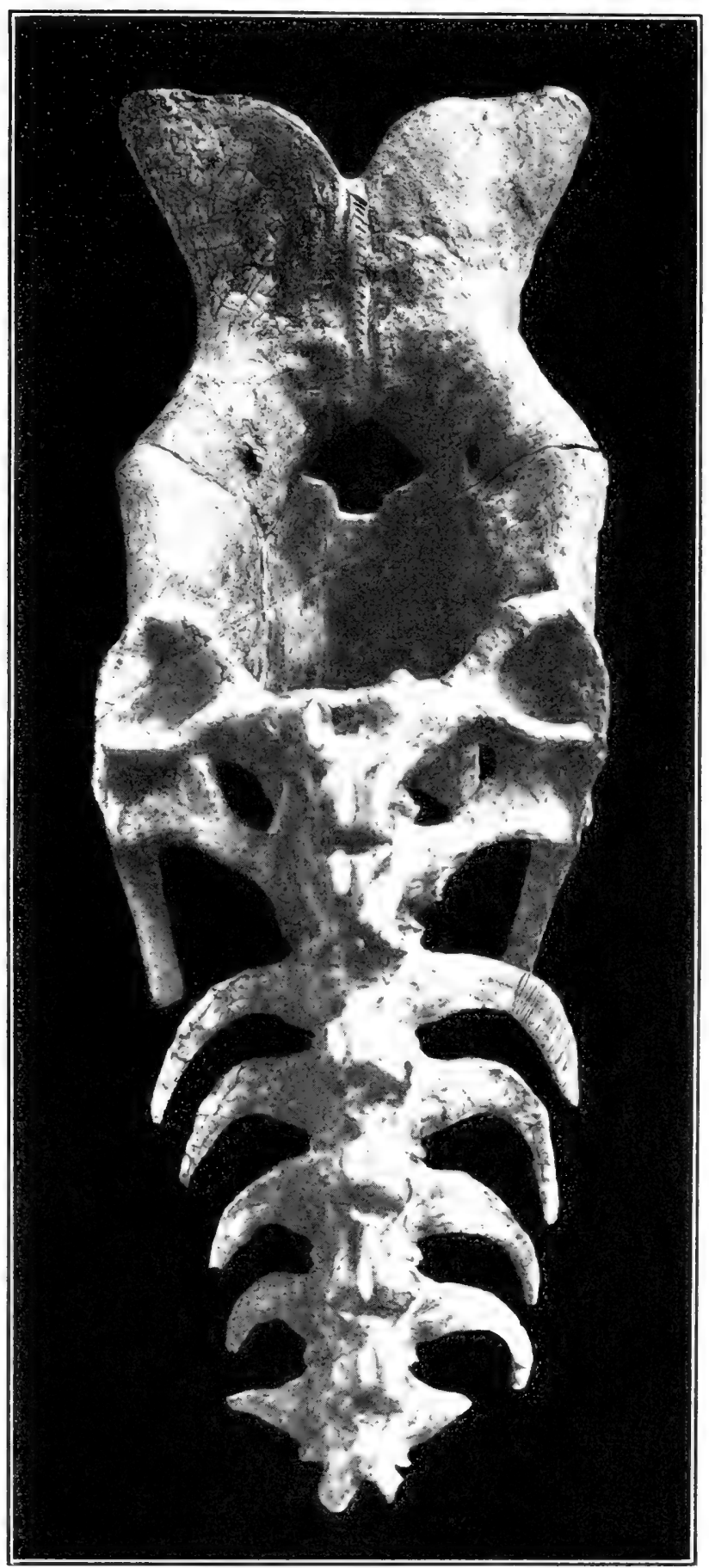

VARANOSALRUS 


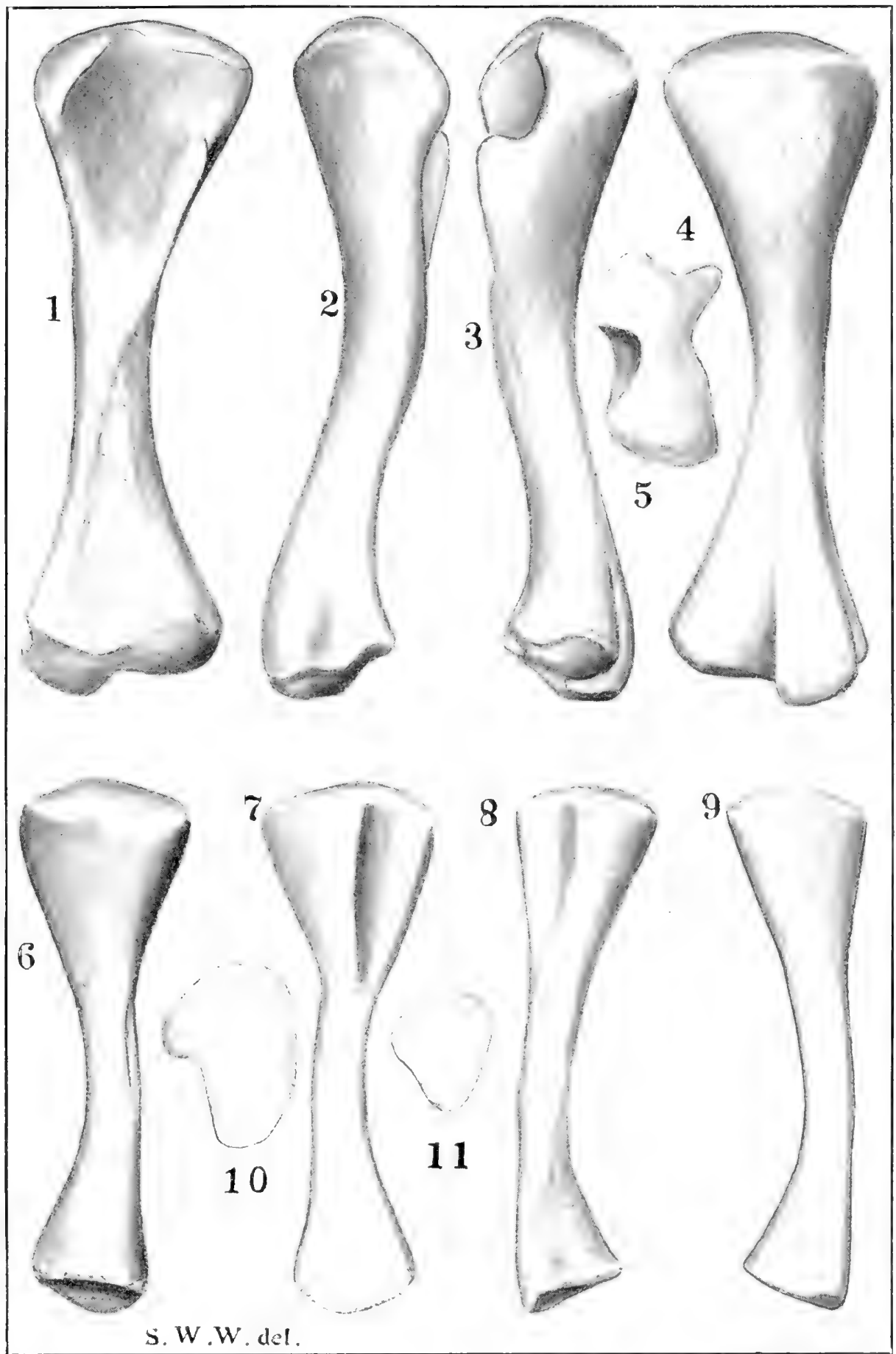



PLATE XIII

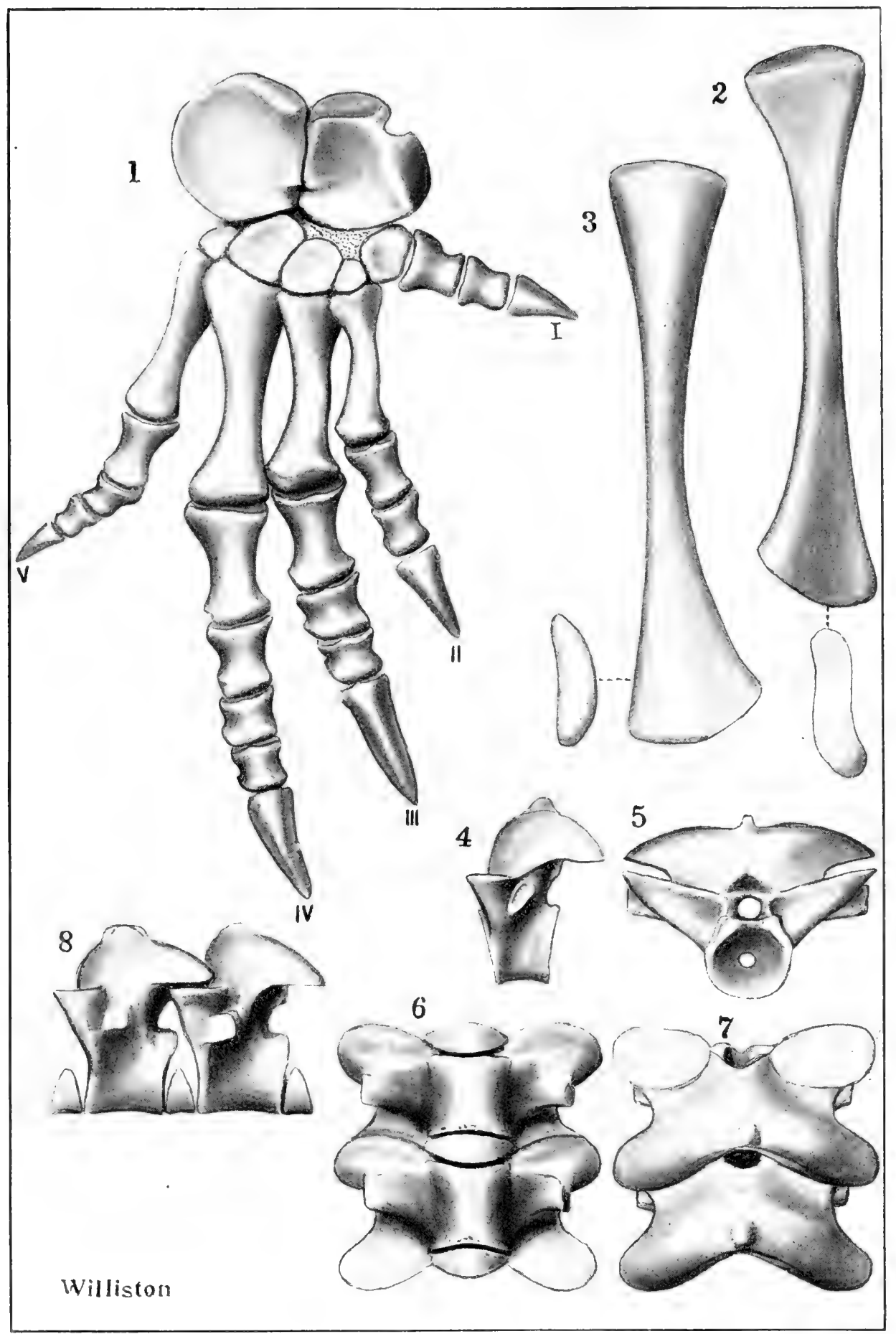





$$
\left.\frac{3}{\Lambda}\right\}
$$





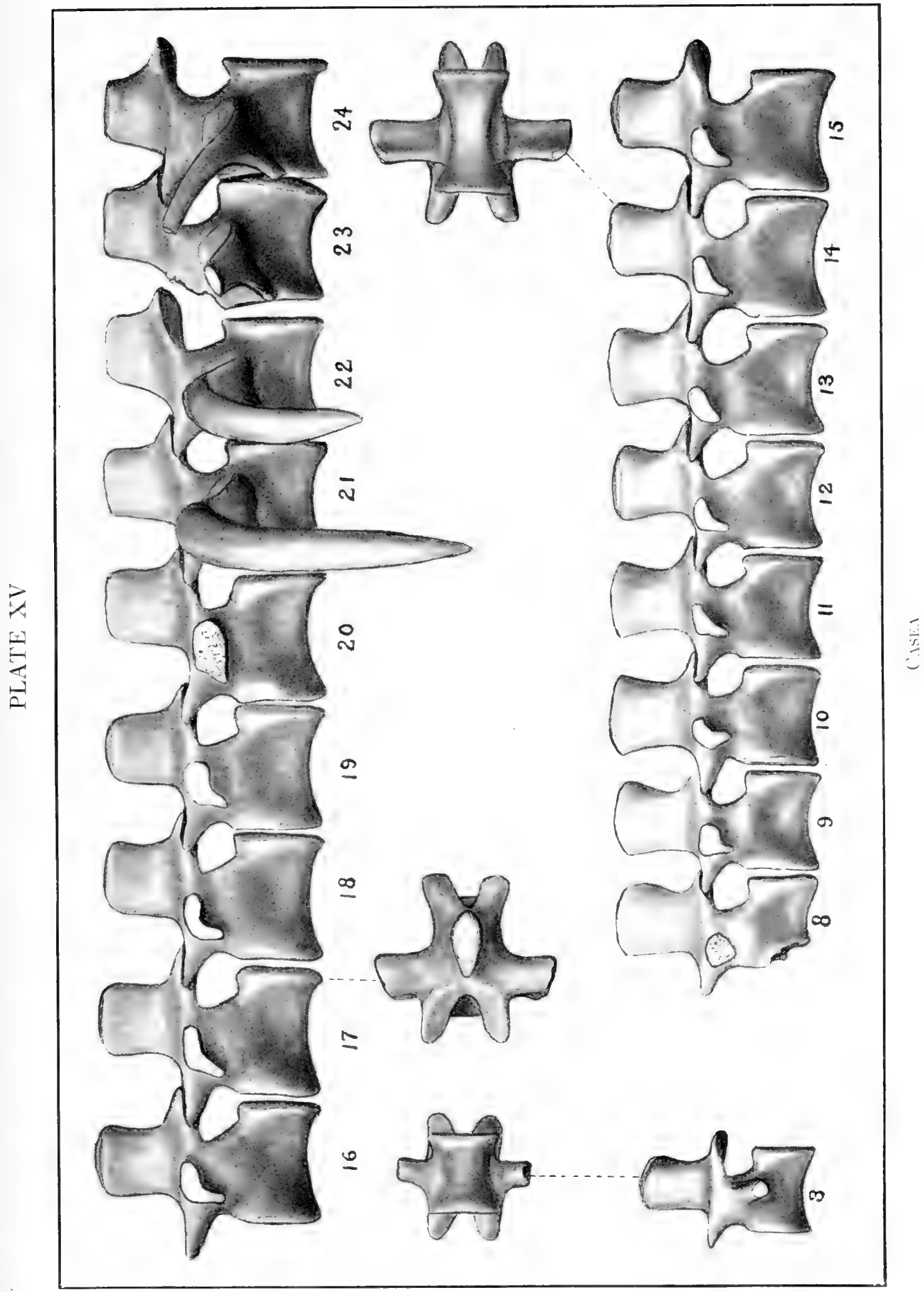


. 



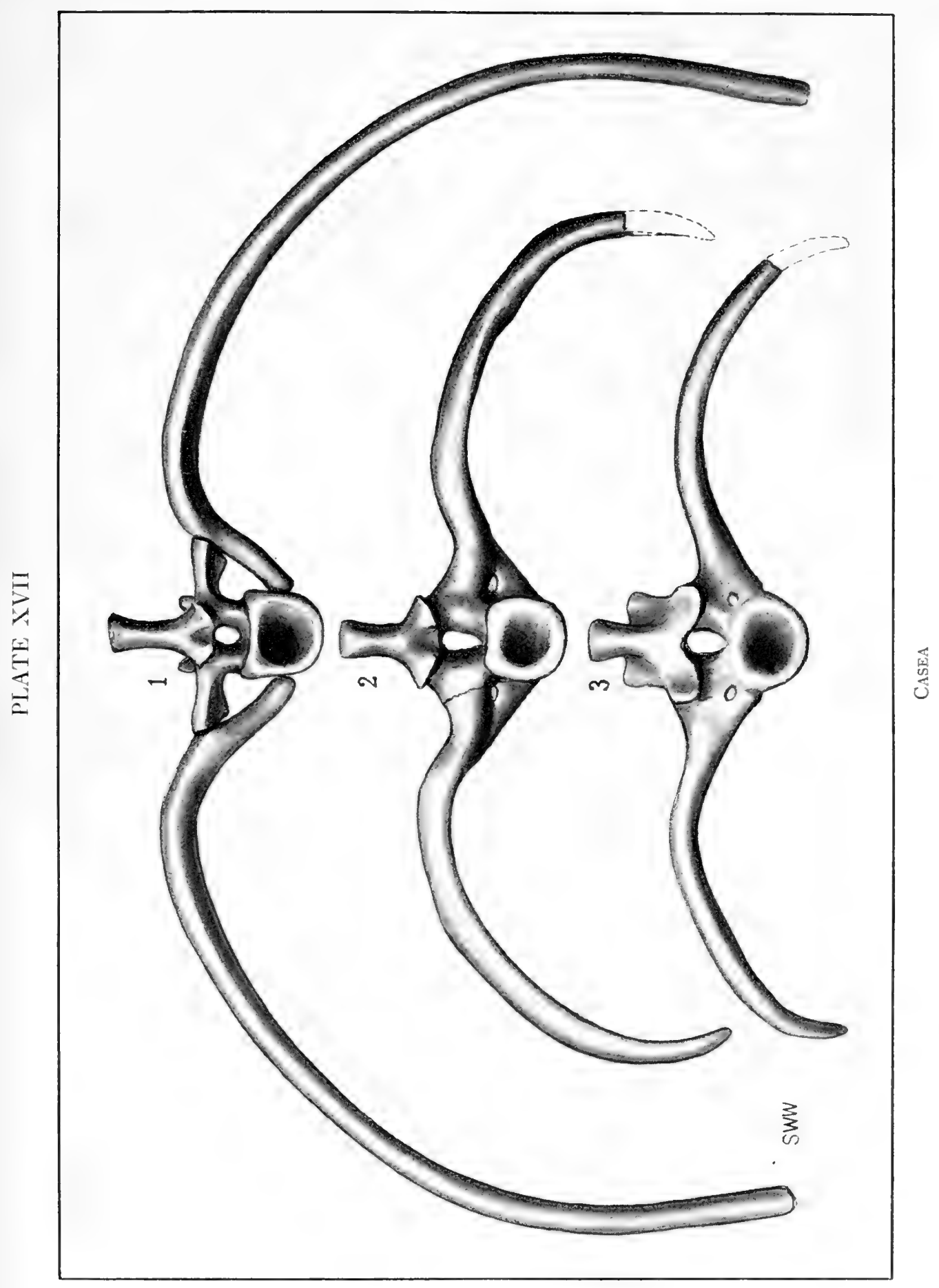


. 
PLATE XVIII

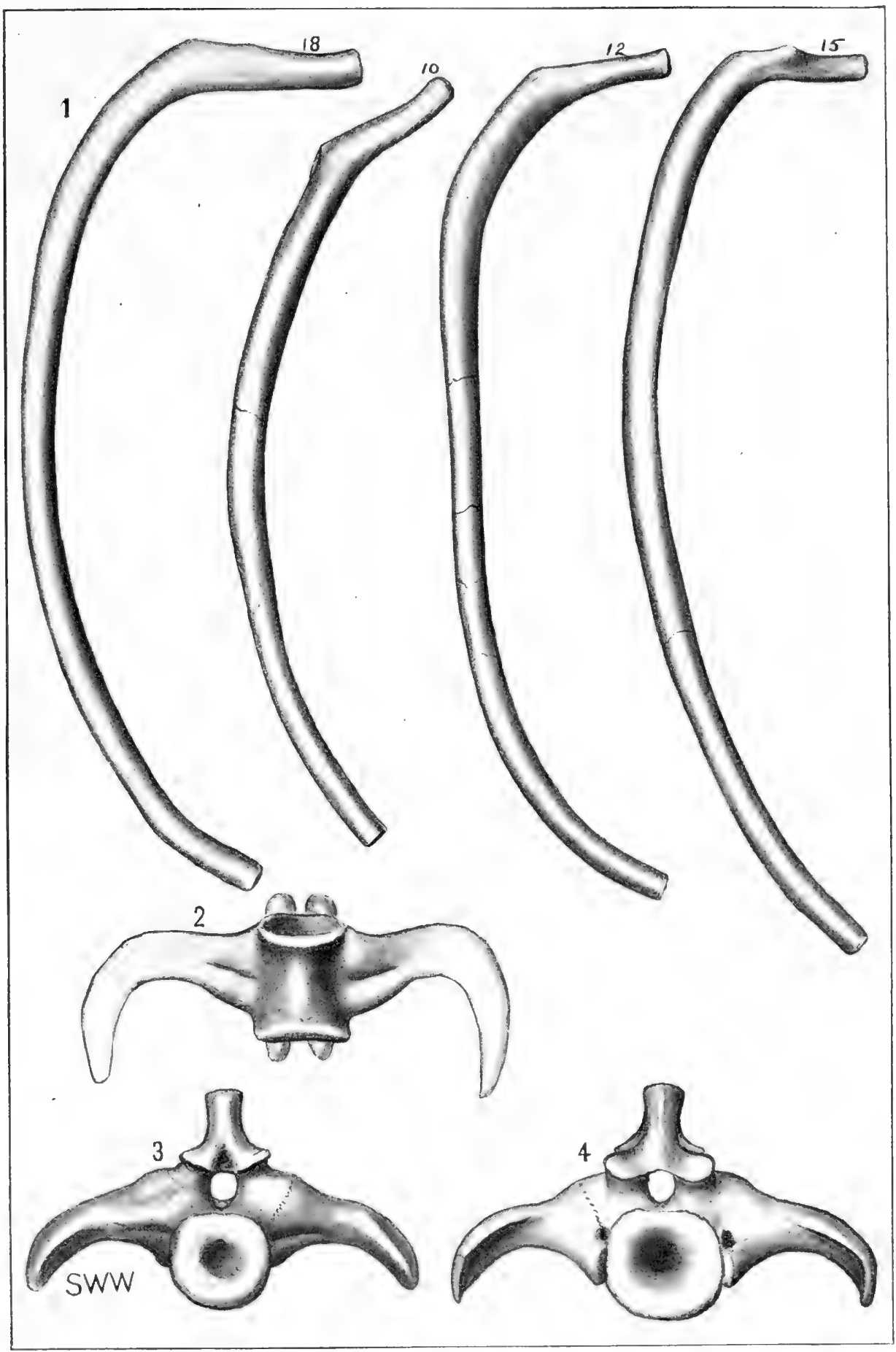



PLATE XIX
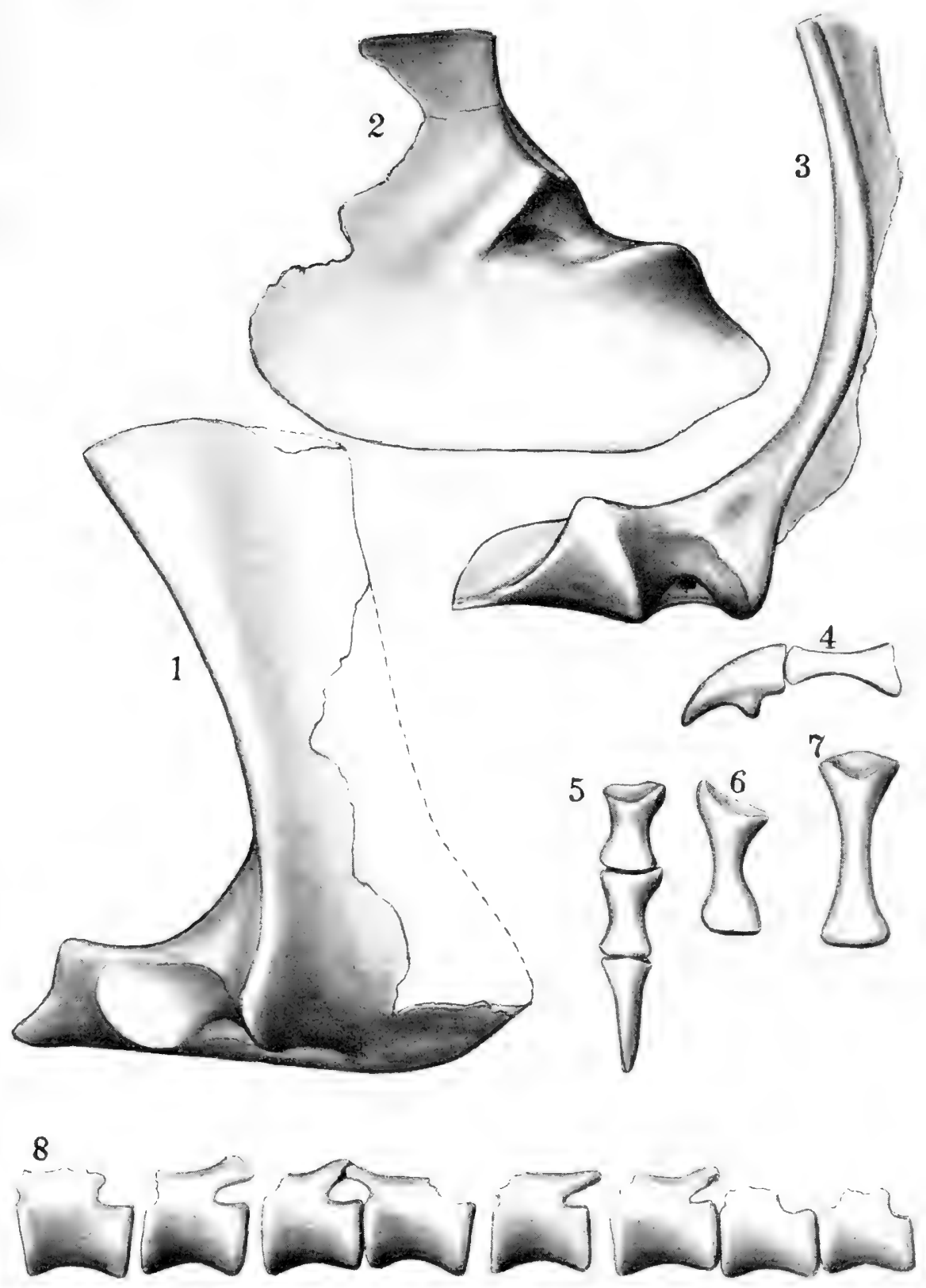

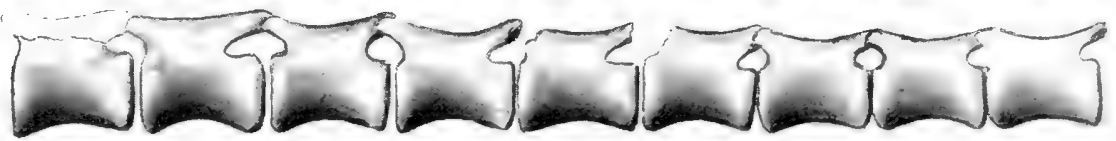



PLATE XX

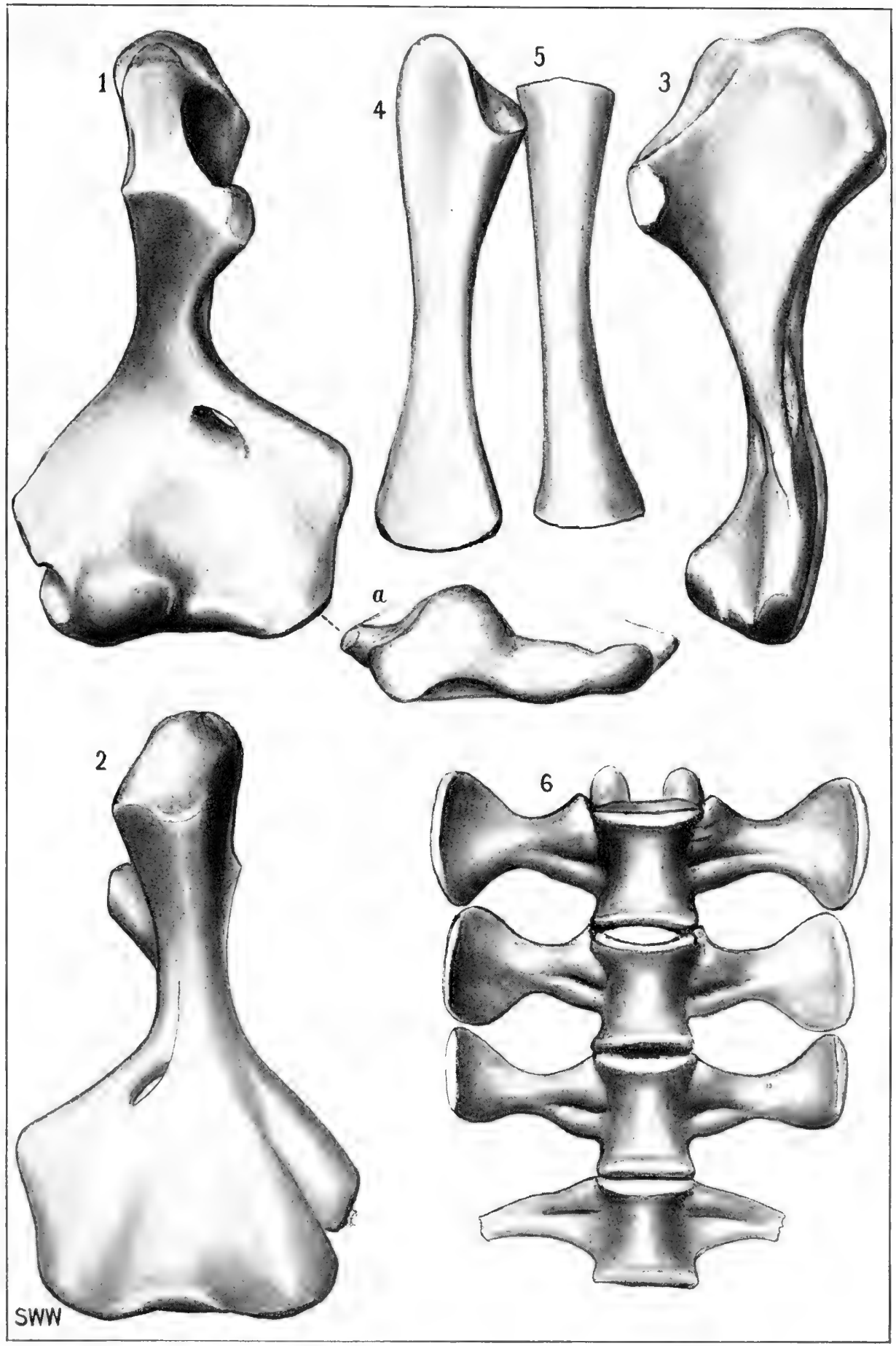


PLATE XXI

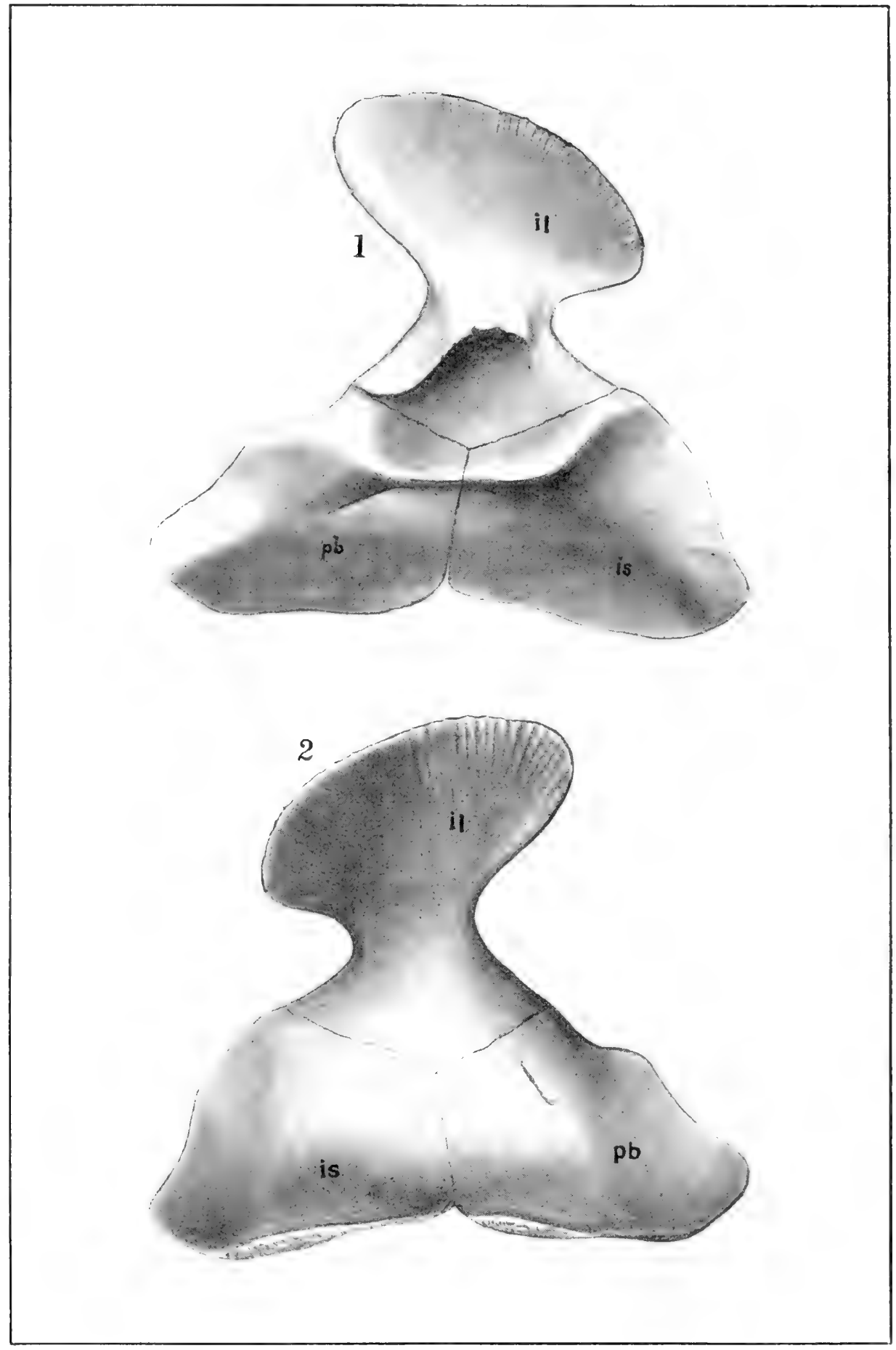

Ciset 


$$
\text { . }
$$




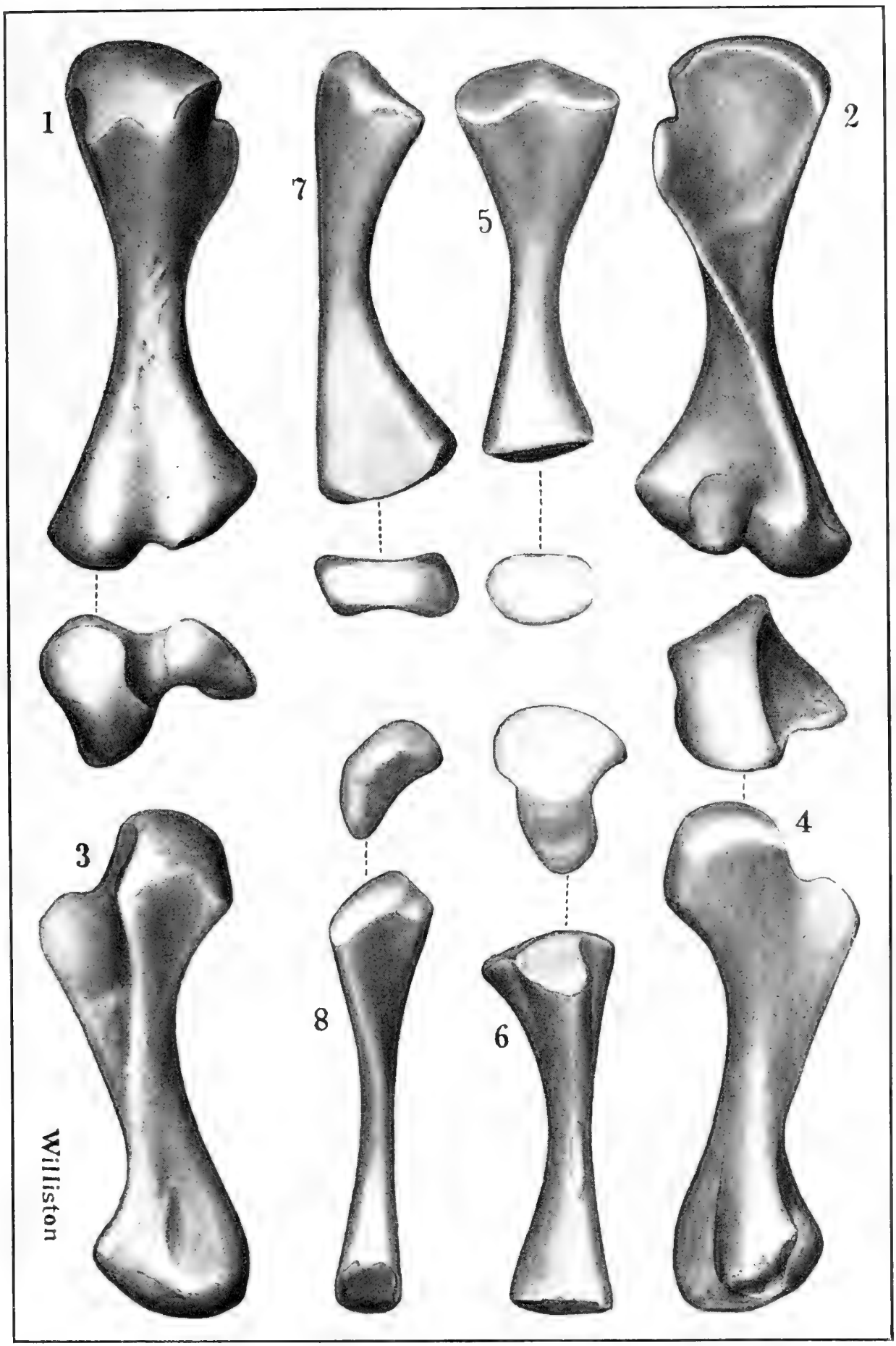




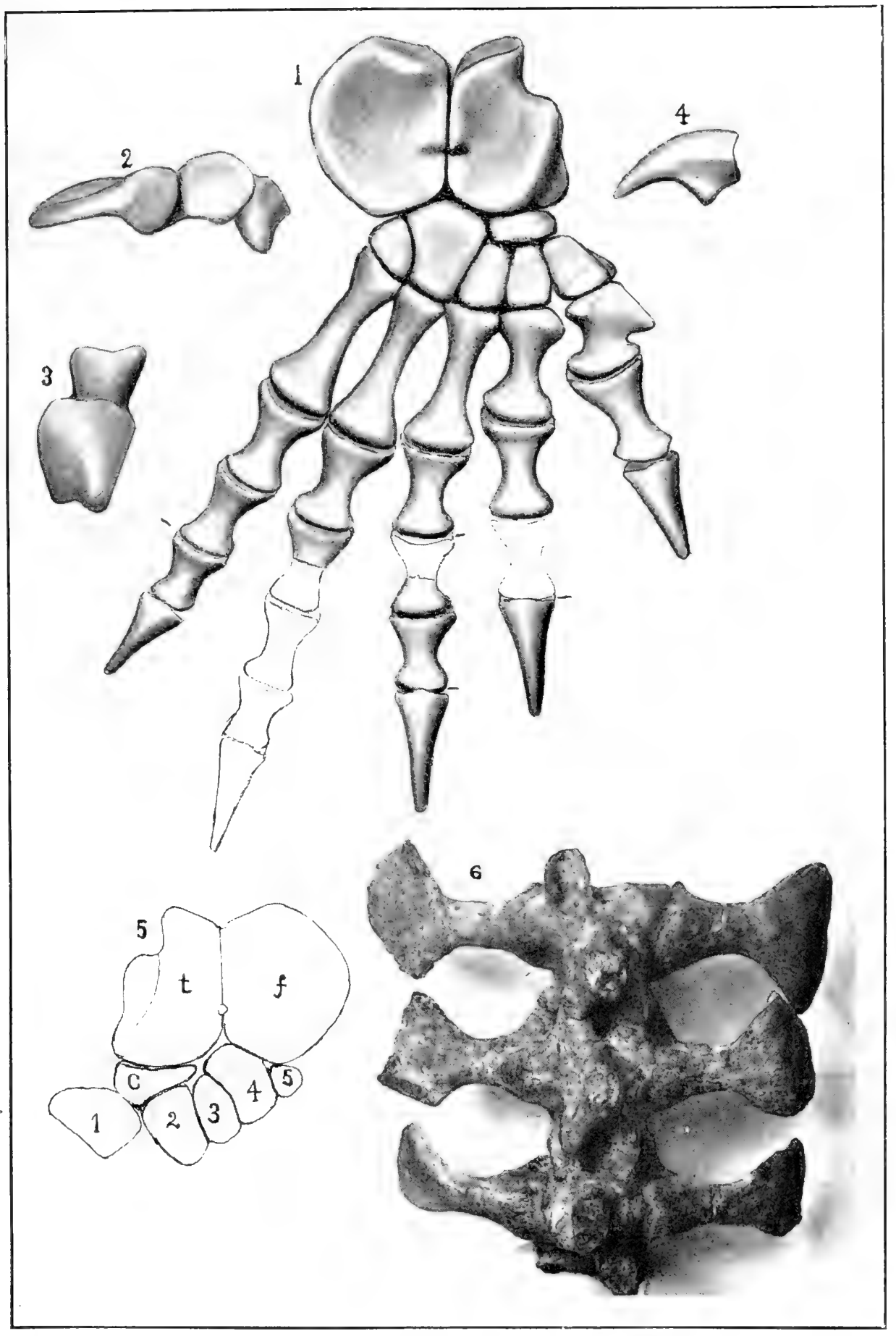


PLATE XXIV

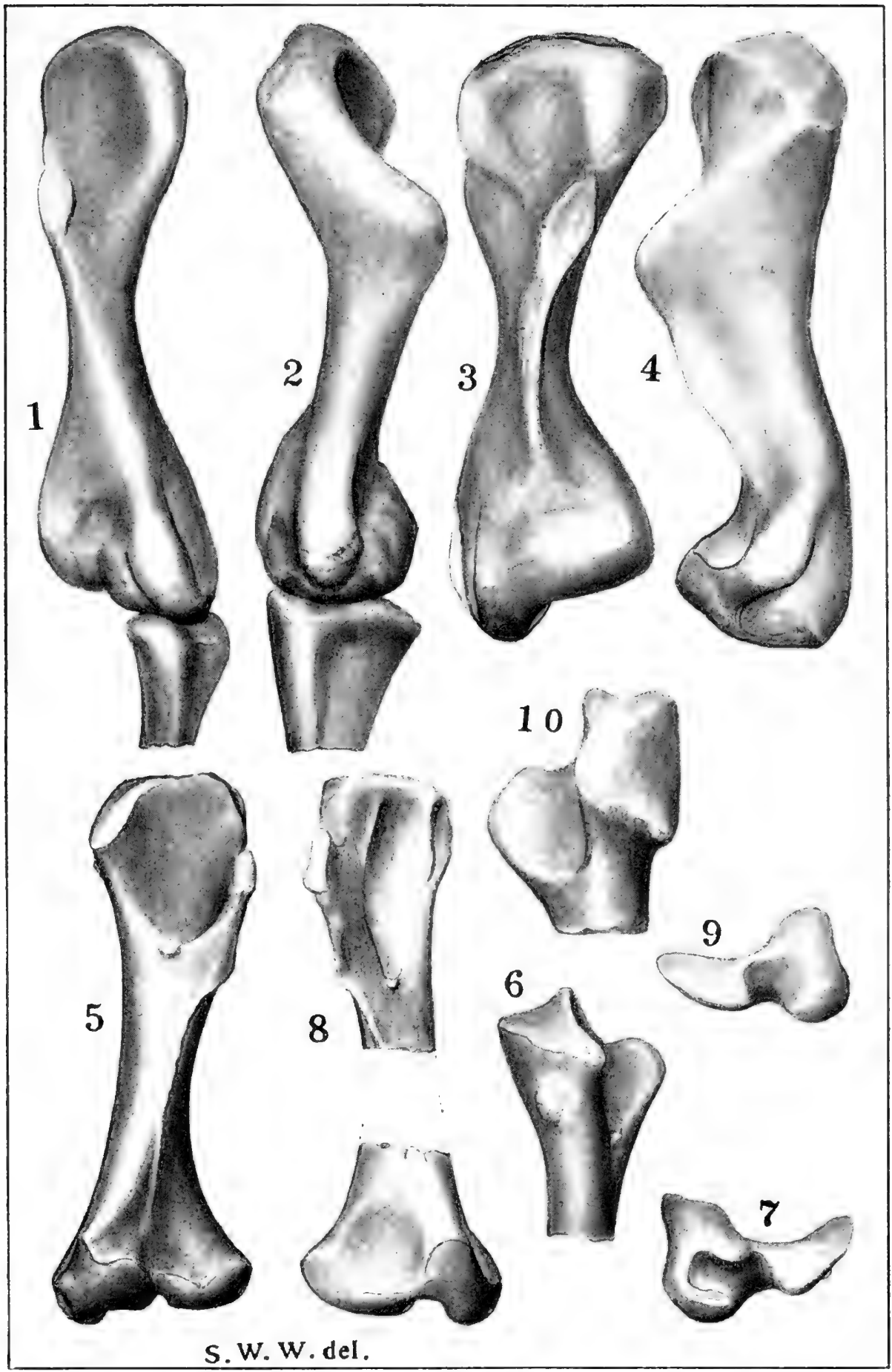

TRISPONDYIJS, CAPTORHINTS 


\section{.}


PLATE XXV

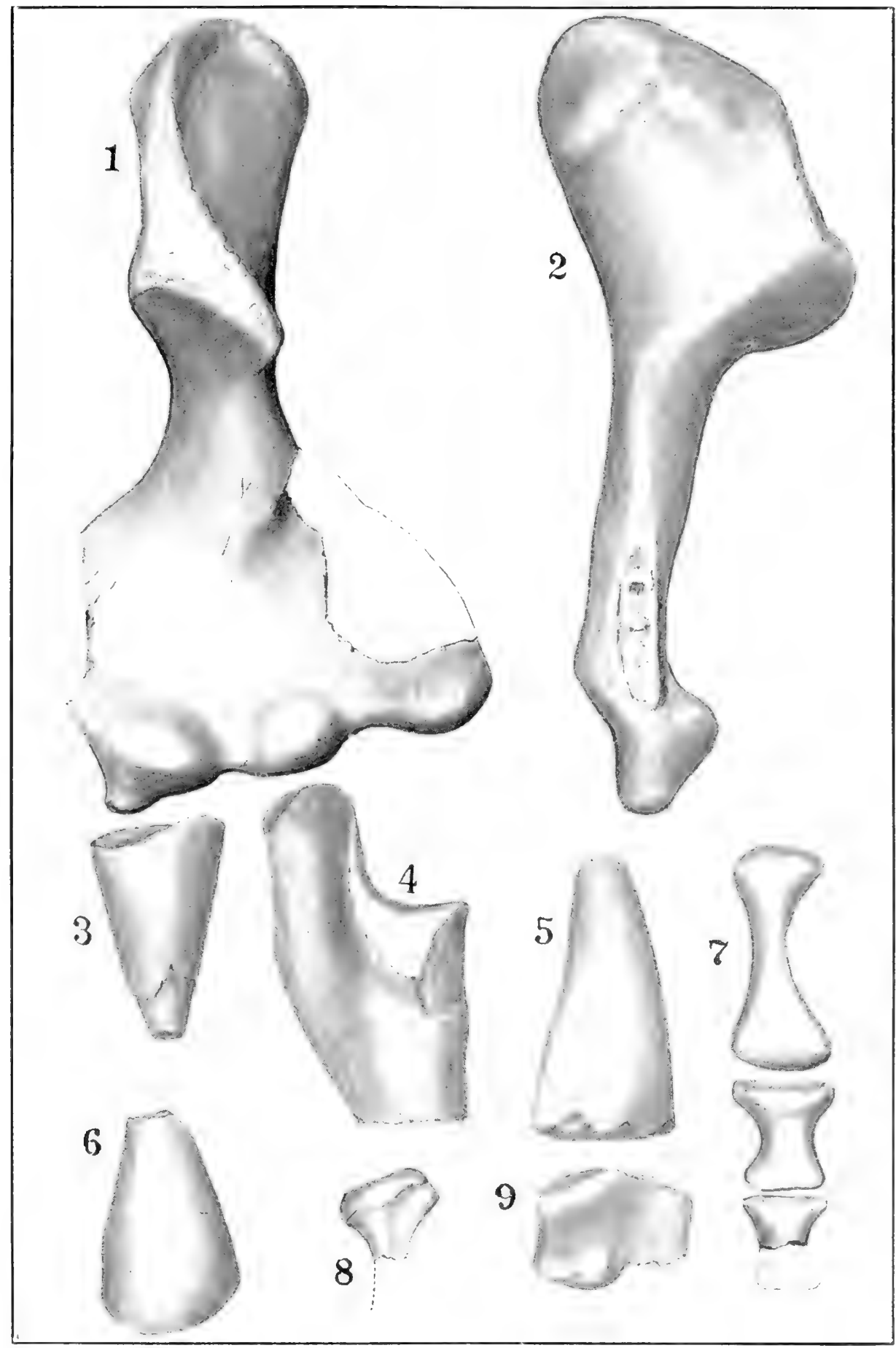

TRISPONDYLUS 


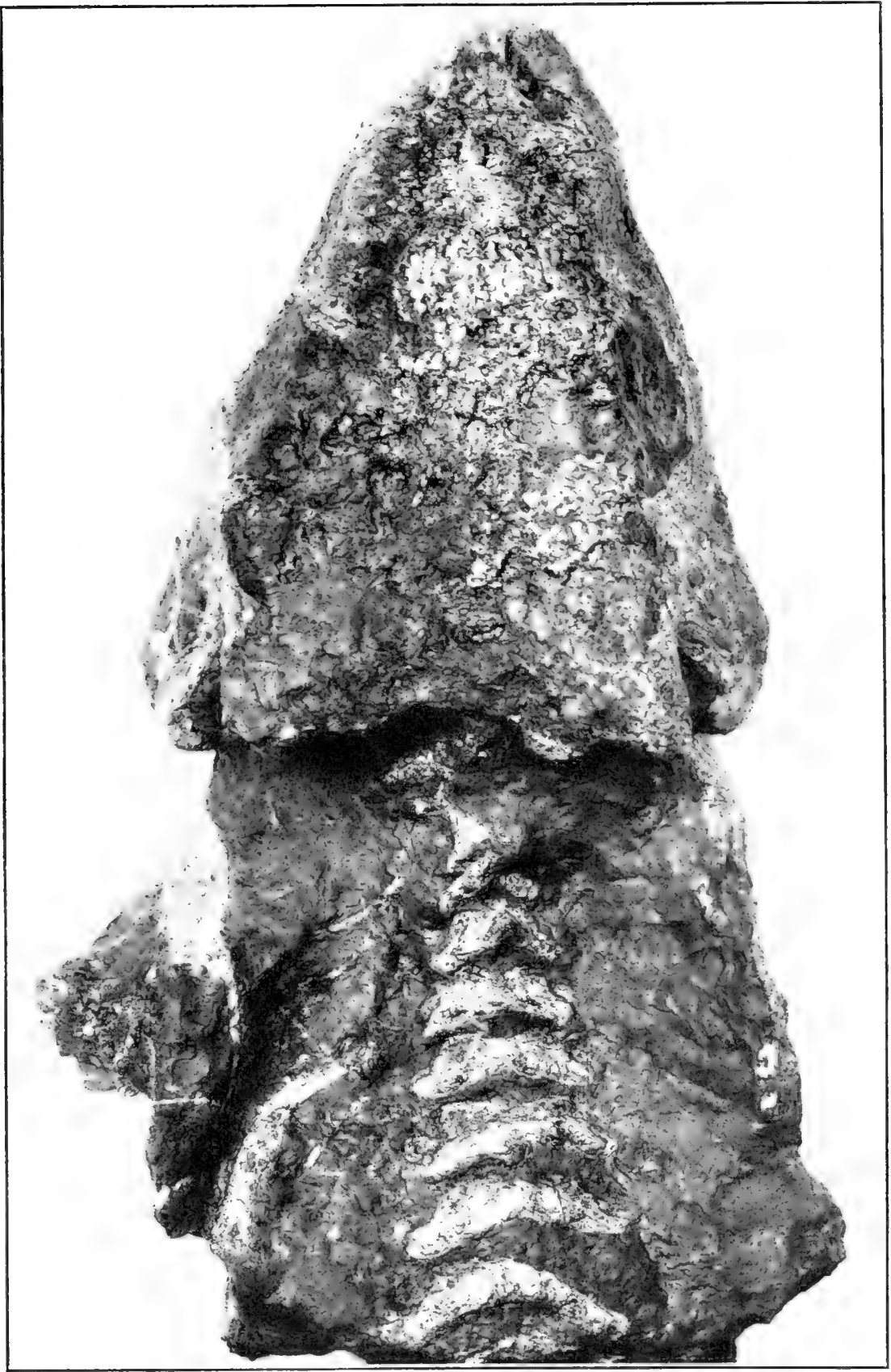

SiYMOTRIA 


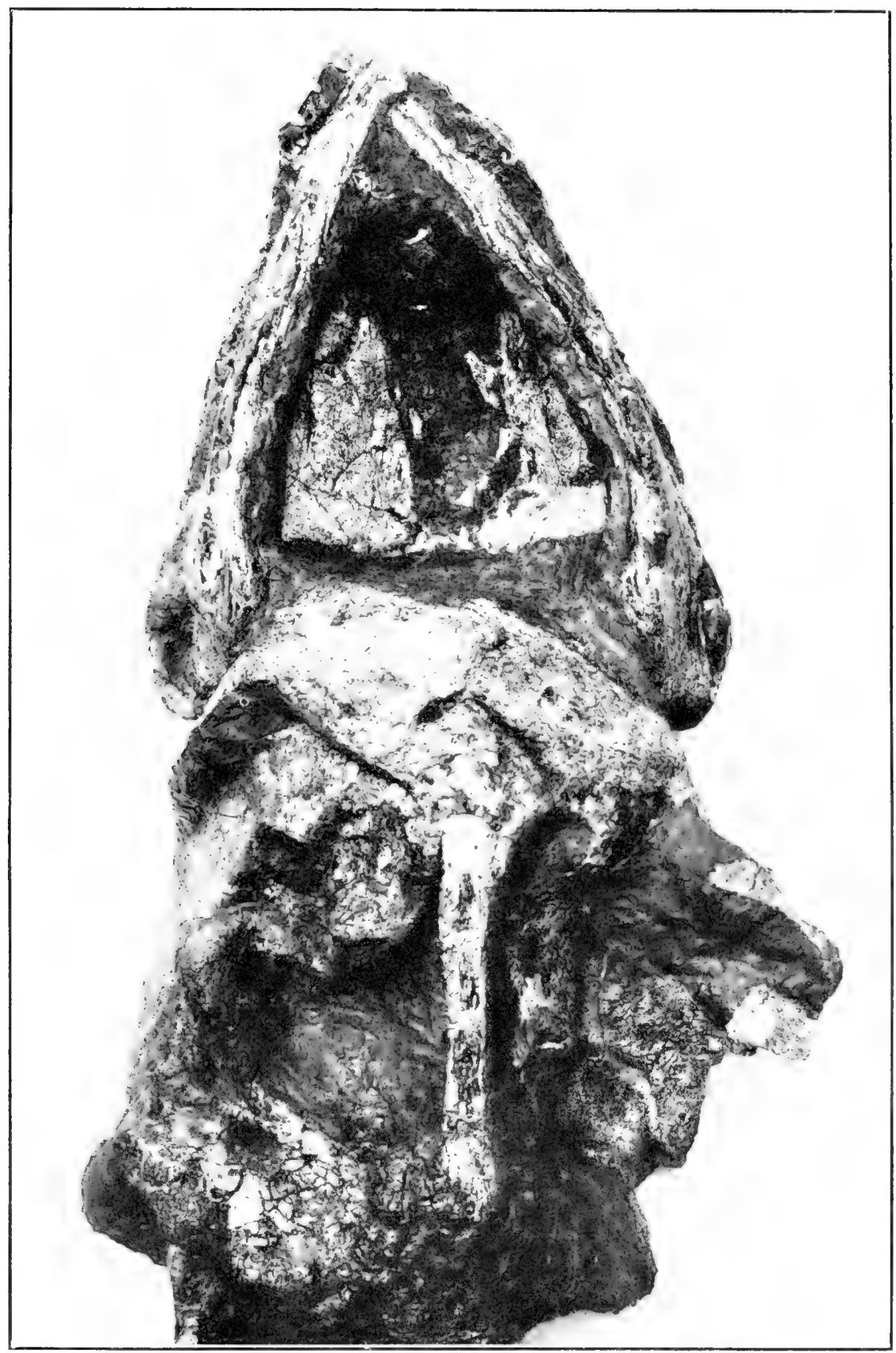

Seymouria 


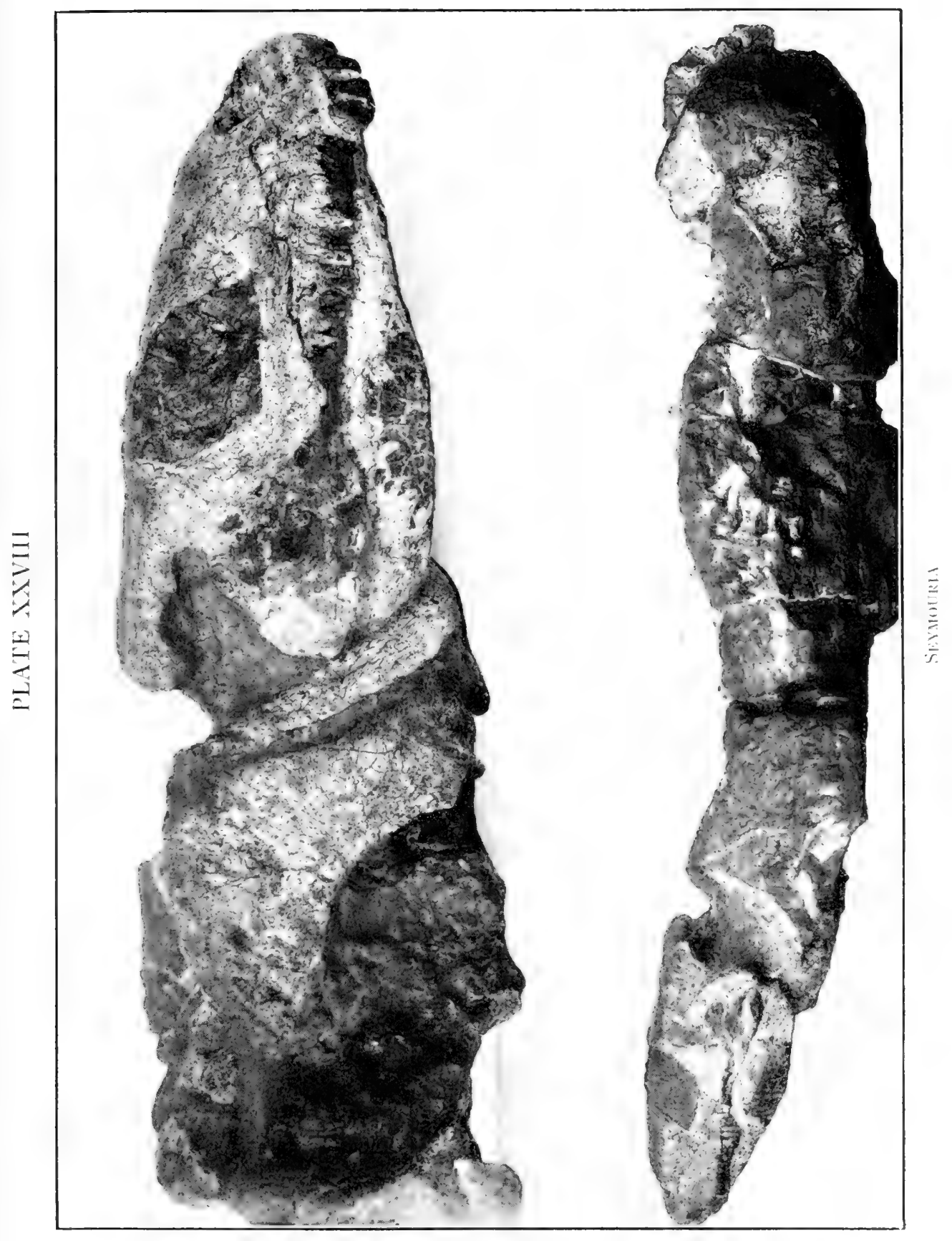




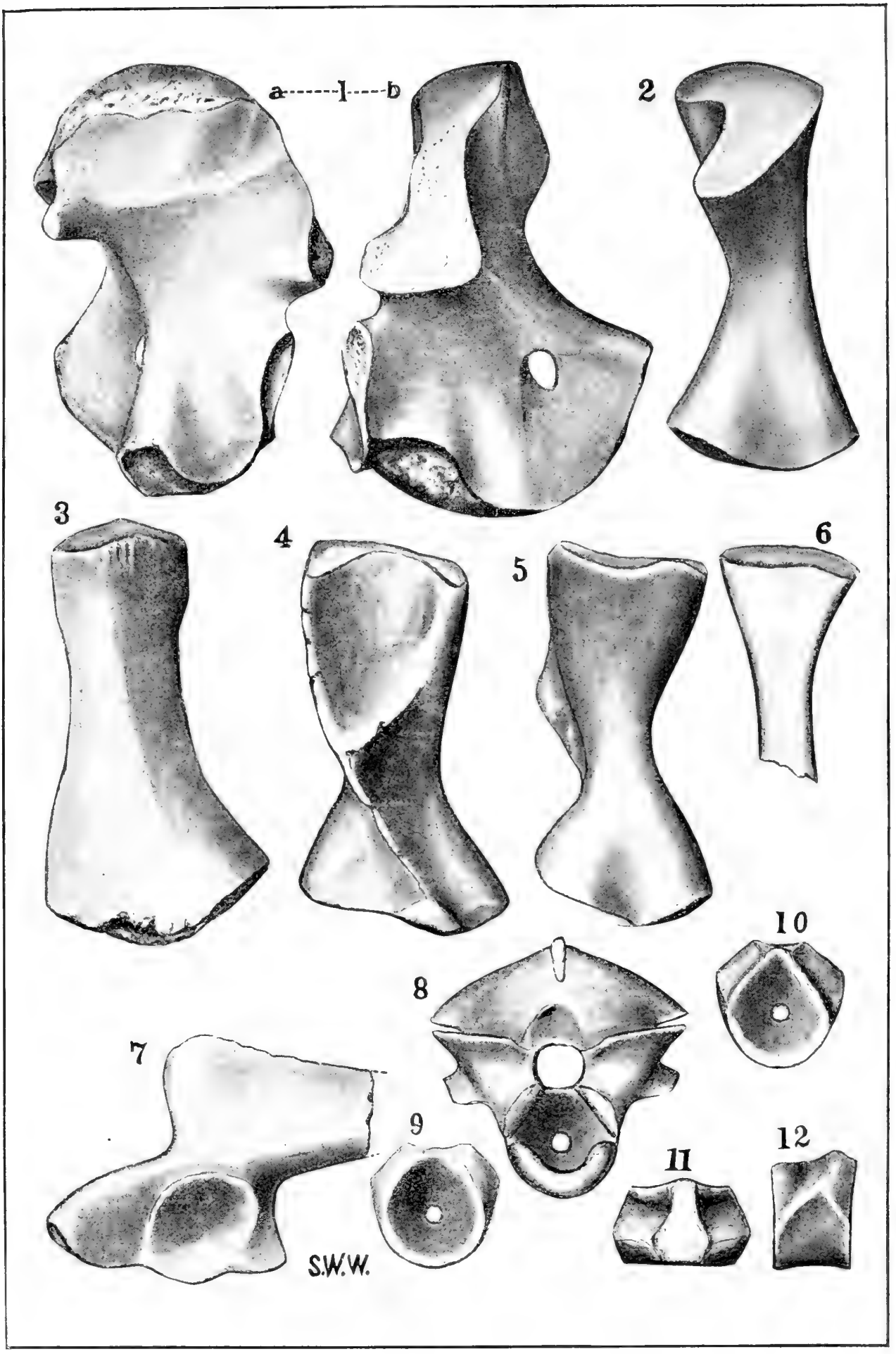


PLATE XXX

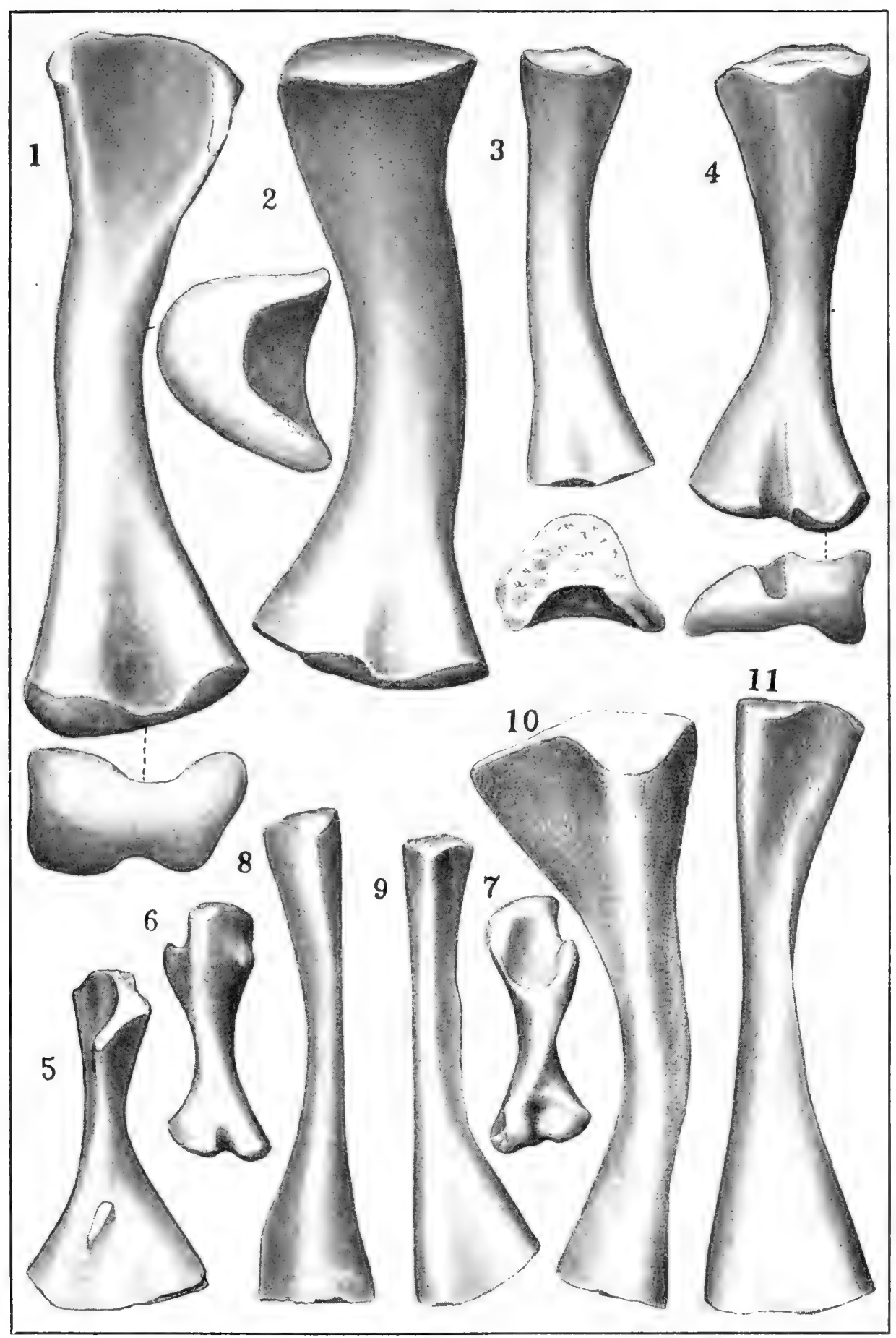

Clepstidrops 


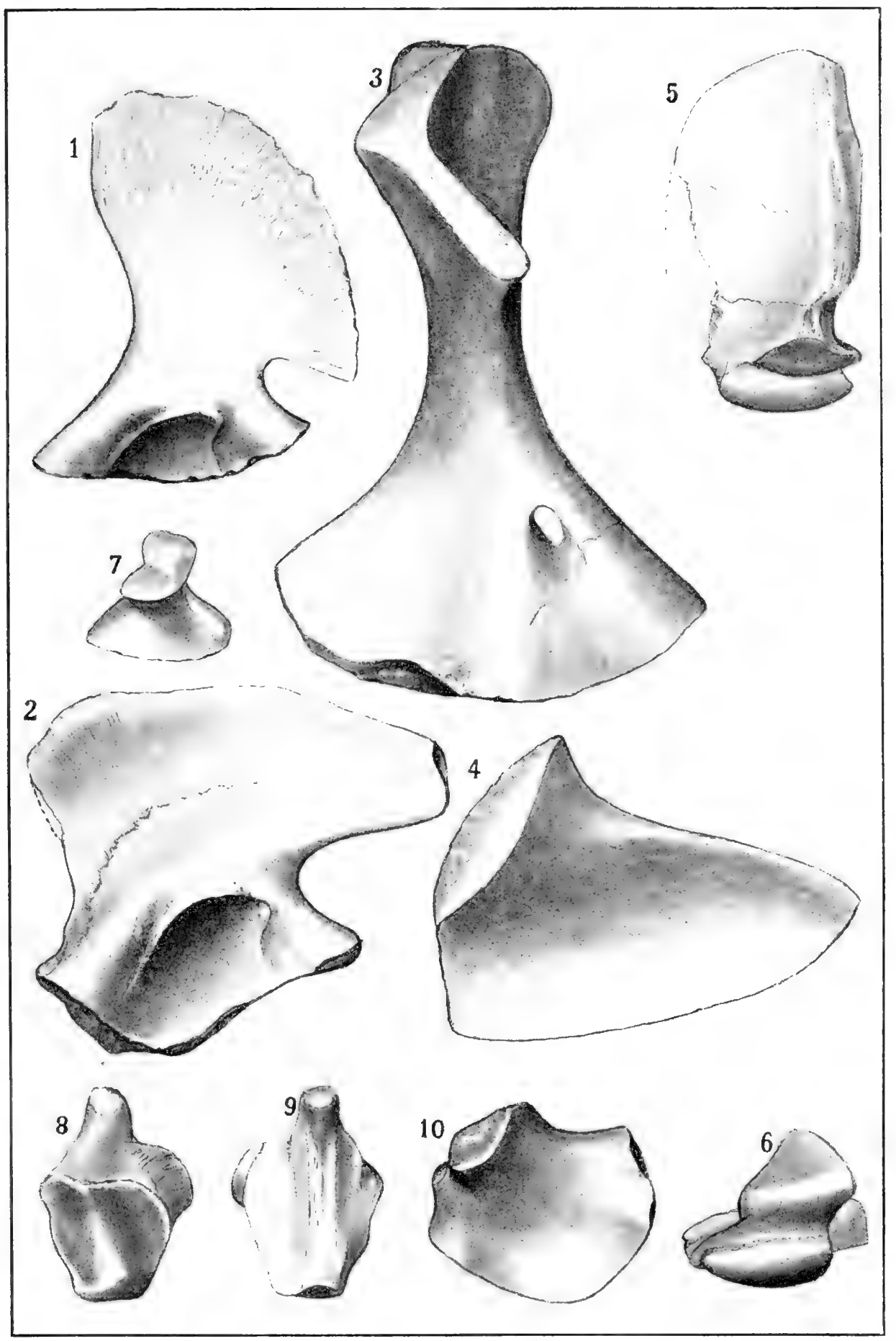

Clepstarops 


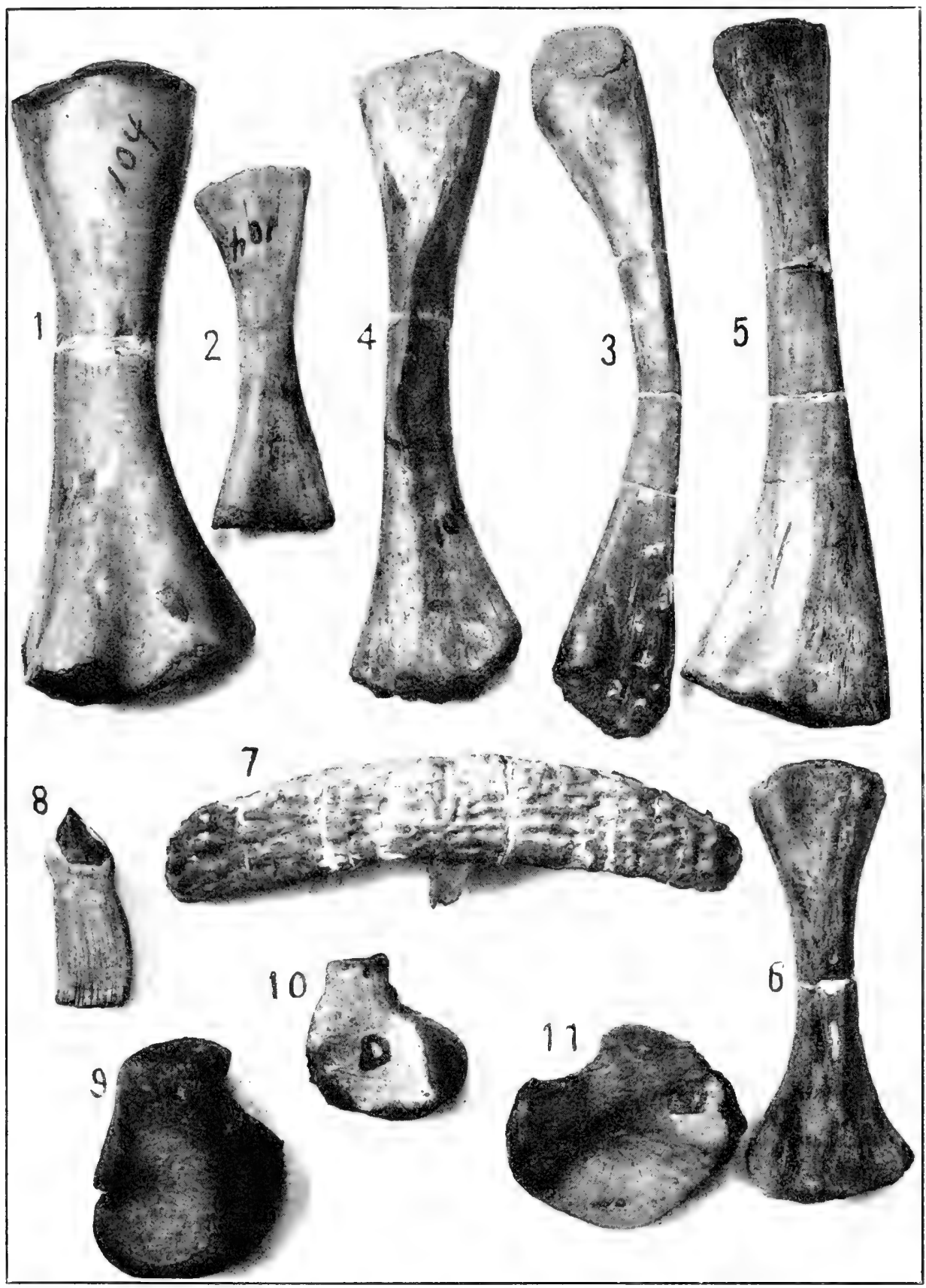

Cr.ADdock Bone-BeD 
PLATE XXXIII

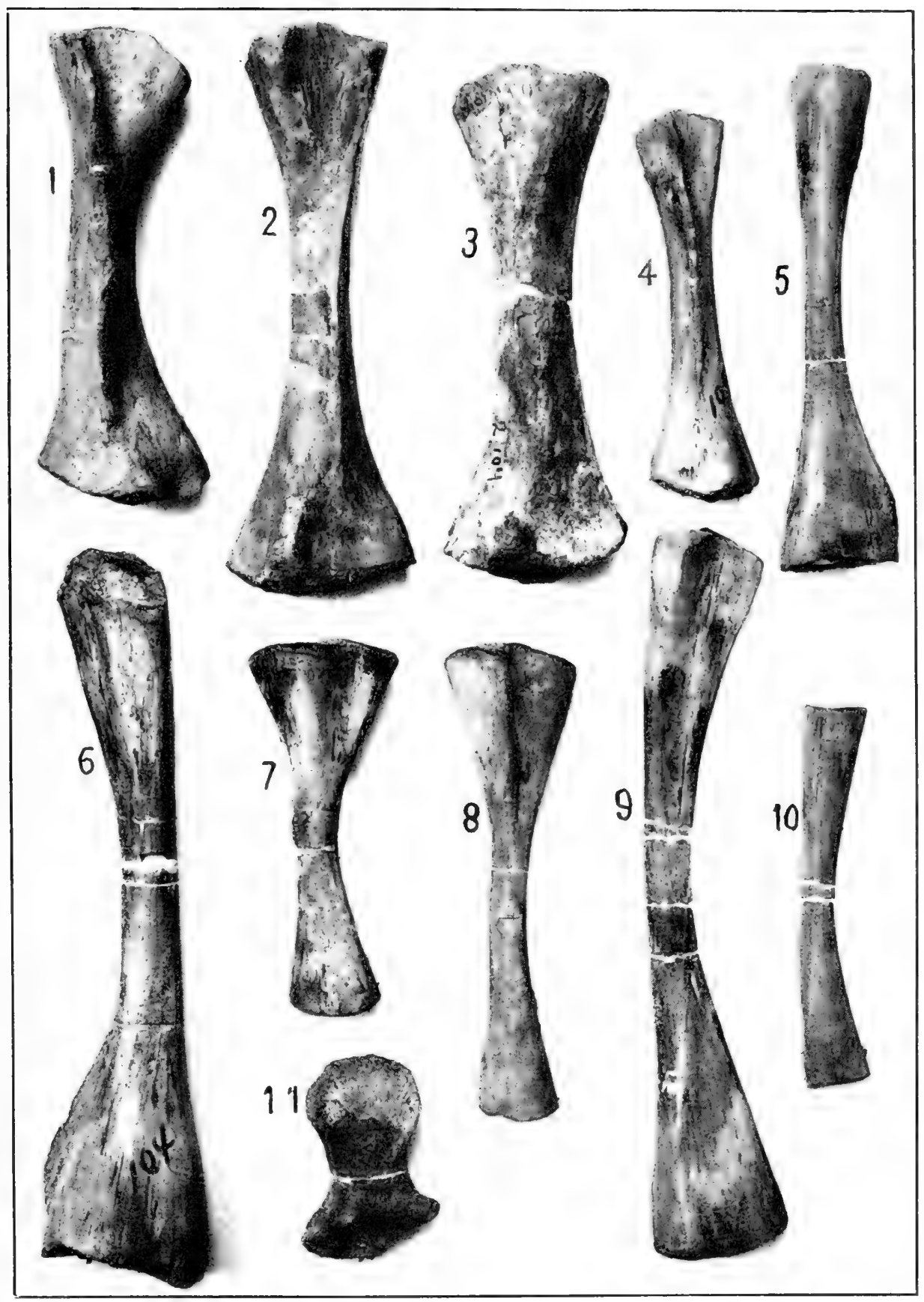

CRADDOCK BONE-BED 


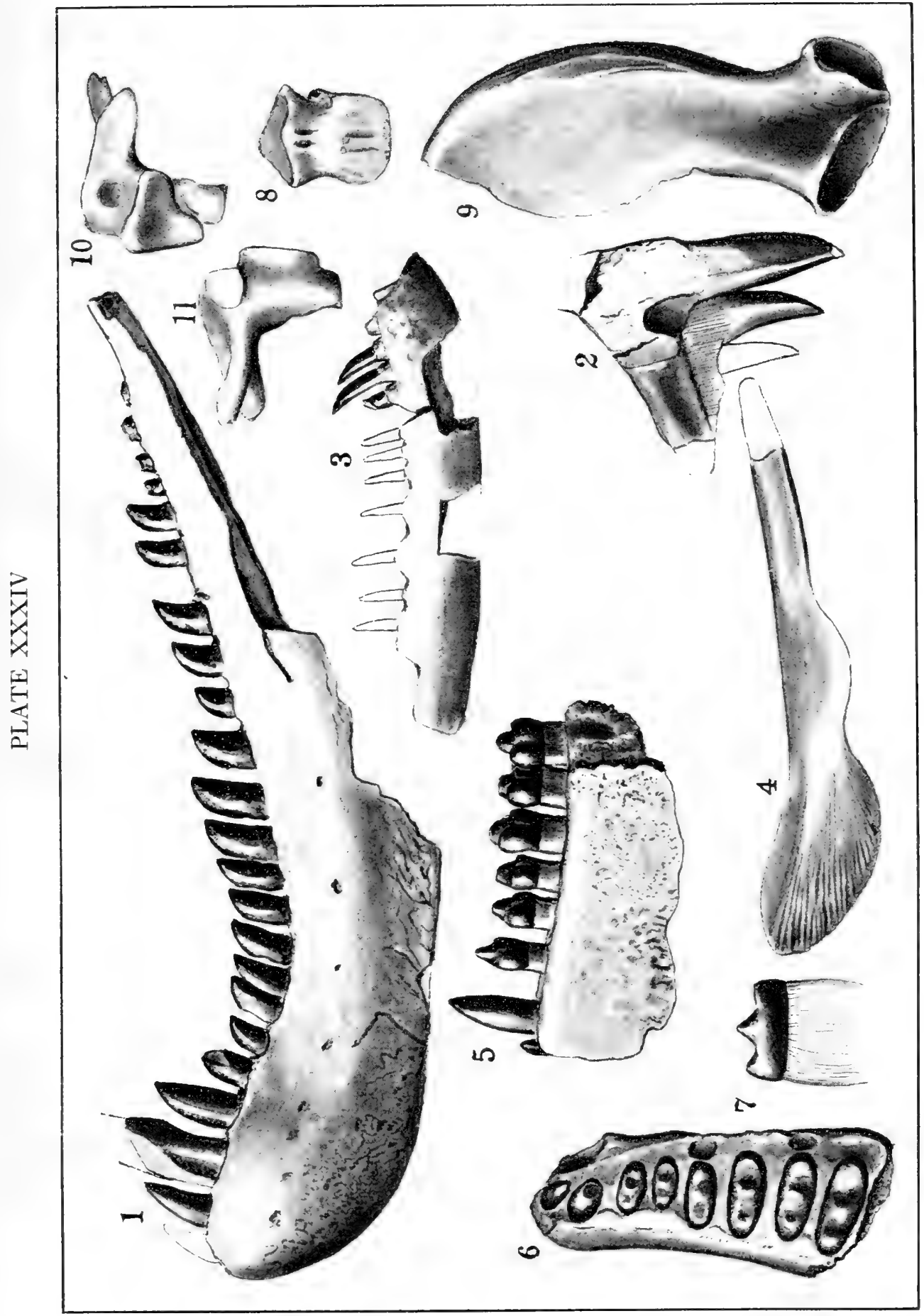

2⿱ 
PLATE XXXY

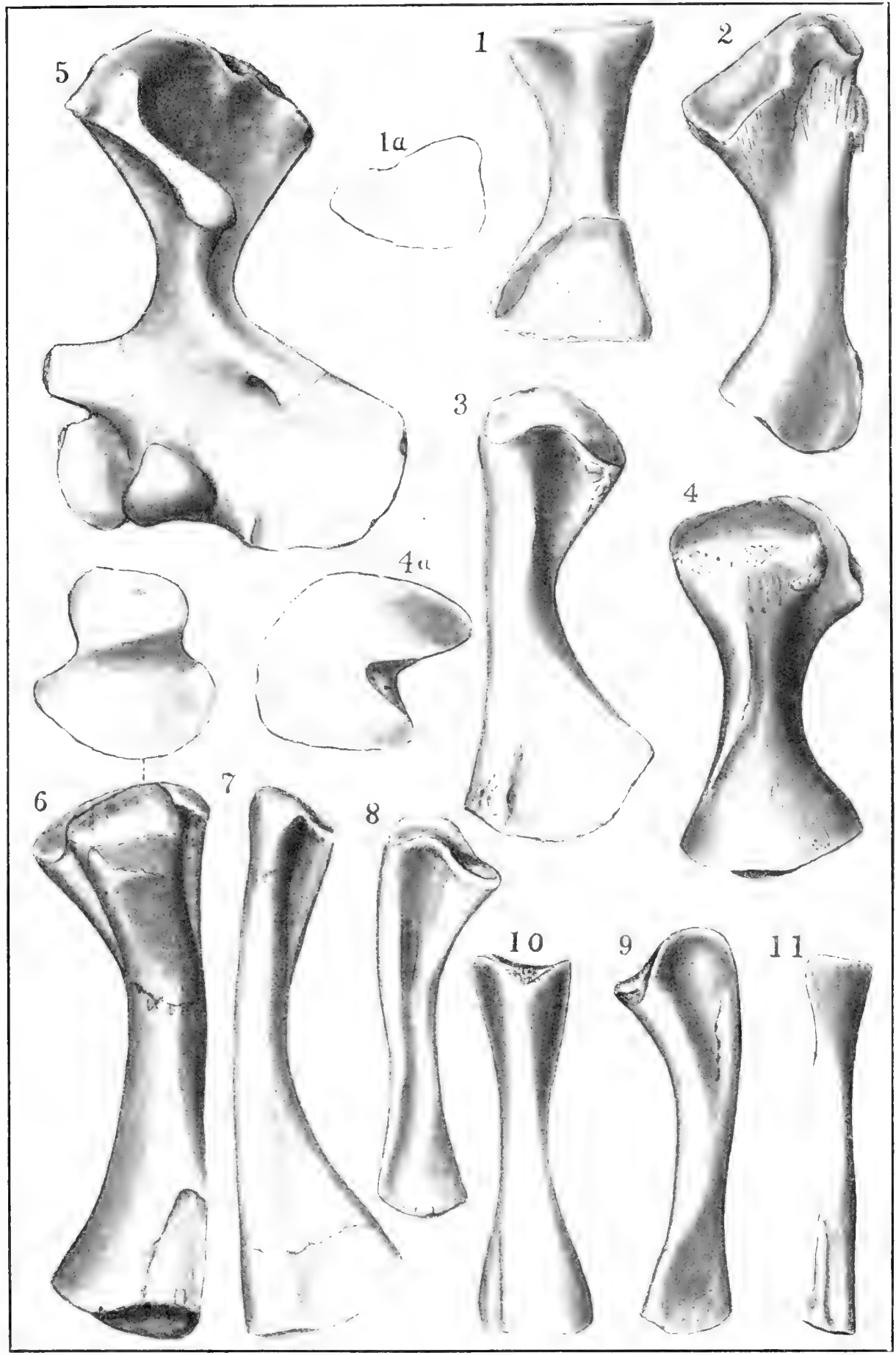


. 
PLATE XXXVI

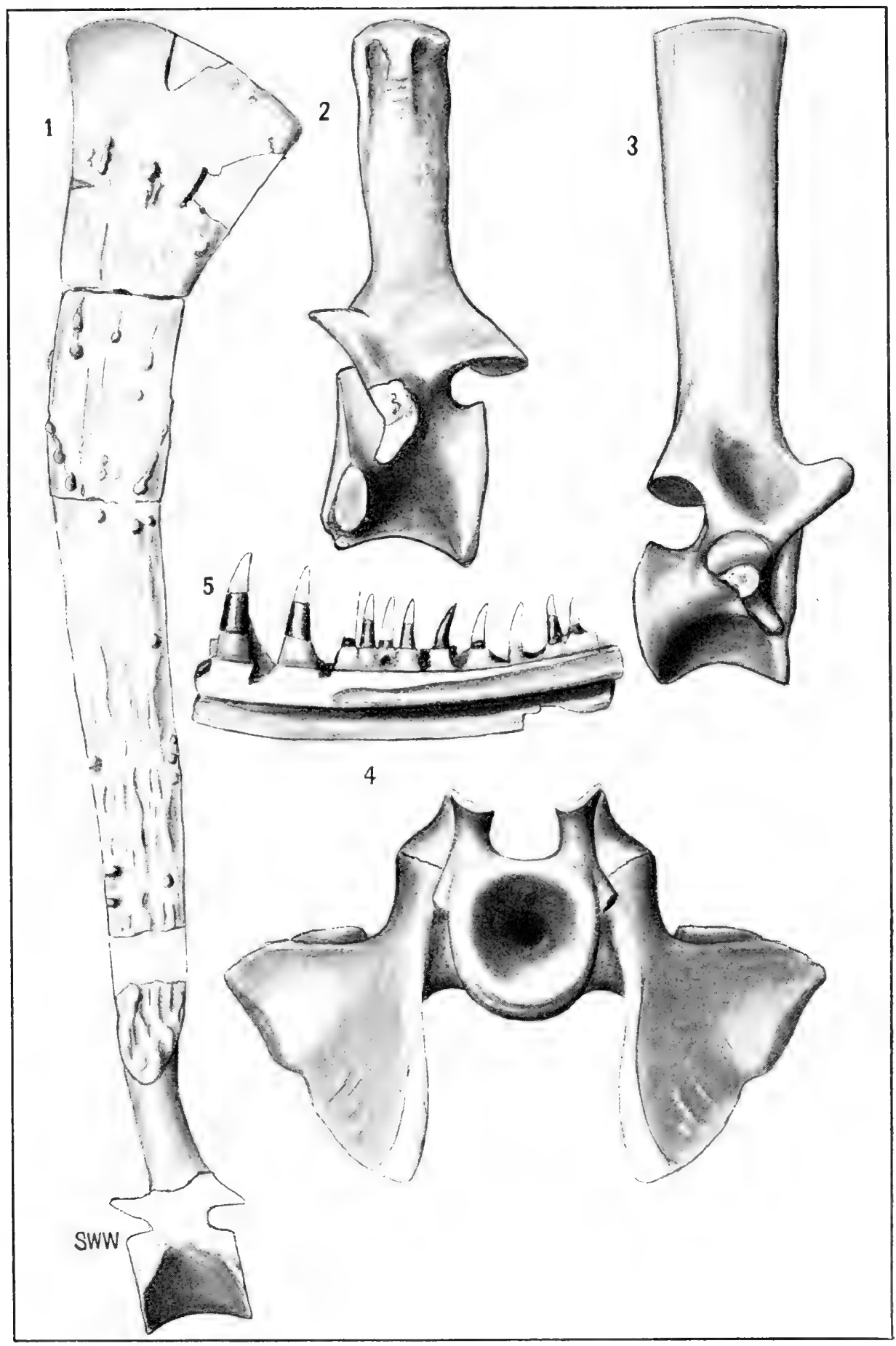

Nothodon, Ophiacodon, Platyhystrix 


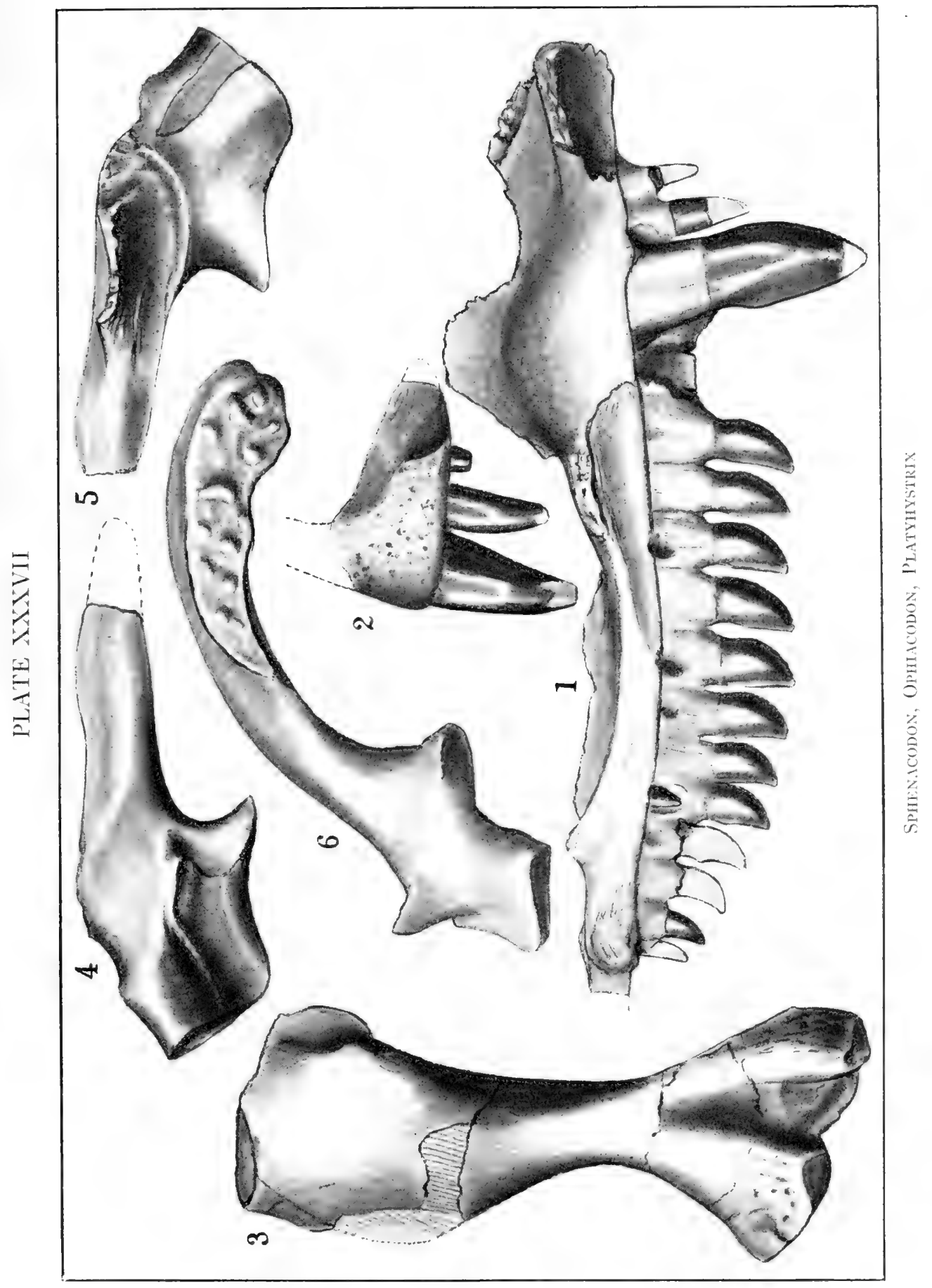








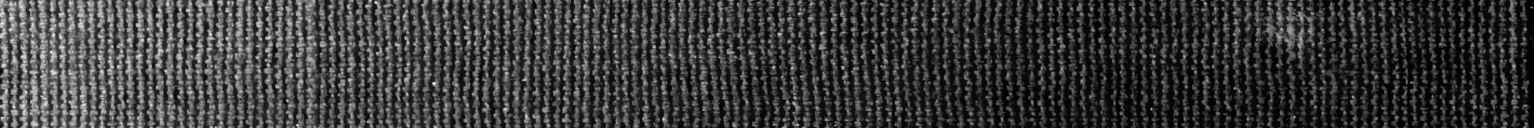

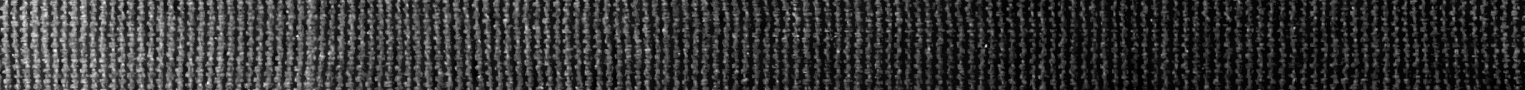
HW w1)

3 3II

3)

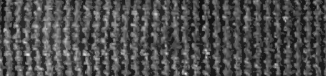

13ำ 317.

(x) 13.

thon

117)

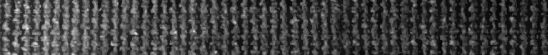

3.

(n)

S1

3) 